\title{
Expression von SLC-Transportern in Melanomzelllinien und Charakterisierung von MATE1 und OCT1 in ihrer Funktion als Zytostatikatransporter
}

\author{
Dissertation \\ zur Erlangung des mathematisch-naturwissenschaftlichen \\ Doktorgrades \\ „Doctor rerum naturalium" \\ der Georg-August-Universität Göttingen
}

\author{
vorgelegt von \\ Julia Grottker \\ aus Braunschweig
}

Göttingen, 2011 
Referentin: Prof. Dr. Claudia Steinem

Korreferent: Prof. Dr. Gerhard Burckhardt

Tag der mündlichen Prüfung: 25.10.2011 




\section{Zusammenfassung}

Ein Problem der heutigen Krebstherapie ist die geringe Ansprechrate bei der Behandlung mit Zytostatika. Ein Teil dieser Chemoresistenz beruht auf der geringen Akkumulation von Zytostatikamolekülen in Tumorzellen. Eine Verbesserung könnte entweder durch Reduktion des Efflux aus den Zellen oder durch Erhöhung der Aufnahme erzielt werden. Besonders am Influx könnten Transporter der Solute-carrier-Familie (SLC-Familie) beteiligt sein. Diese Arbeit befasst sich mit SLC-Transportern - im Hinblick auf die zielgerichtete Therapie des sehr aggressiven malignen Melanoms und darüber hinaus mit der Charakterisierung des OCT1- und MATE1-Transporters als Zytostatikumtransporter.

Die Untersuchungen beinhalteten die Bestimmung der Expressionsspiegel von 29 SLCTransportern in Melanomzellinien. Diese SLC-Transporter konnten anhand der Ergebnisse in drei Kategorien eingeteilt werden: Es gab 12 Transporter, die keine Expression aufwiesen, 14 Transporter, die eine in Melanomzellinien und nicht entarteten Melanozyten gleich hohe oder in Melanomzellinien geringere Expression aufwiesen, sowie schließlich eine Gruppe, die eine signifikant erhöhte Expression aufwiesen. Letztere bestand aus den SLC-Transportern ENT2, OATPA und OATPC. Insbesondere ENT2 ist als Transporter für Zytostatika der Nukleosidanalogaklasse bekannt und ist deshalb ein aussichtsreicher Kandidat für die zielgerichtete Melanomtherapie.

Im zweiten Teil der Arbeit wurde die Interaktion von OCT1 bzw. MATE1 mit Zytostatika festgestellt. Nimustin hemmte die OCT1-vermittelte $\left[{ }^{3} \mathrm{H}\right]$-MPP-Aufnahme in stabil transfizierte $\mathrm{CHO}$-Zellen um über 50 \%. Eine OCT1-vermittelte Zytotoxizität wurde aber nicht gefunden. Von 28 Zytostatika, die im Hinblick auf die Interaktion mit MATE1 untersucht wurden, hemmten Doxorubicin, Mitoxantron, Irinotecan und Etoposid die MATE1-vermittelte $\left[{ }^{3} \mathrm{H}\right]$-MPP-Aufnahme in stabil transfizierte HEK293-Zellen um über $50 \%$. Für Mitoxantron und Irinotecan wurden $\mathrm{IC}_{50}$-Werte von 7,8 $\mu \mathrm{M}$ bzw. 2,9 $\mu \mathrm{M}$ bei einem pH-Wert von 7,4 und 0,6 $\mu \mathrm{M}$ bzw. 1,1 $\mu \mathrm{M}$ bei einem pH-Wert von 8,5 bestimmt. Eine eindeutige MATE1-vermittelte Zytotoxizität wurde für die vier Zytostatika nicht beobachtet.

Die Ergebnisse zur Interaktion von MATE1 und OCT1 mit Zytostatika helfen dabei, das Problem von Pharmakawechselwirkungen, Nebenwirkungen und Chemoresistenz zu verstehen. Die Ergebnisse zur Expression von ENT2 liefern einen Baustein zur zielgerichteten Therapie des Melanoms. 


\section{Abstract}

A challenging problem of current chemotherapy is the low response to antineoplastic agents. Partially, this kind of chemoresistance is based on a low accumulation of these agents in tumour cells. A reduced efflux of antineoplastic agents out of or an increased influx into tumour cells could lead to an increase of chemosensitivity of these cells. Especially for the latter option, an elevated uptake, transport proteins of the solute carrier (SLC) family could be useful. This work deals with SLC transporters - on the one hand in terms of targeted therapy of the very aggressive kind of cancer, malignant melanoma, and on the other hand in terms of the characterisation of OCT1 and MATE1 in their ability to serve as transporters for antineoplastic agents not only in melanoma cells but, more generally, in non-malignant and malignant cells.

The study included the evaluation of expression levels of 29 SLC transporters in melanoma cell lines. These transporters were split up into three categories. 12 transporters did not show any expression in melanoma cell lines, 14 transporters showed an expression level not significantly higher in tumour cells than in non-malignant melanocytes, and three SLC transporters exhibited a significantly higher expression level in melanoma cells than in non-malignant melanocytes. Members of the last group were ENT2, OATP1A2, and OATP1B1. ENT2 is already known from the literature to be able to transport nucleoside analogues. Consequently, particularly ENT2 could be an interesting transporter regarding the targeted uptake of antineoplastic agents into melanoma cells.

In the second part of this study the interaction of antineoplastic agents with OCT1 and MATE1 was evaluated. Nimustine inhibited OCT1-mediated $\left[{ }^{3} \mathrm{H}\right]$-MPP uptake into stably transfected $\mathrm{CHO}$ cells by more than $50 \%$. However, no OCT1-mediated cytotoxicity was measured for nimustine. From 28 antineoplastic agents that have been tested, doxorubicin, mitoxantrone, irinotecan, and etoposide inhibited MATE1-mediated $\left[{ }^{3} \mathrm{H}\right]$-MPP uptake into stably transfected HEK293 cells by more than $50 \%$. For mitoxantrone and irinotecan $\mathrm{IC}_{50}$ values of $7.8 \mu \mathrm{M}$ and $2.9 \mu \mathrm{M}$ have been determined at $\mathrm{pH} 7.4$, respectively. Increasing the $\mathrm{pH}$ value to 8.5 led to decreased $\mathrm{IC}_{50}$ values of $0.6 \mu \mathrm{M}$ for mitoxantrone and $1.1 \mu \mathrm{M}$ for irinotecan. No definite MATE1-mediated cytotoxicity was measured for the four antineoplastic agents mentioned above.

The results of interaction of OCT1 and MATE1 with antineoplastic agents could be helpful in understanding problems during cancer therapy like drug-drug interactions, adverse effects, and chemoresistance. Results of increased expression levels of ENT2 in melanoma cells could contribute to the targeted cancer therapy of melanoma. 




\section{Inhaltsverzeichnis}

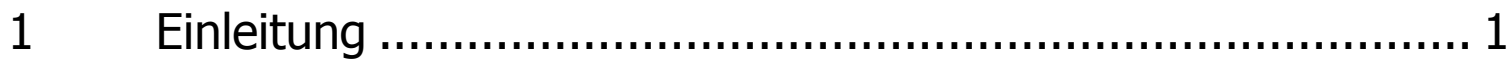

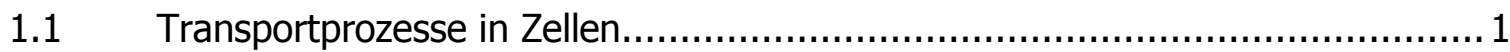

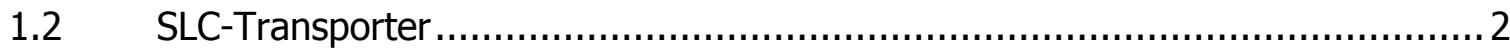

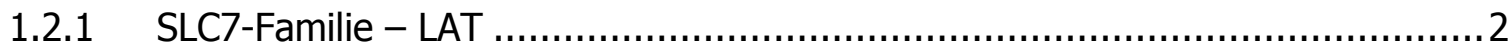

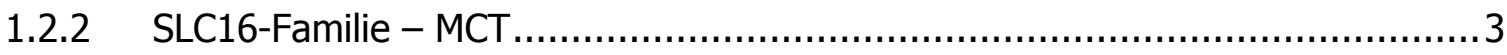

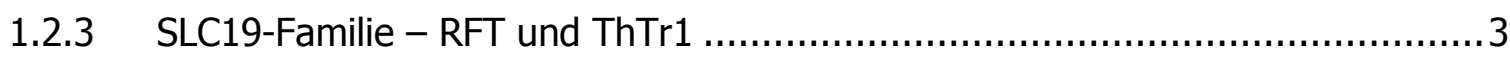

1.2.4 SLC21-Familie - OATP ................................................................ 3

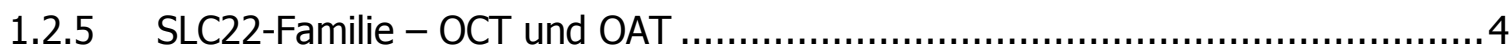

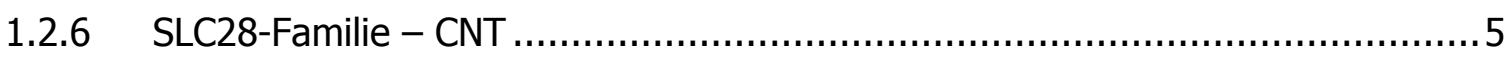

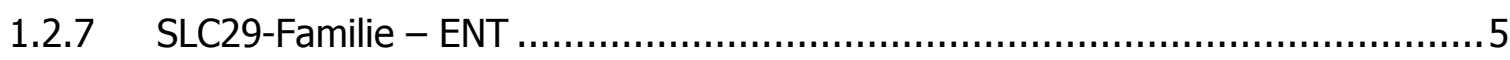

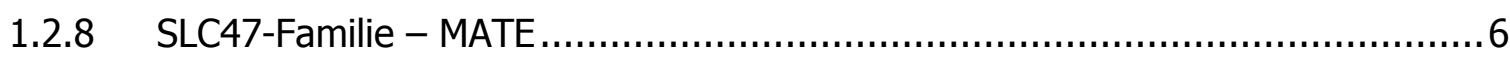

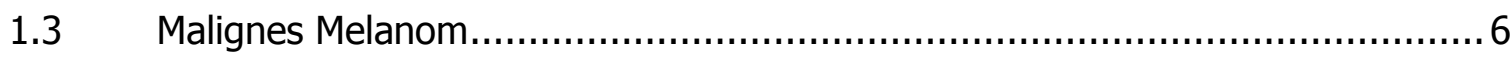

1.3.1 Entstehung eines Melanoms ........................................................... 7

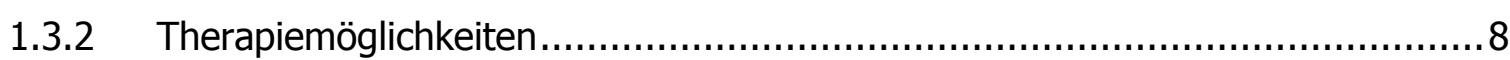

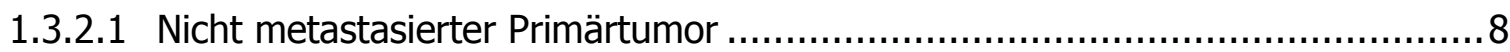

1.3.2.2 Regionale Metastasen, Lokalrezidiv und spezielle Tumorlokalisationen .............8

1.3.2.3 Fernmetastasen ...................................................................... 8

1.3.2.4 Neue Therapiemöglichkeiten des metastasierten Melanoms .........................9

$1.4 \quad$ Zytostatika................................................................................ 10

1.4.1 Auf die DNA einwirkende Zytostatika.............................................. 11

1.4.1.1 Inhibierung der DNA-Synthese: Antimetabolite .................................... 11

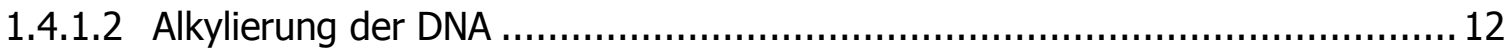

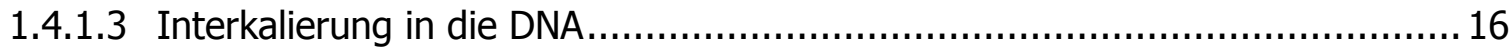

1.4.1.4 Topoisomerasehemmung ........................................................... 17

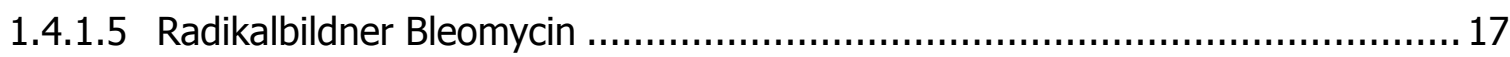

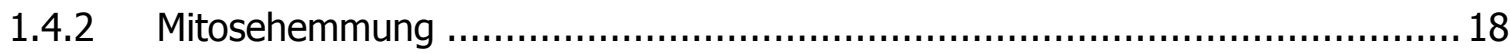

1.4 .3 Weitere Zytostatika ................................................................ 19

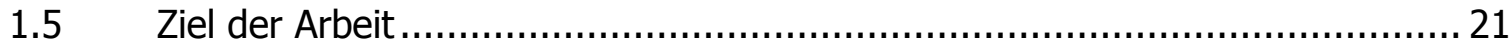

2 Materialien .......................................................... 22

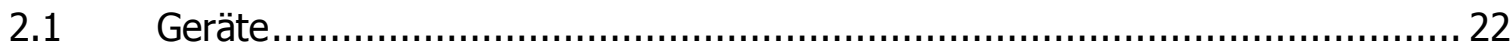

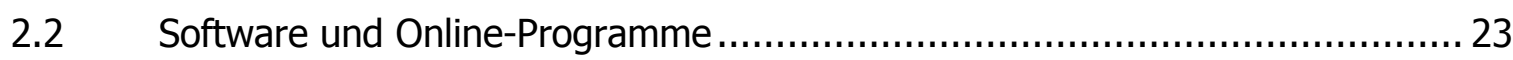

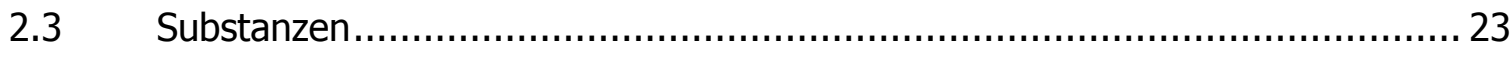

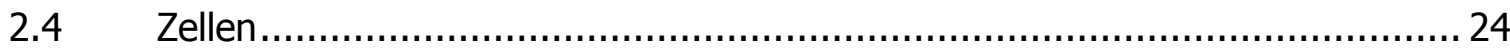

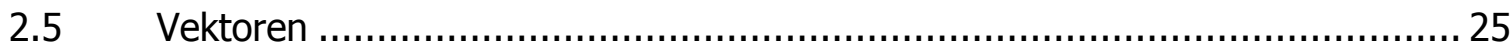

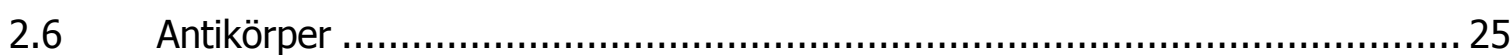




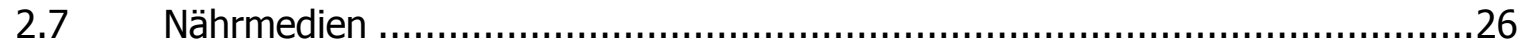

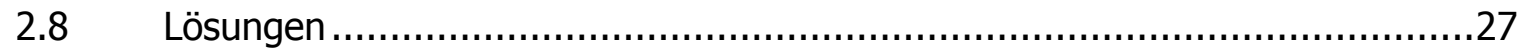

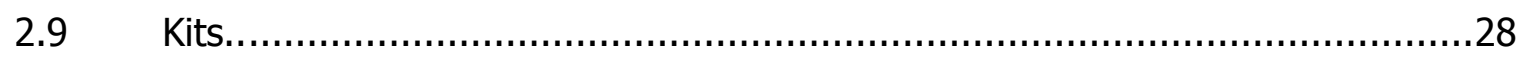

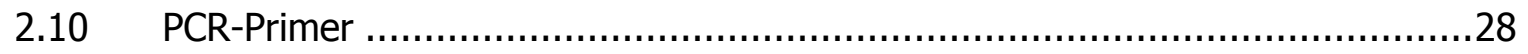

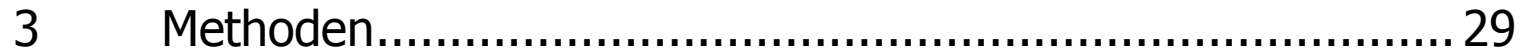

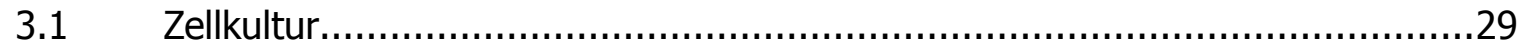

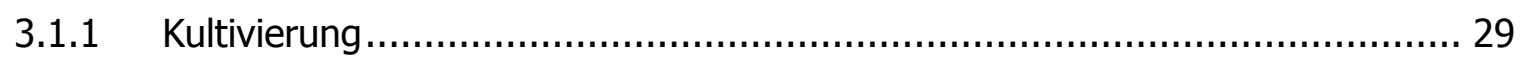

3.1.2 Bestimmung der Zellzahl .............................................................. 29

3.1.3 Einfrieren und Auftauen der Zellen .................................................... 30

3.1.4 Aussaat der Zellen ................................................................. 30

3.2 Generierung von MATE1-HEK293-Zellen.............................................. 30

3.2.1 Vervielfältigung der Ausgangsvektoren in E.coli-Bakterien .......................... 31

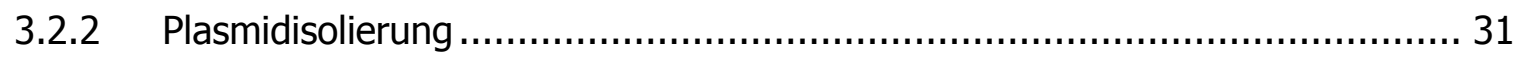

3.2.3 Klonierung des MATE1-Gens in einen Expressionsvektor............................. 32

3.2.4 Transfektion des Expressionsvektors in HEK293-Zellen .............................. 34

3.2.4.1 Transiente Transfektion ........................................................... 35

3.2.4.2 Stabile Transfektion ................................................................ 35

3.3 Aufnahme von radioaktiv markierten Substraten in Zellen ............................36

3.3.1 Charakterisierung der funktionellen Aktivität von MATE1 ............................. 36

3.3.2 Zytostatikainteraktion von MATE1 und OCT1 ...................................... 38

3.3.2.1 Auswertung.............................................................................. 38

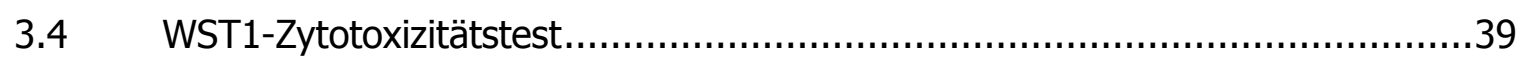

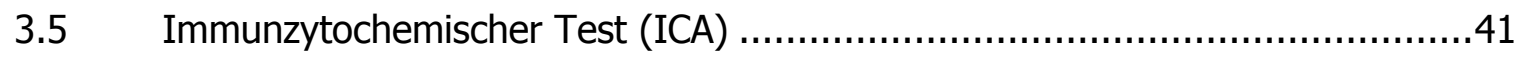

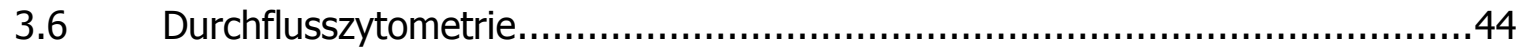

3.7 Expressionsanalyse von SLCs in Melanomzellen ......................................46

3.7.1 RNA-Isolierung und Messung der Konzentration .................................... 46

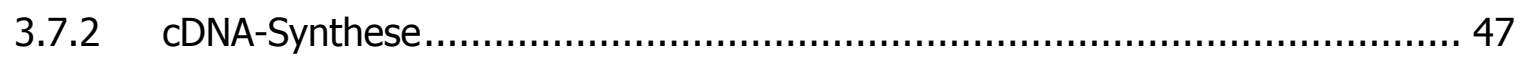

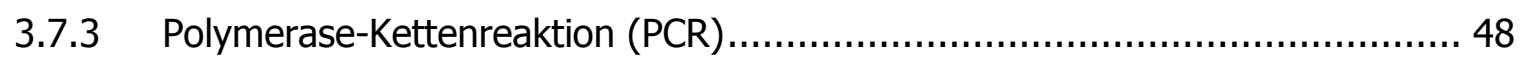

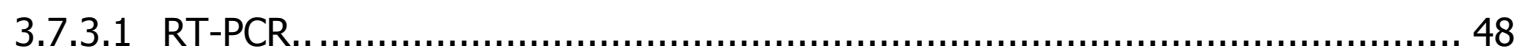

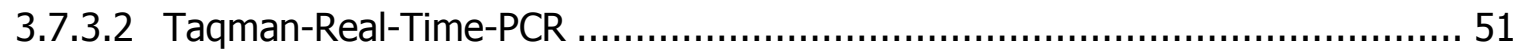

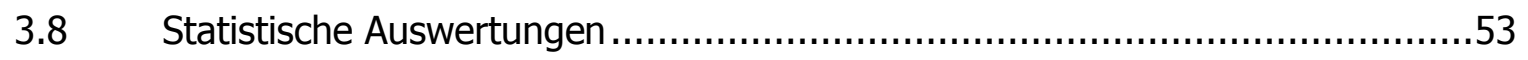

3.8.1 Allgemeines Lineares Modell (ALM) ............................................ 54

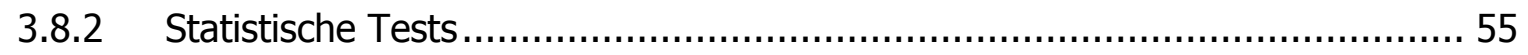

3.8.3 Multiple Tests innerhalb eines ALM ............................................. 56

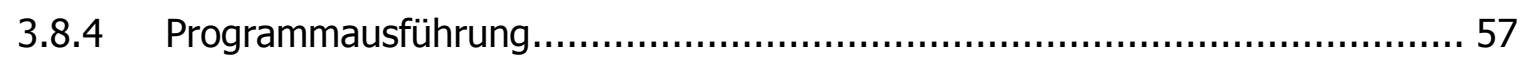

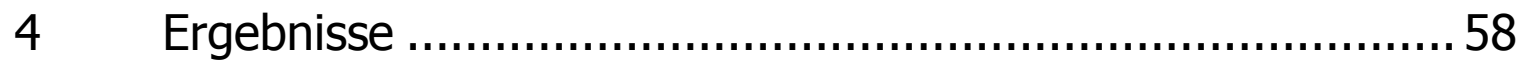


4.1 Expression von SLC-Transportern in Melanomzellen und Melanozyten ............ 58

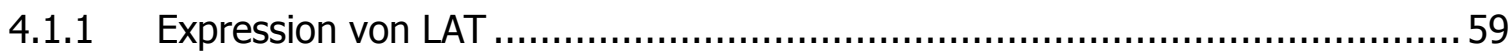

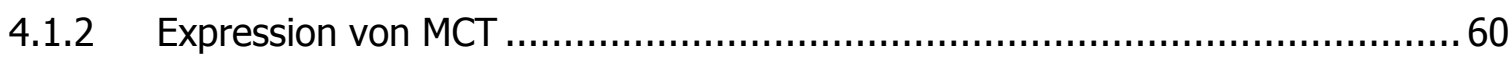

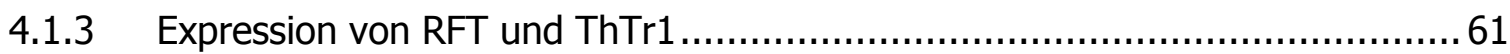

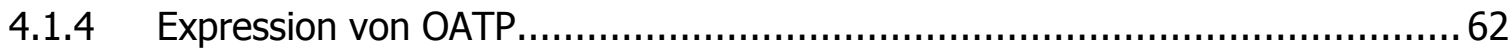

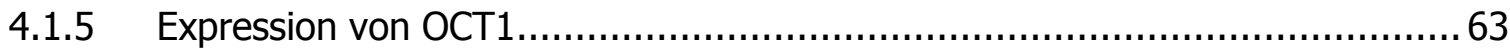

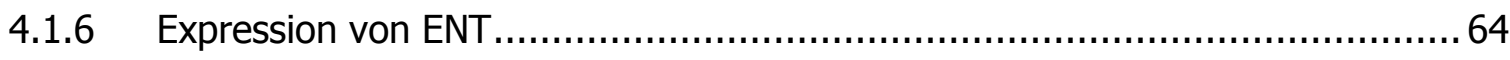

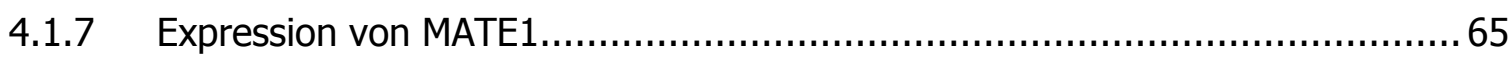

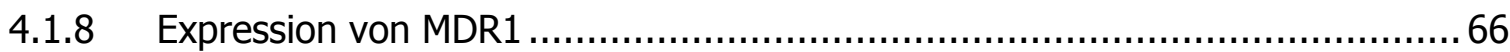

4.2 Eignung von OCT1 und MATE1 als Zytostatikatransporter ..........................67 67

4.2.1 Interaktion von OCT1 und MATE1 mit Zytostatika ................................. 67

4.2.1.1 Funktionelle Charakterisierung von MATE1 .......................................... 68

4.2.1.2 Interaktion von OCT1 und MATE1 mit Zytostatika verschiedener Wirkstoffklassen...................................................................... 73

4.2.1.3 Interaktion von OCT1 und MATE1 mit Temozolomid ................................. 80

4.2.2 MATE1-vermittelter Doxorubicintransport ............................................ 83

4.2.3 Einfluss der MATE1- und OCT1-Expression auf die Anzahl temozolomidinduzierter $\mathrm{O}^{6}$-Methylguanyl-DNA-Addukte.......................................... 84

4.2.3.1 Einfluss von OCT1 auf die Anzahl temozolomid-induzierter DNA-Addukte ....... 85

4.2.3.2 Einfluss von MATE1 auf die Anzahl temozolomid-induzierter DNA-Addukte ..... 86

4.2.4 MATE1- und OCT1-vermittelte Zytotoxizität ........................................ 87

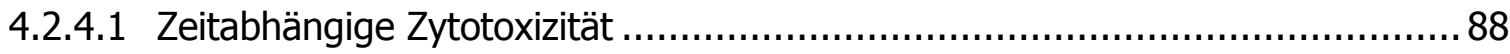

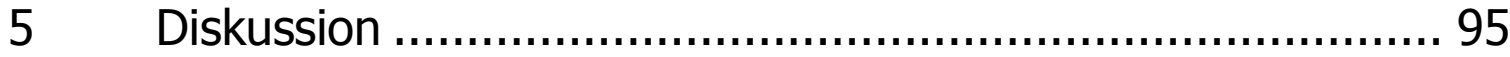

$5.1 \quad$ SLC-Expression in Melanomzelllinien ................................................... 96

5.1.1 Nicht in Melanomzelllinien exprimierte SLC-Transporter ............................. 96

5.1.2 SLC-Transporter mit nicht erhöhter Expression in Melanomzelllinien im Vergleich zu der in Melanozyten...................................................................... 96

5.1.3 SLC-Transporter mit erhöhter Expression in Melanomzelllinien im Vergleich zu der in Melanozyten .................................................................... 97

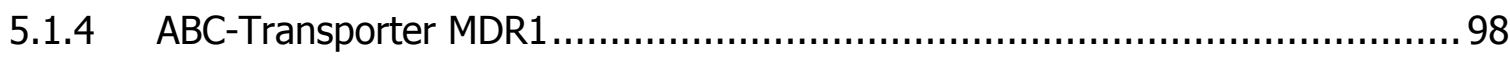

5.2 Eignung von MATE1 und OCT1 als Zytostatikatransporter ......................... 98

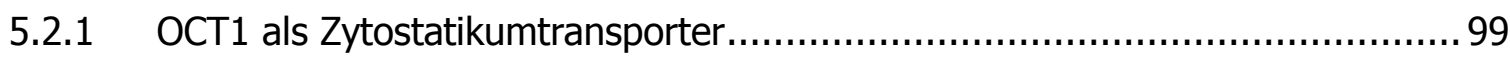

5.2.1.1 Interaktion von OCT1 mit Zytostatika................................................. 99

5.2.1.2 OCT-vermittelte Zellschäden und Zytotoxizität ................................... 100

5.2.2 MATE1 als Zytostatikatransporter ................................................... 102

5.2.2.1 Funktionelle Charakterisierung von MATE1 in transfizierten HEK293-Zellen... 102

5.2.2.2 Interaktion von MATE1 mit Zytostatika........................................... 105

5.2.2.3 MATE1-vermittelte Zytotoxizität.................................................. 108

5.2.2.4 Physiologische und pharmakologische Bedeutung von MATE1 ................... 111 


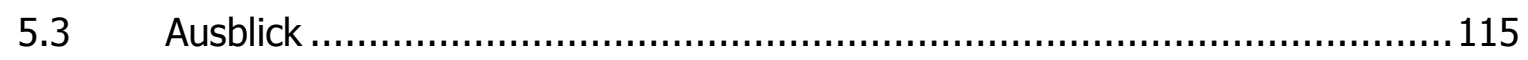

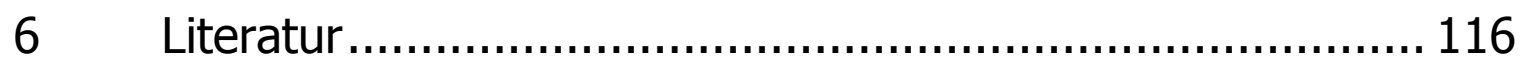

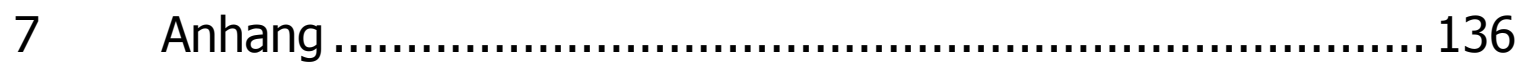

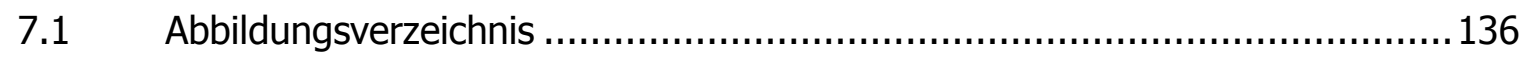

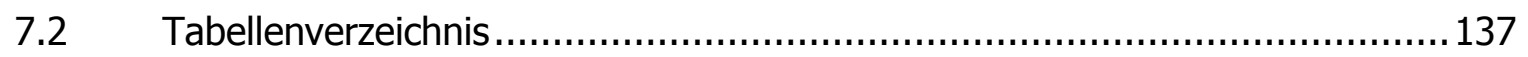

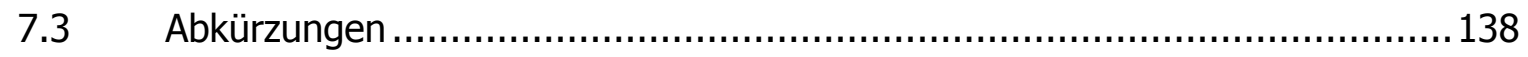

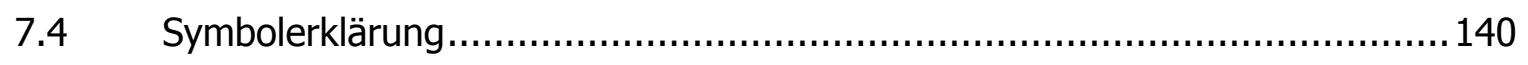

7.5 Chemikalien und biologische Substanzen ....................................... 141

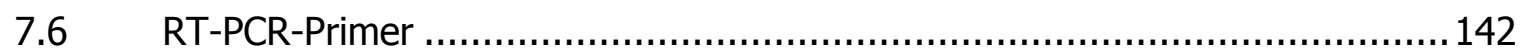

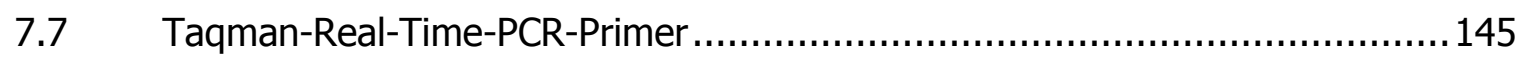

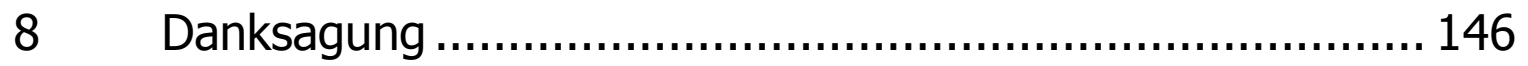

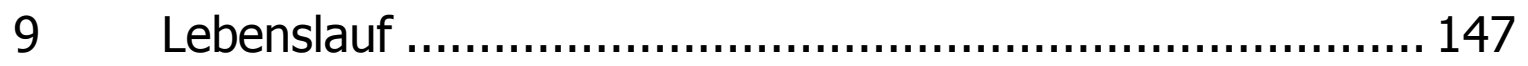

10 Veröffentlichungen ............................................. 148 


\section{$1 \quad$ Einleitung}

\subsection{Transportprozesse in Zellen}

Biologische Zellmembranen bestehen aus einer Lipiddoppelschicht, welche Extra- und Intrazellulärraum voneinander abgrenzen. Ihre Zusammensetzung gibt ihnen die Fähigkeit einer begrenzten und kontrollierten Permeabilität für verschiedene Moleküle und Ionen und ermöglicht, dass unterschiedliche Stoffzusammensetzungen im Zellinnern und in der Umgebung aufrechterhalten werden können. Kleine lipophile Moleküle und einige Gase passieren die Zellmembran ungehindert, für größere und hydrophile Moleküle sind dagegen Transportproteine zuständig, die die Membran durchspannen [67].

Als Transportarten werden die Diffusion von Molekülen in Richtung des elektrochemischen Gradienten (passiver Transport) und der Transport entgegen dem elektrochemischen Gradienten unterschieden (aktiver Transport) bezeichnet. Bei primär aktivem Transport wird ein Substrat unter Energieverbrauch (meistens ATP-Hydrolyse) transportiert. Sekundär aktiver Transport liegt vor, wenn der gleichzeitige Transport eines weiteren Substrats in Richtung seines Gradienten die Triebkraft für den Transport des ersten Substrats entgegen seinem Gradienten liefert. Beim tertiär aktiven Transport liefert ein drittes Substrat die Triebkraft für den Transport des zweiten und das wiederum die Triebkraft für den Transport des ersten Substrats. Die Transportarten werden weiter unterteilt in den Uniport, falls ein Substrat in eine Richtung transportiert wird, den Symport, falls zwei oder mehr Substrate in eine Richtung transportiert werden und den Antiport, falls zwei Substrate in entgegengesetzte Richtungen transportiert werden [67].

Transportproteine werden in Kanäle und Carrier unterteilt. Kanäle bilden wassergefüllte Poren und erlauben den passiven Transmembrantransport. Carrier bilden keine durchgehenden Poren und binden ein Substrat auf einer Membranseite, ändern ihre Konformation und geben es auf der anderen Membranseite wieder frei [6]. Zu dieser Transportproteingruppe gehören die primär aktiv transportierenden ATPasen und ATPBinding-Cassette-Transporter (ABC-Transporter) und die sekundär oder tertiär aktiv oder passiv transportierenden Solute-Carrier (SLC-Transporter), die in dieser Arbeit thematisiert werden.

ABC-Transporter haben unter anderem dadurch Bedeutung erlangt, dass sie Medikamente aus Zellen heraustransportieren (Efflux). Beispielsweise führt der Efflux 
von Zytostatika aus Tumorzellen in der Krebstherapie oft zu Chemoresistenz [148]. ABCTransporter wurden besonders im Hinblick auf die Bekämpfung dieser Resistenzen in den letzten Jahren intensiv untersucht [170]. SLC-Transporter vermitteln meistens den Transport in Zellen hinein (Influx), aber auch den Efflux. Auch ihnen wird inzwischen in der Krebstherapie eine Bedeutung als Zytostatikatransporter zugeschrieben [60], [67], [109], [110], [150]. Verglichen mit den ABC-Transportern sind die SLC-Transporter im Bezug auf Chemoresistenz allerdings wenig erforscht. Es ist vielversprechend, die Forschung auf weitere SLC-Proteine und weitere Krebsarten wie dem malignen Melanom (siehe 1.3) auszuweiten.

\subsection{SLC-Transporter}

In dieser Arbeit wird untersucht, ob SLC-Transporter eine Bedeutung in der Melanomtherapie haben könnten (siehe 1.5). Im Folgenden werden daher humane SLCTransporter vorgestellt, die entweder schon in anderen Tumorzellen gefunden wurden, Zytostatika transportieren oder auf Grund ihrer Lokalisierung und Substratspezifität in nicht entarteten Zellen geeignet erscheinen. Auf die SLC-Transporter MATE1 und OCT1 ist besonders hinzuweisen, da sie in dieser Arbeit eine wesentliche Rolle spielen (siehe 1.5).

Bisher sind 51 SLC-Familien mit insgesamt 378 Mitgliedern bekannt (Information des HUGO gene nomenclature committee). SLC-Proteine befinden sich in der Plasmamembran, aber auch in der Membran von Zellorganellen wie den Mitochondrien [67]. Transportierte Substrate können eine Vielzahl von organischen und anorganischen Kationen, Anionen und ungeladenen Molekülen, darunter Metallionen, Gallensalze, Carboxylate, Urat, Neurotransmitter, Vitamine, Fettsäuren, Nukleoside und Hormone sein [66]. Neben diesen endogenen Substraten transportieren SLC-Proteine außerdem exogene Substrate, wie Toxine und Medikamente, darunter auch Zytostatika [45].

\subsubsection{SLC7-Familie - LAT}

Die L-Aminosäuretransporter LAT1 und LAT2 gehören der SLC7-Genfamilie an. Sie sind in sehr vielen verschiedenen Zellen, LAT2 besonders in der Niere exprimiert, transportieren hauptsächlich große, ungeladene Aminosäuren und tauschen diese im Verhältnis 1:1 gegen eine andere Aminosäure aus. LAT1 transportiert das Zytostatikum Melphalan [28]. Außerdem wurde für LAT1 eine Expression in Keimzell-, Lungen-, Harnblasen-, Uterus-, Blut-, Eierstock- und Drüsengewebstumoren gezeigt, [92], [126], [172]. 


\subsubsection{SLC16-Familie - MCT}

Die Monocarboxylattransporter MCT1, MCT2 und MCT4 (SLC16A1, SLC16A7 und SLC16A3) transportieren größtenteils unverzweigte, aliphatische Monocarboxylate unter Protonen-Symport. MCT1 tauscht zudem Carboxylate gegeneinander aus. MCT transportieren auch Medikamente [65], [106], [169].

MCT1 ist ubiquitär in der apikalen oder basolateralen, MCT2 und 4 in der basolateralen Membran von Epithelzellen exprimiert. MCT2 ist besonders im Hoden, MCT4 vorwiegend in Leukozyten, dem Skelettmuskel und der Plazenta exprimiert [65], [106]. MCT1 und 4 sind außerdem in Brustkrebs-, MCT1 in Gehirntumorzellen exprimiert [127].

\subsubsection{SLC19-Familie - RFT und ThTr1}

Der Reduziertes-Folat-Transporter (RFT) und der Thiamintransporter (ThTr) 1 gehören der SLC19-Familie an (SLC19A1 und SLC19A2). Sie transportieren Substrate im Symport mit Protonen, RFT auch im Antiport mit Hydroxydionen. Beide Proteine sind ubiquitär exprimiert, RFT nicht nur in der Zell-, sondern auch in der mitochondrialen Membran und in Harnblasentumorzellen [1], [48]. Von RFT ist bekannt, dass er die Zytostatika Methotrexat, Pemetrexed und Raltitrexed transportiert [1].

\subsubsection{SLC21-Familie - OATP}

Die Organische-Anionen-Transportpolypeptide (OATP) vermitteln den natriumunabhängigen Transport einer Vielzahl von Substanzen. Mitglieder sind neben weiteren OATP1A2 (OATPA, SLCO1A2), OATP2B1 (OATPB, SLCO2B1), OATP1B1 (OATPC, SLCO1B1), OATP3A1 (OATPD, SLCO3A1), OATP4A1 (OATPE, SLCO4A1) und OATP1B3 (OATP8, SLCO1B3). OATPA ist besonders im Gehirn, geringer in der Leber, den Nieren und weiteren Organen exprimiert. Ebenso ist OATPB in diesen Organen exprimiert, in der Leber in der sinusoidalen Membran. OATPC ist hauptsächlich ebenfalls in der sinusoidalen Membran der Hepatozyten zu finden, OATPD ist dagegen ubiquitär und OATPE besonders im Herzen, der Plazenta und im Skelettmuskel exprimiert. Ein weiteres Mitglied der SLCO-Familie, OATP8 ist hauptsächlich in der Leber exprimiert [20], [61]. SLC-Proteine der OATP-Familie (OATPB, OATPD, OATPE) sind auch in der Haut in Keratinozyten exprimiert [140]. OATPC ist in Lungen- und Darmkrebszellen und OATP8 in Prostata-, Brust-, Darm-, und Plazentakrebszellen exprimiert [110].

OATPB, OATPC und OATP8 vermitteln den ersten Schritt der hepatischen Exkretion von endogenen und exogenen Substanzen wie Toxinen und Medikamenten und transportieren neben Anionen auch Zwitterionen, neutrale Moleküle und große Kationen. 
Zu den transportierten Substanzen gehören Gallensäuren, Hormone und Medikamente [20], [61]. Einige OATP-Mitglieder transportieren auch Zytostatika. OATPA transportiert Methotrexat, Imatinib, Bamet R2 und Bamet UD2, OATPC Methotrexat, Bamet R2, Bamet UD2 und SN38 und OATP8 Docetaxel, Paclitaxel, Methotrexat, SN38 und das in der Melanomtherapie angewandte Imatinib [110].

\subsubsection{SLC22-Familie - OCT und OAT}

Mitglieder der SLC22-Familie sind sehr wichtige polyspezifische Transportproteine im Hinblick auf den Transport von Medikamenten und Zytostatika. Sie setzen sich aus den Organische-Kationen-Transportern (OCT), den Organische-Anionen-Transportern (OAT) und den Organische-Kationen/Carnitin-Transportern zusammen, von denen letztere hier nicht weiter vorgestellt werden [79].

Die Organische-Kationen-Transporter OCT1, OCT2 und OCT3 (SLC22A1, SLC22A2 und SLC22A3) vermitteln den Transport von Kationen, schwachen Basen, Zwitterionen und ungeladenen Molekülen [79]. Zu den von OCTs transportierten Substraten gehören endogene Substanzen wie Hormone und Neurotransmitter, sowie exogene wie Medikamente [78]. OCT1 transportiert die Zytostatika Imatinib, Bamet (R2 und UD2), Oxaliplatin, OCT2 Ifosphamid, Bamet (R2 und UD2), Cisplatin und Oxaliplatin und OCT3 Oxaliplatin [27], [59], [179]. Außerdem wurden Interaktionen von OCT-Proteinen mit weiteren Zytostatika gezeigt [59], [149].

Die wichtigsten Aufgabe der OCT-Proteine ist die Vermittlung des ersten Schritts der hepatischen (OCT1) bzw. der renalen Exkretion (OCT2 und 3). OCT1 ist daher besonders in der sinusoidalen Membran der Hepatozyten, OCT2 und OCT3 besonders in der basolateralen Membran der proximalen Tubuluszellen lokalisiert. Außerdem ist OCT2 in Nervenzellen, ОСТ3 unter anderem auch in Skelettmuskelzellen, Nervenzellen, der Leber und dem Herzen exprimiert [79]. OCT-Proteine sind in Tumorzellen, OCT1 in Darmkrebs-, OCT2 in Lymphom- und OCT3 in Nierenkrebszellen exprimiert [12], [60], [150].

Die Organische-Anionen-Transporter OAT1, OAT3 und OAT4 (SLC22A6, SLC22A8 und SLC22A11) der SLC22-Familie sind Anionen-Antiporter. Für OAT2 (SLC22A7) ist der Transportmechanismus noch nicht vollständig aufgeklärt [16]. Lokalisiert sind sie in den proximalen Tubuluszellen, OAT1, OAT2 und OAT3 in der basolateralen, OAT4 in der luminalen Membran [131]. OAT1 und OAT3 sind des Weiteren im Gehirn, OAT2 in der Leber und OAT4 in der Plazenta lokalisiert [7], [131].

OAT1 und OAT3 vermitteln den ersten Schritt der renalen Sektretion, die Aufnahme von Anionen aus dem Blut in die proximalen Tubuluszellen, durch den gleichzeitigen Efflux 
von $\alpha$-Ketoglutarat. Dessen extrazellulär gerichteter Konzentrationsgradient liefert die Triebkraft für die Aufnahme der Anionen entgegen dem negativen intrazellulären Membranpotential [131]. OAT4 besitzt mehrere Transportmodi. Im Effluxmodus vermittelt er den Efflux von Anionen aus den proximalen Tubuluszellen in den Urin unter der Aufnahme von Chloridionen [16], [63].

OAT besitzen eine weite Substratspezifität für Anionen, aber auch ungeladene Moleküle und wenige Kationen, darunter viele Hormone und Medikamente [15], [16]. OAT besitzen außerdem eine Bedeutung für die Krebstherapie: OAT1 und OAT3 transportieren Methotrexat [166], OAT2 transportiert 5-Fluorouracil und Paclitaxel [77].

\subsubsection{SLC28-Familie - CNT}

Die konzentrierenden Nukleosidtransporter CNT1, CNT2 und CNT3 (SLC28A1, SLC28A2 und SLC28A3) transportieren eine Vielzahl an Nukleosiden im Symport mit Natriumionen [151]. CNT-Proteine bestimmen gemeinsam mit ENT1 und ENT2 die Nukleosidkonzentrationen in Blut und Zellen, indem sie Nukleoside aus Zellen heraustransportieren, welche über die ENT-Proteine aufgenommen wurden. Alle drei Transporter sind in Epithelzellen in der apikalen Membran lokalisiert. CNT1 wurde bisher hauptsächlich in Leber, Niere und Dünndarm, CNT2 und CNT3 außerdem im Gehirn, im Herzen und im Skelettmuskel (CNT2) oder im Knochenmark und der Plazenta (CNT3) gefunden [54]. CNT1 transportiert Nukleoside mit Purinen, CNT2 mit Pyrimidinen und CNT3 mit beiden Basenarten [18]. CNTs transportieren auch eine Vielzahl an Virustatika und Nukleosidanaloga-Zytostatika. CNT1 transportiert Gemcitabin und Fluorouridin, CNT2 Cladribin, Fludarabin, Clofarabin und Fluorouridin und CNT3 Cladribin, Gemcitabin, Fludarabin und Fluorouridin [18], [54].

\subsubsection{SLC29-Familie - ENT}

Die nicht an einen Natriumgradienten gekoppelten äquilibrierenden Nukleosidtransporter ENT1, ENT2 und ENT3 (SLC29A1, SLC29A2, SLC29A3) transportieren ebenso Nukleoside wie die CNT-Proteine, allerdings mit einer geringeren Affinität, passiv und bidirektional. ENT1, 2 und 3 sind ubiquitär, in Epithelzellen in der basolateralen Membran exprimiert [11]. ENT2 ist besonders im Skelettmuskel, ENT3 auch in Mitochondrien- und Kernmembran und ENT1 auch in diversen Tumorzellen, z. B. Brust-, Lymphom-, Leukämie- und Plazentazellen exprimiert [11], [175]. ENT-Proteine transportieren sowohl Purin- als auch Pyrimidinnukleoside [18]. Wie die CNT-Proteine transportieren ENT auch eine Vielzahl an Virustatika und Zytostatika, ENT1 Gemcitabin, Cytarabin, 
Cladribin und Fludarabin, ENT2 Gemcitabin, Cladribin und Clofarabin [11], [18], [175], [178].

\subsubsection{SLC47-Familie - MATE}

Die Multidrug-And-Toxin-Extrusion-Transporter (MATE-Transporter) der SLC47-Familie sind MATE1 (SLC47A1) und MATE2 (SLC47A2) mit einer aktiven (MATE2K) und einer inaktiven Splicevariante (MATE2B). Der erste humane MATE-Transporter (MATE1) wurde 2005 von Otsuka et al. als Protein beschrieben, welches Protonen gegen eine Vielzahl von Substraten austauscht [118]. Ebenso dient MATE2K als Protonen-SubstratAustauscher [99]. MATE1 besitzt 570 Aminosäuren, welche wahrscheinlich in 13 Transmembrandomänen angeordnet sind [159], [173]. MATE1 ist im Skelettmuskel, besonders hoch aber in der luminalen Membran der proximalen Tubuluszellen und in der kanalikulären Membran der Hepatozyten exprimiert [99], [118]. MATE2 ist besonders in der luminalen Membran der proximalen Tubuluszellen exprimiert [99]. MATE-Transporter sind vornehmlich für die Sekretion von endogenen und exogenen Substanzen zuständig. Die transportierten Substrate bestehen aus einer Vielzahl von Kationen wie Methylphenylpyridinium (MPP), Zwitterionen, Anionen und neutralen Molekülen, darunter Medikamente und Toxine [157], [173]. Für die Zytostatika Topotecan, Cisplatin, Oxaliplatin wurde gezeigt, dass sie von MATE1 transportiert werden. Oxaliplatin wird von MATE2 transportiert [109], [158], [174].

\subsection{Malignes Melanom}

Von besonderer Bedeutung für diese Arbeit ist das maligne Melanom. Die Gefahr, im Laufe seines Lebens am Malignen Melanom zu erkranken, liegt bei etwa 1:420. Die Erkrankungsraten sind von 1980-2006 um das 4-fache auf etwa 15 pro 100000 Einwohner angestiegen. Dagegen sind die Sterberaten mit einer Inzidenz von etwa 2 etwa gleich geblieben (Information des Robert-Koch-Insitituts und der Gesellschaft der epidemiologischen Krebsregister in Deutschland). Die konstante Inzidenz trotz steigender Erkrankungszahl liegt an einer verbesserten Früherkennung mit operativer Entfernung des Melanoms oder dessen Vorstufen. Liegt dagegen schon eine Metastasierung in entfernte Organe vor, so erfolgt die Behandlung weiterhin meistens palliativ. Eine Verkleinerung des Tumors um über $50 \%$ wird zwar bei $15-40 \%$ der Tumore erreicht [49], jedoch beträgt die mittlere Überlebensrate nur 6-10 Monate [165]. 


\subsubsection{Entstehung eines Melanoms}

Melanome bilden sich zu $90 \%$ auf der Haut [43], [52]. Seltener treten Melanome an Schleimhäuten, der Netzhaut, dem Innenohr und der Hirnhaut auf. Sie entstehen durch das unkontrollierte Wachstum entarteter Melanozyten.

Melanozyten sind Hautzellen, die sich neben den Keratinozyten in der oberen Hautschicht, der Epidermis, bevorzugt an der Grenze zur Dermis befinden [52]. Ihre Aufgabe ist die Produktion des Hautfarbstoffs Melanin und dessen Weitergabe an die umgebenden Keratinozyten. Melanin fängt durch UV-Strahlung erzeugte reaktive Sauerstoffspezies ab und senkt die Bildung von Photoprodukten aus zwei benachbarten Pyrimidinresten eines DNA-Strangs [17], [76]. Auf diese Weise wird die KeratinozytenDNA vor Schädigung geschützt. An der gesamten Hautpigmentierung, z. B. der Bildung der Melanozyten, der Melaninproduktion und dem Transport zu den Keratinozyten sind mindestens 150 Gene beteiligt [171].

Nicht entartete Melanozyten sind hochdifferenzierte und nur sehr langsam proliferierende Zellen mit einer begrenzten Anzahl an Zellteilungen. Danach erfolgt Seneszenz, also ein Teilungsstopp, ausgelöst durch Tumorsuppressoren wie p53 und RB1 [13]. Wird beispielsweise die Expression und Funktionalität dieser Proteine durch Mutation des kodierenden Gens beeinträchtigt, so kommt es zur Unterdrückung der Seneszenz und zum unkontrollierten Zellwachstum [52].

Die Melanombildung wird durch UV-Strahlung begünstigt. Entstehen so viele UVinduzierte Photoprodukte, dass diese nicht mehr von DNA-Reparatursystemen beseitigt werden, so können Genmutationen erhöht und Seneszenzfaktoren inhibiert werden. Der Einfluss der UV-Strahlung ist von der Menge an Melanin in Haut und Haaren abhängig. Hellhäutige Hauttypen mit blonden oder roten Haaren sind am meisten gefährdet, ein Melanom zu entwickeln [38]. Gefährdet sind außerdem ältere Menschen, da die DNAReparatursysteme mit dem Alter abnehmen [53]. Viele Sommersprossen und viele dysplastische gutartige Muttermale sind auch ein Anzeichen eines erhöhten Melanomrisikos [38], [55], [155], da sie auf eine Mutation in den Genen der Seneszenz einleitenden Proteine hindeuten [105]. Besonders hoch ist die Melanomgefahr für Patienten mit fehlerhaften DNA-Reparatursystemen wie Xeroderma Pigmentosum [83]. 


\subsubsection{Therapiemöglichkeiten}

\subsubsection{Nicht metastasierter Primärtumor}

Besteht ein Melanom nur aus dem Primärtumor und ist noch nicht metastasiert, so wird er operativ entfernt [182]. Wenn auch schon die umgebenden Lymphknoten befallen sind, können diese ebenfalls operativ entfernt werden [40]. Als Prognosefaktor für den Befall weiterer Lymphknoten und Organe dient die Wächterlymphknotenentfernung und -analyse [19].

\subsubsection{Regionale Metastasen, Lokalrezidiv und spezielle Tumor- lokalisationen}

Wenn der Primärtumor zurückgekehrt ist (Lokalrezidiv), er an schwer zugänglichen Körperstellen liegt oder Metastasen in den umliegenden Lymphknoten vorliegen, kommt unter anderem die Strahlentherapie zum Einsatz [144]. Ziel ist es, durch ionisierende Strahlen, z. B. Röntgen- oder Gammastrahlen die Tumorzell-DNA zu schädigen. Selten wird außerdem die Lasertherapie eingesetzt [168].

\subsubsection{Fernmetastasen}

Bei Fernmetastasen in Organen sind die Heilungschancen gering und die Therapie erfolgt meistens palliativ [165]. In Ausnahmefällen wird bei Gehirn- oder Knochenmetastasen die Strahlentherapie angewandt, oft in Kombination mit Chemotherapeutika, [71], [144], [165]. Als weitere Therapieoptionen gelten die Immun-, Chemo- oder Immun-Chemo-Therapie. Als Immuntherapeutika, also gegen Tumorantigene gerichtete Antikörper, werden am häufigsten Interferon $\alpha$ [74] und Interleukin 2 eingesetzt [132]. Nachteil ist ihre hohe Toxizität bei Ansprechraten von 13-25 \% [49]. In Kombination mit Zytostatika wird die Ansprechrate auf bis zu $48 \%$ erhöht [41], jedoch wird auch die Toxizität erhöht und die Überlebenszeit der Patienten nicht verlängert [138].

Als Standardtherapie eines Melanoms mit Fernmetastasen werden einzelne Zytostatika (Monochemotherapie) oder eine Zytostatikakombination (Polychemotherapie) angewandt (Tab. 1-1, [49]). In der Monotherapie werden hauptsächlich Dacarbazin (DTIC), sowie Temozolomid und Fotemustin, die die Blut-Hirn-Schranke überwinden, verwendet [49], [96]. Seltener werden Vinblastin, Vindesin [49], [128] und Mitomycin C verwendet [32]. 
Um Resistenzen zu verringern, werden in der Kombinationstherapie sogenannte Schemata eingesetzt, das heißt Kombinationen aus mehreren Zytostatika verschiedener Wirkstoffklassen (siehe Tab. 1-1). Die Ansprechrate ist im Vergleich zur Monotherapie erhöht, jedoch meistens mit höherer Toxizität verbunden [89]. Die höchsten Ansprechraten von etwa $45 \%$ werden für das CVD-Schema erzielt [90], [165]. Vergleichsweise wenig toxisch ist das BHD-Schema [49]. Weitere Schemata mit ähnlichen Ansprechraten sind das DBCT-Schema [21], [24], das BOLD-Schema [145], das DAC-Tam [164] und das Gem-Treo-Schema [49]. Die Ansprechraten der geläufigsten beim Melanom angewandten Mono- und Polychemotherapien sind in Tab. 1-1 dargestellt.

Tab. 1-1: Chemotherapie des Melanoms

\begin{tabular}{|l|l|l|}
\hline Therapieart & Zytostatika & Ansprechrate (\%) \\
\hline \multirow{4}{*}{ Monotherapie } & Dacarbazin (DTIC) & $12-18$ \\
\cline { 2 - 3 } & Temozolomid & $14-21$ \\
\cline { 2 - 3 } & Fotemustin & $7-24$ \\
\hline \multirow{5}{*}{ Polytherapie } & CVD: Cisplatin, Vindesin, Dacarbazin & $31-45$ \\
\cline { 2 - 3 } & BHD: BCNU, Hydroxyurea, Dacarbazin & $12-30$ \\
\cline { 2 - 3 } & BOLD: Bleomycin, Vincristin, Lomustin, Dacarbazin & $20-40$ \\
\cline { 2 - 3 } & DBCT: Dacarbazin, BCNU, Cisplatin, Tamoxifen & $18-26$ \\
\cline { 2 - 3 } & DAC-Tam: DTIC, Nimustin, Cisplatin, Tamoxifen & 21 \\
\cline { 2 - 3 } & Gem-Treo-Schema: Gemcitabin, Treosulfan & 33 \\
\hline
\end{tabular}
aus [21], [24], [49], [96], [90], [145] und [164]

\subsubsection{Neue Therapiemöglichkeiten des metastasierten Melanoms}

Die mit den bisher angewandten Therapien erzielten geringen Ansprechraten unter vorwiegend palliativer Behandlung verdeutlichen, dass dringend nach neuen Therapiemöglichkeiten gesucht wird.

\subsection{Impftherapie}

Eine Möglichkeit könnte die Impftherapie bieten. Dem Patienten werden von Lymphozyten oder dendritischen Zellen gebildete Antigene oder inaktivierte Tumorzellen verabreicht [180]. Im Vergleich zur Chemotherapie besitzt die Impftherapie generell eine geringere Toxizität für gesunde Zellen und es konnte in einigen Fällen eine Überlebenszeitverlängerung der Patienten erreicht werden [23]. 


\subsection{Zielgerichtete Therapie}

Die aktuelle Forschung befasst sich besonders mit der zielgerichteten Krebstherapie [165]. Grundlage ist es, spezielle Zielstrukturen in Tumorzellen zu finden und gegen diese Wirkstoffe zu entwickeln. Angriffspunkte können spezielle Eigenschaften der Tumorzellen sein, in denen sie sich von nicht entarteten Melanozyten unterscheiden.

Bekannt ist inzwischen, dass Melanomzellen an vielen Stellen veränderte Signalwege aufweisen. Angriffspunkte sind z. B. der Zellzyklus, der MAPK-Signalweg [85], RezeptorTyrosinkinase-Inhibitoren wie Imatinib und Sunitinib [68], Onkogen-Inhibitoren wie Oblimersen [34], [68] oder Inhibitoren von Angiogenesewachstumsfaktoren wie Axitunib [68]. Gerade erst wurde der Antikörper Ipilimumab als Medikament zugelassen (Fachinformation Bristol-Myers Squibb), welcher die Überlebenszeit der Patienten verlängern kann [165]. Viele weitere Substanzen befinden sich in der Entwicklung [43].

Weitere Zielstrukturen können Transportproteine sein. Melanomzellen exprimieren eine Reihe von Efflux-Transportern der ABC-Familie [22]. Die Strategie wäre es, wirksame Inhibitoren zu finden, um den Efflux zu unterbinden. MDR-Transporter-Inhibitoren wurden bereits in klinischen Studien bei anderen Krebsarten getestet [91], [122].

Andererseits besteht die Möglichkeit, dass auch Aufnahmetransporter der SLC-Familie in der Therapie des Melanoms eine Rolle spielen können (siehe 1.5).

\subsection{Zytostatika}

Zytostatika sind Chemotherapeutika, welche in den Zellzyklus eingreifen, so die Proliferation der Zellen unterbinden und sie schließlich zur Apoptose bringen. Diese Wirkungsweise hat zur Folge, dass Tumorzellen besonders stark angegriffen werden, da sie schnell proliferieren, also sehr kurze Zellzyklen besitzen.

Man unterscheidet folgende Wirkstoffklassen: Der größte Teil der Zytostatika greift die Tumorzell-DNA an. Weiterhin gibt es Zytostatika, welche in die Mitose eingreifen. Sehr viel seltener wirken Zytostatika auf Grund anderer Mechanismen, z. B. durch die Bindung an Hormonrezeptoren, wodurch die Ausschüttung von Wachstumsfaktoren verhindert und die Proliferation auf diesem Weg unterbunden wird [5].

Das Thema dieser Arbeit ist die potentielle Bedeutung von SLC-Transportern für die Melanomtherapie und die Charakterisierung von MATE1 und OCT1. Um die offenen Fragen zu beantworten, wurden unterschiedliche Zytostatika an Modellzellen eingesetzt.

Kriterien bei der Wahl der Zytostatika waren die Anwendung in der Melanomtherapie oder die häufige Anwendung in der sonstigen praktischen Krebstherapie. Die Zytostatika 
wurden auch danach ausgesucht, dass möglichst viele unterschiedliche chemische Strukturen vertreten waren, denn MATE1 ist in der Lage, sehr viele verschiedene Moleküle zu transportieren [157].

\subsubsection{Auf die DNA einwirkende Zytostatika}

Von den oben genannten Wirkstoffklassen bilden die auf die DNA-einwirkenden Zytostatika die größte Gruppe. Im Folgenden werden mehrere Vertreter dieser Kategorie beschrieben. In den folgenden Tabellen sind die chemische Struktur der Zytostatika, die Krebsarten in denen sie eingesetzt werden, ihre hauptsächlichen Nebenwirkungen und falls bekannt, ihre Interaktion mit SLC-Transportern dargestellt.

\subsubsection{Inhibierung der DNA-Synthese: Antimetabolite}

Antimetabolite sind modifizierte Stoffwechselmoleküle, welche die Stellen der "richtigen" Metaboliten einnehmen und so die Funktion der Metabolite inhibieren (Antagonisten). In diesem Fall ist der Wirkort die DNA und die bindenden Antimetabolite behindern ihre Synthese. Zu den Antimetaboliten gehören der Folsäureantagonist Methotrexat und die Purin- und Pyrimidinanaloga.

\subsection{Folsäureantagonist Methotrexat}

Das Folsäurederivat Methotrexat ist ein Prodrug, wird also in den Zellen in seine aktive Form umgewandelt. Es inhibiert die Dihydrofolatreduktase, so dass weniger Tetrahydrofolat für die Purin- und Pyrimidinsynthese zur Verfügung steht. Somit werden weniger Purin- und Pyrimidinmoleküle gebildet, die DNA-Synthese verringert und die Zelle geht in die Apoptose über [5].

Tab. 1-2: Folsäureantagonist

\begin{tabular}{|l|l|l|l|}
\hline Methotrexat & Krebsarten & Nebenwirkungen & \begin{tabular}{c}
\multicolumn{1}{c|}{ SLC- } \\
Interaktion
\end{tabular} \\
\hline & & & Transport: \\
RFT, OATPA, \\
OATPC, \\
OATP8, \\
OAT1, OAT3, \\
Wechsel- \\
wirkung: \\
OAT4
\end{tabular}

aus [5], [59], [61], [62] und [131] 


\subsection{Purin- und Pyrimidinanaloga}

Purin- oder Pyrimidinderivate sind ebenfalls Prodrugs und werden nach Metabolisierung in die DNA eingebaut. Es ist seit einiger Zeit bekannt, dass diese Zytostatika von den Nukleosidtransportern der CNT- und ENT-Familie transportiert werden [18], [54], [175]. Die Purinanaloga Fludarabin und Cladribin (Tab. 1-3) inhibieren die DNA-Polymerase, wodurch die Strangverlängerung während der DNA-Synthese abgebrochen wird [5]. Außerdem werden DNA-Primase und -Ligase und die Ribonukleotid-Reduktase inhibiert, wodurch weniger Desoxynukleotide für die DNA-Synthese zur Verfügung stehen [57]. Cladribin inhibiert zusätzlich DNA-Reparaturmechanismen für Einzelstrangbrüche [153].

Das Pyrimidinanalogon 5-Fluorouracil (Tab. 1-3) inhibiert die Thymidilatsynthase, welche Nukleotide synthetisiert [94]. Cytarabin [119], und Gemcitabin inhibieren die DNAPolymerase. Gemcitabin blockiert außerdem die Ribonukleotid-Reduktase [102].

Tab. 1-3: Purin- und Pyrimidinanaloga

\begin{tabular}{|c|c|c|c|c|}
\hline \multicolumn{2}{|c|}{ Purin- und Pyrimidinanaloga } & Krebsarten & Nebenwirkungen & SLC-Interaktion \\
\hline $\mathrm{NH}_{2}$ & $\begin{array}{l}\text { Cladribin: } \\
\mathrm{R}_{1}=\mathrm{Cl} \\
\mathrm{R}_{2}=\mathrm{OH} \\
\text { Fludarabin } \\
: \\
\mathrm{R}_{1}=\mathrm{F} \\
\mathrm{R}_{2}=\mathrm{H}\end{array}$ & Leukämie, Lymphom & $\begin{array}{l}\text { Knochenmark- } \\
\text { schädigung, } \\
\text { Immunsuppres- } \\
\text { sion }\end{array}$ & $\begin{array}{l}\text { Transport CNT2, } \\
\text { CNT3, ENT1; } \\
\text { ENT2 (Cladribin) }\end{array}$ \\
\hline \multicolumn{2}{|c|}{ (-Fluorouracil } & $\begin{array}{l}\text { Darm-, Prostata-, } \\
\text { Harnblasen-, } \\
\text { Magen-, Brustkrebs, } \\
\text { Kopf-Halskarzinom }\end{array}$ & $\begin{array}{l}\text { Knochenmark- } \\
\text { schädigung, } \\
\text { Magen-Darm- } \\
\text { störung, Neuro- } \\
\text { toxizität }\end{array}$ & Transport: OAT2 \\
\hline \multicolumn{2}{|r|}{$\begin{array}{l}\text { Cytarabin: } \\
\mathrm{R}_{1}=\mathrm{OH} \\
\mathrm{R}_{2}=\mathrm{H}\end{array}$} & $\begin{array}{l}\text { Leukämie, } \\
\text { Lymphom }\end{array}$ & $\begin{array}{l}\text { Knochenmark- } \\
\text { schädigung, } \\
\text { Anämie, Neuro- } \\
\text { toxizität }\end{array}$ & Transport: ENT1 \\
\hline & $\begin{array}{l}\text { Gemcitabin: } \\
\mathrm{R}_{1}, \mathrm{R}_{2}=\mathrm{F}\end{array}$ & $\begin{array}{l}\text { Pankreas-, Brust-, } \\
\text { Lungen-, Harnbla- } \\
\text { sen-, Eierstockkrebs, } \\
\text { Leukämie }\end{array}$ & $\begin{array}{l}\text { Knochenmark- } \\
\text { schädigung }\end{array}$ & $\begin{array}{l}\text { Transport: CNT1, } \\
\text { CNT2, CNT3, } \\
\text { CNT1, ENT2 }\end{array}$ \\
\hline
\end{tabular}

aus [5], [11], [16], [18], [54], [57], [77], [79], [94], [102], [131], [146], [175].

\subsubsection{Alkylierung der DNA}

Die Alkylantien bilden die größte Gruppe der Zytostatika. Ihre Wirkung beruht auf einer Alkylierung durch nukleophilen Angriff von Stickstoff- oder Sauerstoffatomen der Purinbasen der DNA, besonders des $\mathrm{N}^{7}$-Atoms von Guanin, seltener auch des $\mathrm{O}^{6}$-Atoms 
von Guanin (Temozolomid, Tab. 1-7), der $\mathrm{N}^{1}$ - und $\mathrm{N}^{3}$-Atome von Adenin und des $\mathrm{N}^{3}$ Atoms von Cytosin [5]. Die Alkylierung führt zu falschen Basenpaarungen und dies zu einer fehlerhaften Transkription. Außerdem werden, resultierend aus der Alkylierung, Guanin oder Adenin von der DNA abgespalten. Durch eine zweite Alkylierung desselben Zytostatikummoleküls (Bifunktionalität) kann es zur Quervernetzung mit Proteinen oder dem zweiten DNA-Strang kommen, wodurch die Strangteilung inhibiert wird [113].

\subsection{Stickstoff-Lost-Derivate}

Chlorambucil, Melphalan und Bendamustin (Tab. 1-4) sind bifunktionelle Moleküle, die durch Abspaltung eines Chloridions ein Aziridiniumion bilden, welches bevorzugt vom $\mathrm{N}^{7}$-Atom von Guanin nukleophil angegriffen wird [156], [136], [137]. Bendamustin wird vorher durch Hydroxylierung aktiviert [156].

Tab. 1-4: Stickstoff-Lost-Derivate

\begin{tabular}{|l|l|l|l|}
\hline Stickstoff-Lost-Derivate & Krebsarten & \multicolumn{1}{|c|}{ Nebenwirkungen } & SLC-Interaktion \\
\hline Lymphom, & $\begin{array}{l}\text { Myelom, } \\
\text { Leukämie, } \\
\text { Lungenkrebs }\end{array}$ & $\begin{array}{l}\text { leichte Anämie, Thrombo- } \\
\text { zytopenie }\end{array}$ & $\begin{array}{l}\text { Wechselwirkung: } \\
\text { OAT3 }\end{array}$ \\
\hline
\end{tabular}

\subsection{Oxazaphosphorine}

Cyclophosphamid, Ifosphamid und Trofosphamid (Tab. 1-5) werden zunächst hauptsächlich in der Leber, aber auch in anderen Zellen, z. B. Tumorzellen enzymatisch metabolisiert [177]. Nach Bildung eines Aziridiniumions reagieren sie ähnlich wie die Stickstoff-Lost-Derivate. Von Ifosphamid ist bekannt, dass es über das SLC-Protein OCT2 in Zellen transportiert wird. 
Tab. 1-5: Oxazaphosphorine

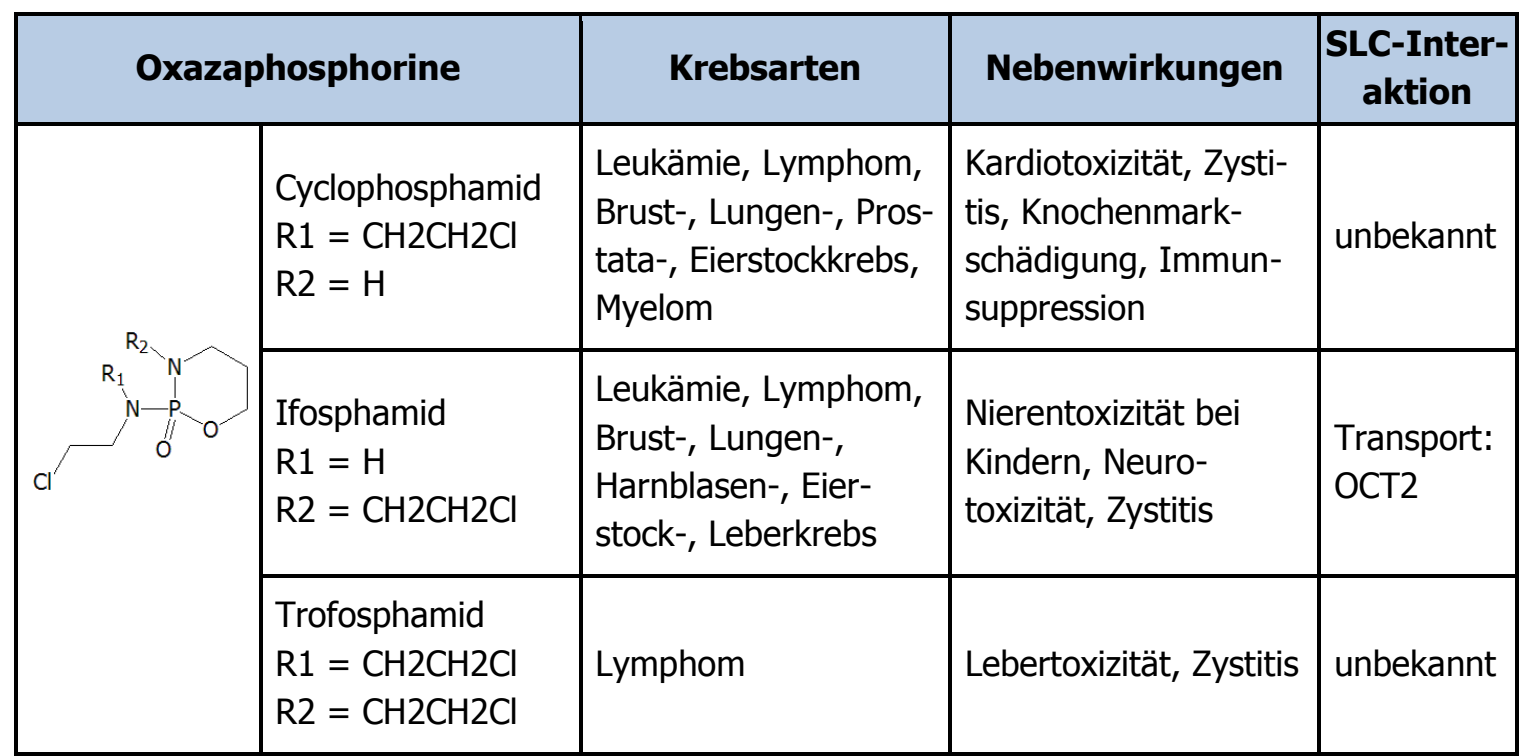

aus [27], [176], [177], [176]

\subsection{Weitere Alkylantien}

Die Alkylsulfonate Busulfan und Treosulfan sind bifunktionale Zytostatika (Tab. 1-6). Busulfan wird vor Alkylierung unter Abspaltung von Sulfonsäure in Methylsulfonat umgewandelt und Treosulfan wird durch Diepoxidbutanbildung aktiviert [5].

Das Nitrosoharnstoffderivat Nimustin besitzt einen ähnlichen Wirkmechanismus wie Stickstoff-Lost-Derivate. Es bildet Chlorethyladdukte mit DNA-Basen und bildet Komplexe mit Proteinen [80].

Das Phosphorthioethylenamid Thiotepa ist ein trifunktionelles Alkylans, welches drei reaktive Ethylenimingruppen besitzt. Diese werden nukleophil besonders vom $\mathrm{N}^{7}$-Atom von Guanin angegriffen [97].

Das bifunktionelle Alkylans Mitomycin C wird enzymatisch zu seinem aktiven Metaboliten, einem Hydrochinon reduziert [167]. Die Hauptwirkung besteht in der Adduktbildung an das $\mathrm{N}^{2}$ - und seltener auch das $\mathrm{N}^{7}$-Atom des Guanins [161]. 
Tab. 1-6: Verschiedene Alkylantien

\begin{tabular}{|l|l|l|}
\hline verschiedene Alkylantien & \multicolumn{1}{|c|}{ Krebsarten } & \multicolumn{1}{c|}{ Nebenwirkungen } \\
\hline Knochenmarkschädigung, \\
Hauttoxizität
\end{tabular}

aus [5], [32], [80], [97], [161], [167]; Interaktion von SLC mit diesen Zytostatika unbekannt

\subsection{Imidazotetrazinonderivat Temozolomid}

Ein wichtiges, in dieser Arbeit untersuchtes Zytostatikum, welches beim Melanom angewendet wird, ist Temozolomid. Es zerfällt bei pH 7 und höher in wässriger Lösung spontan zu MTIC, dann zu AIC und einem Diazoniumion (Tab. 1-7). Letzteres wird nukleophil vom $\mathrm{O}^{6}$-Atom, aber auch vom $\mathrm{N}^{7}$-Atom von Guaninmolekülen der DNA angegriffen [135]. Die $0^{6}$-Methylierungen haben dabei die größere Bedeutung, da sie stabiler als $\mathrm{N}^{7}$-Methylierungen sind. 
Tab. 1-7: Eigenschaften und Zerfall des Alkylans Temozolomid

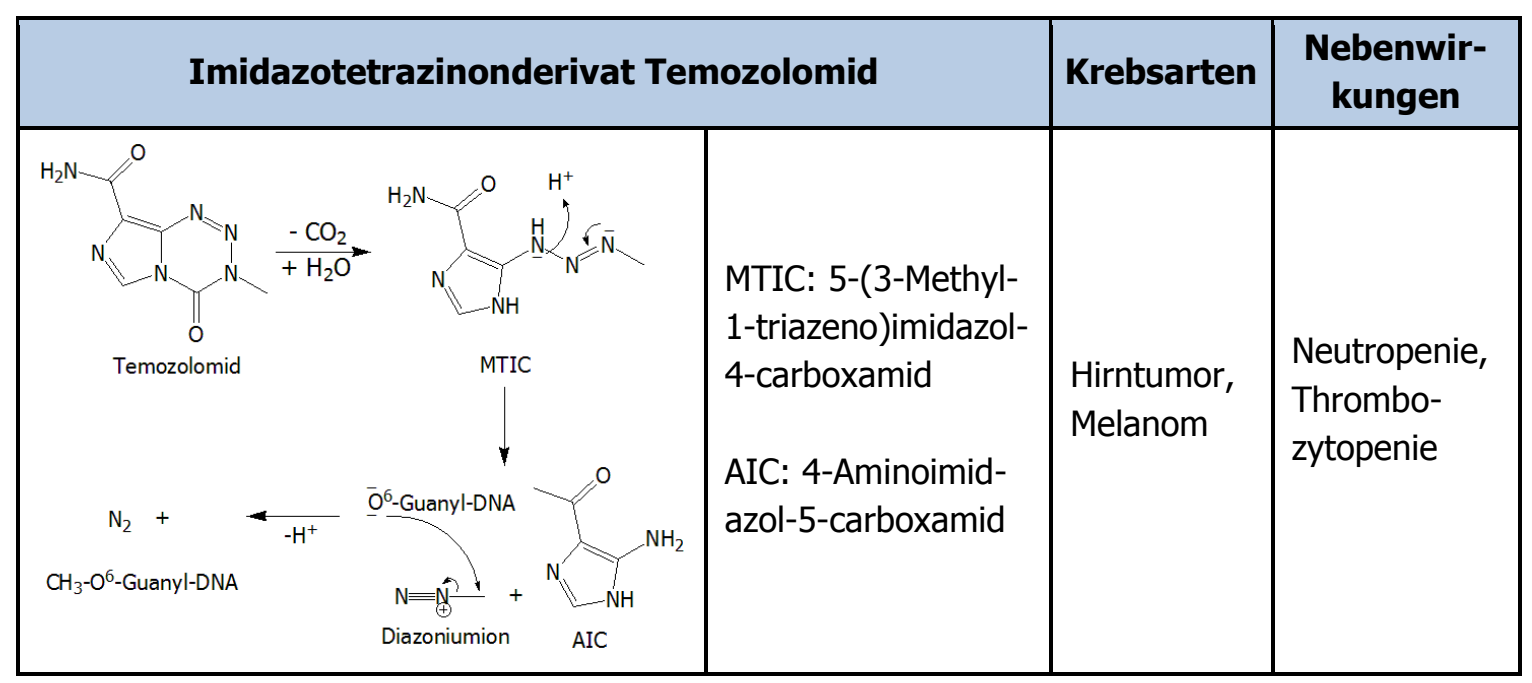

aus [30], [135]

\subsubsection{Interkalierung in die DNA}

Zytostatika dieser Klasse ordnen sich zwischen DNA-Basen an. Ermöglicht wird dies durch die planaren Ringstrukturen der Anthrazyklinderivate. Doxorubicin ist ein weit verbreitetes Zytostatikum, dessen Wirkmechanismen noch nicht vollständig aufgeklärt sind. Die Hauptwirkung besteht in seiner Fähigkeit, in die DNA zu interkalieren und so zur fehlerhaften Transkription zu führen. Außerdem wird der Chinonring des Doxorubicinmoleküls im Körper enzymatisch zu Hydrochinon reduziert.

Tab. 1-8: Interkalantien

\begin{tabular}{|l|l|l|l|}
\hline \multicolumn{1}{|c|}{ Krebsarten } & Nebenwirkungen & SLC-Interaktion \\
\hline Lymphom, & $\begin{array}{l}\text { Kronchialkarzinom, } \\
\text { Brustkrebs, Sarkom, } \\
\text { Tumore bei Kindern }\end{array}$ & $\begin{array}{l}\text { Kardiotoxizität, } \\
\text { Knochenmarkschä- } \\
\text { digung }\end{array}$ & $\begin{array}{l}\text { Wechselwirkung: } \\
\text { OCT6, OCTN1 }\end{array}$ \\
\hline
\end{tabular}

aus [103]

Bei der spontanen Rückreaktion werden reaktive Sauerstoffspezies gebildet, die zu DNAund Zellmembranschäden führen. Ein dritter Wirkmechanismus von Doxorubicin ist die 
Topoisomerase-II-Hemmung, die zu DNA-Strangbrüchen führt (Tab. 1-8) [103]. Mitoxantron interkaliert ebenso wie Doxorubicin in die DNA und hemmt die Topoisomerase II. Die Sauerstoffradikalbildung ist weniger ausgeprägt als bei Doxorubicin [103].

\subsubsection{Topoisomerasehemmung}

Topoisomerasen binden während der Replikation an die DNA, brechen die Stränge auf und fügen sie nach (Ent-)Windung wieder zusammen, so dass die Superhelixstruktur erhalten bleibt. Topoisomerase I bindet an DNA-Einzelstränge, Topoisomerase II an Doppelstränge. Topoisomerasehemmstoffe binden nach dem Strangbruch an den Topoisomerase-DNA-Komplex und verhindern das Zusammenfügen der DNA. Das Prodrug Irinotecan ist ein Camptothecinderivat (Tab. 1-9) und wird vor allem in der Leber enzymatisch zu SN38 metabolisiert. SN38 bindet an die Topoisomerase I [108], [158]. Etoposid (Tab. 1-9) ist ein halbsynthetisches Podophyllotoxin und hemmt die Topoisomerase II [64].

Tab. 1-9: Topoisomerasehemmer

\begin{tabular}{|c|c|c|c|}
\hline $\begin{array}{l}\text { Camptothecin- und Podophyllo- } \\
\text { toxinderivat }\end{array}$ & Krebsarten & $\begin{array}{l}\text { Nebenwirkun- } \\
\text { gen }\end{array}$ & $\begin{array}{c}\text { SLC- } \\
\text { Interaktion }\end{array}$ \\
\hline Irinotecan & $\begin{array}{l}\text { Darm-, Lungen-, } \\
\text { Magen-, } \\
\text { Eierstockkrebs }\end{array}$ & $\begin{array}{l}\text { Knochenmark- } \\
\text { schädigung, } \\
\text { Darmstörung }\end{array}$ & $\begin{array}{l}\text { Wechselwir- } \\
\text { kung: OCT1, } \\
\text { OCT3 }\end{array}$ \\
\hline Etoposid & $\begin{array}{l}\text { Bronchial-, } \\
\text { Hoden-, Eier- } \\
\text { stockkrebs, } \\
\text { Leukämie, } \\
\text { Lymphom, } \\
\text { Gliom }\end{array}$ & $\begin{array}{l}\text { Knochenmark- } \\
\text { schädigung, } \\
\text { Leukämie }\end{array}$ & $\begin{array}{l}\text { Inhibierung: } \\
\text { OCT1, OCT2, } \\
\text { OCT3 }\end{array}$ \\
\hline
\end{tabular}

aus [5], [59], [108], [150], [64]

\subsubsection{Radikalbildner Bleomycin}

Bleomycin (Tab. 1-10) hebt sich in seinem Wirkmechanismus von den bisher genannten, auf die DNA einwirkenden Zytostatika ab. Es bildet nach Aktivierung einen Bleomycin-

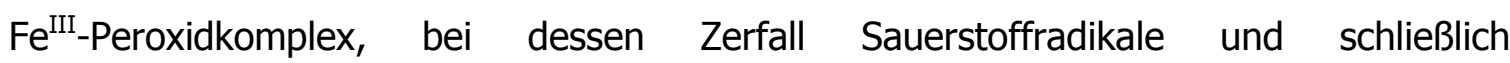


Hydroxylradikale gebildet werden. Diese spalten Wasserstoffatome von Desoxyribosemolekülen der DNA ab, wodurch schließlich eine Abspaltung von Purin- und Pyrimidinbasen stattfindet [5], [47], [154].

Tab. 1-10: Radikalbildner

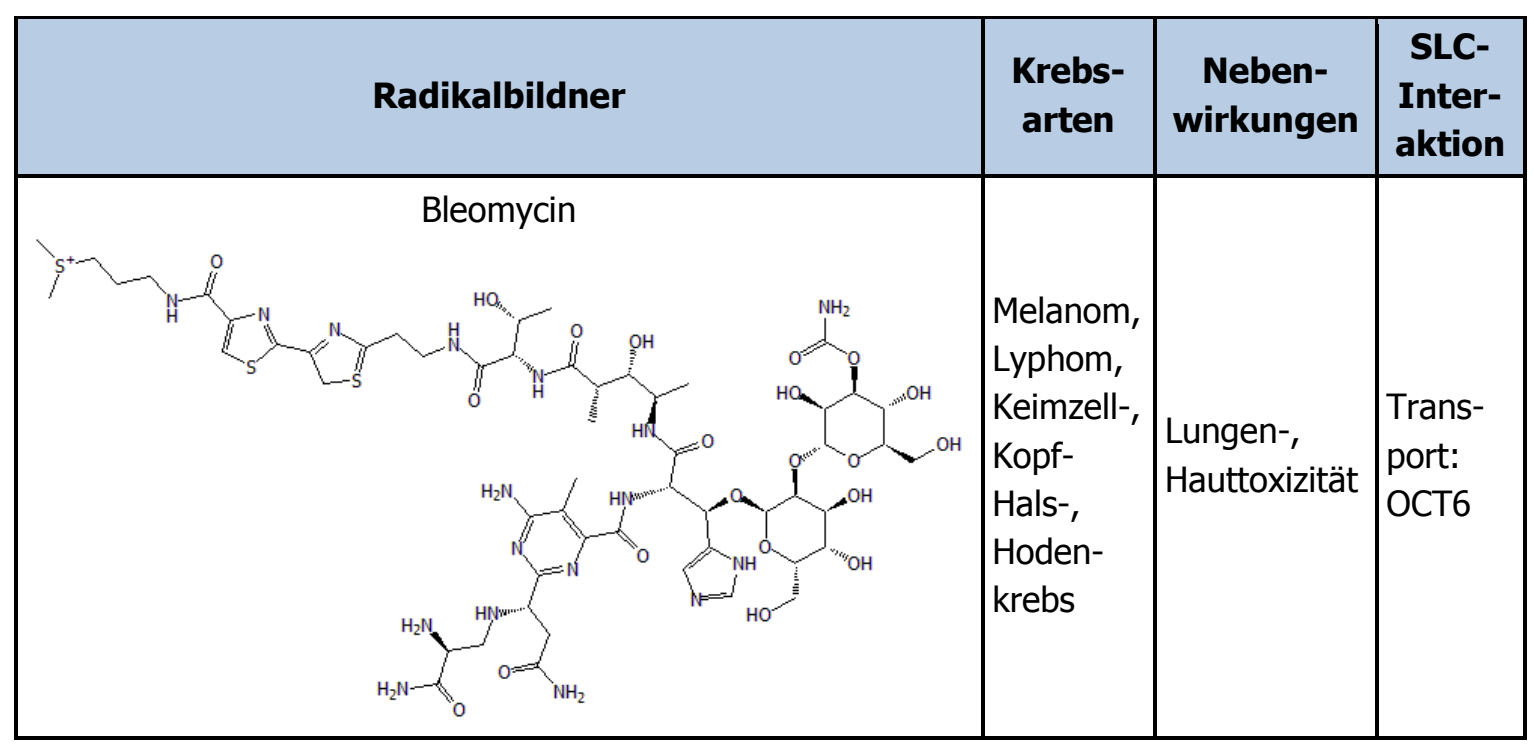

aus [5], [9], [47], [145], [154]

\subsubsection{Mitosehemmung}

Neben den bisher vorgestellten Zytostatika, die die DNA angreifen, bilden die Mitosehemmstoffe eine weitere Klasse. Während der Mitose kommt es zur Ausbildung des Spindelapparats, welcher die Aufgabe hat, die Chromosomen in ihre Chromatiden aufzuspalten. Er besteht aus polymerisiertem Tubulin, den Mikrotubuli. Mikrotubulin liegt mit nicht polymerisiertem Tubulin im dynamischen Gleichgewicht. Mitosehemmstoffe (Tab. 1-11) wirken auf dieses dynamische Gleichgewicht ein, indem sie entweder die Polymerisation oder die Depolymerisation hemmen. Die Mitose wird so unterbunden und es kommt zur Apoptose.

Die Vincaalkaloide Vinblastin, Vincristin und Vindesin verhindern die Polymerisation der Tubuli, das Taxan Paclitaxel verhindert nach enzymatischer Aktivierung die Depolymerisation der Mikrotubuli [100].

Estramustin besteht aus einem Stickstoff-Lost- und einem Estradiolanteil. Dennoch besteht seine Hauptwirkung nicht in der Alkylierung von DNA oder der Bindung an Hormonrezeptoren, sondern in der Einwirkung auf die Mikrotubuli. Einerseits stabilisiert es vermutlich die Mikrotubuli gegenüber Depolymerisation, anderseits inhibiert es vermutlich die mikrotubuli-bindenen Proteine [104]. 
Tab. 1-11: Mitoseinhibitoren

\begin{tabular}{|c|c|c|c|}
\hline Vincaalkaloide und Taxan & Krebsarten & $\begin{array}{l}\text { Nebenwir- } \\
\text { kungen }\end{array}$ & $\begin{array}{l}\text { Inter- } \\
\text { aktion }\end{array}$ \\
\hline$\left(\begin{array}{l}\text { Vinblastin: } \\
\text { R1 = CH3 } \\
\text { R2 = OCH3 } \\
\text { R3 = COCH3 }\end{array}\right.$ & $\begin{array}{l}\text { Leukämie, Lymphom, } \\
\text { Bronchialkarzinom, } \\
\text { Brustkrebs }\end{array}$ & $\begin{array}{l}\text { Knochenmark- } \\
\text { schädigung }\end{array}$ & unbekannt \\
\hline $\begin{array}{l}\text { Vincristin: } \\
\text { R1 = CHO } \\
\text { R2 = OCH3 } \\
\text { R3 }=\text { COCH3 }\end{array}$ & $\begin{array}{l}\text { Lymphom, } \\
\text { Hirntumor, Brust-, } \\
\text { Lungenkrebs, } \\
\text { Melanom, Myelom }\end{array}$ & Neurotoxizität & unbekannt \\
\hline $\begin{array}{l}\text { Vindesin: } \\
\text { R1 }=\mathrm{CH} 3 \\
\mathrm{R} 2=\mathrm{NH} 2 \\
\mathrm{R} 3=\mathrm{H}\end{array}$ & $\begin{array}{l}\text { Melanom, Lungen-, } \\
\text { Brust-, Hals-Kopf- } \\
\text { Karzinom, Lymphom, } \\
\text { Leukämie }\end{array}$ & $\begin{array}{l}\text { Knochenmark- } \\
\text { schädigung }\end{array}$ & unbekannt \\
\hline Vincaalkaloide und Taxan & Krebsarten & $\begin{array}{l}\text { Nebenwir- } \\
\text { kungen }\end{array}$ & $\begin{array}{l}\text { Inter- } \\
\text { aktion }\end{array}$ \\
\hline Paclitaxe & $\begin{array}{l}\text { Brust-, Eierstock-, } \\
\text { Lungenkrebs, Kopf- } \\
\text { Hals-Karzinom }\end{array}$ & $\begin{array}{l}\text { Knochenmark- } \\
\text { schädigung, } \\
\text { Brochnospas- } \\
\text { mus, Neuro-, } \\
\text { Kardio-, } \\
\text { Muskeltoxizität }\end{array}$ & $\begin{array}{l}\text { Transport: } \\
\text { OATP8, } \\
\text { OAT2 } \\
\text { Wechsel- } \\
\text { wirkung: } \\
\text { OCT1 } \\
\text { Inhibierng: } \\
\text { OCT2, } \\
\text { OCT3 }\end{array}$ \\
\hline Estramustin & Prostatakrebs & $\begin{array}{l}\text { Kardio-, } \\
\text { Magen- und } \\
\text { Darmtoxizität }\end{array}$ & unbekannt \\
\hline
\end{tabular}

aus [39], [51], [59], [61], [77], [100]

\subsubsection{Weitere Zytostatika}

Zwei Zytostatika, welche weder auf die DNA noch auf die Mitose wirken, sind Tamoxifen und Clodronat (Tab. 1-12). Der Hormonrezeptorantagonist Tamoxifen schädigt Zellen, welche Estrogenrezeptoren exprimieren. Es bindet nach enzymatischer Metabolisierung an diese Rezeptoren und blockiert sie für die Bindung von Estrogen. Damit wird die Produktion von Wachstumsfaktoren und dadurch wiederum die DNA- und RNAPolymerase während der Replikation und Transkription gehemmt [46]. 
Das Bisphosphonat Clodronat wurde ursprünglich bei der Tumortherapie in Kombination mit Zytostatika eingesetzt, um Knochenschäden und -schmerzen zu verringern. Die Substanz wirkt jedoch auch gegen Knochenmetastasen bei Krebsarten wie dem Mammakarzinom in Kombination mit Zytostatika. Die Clodronatmoleküle akkumulieren an der Knochenoberfläche, zerstören bereits vorhandene Tumorzellen und verhindern die Einlagerung neuer Tumorzellen [35].

Tab. 1-12: Hormonrezeptorantagonist und Bisphosphonat

\begin{tabular}{|c|c|c|}
\hline Weitere Zytostatika & Krebsarten & Nebenwirkungen \\
\hline Tamoxifen & Brustkrebs & 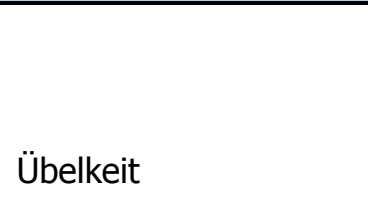 \\
\hline 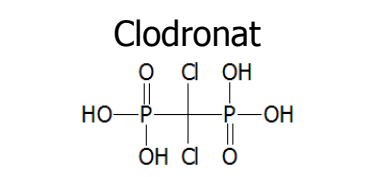 & Mammakarzinom, Myelom & (Nephrotoxizität) \\
\hline
\end{tabular}

aus [104] 


\subsection{Ziel der Arbeit}

Die Ansprechraten von Tumorzellen bei der Therapie mit Zytostatika sind auf Grund von Chemoresistenz oft gering. Ein Teil der Resistenz entsteht durch eine geringe Akkumulation der Zytostatika in Tumorzellen, bedingt durch den Efflux über $A B C$ Transportproteine [181]. Durch die vermehrte Aufnahme von bestimmten Zytostatika in Tumorzellen über spezielle Aufnahmeproteine der SLC-Familie könnte die Zytostatikaakkumulation und damit die Chemosensitivität der Tumorzellen gesteigert werden.

Ziel der Arbeit ist es, zu untersuchen, ob SLC-Transporter eine Möglichkeit darstellen, die efflux-bedingte Resistenz in Melanomzellen zu verringern. Es soll erstens untersucht werden, welche potentiell zytostatika-transportierenden SLC-Transporter in Melanomzelllinien exprimiert sind, zweitens mit welchen Zytostatika sie interagieren und drittens, ob eine SLC-vermittelte Zytotoxizität für die interagierenden Zytostatika vorliegt.

Ein Nebeneffekt der Krebstherapie mit Chemotherapeutika ist deren hohe Toxizität für nicht entartete Zellen, besonders für jene der Sekretionsorgane Leber und Niere. Ein weiteres Ziel dieser Arbeit ist es, zu klären, inwiefern bestimmte, in diesen Zellen exprimierte SLC-Proteine durch den Transport von Zytostatika an diesen unerwünschten Wirkungen beteiligt sein können. Zu diesem Zweck soll erstens untersucht werden, mit welchen weiteren Zytostatika außer den bereits bekannten, die SLC-Proteine MATE1 und OCT1 interagieren. Zweitens soll untersucht werden, ob für diese Zytostatika eine MATE1- bzw. OCT1-vermittelte Zytotoxizität vorliegt.

Die Arbeit entstand im Rahmen des Projektes "Die Bedeutung genetischer Polymorphismen in der Onkologie: Von den Grundlagen zur individualisierten Therapie" des Graduiertenkollegs 1034. Die Projekte des Graduiertenkollegs verfolgen das übergeordnete Ziel, die Tumorbehandlung zu verbessern und unerwünschte Nebenwirkungen zu reduzieren ${ }^{1}$.

\footnotetext{
${ }^{1}$ Graduiertenkolleg 1034: „Die Bedeutung genetischer Polymorphismen in der Onkologie: Von den Grundlagen zur individualisierten Therapie", Leiter: Prof. Dr. J. Brockmöller, Universität Göttingen http://www.gcpg.de, gefördert von der Deutschen Forschungsgemeinschaft
} 


\section{Materialien}

Für die Durchführung der Untersuchungen nach der in Kapitel 3 beschriebenen Methodik wurden verschiedene Materialien eingesetzt. Diese und deren Bedeutung für die Untersuchungen werden folgend beschrieben.

\subsection{Geräte}

Die in der Zellkultur, Polymerase-Kettenreaktion (PCR) und weitere verwendete Geräte sind in Tab. 2-1 aufgeführt.

Tab. 2-1: Geräte

\begin{tabular}{|c|c|c|}
\hline Art & Gerätetyp & Herkunft \\
\hline \multicolumn{3}{|l|}{ Zellkultur } \\
\hline $\mathrm{CO}_{2}$-Inkubator & Function Line BB16 & Heraeus, Hanau \\
\hline Neubauer-Zählkammer & & Saaringia, Saarlouis \\
\hline \multirow{2}{*}{ Sterilbänke } & Microflow & Nunc, Langenselbold \\
\hline & Safe 2020 & Thermo Scientific, Langenselbold \\
\hline \multicolumn{3}{|c|}{ PCR und Agarosegel-Elektrophorese } \\
\hline Geldokumentation & Gel Print 2000 I & Biophotonics, Ann Arbor, MI, USA \\
\hline Gelkammer & Midi & \multirow{2}{*}{ Eurofins MWG Operon, Ebersberg } \\
\hline Labornetzteil & Power supply PPS200-1D & \\
\hline Peltier-Thermal-Cycler & PTC-200 & MJ Research Inc., St. Bruno, Kanada \\
\hline Real-Time-Thermal-Cycler & Mx3005p & Agilent Technologies, Waldbronn \\
\hline UV-Transilluminator & TM40 & UVP, Upland, USA \\
\hline \multicolumn{3}{|l|}{ Weitere Geräte } \\
\hline Durchflusszytometer & BD FACS Calibur & BD, New Jersey, USA \\
\hline \multirow{2}{*}{ Feinwaagen } & 2002 MP1 & \multirow{2}{*}{ Sartorius, Göttingen } \\
\hline & LC621S & \\
\hline Magnetrührer & RCT basic & IKA-Labortechnik, Staufen \\
\hline \multirow{2}{*}{ Mikroskope } & Telaval 31 & \multirow{2}{*}{ Zeiss, Jena } \\
\hline & Axio Imager.M1 & \\
\hline Mikrowelle & Privileg 8521 & Quelle Schikedanz, Fürth \\
\hline Multi-Plate-Reader & Mithras LB940 & Berthold Technologies, Bad Wildbad \\
\hline pH-Meter & InoLab pH/ION Level2 & WTW, Weilheim \\
\hline Schüttler & KS 250 basic & IKA-Labortechnik \\
\hline Spektrophotometer & GeneQuant II & Pharmacia Biotech, Freiburg \\
\hline Szintillationszähler & 1500 Tri-Carb & Packard Instruments, Meriden, USA \\
\hline Trockeninkubator & B15 & Heraeus \\
\hline Vortex & MS 1 & IKA-Labortechnik \\
\hline Waage & 1474 & Sartorius \\
\hline \multirow{4}{*}{ Zentrifugen } & Biofuge fresco & \multirow{2}{*}{ Heraeus } \\
\hline & Labofuge 400R & \\
\hline & $5415 \mathrm{D}$ & \multirow{2}{*}{ Eppendorf, Hamburg } \\
\hline & Mini Spin & \\
\hline
\end{tabular}




\subsection{Software und Online-Programme}

Zur Steuerung von Messungen und zur Datenanalyse wurden die in Tab. 2-2 genannten Programme verwendet.

Tab. 2-2: Software und Onlineprogramme

\begin{tabular}{|l|l|l|}
\hline \multicolumn{2}{|l|}{ Bezeichnung } & \multicolumn{2}{l|}{ Anwendung } \\
\hline Software & Mikroskopie & ZEISS, Jena \\
\hline Axio Vision 3.0 & Durchflusszytometrie & BD Biosciences, Heidelberg \\
\hline Cell Quest Pro & Chemische Strukturformeln & $\begin{array}{l}\text { Cambridge Soft, Massachusetts, } \\
\text { USA }\end{array}$ \\
\hline Chem Draw & Erstellung von Graphiken & Corel Corporation, Ottawa, Kanada \\
\hline $\begin{array}{l}\text { Corel Draw Graphics } \\
\text { Suite X3 }\end{array}$ & Durchflusszytometrie & Tree Star Inc., Oregon, USA \\
\hline FlowJo 6.1.1 & Bildbearbeitung & NIH, Bethesda, USA \\
\hline Image J & Agarosegel-Bildaufnahme & $\begin{array}{l}\text { Intas Science Imaging Instruments } \\
\text { GmbH, Göttingen }\end{array}$ \\
\hline Intas Gel Capture & & Microsoft, Redmond, USA \\
\hline Microsoft Office 2007 & Daten- und Textverarbeitung & Berthold Technologies, Bad Wildbad \\
\hline Micro Win 2000 & Absorptionsmessung & Agilent Technologies, Waldbronn \\
\hline MxPro - Mx3000P & Real-Time-PCR & SAS Institute GmbH, Cary, USA \\
\hline SAS 9.2 & Statistische Auswertungen & $\begin{array}{l}\text { Systat Software GmbH, San José, } \\
\text { USA }\end{array}$ \\
\hline Sigma Plot 11.0 & Datenanalyse, Erstellung von \\
& Graphiken & $\begin{array}{l}\text { http://blast.ncbi.nlm.nih.gov/Blast. } \\
\text { cgi, NCBI, Bethesda USA }\end{array}$ \\
\hline Onlineprogramme & Sequenzvergleich & $\begin{array}{l}\text { http://www.ebi.ac.uk/Tools/msa/ } \\
\text { clustalw2/, EBI, Heidelberg }\end{array}$ \\
\hline BLAST & Sequenzvergleich & $\begin{array}{l}\text { http://www.bioinformatics. } \\
\text { org/sms/rev_comp.html }\end{array}$ \\
\hline Clustal W2 & $\begin{array}{l}\text { Umwandlung in reverse, } \\
\text { komplementäre Sequenz }\end{array}$ & http://archemcalc.com/sparc/ \\
\hline Reverse complement & Berechnung von pKs-Werten & \\
\hline SPARC online calculator & &
\end{tabular}

\subsection{Substanzen}

Die in dieser Arbeit eingesetzten allgemeinen Chemikalien und biologischen Substanzen wurden bei Applichem (Darmstadt), Invitrogen (Carlsbad, USA), Roth (Karlsruhe) und Sigma Aldrich (Taufkirchen) bezogen. Radioaktiv markierte Substrate wurden bei American Radiolabeled Chemicals (St. Louis, USA) bestellt. Eine ausführliche Tabelle mit Substanzen befindet sich im Anhang (7.5). Die verwendeten Zytostatika sind in Tab. 2-3 dargestellt. 
Tab. 2-3: Zytostatika

\begin{tabular}{|l|l|}
\hline Zytostatikum / Medikament & Herkunft \\
\hline 5-Fluorouracil & Gry-Pharma / Teva Pharm, Radebeul \\
\hline Bendamustin / Ribomustin & Ratiopharm, Ulm \\
\hline Bleomycin / Bleomedac & Medac, Hamburg \\
\hline Busulfan & Sigma Aldrich, Taufkirchen \\
\hline Chlorambucil & Sigma Aldrich \\
\hline Cladribin & Sigma Aldrich \\
\hline Clodronsäure & Sigma Aldrich \\
\hline Cyclophosphamid & Prof. Ciarimboli, Exp. Nephrologie, Universität Münster \\
\hline Cytosinarabinosid & Sigma Aldrich \\
\hline Doxorubicin & Applichem, Darmstadt \\
\hline Estramustin / Estracyt & Pfizer, Berlin \\
\hline Etoposid & Sigma Aldrich \\
\hline Fludarabin & Sigma Aldrich \\
\hline Gemcitabin / GEMZAR & Lilly, Bad Homburg \\
\hline Ifosfamid & Prof. Ciarimboli, Exp. Nephrologie, Universität Münster \\
\hline Irinotecan / Campto & Pfizer \\
\hline Melphalan & Sigma Aldrich \\
\hline Methotrexat & Sigma Aldrich \\
\hline Mitomycin / -2-medac & Medac \\
\hline Mitoxantron / ONKOTRONE & Baxter, Halle / Westfalen \\
\hline Nimustin / ACNU & Baxter \\
\hline Paclitaxel / Taxol & Applichem \\
\hline Tamoxifen & Sigma Aldrich \\
\hline Temozolomid & Schering-Plough, Kenilworth, USA \\
\hline Treosulfan / Ovastat & Medac \\
\hline Trofosfamid & Asta Medica, Bad Homburg \\
\hline Vincristin & Gry-Pharma \\
\hline Vindesin / Elsidin & Teva Pharm \\
\hline & \\
\hline
\end{tabular}

\section{$2.4 \quad$ Zellen}

In dieser Arbeit wurden Zellen als Untersuchungssysteme eingesetzt. Die Expressionsanalyse (siehe 4.1) wurde an Melanomzellen und nicht entarteten Melanozyten durchgeführt. Die Untersuchungen zu den speziellen SLC-Transportern MATE1 und OCT1 (siehe 4.2) wurde an den stabil transfizierten Modellzellen HEK293 (Human embryonic kidney 293) und $\mathrm{CHO}$ (chinese hamster ovary) durchgeführt.

Die Expression von SLC-Proteinen wurde in den Melanomzelllinien MelA (MM358), MelB (MM201), MelC (MM254), LIBR und KAII bestimmt (siehe 4.1). Sie wurden freundlicherweise von Herrn Prof. Dr. Emmert (Dermatologie und Venerologie, Universitätsmedizin Göttingen) zur Verfügung gestellt. MelA, MelB und MelC stammen aus Lymphknoten metastasen, LIBR aus einem Primärtumor und KAII aus einer kutanen 
Metastase von Malignen Melanomen verschiedener, sowohl männlicher als auch weiblicher Patienten im Alter von 65-73 Jahren [134], [142].

Als Referenz zu den Melanomzelllinien wurde die Expression von SLC-Transportern in Melanozyten von gesunden Spendern untersucht. Die adhärenten Melanozytenzelllinien M02-09 und M10-09 wurden freundlicherweise von Herrn Prof. Dr. Gutzmer (Dermatologie, Medizinische Hochschule Hannover) zur Verfügung gestellt. Des Weiteren wurden die primären Melanozyten NHEM1 (normal human epidermal melanocytes), NHEM2 und NHEM3 als Pellets von Promo Cell (Heidelberg, C-14042) bezogen. Sie stammen aus verschiedenen Hautpartien sowohl männlicher als auch weiblicher Spender im Alter zwischen 20 und 55 Jahren. Die adhärenten Zellen waren gemäß der Produktinformation von Promo Cell in der dritten Kultur in der zweiten Passage geerntet worden.

Flp-In-T-REx-HEK293-Zellen (Invitrogen, Carlsbad, USA, R780-07) wurden mit Vektoren mit dem MATE1-Gen transfiziert (siehe 3.2), um dessen Transportaktivität zu untersuchen (siehe 4.2.1). CHO-OCT1-Zellen (von Herrn Prof. Koepsell, Institut für Anatomie und Zellbiologie, Universität Würzburg) wurden eingesetzt, um die Transportaktivität von OCT1 zu untersuchen (siehe 4.2.1).

\subsection{Vektoren}

Zur Klonierung der SLC-Gene MATE1 und MATE2 sowie zu deren Transfektion in HEK293-Zellen dienten die in Tab. 2-4 genannten Vektoren.

Tab. 2-4: Für Klonierung und stabile Transfektion verwendete Vektoren

\begin{tabular}{|l|l|l|}
\hline Bezeichnung & Artikelnummer & Herkunft \\
\hline pCDNA5/FRT/TO/RfB-DEST & & $\begin{array}{l}\text { Innerhalb der Arbeitsgruppe } \\
\text { von Frau Dr. S. Gupta } \\
\text { generiert [60] }\end{array}$ \\
\hline pCMV-SPORT6/MATE1 & IRATp970A099D & ImaGenes, Berlin \\
\cline { 1 - 2 } pCMV-SPORT6/MATE2 & IRATp970E1176D & \multirow{2}{*}{ Invitrogen, Carlsbad, USA } \\
\cline { 1 - 2 } pDonr221 & $12536-017$ & \\
\hline pEF5/FRT/V5-DEST & V6020-20 & V6005-20 \\
\hline pOG44 & &
\end{tabular}

\subsection{Antikörper}

Bei immunozytochemischen Tests mit dem Zytostatikum Temozolomid (siehe 4.2.3) wurden der folgende Primär- und Sekundärantikörper eingesetzt. Der Primärantikörper war gegen $0^{6}$-Methylguanyl-DNA-Addukte gerichtet. Der Sekundärantikörper war gegen 
den Primärantikörper gerichtet und trug das Fluorochrom Indocarbocyanin (Су3), welches der fluoreszenzmikroskopischen Detektion diente.

Tab. 2-5: Antikörper für Immunzytochemische Tests

\begin{tabular}{|l|l|l|}
\hline Bezeichnung & Konzentration & Herkunft/Artikelnummer \\
\hline $\begin{array}{l}\text { Primärantikörper Anti-O }{ }^{6} \text { - } \\
\text { MeG-EM2-3, monoklonal, aus } \\
\text { der Maus }\end{array}$ & $\begin{array}{l}50 \mu \mathrm{g} / \mathrm{ml} \text { in } 1 \mathrm{ml} 1 \% \text { igem } \\
\text { BSA (m/V in PBS) }\end{array}$ & $\begin{array}{l}\text { Herr PD Dr. Thomale, } \\
\text { Institut für Zellbiologie, } \\
\text { Universitätsklinikum Essen }\end{array}$ \\
\hline $\begin{array}{l}\text { Sekundärantikörper aus der } \\
\text { Ziege, anti-Maus IgG (H+L) } \\
\text { mit Indocarbocyanin (Cy3) }\end{array}$ & $1,5 \mathrm{mg} / \mathrm{ml}$ in dd Wasser & $\begin{array}{l}\text { Dianova, Hamburg/115-165- } \\
062\end{array}$ \\
\hline
\end{tabular}

\subsection{Nährmedien}

Die Nährmedien für Zellen und Bakterien (Tab. 2-6) wurden sterilisiert. Für zellspezifische Medien wurden die Grundmedien mit $10 \%(\mathrm{~V} / \mathrm{V})$ sterilem FCS und $1 \%(\mathrm{~V} / \mathrm{V})$ sterilem Penicillin/Streptomycin versetzt.

Tab. 2-6: Nährmedien

\begin{tabular}{|c|c|}
\hline Bezeichnung & Zusammensetzung \\
\hline LB-Agar & $\begin{array}{l}\text { LB-Medium, 1,5 \% (m/V) Agarose, 0,1 \% (V/V) Ampicillin- } \\
\text { Stammlösung }\end{array}$ \\
\hline LB-Medium (Luria-Broth) & $\begin{array}{l}10 \mathrm{~g} \mathrm{NaCl}, 10 \mathrm{~g} \text { Trypton, } 5 \mathrm{~g} \text { Hefeextrakt, mit doppelt } \\
\text { destilliertem (dd) Wasser auf } 1 \text { I aufgefüllt, pH 7,0 mit } 5 \mathrm{M} \\
\mathrm{NaOH}\end{array}$ \\
\hline \multicolumn{2}{|l|}{ Grundmedien } \\
\hline DMEM-HG & $\begin{array}{l}\text { 13,44 g DMEM-HG, 3,7 g NaHCO } 3 \text {, mit dd Wasser auf } 1 \text { I } \\
\text { aufgefüllt }\end{array}$ \\
\hline DMEM-LG & $\begin{array}{l}10,03 \mathrm{~g} \mathrm{DMEM}-\mathrm{LG}, 3,7 \mathrm{~g} \mathrm{NaHCO}_{3} \text {, mit dd Wasser auf } 1 \mathrm{I} \\
\text { aufgefüllt }\end{array}$ \\
\hline RPMI 1640 & $\begin{array}{l}\text { 10,39 g RPMI-1640, } 2 \mathrm{~g} \mathrm{NaHCO}_{3} \text {, mit dd Wasser auf } 1 \mathrm{I} \\
\text { aufgefüllt }\end{array}$ \\
\hline \multicolumn{2}{|l|}{ Zellspezifische Medien } \\
\hline CHO-Zellen & $\begin{array}{l}\text { DMEM-LG, } 150 \mu \mathrm{g} / \mathrm{ml} \text { L-Prolin, für CHO-OCT1-Zellen zusätzlich } \\
300 \mu \mathrm{g} / \mathrm{ml} \text { Hygromycinlösung zur Selektion von Kontrollzellen }\end{array}$ \\
\hline Flp-In-T-REx-HEK293-Zellen & $\begin{array}{l}\text { DMEM-HG, für HEK293-MATE1-Zellen zusätzlich } 175 \text { } \mu \mathrm{g} / \mathrm{ml} \\
\text { Hygromycinlösung zur Selektion von Kontrollzellen }\end{array}$ \\
\hline MelA, MelB, MelC, LIBR, KAII & RPMI-1640, 1 \% (V/V) Amphotericin-Stammlösung \\
\hline M02-09, M10-09, NHEM & Melanocyte Growth Medium M2, Supplemental Mix \\
\hline \multicolumn{2}{|l|}{ Einfriermedien } \\
\hline $\begin{array}{l}\text { Zellspezifische Medien mit } \\
\text { DMSO }\end{array}$ & Zugabe von $10 \%(\mathrm{~V} / \mathrm{V}) \mathrm{DMSO}$ \\
\hline
\end{tabular}




\subsection{Lösungen}

Die verwendeten Lösungen sind in Tab. 2-7 dargestellt. Das verwendete Wasser war zweifach destilliert. Lösungen, die in der Zellkultivierung eingesetzt wurden, wurden sterilisiert.

Tab. 2-7: Lösungen

\begin{tabular}{|c|c|}
\hline Bezeichnung & Zusammensetzung \\
\hline $\begin{array}{l}\text { Agarosegel-Elektrophorese- } \\
\text { Ladepuffer }(5 x)\end{array}$ & $\begin{array}{l}\text { 6,3 g Glycerol, } 2 \mathrm{ml} \mathrm{0,5} \mathrm{M} \mathrm{EDTA-Lösung,} \mathrm{pH} \mathrm{8.0,} 50 \mu \mathrm{l} \mathrm{Tris/HCl} \\
\mathrm{pH} 7,6,0,001 \%(\mathrm{~m} / \mathrm{V}) \text { Bromphenolblau, 0,001 \% }(\mathrm{m} / \mathrm{V}) \\
\text { Xylencyanol FF, mit nukleasefreiem Wasser auf } 10 \mathrm{ml} \text { aufgefüllt }\end{array}$ \\
\hline $\begin{array}{l}\text { Agarosegel-Elektrophorese- } \\
\text { Marker }\end{array}$ & $\begin{array}{l}\text { 1) Fermentas, SM0321: } 100 \mu \mathrm{l} \text { Marker, } 100 \mu \mathrm{l} 6 \mathrm{x} \text {-Ladepuffer } \\
\text { (Fermentas), } 400 \mu \mathrm{l} \text { nukleasefreies Wasser } \\
\text { 2) Invitrogen, } 15628-050: 10 \mu \mathrm{l} \text { Marker, } 40 \mu \mathrm{l} 5 \text { x Ladepuffer, } \\
150 \mu \mathrm{l} \text { nukleasefreies Wasser }\end{array}$ \\
\hline Alkalilösung & $2,8 \mathrm{~g} \mathrm{NaOH}, 8,2 \mathrm{~g} \mathrm{NaCl}$, mit Wasser auf $1 \mathrm{I}$ aufgefüllt \\
\hline Amphotericin-Stammlösung & 25 mg Amphotericin/ml DMSO \\
\hline Ampicillin-Stammlösung & $100 \mathrm{mg}$ Ampicillin/ml Wasser \\
\hline BSA-Lösung & $0,1 \mathrm{~g}$ BSA in $10 \mathrm{ml}$ sterilem PBS \\
\hline Ethidiumbromidstammlösung & $10 \mathrm{mg}$ Ethidiumbromid in $1 \mathrm{ml}$ nukleasefreiem Wasser \\
\hline EDTA-Lösung & $0,02 \% \mathrm{~m} / \mathrm{V}$ in PBS \\
\hline Hygromycinlösung & $50 \mathrm{mg} / \mathrm{ml} \mathrm{PBS}$ \\
\hline Kanamycinstammlösung & $50 \mathrm{mg} / \mathrm{ml}$ Wasser \\
\hline Magermilchlösung & $2,5 \mathrm{~g}$ Magermilchpulver in $50 \mathrm{ml} \mathrm{PBS}$ \\
\hline Mammalian Ringer (MR) & $\begin{array}{l}130 \mathrm{mM} \mathrm{NaCl}, 4 \mathrm{mM} \mathrm{KCl} 1 \mathrm{mM} \mathrm{CaCl}_{2}, 1 \mathrm{mM} \mathrm{MgSO}_{4}, 20 \mathrm{mM} \\
\mathrm{HEPES}, 1 \mathrm{mM} \mathrm{NaH} \mathrm{PO}_{3}, 18 \mathrm{mM} \text { Glucose, mit dd Wasser auf } 1 \text { I } \\
\text { aufgefüllt, pH 5,5, 7,4 oder 8,5 mit } \mathrm{HCl} \text { oder } \mathrm{NaOH}\end{array}$ \\
\hline PBS & 9,55 g PBS/I Wasser \\
\hline PBS-Glycin-Lösung & 2 g Glycin/l PBS-Lösung \\
\hline PBS-Tween20-Lösung & 2,5 ml Tween20/I PBS-Lösung \\
\hline RT-PCR-Puffer, 10x & $\begin{array}{l}500 \mathrm{mM} \mathrm{KCl}, 100 \mathrm{nM} \text { Tris in } \mathrm{H}_{2} \mathrm{O}, 15 \mathrm{mM} \mathrm{MgCl}, 1 \% \text { Triton } \\
\mathrm{X}-100(\mathrm{~m} / \mathrm{V})\end{array}$ \\
\hline Pepsin-Lösung & $\begin{array}{l}4 \mathrm{mg} \text { Pepsin, } 1 \mathrm{ml} \text { Wasser, } 40 \mathrm{ml} \text { von dieser Lösung und } 40 \mu \mathrm{l} \\
1 \mathrm{M} \mathrm{HCl} \text { mit } 1920 \mu \mathrm{l} \text { Wasser aufgefüllt }\end{array}$ \\
\hline Poly-D-Lysinlösung & $0,2 \mathrm{mg}$ Poly-D-Lysin/ml Wasser \\
\hline Proteinase-K-Lösung & $1 \mathrm{mg}$ Proteinase-K/ml Proteinase-K-Puffer \\
\hline Proteinase-K-Puffer & $\begin{array}{l}\text { 2,42 g Tris/HCl, pH 7,5, } 294 \mathrm{mg} \mathrm{CaCl} \text {, mit Wasser auf } 1 \text { I } \\
\text { aufgefüllt }\end{array}$ \\
\hline $\begin{array}{l}\text { TBE-Puffer (Tris-Borat- } \\
\text { EDTA), } 5 x\end{array}$ & $\begin{array}{l}54 \mathrm{~g} \text { Tris, } 27,5 \mathrm{~g} \text { Borsäure, } 20 \mathrm{ml} \mathrm{0,5} \text { M EDTA, pH 8,5, mit } \\
\text { Wasser auf } 1 \text { I aufgefüllt }\end{array}$ \\
\hline Trypsin-Lösung & $0,1 \%(\mathrm{~m} / \mathrm{V})$ in PBS \\
\hline
\end{tabular}




\section{$2.9 \quad$ Kits}

Die nachfolgenden Kits wurden eingesetzt, um RNA aus Melanomzelllinien und Melanozyten zu isolieren, cDNA zu synthetisieren, Plasmide aus E.coli-Bakterien zu isolieren und Vektorkonstrukte zu generieren.

Tab. 2-8: Kits

\begin{tabular}{|c|c|c|}
\hline Bezeichnung, Artikelnummer & Anwendung & Herkunft \\
\hline $\begin{array}{l}\text { Moloney-Maus-Leukämie-Virus- } \\
\text { Reverse-Transkriptase (M-MuLV- } \\
\text { RT) RNase H minus, } 200 \mathrm{u} / \mu \mathrm{l} \text {, } \\
\text { A5211 }\end{array}$ & cDNA-Synthese & Applichem, Darmstadt \\
\hline $\begin{array}{l}\text { Superscript-II-Reverse-Trans- } \\
\text { kriptase, } 200 \mathrm{u} / \text { Ml, 18064-014 }\end{array}$ & cDNA-Synthese & Invitrogen, Carlsbad, USA \\
\hline $\begin{array}{l}\text { NucleoSpin-Plasmid-Kit, } \\
740588.50\end{array}$ & Plasmidpräparation (mini) & Macherey-Nagel, Düren \\
\hline $\begin{array}{l}\text { CompactPrep Plasmid Midi Kit } \\
100,12745\end{array}$ & Plasmidpräparation (midi) & Qiagen, Hilden \\
\hline $\begin{array}{l}\text { Gateway BP Clonase II Enzyme } \\
\text { Mix, } 11789-020\end{array}$ & \multirow{3}{*}{ Klonierung } & \multirow{3}{*}{ Invitrogen } \\
\hline $\begin{array}{l}\text { Gateway LR Clonase II Enzyme } \\
\text { Mix, 11791-019 }\end{array}$ & & \\
\hline $\begin{array}{l}\text { One Shot } c c d B \text { Survival T1R } \\
\text { Competent Cells, C7510-03 }\end{array}$ & & \\
\hline RNeasy Mini Kit, 74104 & RNA-Isolierung & Qiagen \\
\hline
\end{tabular}

\subsection{PCR-Primer}

Die Nukleotidsequenzen der in der RT-PCR (3.7.3.1) eingesetzten SLC-spezifischen Primer wurden in dieser Arbeit nach den in 3.7.3.1 beschriebenen Kriterien ausgewählt und bei MWG Biotech, Ebersberg bestellt oder von [150] übernommen. Die für die Taqman-Real-Time-PCR (4.1) eingesetzten Primer (Taqman-Gene-Expression-Assays) wurden bei Applied Biosystems, Forster City, USA bezogen. Die Primer sind im Anhang 7.6 und 7.7 aufgelistet. 


\section{Methoden}

In diesem Kapitel werden Methoden beschrieben, die eingesetzt wurden, um die Erkenntnisse zu der einleitend beschriebenen Zielsetzung zu gewinnen.

\subsection{Zellkultur}

Die Zellen wurden unter sterilen Bedingungen kultiviert, ausgesät und aufbewahrt. Die Aufbewahrung erfolgte im Brutschrank bei $37^{\circ} \mathrm{C}$ unter $5 \%$ iger $\mathrm{CO}_{2}$-Atmosphäre.

\subsubsection{Kultivierung}

Die Zellen wurden in zellspezifischem Nährmedium (siehe 2.7) unter den in Tab. 3-1 dargestellten Bedingungen kultiviert. Alle drei Tage erfolgte ein Mediumwechsel. Um sie zu passagieren, wurde das Medium entfernt, mit PBS gewaschen und die Zellen mit Trypsinlösung von den Zellkulturgefäßen abgelöst. Bei den Melanozyten erfolgte zuvor eine Vereinzelung mittels EDTA-Lösung. Nach Zentrifugation wurde das Zellpellet in Medium resuspendiert und ein Teil der Zellen auf neuen Kulturgefäßen in Medium ausgesät.

Tab. 3-1: Zellkultivierung

\begin{tabular}{|c|c|c|c|c|}
\hline Schritt & HEK293-Zellen & CHO-Zellen & Melanomzellen & Melanozyten \\
\hline Aufbewahrung & \multicolumn{3}{|c|}{ Kulturschalen, 10 oder $15 \mathrm{~cm} \varnothing$} & $\begin{array}{l}\text { Flaschen, } \\
25 \mathrm{~cm}^{2} \text { Fläche }\end{array}$ \\
\hline Teilung & $\begin{array}{l}\text { nach } 6 \mathrm{~d} \text { im Ver- } \\
\text { hältnis } 1: 5\end{array}$ & $\begin{array}{l}\text { nach } 10 \mathrm{~d}, \mathrm{im} \\
\text { Verhältnis } 1: 10\end{array}$ & $\begin{array}{l}\text { nach } 6 \mathrm{~d} \text { im } \\
\text { Verhältnis } 1: 3 \\
\text { (MelC), } \\
1: 4 \text { (MelA, MelB), } \\
1: 6 \text { (LIBR, KAII) }\end{array}$ & $\begin{array}{l}\text { 1:3 nach: } \\
9 \text { d (M02-09) } \\
6 \text { d (M10-09) }\end{array}$ \\
\hline Ablösen & \multicolumn{3}{|c|}{$\begin{array}{l}3 \text { bzw. } 4 \mathrm{ml} \text { Trypsinlösung, bei CHO-Zellen } 5 \mathrm{~min} \text { bei } 37^{\circ} \mathrm{C} \\
\text { inkubiert, bei den anderen Zellen direkt abgelöst }\end{array}$} & $\begin{array}{l}\text { erst } 4 \text { ml EDTA- } \\
\text { Lösung dann } \\
5 \text { ml } \\
\text { Trypsinlösung, } \\
5 \text { min bei } 37^{\circ} \mathrm{C}\end{array}$ \\
\hline Zentrifugieren & \multicolumn{3}{|l|}{$1000 \mathrm{U} / \mathrm{min}, 4 \mathrm{~min}$} & $\begin{array}{l}900 \mathrm{U} / \mathrm{min}, \\
3 \mathrm{~min}\end{array}$ \\
\hline
\end{tabular}

\subsubsection{Bestimmung der Zellzahl}

Zur Bestimmung der Zellzahl wurden $10 \mu \mathrm{l}$ der Zellsuspension wurden im Verhältnis 1:20 in Medium verdünnt und in einer Neubauer-Zählkammer unter einem Lichtmikroskop gezählt. Die Neubauer-Zählkammer ist eine Glaskammer, in die ein definiertes Volumen einer Zellsuspension gefüllt wird. Sie besitzt eine Rasterung in Form von vier Quadranden, die wiederum in jeweils 16 Quadrate unterteilt sind. Die Zellen in jedem 
Quadranden wurden gezählt und der Mittelwert über alle vier Quadranden gebildet. Dieser Wert wurde mit dem Verdünnungsfaktor 20 multipliziert und man erhielt die Zellzahl pro Quandrand. Da der Quadrand ein Volumen von 0,1 $\mu$ l besaß, wurde die Zellzahl mit 10000 multipliziert, um die Zellzahl pro ml Medium zu erhalten.

\subsubsection{Einfrieren und Auftauen der Zellen}

Die Zellen wurden von den Kulturgefäßen gelöst, zentrifugiert und der Überstand abgenommen. Das Zellpellet wurde in $1 \mathrm{ml}$ Medium resuspendiert und die Zellzahl bestimmt. Nach Zentrifugation und Abnahme des Überstands wurden je $1 \cdot 10^{6}$ Zellen in $1 \mathrm{ml}$ Einfriermedium resuspendiert und je $1 \mathrm{ml}$ Suspension in ein Kryoröhrchen überführt, welches auf $0^{\circ} \mathrm{C}$ vorgekühlt war. Die Zellen wurden für 30 min bei $0^{\circ} \mathrm{C}$, für $24 \mathrm{~h}$ bei $-80^{\circ} \mathrm{C}$ und danach bis zur Verwendung bei $-196{ }^{\circ} \mathrm{C}$ in flüssigem Stickstoff gelagert.

Um die in flüssigem Stickstoff gelagerten Zellen in Kultur zu bringen, wurden sie im Wasserbad bei $37^{\circ} \mathrm{C}$ aufgetaut. Die Zellsuspension wurde in ein Kulturgefäß mit Medium gegeben. Nach $24 \mathrm{~h}$ wurde das Medium auf zellspezifisches Medium ohne DMSO gewechselt.

\subsubsection{Aussaat der Zellen}

Bei einer $80 \%$ igen Konfluenz wurden die Zellen von den Kulturschalen abgelöst und zentrifugiert (siehe 3.1.1). Das Zellpellet wurde in $1 \mathrm{ml}$ Medium resuspendiert, die Zellzahl bestimmt (siehe 3.1.2) und die Zellen in 6-, 24- bzw. 96-Loch-Zellkulturplatten ausgesät. Da HEK293-Zellen nur schwach adhärent sind, wurde für diese Zellen der Boden der Platten vor der Aussaat für $10 \mathrm{~min}$ mit Poly-D-Lysin benetzt, danach das überschüssige Poly-D-Lysin entfernt und die Platten bei Raumtemperatur getrocknet.

\subsection{Generierung von MATE1-HEK293-Zellen}

Das Gen des SLC-Proteins MATE1 wurde in HEK293-Zellen transportiert und vervielfältigt. Dieser Vorgang wird Transfektion bezeichnet (siehe 3.2.4). Die Zellen exprimierten MATE1, so dass auf diese Weise seine Transportaktivität und Interaktion mit Zytostatika untersucht werden konnte (siehe 3.3).

Der Transfektion des MATE1-Gens in HEK293-Zellen gingen die folgenden vorbereitenden Schritte voraus:

- Die Gensequenz von MATE1 war in den PCMV-SPORT6-Vektor insertiert und befand sich in E.coli-Bakterien. Vektoren sind Nukleinsäuremoleküle, zum Beispiel Plasmide, 
welche den Transport der integrierten DNA-Fragmente in Wirtszellen vermitteln. Im ersten vorbereitenden Schritt wurden die Bakterien, das heißt die Wirtszellen, vereinzelt und vervielfältigt (3.2.1).

- Es folgte die Isolierung der das MATE1-Gen enthaltenden Plasmide aus den E.coliBakterien (3.2.2).

- Da der pCMV-SPORT6-Vektor nicht die für die Transfektion benötigten Nukleotidsequenzen trug, wurde das MATE1-Gen anschließend in einen geeigneten Vektor kloniert (3.2.3). Als Klonierung wird die Rekombination von DNA-Fragmenten bezeichnet.

- Der klonierte MATE1-Vektor wurde zur Vervielfältigung erneut in E.coli-Bakterien transportiert. Diesen Vorgang bezeichnet man als Transformation (3.2.3).

- Nach erneuter Plasmidisolierung konnte die Transfektion des MATE1-Vektors in HEK293-Zellen erfolgen (3.2.4).

\subsubsection{Vervielfältigung der Ausgangsvektoren in E.coli-Bakterien}

Die E.coli-Bakterien, welche den Ausgangs-Expressionsvektor pCMV-SPORT6-Vektor mit MATE1-Gen enthielten, wurden auf Nährböden vereinzelt. Nach Vervielfältigung wurden einzelne Bakterienklone, das heißt genetisch identische Bakterienkolonien, welche aus demselben Bakterium stammen, entnommen. Diese wurden unter Anwesenheit des Antibiotikums Ampicillin erneut vervielfältigt. Da der eingeschleuste Vektor ein Ampicillinresistenzgen trug, überlebten nur Bakterien mit diesem Vektor. Der Vektor trug außerdem einen Replikationsursprung, welcher die von der Bakterienzellteilung unabhängige Vervielfältigung der Plasmide ermöglichte. So war es möglich, eine sehr hohe Anzahl an Plasmiden zu erhalten. Die beschriebene Vervielfältigung der Ausgangsvektoren lief nach folgender Prozedur ab:

- Die E.coli-Bakterien wurden in $100 \mu$ LB-Medium gelöst und nach Verdünnung im Verhältnis 1:100 bzw. 1:1000 mit LB-Medium auf Agar-Nährboden ausgestrichen.

- Nach $12 \mathrm{~h}$ Inkubation bei $37^{\circ} \mathrm{C}$ wurden einzelne Bakterienklone entnommen und zu $20 \mathrm{ml}$ sterilem LB-Medium gegeben, welches zur Selektion $100 \mu \mathrm{g} / \mathrm{ml}$ Ampicillin enthielt.

- Die E.coli-Schüttelkulturen wuchsen bei $37^{\circ} \mathrm{C}$ und $220 \mathrm{U} / \mathrm{min}$ für $12 \mathrm{~h}$.

\subsubsection{Plasmidisolierung}

Um die in den E.coli-Bakterien angereicherten Plasmide zu gewinnen, wurden die Zellmembranen der Bakterien zerstört. Die Freisetzung der Plasmide bezeichnet man als Plasmidisolierung. Sie erfolgte für bis zu $40 \mu \mathrm{g}$ Plasmid-DNA mit dem NucleoSpin- 
Plasmid-Kit (Mini-Kit) und für bis zu $10 \mathrm{mg}$ Plasmid-DNA mit dem Compact-PrepPlasmid-Midi-Kit. Die Durchführung wurde nach dem im Handbuch des Herstellers beschriebenen Verfahren durchgeführt (Macherey-Nagel).

\subsubsection{Klonierung des MATE1-Gens in einen Expressionsvektor}

Als Klonierung werden der Austausch und die Neuanordnung (Rekombination) von DNAFragmenten bezeichnet. In dieser Arbeit wurde die MATE1-Gensequenz mittels Gateway Clonase System (siehe 2.9) von dem Ausgangs-Expressionsvektor PCMV-SPORT6, im Folgenden als Ausgangsvektor bezeichnet, in einen neuen Expressionsvektor kloniert, der die für die nachfolgende Transfektion notwendigen Schnittstellen und Gene besaß (pEF/FRT/V5, im Folgenden als Expressionsvektor bezeichnet, Abb. 3-2 c). Die beteiligten Plasmide wurden von Enzymen der Bakteriophage $\lambda$ an Stellen mit spezifischen Nukleotidsequenzen geschnitten und mit anderen Sequenzen vertauscht. Die Gateway-Klonierung besteht aus der BP- und der LR-Reaktion, welche nach den Rekombinationsstellen der beteiligten Plasmide benannt sind (Abb. 3-1 und Abb. 3-2).

Bei der BP-Reaktion, benannt nach den beteiligten Schnittstellen der Vektoren, wird das MATE1-Gen des Ausgangsvektors (Abb. 3-1 a) gegen das ccdB-Gen des Donorvektors (Abb. 3-1 b) ausgetauscht. Das Plasmid wird an den Stellen attB1/attB2 bzW. attP1/attP2 geschnitten. Dabei entsteht der Entry-Vektor (Abb. 3-1 c) mit dem MATE1-Fragment und ein Vektor mit dem Gen ccdB (Abb. 3-1 d), welches für Bakterien, die den Vektor in sich tragen, toxisch ist, so dass nur Bakterien mit Entry-Vektor überlebensfähig sind. Der Entry-Vektor trägt zusätzlich ein Kanamycin-Resistenzgen, um Bakterien mit diesem Vektor von denen ohne ihn durch Kanamycin zu selektieren.

a)

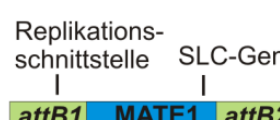

b)

toxisches Gen

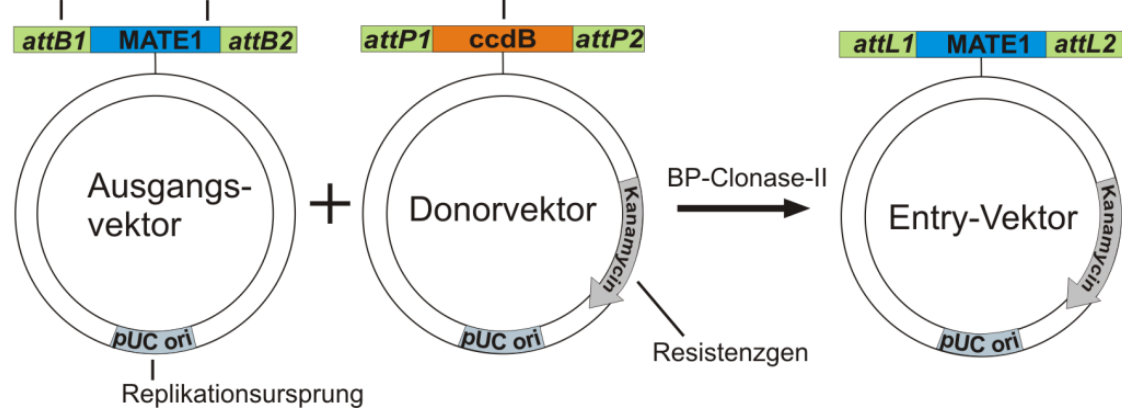

d)

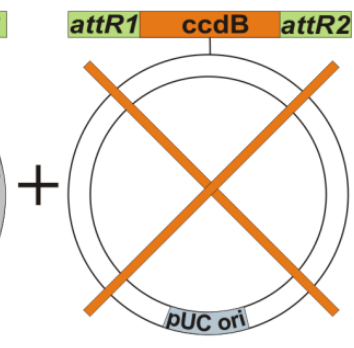

Abb. 3-1: Generierung des Entry-Vektors (BP-Reaktion):

Rekombinierung von attB1 und attB2 des Ausgangsvektors (a) mit attP2 bzw. attP1 des Donorvektors (b) zum Entry-Vektor (c) und Vektor mit toxischem ccdB-Gen (d)

Bei der LR-Reaktion rekombinieren die attL-Stellen des Entry-Vektors (Abb. 3-2 a) mit den attR-Stellen des Zielvektors (Abb. 3-2 b). Es entsteht der neue Expressionsvektor 
(Abb. 3-2 c) und als Nebenprodukt ein Vektor, der wiederum das toxische ccdB-Gen trägt (Abb. 3-2 d). Die Selektion erfolgt ebenfalls über ein Ampicillinresistenzgen auf dem neuen Expressionsvektor. Der so entstandene Expressionsvektor mit MATE1-Gen trägt die benötigten Nukleotidsequenzen für die nachfolgende Transfektion (siehe 3.2.4).

a)

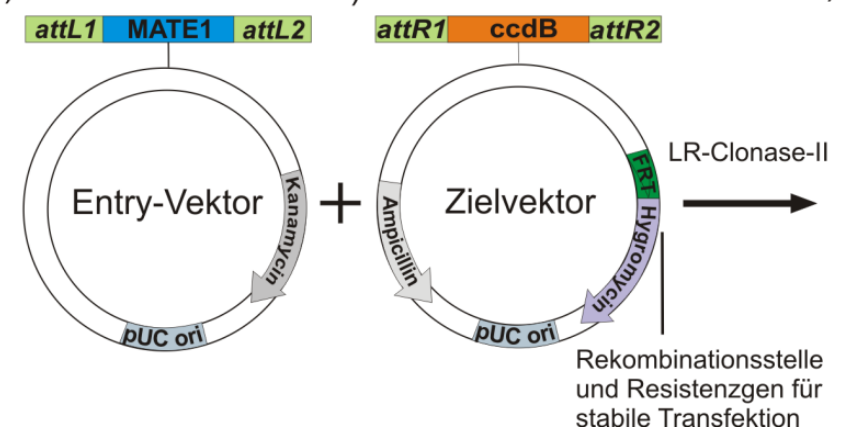

c)

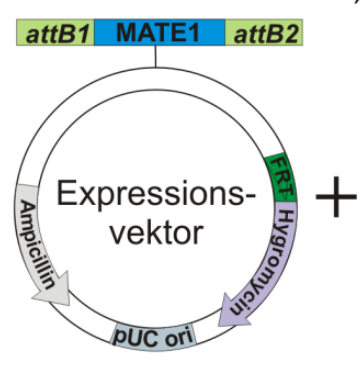

d)

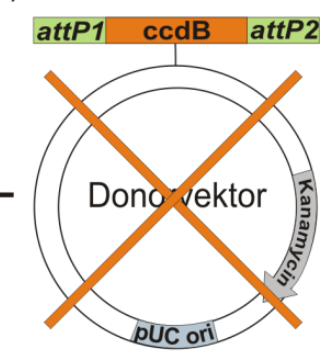

Abb. 3-2: Generierung des Expressionsvektors (LR-Reaktion):

Rekombinierung von attL1 und attL2 des Entry-Vektors (a) mit attR2 bzw. attR1 des Zielvektors (b) zum Expressionsvektor (c) und Vektor mit toxischem ccdB-Gen (d)

Der bei der BP-Reaktion gebildete Entry-Vektor und der bei der LR-Reaktion gebildete Expressionsvektor wurden in E.coli-Bakterien transformiert. Transformation ist der Transport von DNA über Vektoren in Bakterienzellen. Sie dient der Vervielfältigung der klonierten Vektoren. Die Bakterienzellen müssen dazu fähig sein, die Vektoren aufzunehmen (Kompetenz). Hier wurden genetisch modifizierte E.coli-Bakterien eingesetzt, welche keine natürliche Kompetenz besaßen. Die E.coli-Bakterien wurden daher einem Hitzeschock ausgesetzt, wodurch sich Poren in der Bakterienmembran bildeten, über die die Vektoren aufgenommen werden konnten. Die transformierten Vektoren konnten, da sie einen Replikationsursprung besaßen, unabhängig von der Bakterienzellteilung repliziert werden, so dass eine sehr hohe Anzahl an vervielfältigten Vektoren gewonnen wurde.

Die Generierung des Entry-Vektors mit anschließender Transformation lief wie folgt ab:

- $100 \mathrm{ng}$ des isolierten PCMV-SPORT6-MATE-Plasmids (Ausgangsvektor) und $150 \mathrm{ng}$ pDONR221-Vektor (Donorvektor) wurden mit 3,6 $\mu$ TE-Puffer mit pH 8 auf $8 \mu \mathrm{l}$ aufgefüllt.

- $2 \mu \mathrm{BP}$-Clonase-II-Enzymmix wurden hinzugegeben und für $1 \mathrm{~h}$ bei $25^{\circ} \mathrm{C}$ inkubiert.

- Durch Zugabe von $1 \mu$ l Proteinase-K-Lösung wurden die Enzyme deaktiviert und die Proben für 10 min bei $37^{\circ} \mathrm{C}$ inkubiert.

- Für die Transformation des Entry-Vektors in One-Shot-OmniMAX-2-T1-PhageResistant-Zellen wurden $50 \mu$ der Zellen mit $1 \mu$ der BP-Produkte für 30 min bei $0{ }^{\circ} \mathrm{C}$ und für $30 \mathrm{~s}$ bei $42{ }^{\circ} \mathrm{C}$ gelagert. 
- Die Proben wurden unter Schütteln für $1 \mathrm{~h}$ bei $37^{\circ} \mathrm{C}$ mit $250 \mu \mathrm{l}$ S.O.C.-Medium inkubiert.

- $20 \mu \mathrm{l}$ bzw. $100 \mu \mathrm{l}$ der transformierten Zellen wurden auf Nährböden mit $100 \mu \mathrm{l}$ LBMedium und $50 \mu \mathrm{g} / \mathrm{ml}$ Kanamycin verteilt und $12 \mathrm{~h}$ bei $37^{\circ} \mathrm{C}$ inkubiert.

- Einzelne Klone wurden isoliert und zur Kontrolle der erfolgreichen Generierung des Entry-Klons mit insertiertem MATE1-Gen eine RT-PCR (3.7.3.1) mit MATE1-Primern angefertigt.

- Die isolierten Klone wurden in $7 \mathrm{ml} \mathrm{LB}$-Medium für $12 \mathrm{~h}$ bei $37^{\circ} \mathrm{C}$ und $220 \mathrm{U} / \mathrm{min}$ vervielfältigt und der Entry-Vektor per Plasmidpräparation (3.2.2) isoliert.

Die Generierung des Expressionsvektors mittels der LR-Reaktion lief genau wie die vorherige Generierung des Entry-Vektors ab, mit der Ausnahme, dass anstatt des Ausgangsvektors und Donorvektors, Entry-Vektor und Zielvektor eingesetzt wurden und die Reaktion vom LR-Clonase-II-Enzymmix katalysiert wurde. Die mit den gebildeten Vektoren transformierten E.coli-Bakterien wurden weiterhin nicht auf Nährböden mit Kanamycin, sondern Ampicillin verteilt.

\subsubsection{Transfektion des Expressionsvektors in HEK293-Zellen}

In 3.2.1-3.2.3 wurden die vorbereitenden Schritte für die Transfektion des MATE1-Gens in HEK293-Zellen beschrieben. Um nun die Transportaktivität von MATE1 untersuchen zu können, wurde als letzter Schritt der Prozedur seine Gensequenz in HEK293-Zellen transfiziert.

Transfektion ist der Transfer von fremden DNA-Fragmenten in eukaryotische Zellen. Die DNA-Fragmente werden in Plasmide integriert, welche den Transfer ermöglichen, sogenannte Vektoren. Enthalten die DNA-Fragmente die Sequenz für ein Gen, so kann dieses von den Wirtszellen exprimiert werden. Die transfizierten DNA-Fragmente können vorübergehend (transiente Transfektion, 3.2.4.1) oder permanent (stabile Transfektion, 3.2.4.2) in die Wirtszellen integriert sein. Im Gegensatz zur transienten insertiert bei der stabilen Transfektion das exogene DNA-Fragment in das chromosomale Genom der Wirtszellen und wird bei Zellteilung an die Tochterzellen weitergegeben.

Im ersten Schritt der Transfektion wurde das MATE1-Gen transient in HEK293-Zellen transfiziert. An den transient transfizierten Zellen sollte getestet werden, ob MATE1 von den HEK293-Zellen exprimiert wurde und ob es eine Transportaktivität aufwies (siehe 3.3). Nur bei vorhandener Transportaktivität wurde der aufwändigere Schritt der stabilen Transfektion durchgeführt, um die Interaktion von MATE1 mit Zytostatika zu testen (siehe 3.3.2). 


\subsubsection{Transiente Transfektion}

- $1,5 \cdot 10^{5}$ Zellen wurden pro Loch einer 24-Loch-Platte ausgesät.

- Nach $12 \mathrm{~h}$ wurden $1 \mathrm{\mu g}$ des MATE1-Expressionsvektors (Abb. 3-2) mit TREx-Medium ohne FCS auf $50 \mu \mathrm{l}$ aufgefüllt. Eine zweite Lösung bestand aus $48 \mu \mathrm{l}$ TREx-Medium ohne FCS und $2 \mu$ Lipofectamin. Beide Lösungen wurden einzeln für 5 min inkubiert.

- Die Lösungen wurden zusammengegeben, 20 min inkubiert und $100 \mu \mathrm{l}$ zu $400 \mu \mathrm{l}$ FCSfreiem TREx-Medium in je ein Loch auf die Zellen gegeben.

- Nach 5 h Inkubation wurde die Lösung entfernt und $500 \mu \mathrm{l} /$ Loch TREx-Medium mit FCS hinzugegeben

- Nach 24 h wurden radioaktive Transporttests durchgeführt (3.3).

\subsubsection{Stabile Transfektion}

Nachdem mittels radioaktiven Transporttests mit transient transfizierten Flp-In-TRExHEK293-Zellen eine funktionelle Aktivität von MATE1 im Expressionsvektor nachgewiesen worden war, wurde dieser stabil in Flp-In-TREx-HEK293-Zellen transfiziert, um die Interaktion von MATE1 mit Zytostatika zu untersuchen. Weiterhin wurde der pOG44-Vektor in die Zellen transfiziert, welcher das Enzym Flp-InRekombinase exprimierte. Dieses ermöglichte die Rekombination von Flp-In-TRExHEK293-Zellen und Expressionsvektor an der FRT-Rekombinationsstelle (Abb. 3-2). Außerdem fügte die Rekombinase eine Nukleotidsequenz ein, welche die Expression des auf dem Expressionsvektor befindlichen Hygromycin-Resistenzgen ermöglichte, den sogenannten Promotor. So konnten bei Zugabe von Hygromycin die transfizierten Zellen von Zellen, die den MATE1-Expressionsvektor nicht trugen, selektiert werden.

- Für die transiente Transfektion wurden in zwei Kulturschalen mit 35 mm Durchmesser $6 \cdot 10^{5}$ Zellen ausgesät und $12 \mathrm{~h}$ im Brutschrank wachsen gelassen.

- Je Kulturschale wurden 0,35 $\mu \mathrm{g}$ pEF/FRT/V5/MATE1 und $3 \mu \mathrm{g}$ pOG44-Vektor mit FCSfreiem DMEM-HG-Medium auf $1 \mathrm{ml}$ aufgefüllt. Eine zweite Lösung bestand aus $10 \mu \mathrm{l}$ Lipofectamin in $990 \mu$ FCS-freiem DMEM-HG-Medium.

- Nach fünfminütiger Inkubation wurden beide Lösungen zusammengegeben und nach 25 min Inkubation bei Raumtemperatur auf die Zellen gegeben.

- Nach $5 \mathrm{~h}$ Inkubation im Brutschrank wurde das Medium auf DMEM-HG-Medium mit 10 \% FCS gewechselt und die Zellen für $24 \mathrm{~h}$ im Brutschrank inkubiert.

- Zur Vermehrung wurden die Zellen von den Kulturschalen abgelöst und auf $10 \mathrm{~cm}$ Kulturschalen ausgesät. Nach 5 h wurden dem Medium $175 \mu \mathrm{g} / \mathrm{ml}$ Hygromycin zur Selektion hinzugefügt. 
- Anschließend wurden radioaktive Transporttests durchgeführt.

\subsection{Aufnahme von radioaktiv markierten Substraten in Zellen}

Wie in Abschnitt 1.5 dargelegt, verfolgte diese Arbeit das Ziel, die Transportfähigkeit von SLC-Proteinen für Zytostatika zu untersuchen. Der indirekte Nachweis für diese Transportfähigkeit erfolgte über radioaktive Aufnahmeexperimente. Hierzu wurden mit MATE1 transfizierte HEK293-Zellen verwendet (siehe 3.2). Zunächst wurde gezeigt, dass die HEK293-Zellen das MATE1-Protein exprimierten und dieses eine Transportaktivität besaß. Anschließend wurde untersucht, mit welchen Zytostatika MATE1 wechselwirkte. Für Zytostatika, welche eine Interaktion zeigten, wurde eine $\mathrm{IC}_{50}$-Bestimmung durchgeführt. Allerdings war die Wechselwirkung noch kein Nachweis für den Transport des Zytostatikums, so dass weitere Untersuchungen durchgeführt wurden.

Noch ein zweites SLC-Protein, der Organische-Kationen-Transporter 1 (OCT1), wurde analysiert. Für diesen ist bereits bekannt, dass er Zytostatika in Zellen aufnehmen kann [59]. Ob diese Fähigkeit von OCT1 auch bei weiteren Zytostatika zu beobachten ist, wurde in Abschnitt (siehe 4.2.1.2) untersucht.

Bei den radioaktiven Aufnahmeexperimenten wurden die Substanzen $\left[{ }^{3} \mathrm{H}\right]-$ Methyl-4phenylpyridiniumiodid $\left(\left[{ }^{3} \mathrm{H}\right]-\mathrm{MPP}\right)$ und $\left[{ }^{14} \mathrm{C}\right]$-Tetraethylammoniumbromid $\left(\left[{ }^{14} \mathrm{C}\right]-\mathrm{TEA}\right)$ verwendet. Von diesen ist bekannt, dass sie von MATE1 bzw. OCT1 transportiert werden [79], [157]. Sie werden im Folgenden als Modellsubstrate bezeichnet.

\subsubsection{Charakterisierung der funktionellen Aktivität von MATE1}

Zunächst wurde untersucht, ob MATE1 in den transfizierten HEK293-Zellen eine Transportaktivität besaß. Dazu wurde eine Referenzlösung aus radioaktiv markiertem Substrat in der Salzlösung Mammalian Ringer (MR) hergestellt. Eine zweite Lösung bestand ebenfalls aus radioaktiv markiertem MPP und zusätzlich einem sehr viel höheren Anteil an unmarkiertem MPP. Referenz- und Testlösung wurden auf die Zellproben gegeben (Referenzprobe und Testprobe). Anschließend wurde die Zerfallsrate der in den Zellen enthaltenen radioaktiv markierten MPP-Moleküle in beiden Proben gemessen und daraus die Aufnahmerate berechnet (siehe 3.3.2.1). Bei der Testprobe konkurrieren die Moleküle des markierten mit denen des unmarkierten MPPs um die Bindungsstellen des MATE1-Proteins. Eine verringerte Aufnahmerate in der Testprobe gegenüber der Referenzprobe bedeutete, dass das unmarkierte MPP anstelle des radioaktiv markierten MPPs über MATE1 in die Zellen aufgenommen wurde, dass MATE1 also eine funktionelle Aktivität besaß. Eine in der Testprobe unveränderte Transportrate bedeutete, dass 
MATE1 nicht funktionell aktiv war und das radioaktiv markierte MPP auf anderem Weg in die Zellen gelangte.

Um die Ergebnisse abzusichern, wurden parallel zur Testlösung mit unmarkiertem MPP, zwei weitere Testlösungen mit Tetraethylammoniumchlorid (TEA) und Chinin auf verschiedene Zellproben gegeben und auch die Aufnahmerate des radioaktiv markierten MPPs in diesen Lösungen mit der der Referenzprobe verglichen. TEA ist eine weitere Substanz, welche von MATE1 transportiert wird, Chinin ist dagegen ein Hemmstoff, welcher die Transportaktivität von MATE1 unterbindet.

Analog zu diesen Aufnahmeexperimenten in den mit MATE1 transfizierten Zellen wurden Experimente in nicht transfizierten Kontrollzellen durchgeführt. Eine verringerte Aufnahmerate der radioaktiv markierten MPP-Moleküle in diese Zellen im Vergleich zu den Aufnahmeraten der entsprechenden Proben in den MATE1-Zellen bedeutete eine MATE1-vermittelte Aufnahme von radioaktiv markiertem MPP. Bei einer nicht von MATE1 vermittelten Aufnahme wäre bei Anwesenheit der verschiedenen unmarkierten Substrate keine Veränderung der Aufnahmerate im Vergleich zur Referenzlösung vorhanden gewesen.

MATE1 ist ein Transportprotein, welches Substanzen gegen Protonen austauscht (siehe 1.2.8, [118]). Als letztes Indiz für eine Transportaktivität von MATE1 sollte daher getestet werden, ob die Aufnahmerate von radioaktiv markiertem MPP in HEK293-Zellen vom pH-Wert abhängig war. Die oben erläuterten Experimente wurden daher in MRLösung bei $\mathrm{pH} 7,4$ und bei $\mathrm{pH}$ 8,5 durchgeführt. Bei $\mathrm{pH} \mathrm{8,5}$ müsste die Aufnahmerate von radioaktiv markiertem MPP in die MATE1-Zellen erhöht gewesen sein. Ein Experiment lief folgendermaßen ab:

- $2 \cdot 10^{5}$ MATE1-HEK293- und nicht transfizierte Kontrollzellen wurden pro Loch einer 24-Loch-Platte ausgesät und für $72 \mathrm{~h}$ im Brutschrank inkubiert.

- Das Medium wurde abgenommen, die Zellen zweimal mit $500 \mu \mathrm{PBS}\left(37^{\circ} \mathrm{C}\right)$, einmal mit $500 \mu \mathrm{MR}\left(37^{\circ} \mathrm{C}\right)$ gewaschen und mit $500 \mu \mathrm{l}$ MR bedeckt.

- Für die Herstellung der Referenzlösung wurden $20 \mathrm{nM}\left[{ }^{3} \mathrm{H}\right]-\mathrm{MPP}$ und zusätzlich 980 nM MPP in MR gegeben, um die Menge an radioaktiv markiertem Substrat gering zu halten. Für die Testlösungen wurden der MR-[ $\left.{ }^{3} \mathrm{H}\right]$-MPP-Lösung zusätzlich $500 \mu \mathrm{M}$ unmarkiertes MPP, $500 \mu \mathrm{M}$ TEA bzw. $500 \mu \mathrm{M}$ Chinin hinzugefügt.

- Die MR-Lösung wurde von den Zellen abgenommen und je $200 \mu \mathrm{l}$ Transportlösung pro Zellprobe zugegeben. 
- Nach 5 min wurde die Lösung entfernt und die Zellen dreimal mit $500 \mu \mathrm{PBS}\left(0^{\circ} \mathrm{C}\right)$ gewaschen.

- Die Zellproben wurden mit 500 l $1 \mathrm{M}$ Natronlauge unter Schütteln für $1 \mathrm{~h}$ lysiert, mit 500 l 1 M Salzsäure neutralisiert und in Szintillationsgefäße überführt.

- Nach Zugabe von 2,5 ml Szintillationscocktail wurden die Proben im Szintillationszählgerät gemessen. Jedes Experiment wurde dreimal an drei verschiedenen Versuchstagen mit je drei Proben pro Versuchsbedingung durchgeführt.

\subsubsection{Zytostatikainteraktion von MATE1 und OCT1}

Nachdem die funktionelle Aktivität von MATE1 in stabil transifzierten HEK293-Zellen gezeigt wurde, sollte untersucht werden, ob MATE1 und OCT1 mit Zytostatika wechselwirkten. Anschließend wurden Zytostatika, welche eine Interaktion mit MATE1 und OCT1 zeigten, durch Bestimmung des $\mathrm{IC}_{50}$-Werts weiter charakterisiert.

Der $\mathrm{IC}_{50}$-Wert ist ein Maß für die Hemmung einer Substrat-Enzymwechselwirkung durch eine unbekannte Substanz. Er gibt die Konzentration der unbekannten Substanz an, bei der die Substrat-Enzymwechselwirkung halbmaximal gehemmt wird. Hier wurde ermittelt, welche Konzentration eines Zytostatikums eine halbmaximale Hemmung des MATE1-vermittelten Transports der radioaktiv markierten Substrate in HEK293-Zellen hervorrief.

Die Experimente zur Zytostatikainteraktion und $\mathrm{IC}_{50}$-Bestimmung mit MATE1 glichen denen zum Test der Transportaktivität (siehe 3.3.1). In den Testlösungen waren allerdings anstatt der unmarkierten Substrate Zytostatika vorhanden. Zum Test der Interaktion von MATE1 mit Zytostatika wurden 28 Zytostatika aus verschiedenen Wirkstoffklassen getestet. Auf die gleiche Weise wurde die Wechselwirkung von OCT1 mit Zytostatika untersucht. Für die $\mathrm{IC}_{50}$-Bestimmung wurden in den Testlösungen unterschiedliche Konzentrationen eines Zytostatikums eingesetzt.

\subsubsection{Auswertung}

Ziel der Auswertung der Aufnahmeexperimente war es, zu zeigen, ob es signifikante Unterschiede in den Aufnahmeraten des radioaktiv markierten Substrats [ $\left.{ }^{3} \mathrm{H}\right]$-MPP unter verschiedenen Bedingungen, nämlich in transfizierten oder Kontrollzellen, in reiner MRReferenzlösung oder Substrat- bzw. Zytostatikumlösung und bei pH 7,4 oder pH 8,5 gab. Aus den mittels Szintillationscounter gemessenen DPM-Werten (Zerfälle pro Minute) wurde die Aufnahme von $\left[{ }^{3} \mathrm{H}\right]-$ MPP für die entsprechende Probe nach folgender Formel berechnet. Die Aufnahmeraten wurden statistisch mit SAS ausgewertet (siehe 3.8). 


$$
\begin{aligned}
& S A=\frac{M W(S t d)}{c(M P P) \cdot V(S t d)} \\
& R=\frac{D P M(\text { Probe })}{S A \cdot V(\text { Probe })} \\
& R \quad \text { - Aufnahmerate }\left(\left[{ }^{3} \mathrm{H}\right]-\mathrm{MPP}\right) / 5 \mathrm{~min} / \text { Loch } \\
& S A \quad \text { - Spezifische Aktivität } \\
& D P M \text { - gemessene Zerfälle pro Minute } \\
& c \text { - Konzentration } \\
& M W \text { - Mittelwert } \\
& \text { Std - Standard }
\end{aligned}
$$

\subsection{WST1-Zytotoxizitätstest}

Im vorherigen Abschnitt wurde mittels radioaktiven Aufnahmeexperimenten gezeigt, welche Zytostatika mit den SLC-Proteinen MATE1 und OCT1 wechselwirken. Ein Indiz dafür, dass ein Zytostatikum anstelle des radioaktiv markierten Substrats über das SLCProtein in die Zellen aufgenommen und dort akkumuliert wurde, ist die Zellsterberate (Zytotoxizität). Mit dem WST1-Zytotoxizitätstest wurde untersucht, ob MATE1-HEK293und OCT1-CHO-Zellen nach einer Zytostatikumbehandlung eine höhere Zytotoxizität aufwiesen als Kontrollzellen. Die Zytotoxizität wurde für die Zytostatika, welche den Transport des radioaktiv markierten Modellsubstrats in die Zellen hemmten (siehe 4.2.1), analysiert.

WST1 ist ein wasserlösliches Tetrazoliumsalz (Dinatrium-4-[3-(4-Iodophenyl)-2-(4nitrophenyl)-2H-5-tetrazolio]-1,3-Benzol-Disulfonat), welches bei Reduktion zu einem intensiv orangefarbenen Formazan (Dinatrium-(4-iodophenyldiazenyl-2-(4-nitrophenyl)hydrazinyliden-methyl)-1,3-Benzol-Disulfonat) reagiert (Abb. 3-3). Diese Eigenschaft wurde zur Messung des Anteils von lebenden zu toten Zellen genutzt: Lebende Zellen besitzen einen Komplex der Atmungskette, das Succinat-Tetrazoliumsalz-ReduktaseSystem, welches WST1 zu Formazan reduziert. Nach dem Zelltod ist keine ReduktaseAktivität mehr vorhanden, so dass die Menge an Formazan proportional zur Menge an lebenden Zellen ist. Da das Formazan eine intensivere Farbe besitzt, kann der Formazananteil über eine Absorptionsmessung bei $420-480 \mathrm{~nm}$, der maximalen Wellenlänge des Formazans, erfolgen [123]. 
<smiles></smiles>

WST1

leicht orangefarben

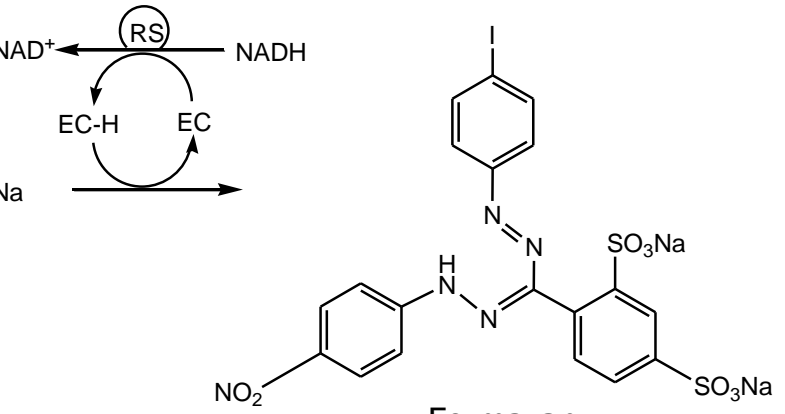

Formazan

intensiv orange

Abb. 3-3: WST1-Zytotoxizitätstest:

Reduktion von WST1 durch das Succinat-Tetrazoliumsalz-Reduktase-System (RS) zu Formazan; Elektronenübertragungsreagenz EC; Koenzym NAD (NicotinsäureamidAdenin-Dinukleotid)

Die WST-Experimente bestanden aus folgenden Schritten:

- $0,5 \cdot 10^{4}$ CHO-OCT1-Zellen oder $1 \cdot 10^{4}$ MATE1-HEK293-Zellen und Kontrollzellen wurden pro Loch einer 96-Loch-Platte ausgesät und für $48 \mathrm{~h}$ im Brutschrank inkubiert.

- Nach Entfernung des Mediums wurden die Zellproben mit $50 \mu \mathrm{l}$ einer Lösung aus Zytostatikum in Medium oder MR inkubiert. Als Referenz dienten unbehandelte Zellen, welche nur in Medium- oder MR inkubiert wurden.

- Die Lösungen wurden abgenommen, die Zellproben mit $100 \mu \mathrm{l}$ Medium/MR gewaschen und für $24 \mathrm{~h}$ in $50 \mu \mathrm{l}$ Medium im Brutschrank inkubiert.

- Das Medium wurde abgenommen und $50 \mu$ einer Lösung aus $10 \%$ (V/V) WST1Reagenz in Medium hinzugegeben.

- Nach 3 h Inkubation im Brutschrank wurde die Absorption bei 450 nm im MultiplateReader gemessen.

Die Auswertung der Absorptionswerte erfolgte statistisch mit SAS (3.8).

Tab. 3-2: Versuchsbedingungen des WST1-Tests mit MATE1-HEK293- und OCT1-CHO-Zellen

\begin{tabular}{|l|l|l|l|}
\hline Zellart & Versuchsart & Zytostatikum & Inkubationszeit \\
\hline \multirow{3}{*}{$\begin{array}{l}\text { MATE1-HEK293- } \\
\text { Zellen }\end{array}$} & $\begin{array}{l}\text { Zytotoxizität in Medium, } \\
\mathrm{pH} \mathrm{7,4}\end{array}$ & $\begin{array}{l}100 \mu \mathrm{M} \text { Mitoxantron, } \\
\text { Irinotecan, Etoposid, } \\
\text { Doxorubicin, }\end{array}$ & 15, 60, 240 min \\
\cline { 2 - 4 } & $\begin{array}{l}\text { pH-Abhängigkeit der } \\
\text { Zytotoxizität in MR: } \\
\text { pH 5,5, 7,4 und 8,5 }\end{array}$ & $\begin{array}{l}100 \mu \mathrm{M} \text { Mitoxantron, } \\
\text { Irinotecan, Etoposid, } \\
\text { Doxorubicin }\end{array}$ & $15 \mathrm{~min}$ \\
\cline { 2 - 4 } & $\begin{array}{l}\text { Dosis-Wirkungskurve in } \\
\text { MR: pH 5,5, 7,4 und 8,5 }\end{array}$ & $\begin{array}{l}1 \mathrm{nM}-500 \mu \mathrm{M} \\
\text { Mitoxantron }\end{array}$ & $15 \mathrm{~min}$ \\
\hline \multirow{2}{*}{ OCT1-CHO-Zellen } & $\begin{array}{l}\text { Zytotoxizität in Medium, } \\
\mathrm{pH} 7,4\end{array}$ & $\begin{array}{l}100 \mu \mathrm{M} \text { Nimustin, } 100 \\
\text { und } 800 \mu \mathrm{M} \\
\text { Temozolomid }\end{array}$ & 1,5 und 24 h \\
\hline
\end{tabular}




\subsection{Immunzytochemischer Test (ICA)}

Ziel war es, die Interaktion der SLC-Proteine MATE1 und OCT1 mit Zytostatika zu untersuchen. Eines dieser Zytostatika war Temozolomid. Es induziert in Zellen spezifische DNA-Addukte, welche durch Immuncytochemische Tests (ICA) nachgewiesen werden können. Nachfolgend wird beschrieben, wie die mit Temozolomid behandelten Zellen mit Antikörpern markiert werden (Abb. 3-4) und wie die Detektion mittels ICA erfolgte (Abb. 3-5). Anschließend wird der Ablauf eines ICA-Experiments erklärt.

Temozolomid hat die Eigenschaft, das $0^{6}$-Atom der DNA-Base Guanin zu methylieren. Diese DNA-Addukte (Antigene) können mit einem spezifischen Antikörper markiert werden. Abb. 3-4 zeigt die Koordinierung eines Antikörpers an das Antigen. Den an das Antigen koordinierenden Teil des Antikörpers bezeichnet man als Paratop, den komplementären Teil des Antigens als Epitop. Nur wenn Paratop und Epitop eine genau komplementäre Struktur aufweisen, findet die hochspezifische Koordination statt.

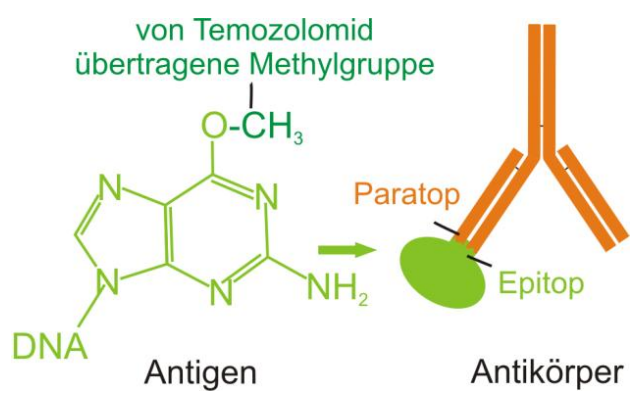

Abb. 3-4: Koordination eines Antikörpers mit $0^{6}$-Methylguanyl-DNA-Addukt als Antigen: Interaktion des Paratops des Antikörpers mit dem Epitop des Antigens [95]

Ein ICA ist der Nachweis eines Antigens in isolierten Zellen oder Gewebe mittels Antikörper. Bei dem hier durchgeführten ICA erfolgte die Detektion des Antigens nicht über den direkt daran koordinierenden primären Antikörper (direktes ICA), sondern über einen sekundären, mit einem Fluoreszenzfarbstoff markierten Antikörper (indirektes ICA, Abb. 3-5). Dieser ist gegen die Spezies, aus der der primäre Antikörper stammt, gerichtet und dient der Signalamplifikation, da mehrere Moleküle von ihm an einen primären Antikörper koordinieren können. An den sekundären Antikörper ist ein Fluoreszenzfarbstoff, das Fluorochrom, gebunden, welches fluoreszenzmikroskopisch detektiert wird. Die Gesamt-DNA wird ebenfalls, allerdings mit einem anderen Fluoreszenzfarbstoff markiert und über die relative Intensität der beiden Fluoreszenzsignale der Anteil der temozolomid-induzierten DNA-Addukte im Verhältnis zur Gesamt-DNA bestimmt. 


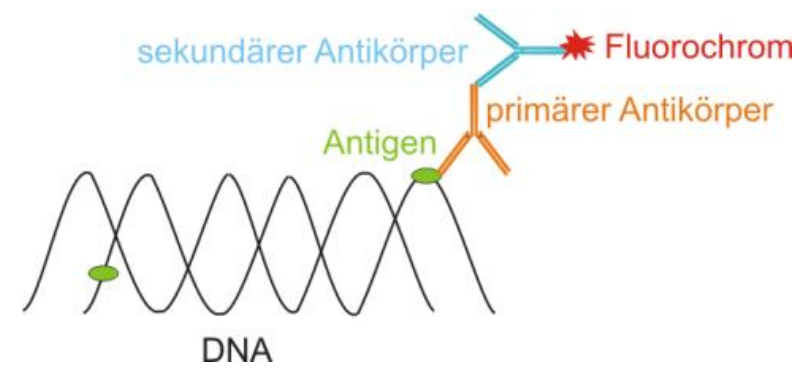

Abb. 3-5: Indirektes ICA zur Detektion von temozolomid-induzierten $0^{6}$-Methylguanyl-DNAAddukten:

Koordination eines gegen das Antigen gerichteten, primären Antikörpers und eines gegen den primären gerichteten, sekundären Antikörpers mit Fluorochrom

Ein ICA-Experiment bestand aus folgenden Schritten:

- Zur Vorbereitung der Zellen für das ICA wurden $4 \cdot 10^{5}$ OCT1-CHO- und Kontrollzellen in 2,5 ml Medium in 6-Loch-Platten ausgesät und für $1 \mathrm{~d}$ im Brutschrank inkubiert.

- Das Medium wurde abgenommen und die Zellen für 5 min, 10 min, 15 min, $1 \mathrm{~h}$ und $3 \mathrm{~h}$ mit 2,5 ml $800 \mu \mathrm{M}$ Temozolomid in Medium bzw. als Kontrolle mit dem Temozolomid-Lösungsmittel DMSO in Medium inkubiert.

- Anschließend wurden die Lösungen entfernt, die Zellen dreimal mit $2 \mathrm{ml}$ PBS (Raumtemperatur) gewaschen, die Zellzahl bestimmt und mit PBS auf $1 \cdot 10^{6} \mathrm{Z} / \mathrm{ml}$ verdünnt.

- Je $10 \mu \mathrm{l}$ der Zelllsuspensionen wurden auf Immuno-Select-Adhäsions-Objektträger (Squarix, Marl) gegeben und bei Raumtemperatur getrocknet.

Der Ablauf der Immunfärbung der Zellen ist in Tab. 3-3 dargestellt. 
Tab. 3-3: Immunfärbung von Zellen

\begin{tabular}{|c|c|}
\hline Schritt & Bedingungen \\
\hline Eingrenzung der Zellproben & Mit Fettstift (Pap Pen, Dako) \\
\hline Fixierung auf Objektträgern & 30 min bei $-20^{\circ} \mathrm{C}$ in Methanol \\
\hline Waschen & 5 min in PBS bei Raumtemperatur \\
\hline Denaturierung in Alkalilösung & $\begin{array}{l}\text { Lösung mit } 40 \%(\mathrm{~V} / \mathrm{V}) \text { Methanol versetzt, } \\
5 \text { min bei } 0{ }^{\circ} \mathrm{C}\end{array}$ \\
\hline Waschen & 5 min in PBS \\
\hline Membranpermeabilisierung & $\begin{array}{l}10 \text { min bei } 37^{\circ} \mathrm{C} \text { in } 100 \mu \mathrm{l} 80 \mu \mathrm{g} / \mathrm{ml} \\
\text { Pepsinlösung }\end{array}$ \\
\hline Waschen & $5 \mathrm{~min}$ in PBS \\
\hline Membranpermeabilisierung & $\begin{array}{l}10 \text { min bei } 37^{\circ} \mathrm{C} \text { in } 100 \mu \mathrm{l} 40 \mu \mathrm{g} / \mathrm{ml} \\
\text { Proteinase-K-Lösung }\end{array}$ \\
\hline \multirow[b]{2}{*}{$\begin{array}{l}\text { Verhinderung von unspezifischen } \\
\text { Antikörperbindungen }\end{array}$} & 10 min in PBS-Glycin-Lösung \\
\hline & $\begin{array}{l}\text { 30-minütige Inkubation in 5\%iger } \\
\text { Magermilchlösung (in PBS) }\end{array}$ \\
\hline Koordination des primären Antikörpers & $\begin{array}{l}\text { Verdünnung des Antikörpers: } 1: 4000 \text { mit } \\
1 \% \text { igem BSA (m/V) in PBS, } 100 \mu \mathrm{l} \text { je } \\
\text { Zellprobe, Inkubation für } 12 \mathrm{~h} \text { bei } 4^{\circ} \mathrm{C} \text { in } \\
\text { Feuchtkammer }\end{array}$ \\
\hline Waschen & $\begin{array}{l}5 \text { min in PBS-Tween-Lösung, } 5 \text { min in PBS- } \\
\text { Lösung }\end{array}$ \\
\hline $\begin{array}{l}\text { Verhinderung von unspezifischen } \\
\text { Antikörperbindungen }\end{array}$ & $\begin{array}{l}\text { 30-minütige Inkubation in 5\%iger } \\
\text { Magermilchlösung (in PBS) }\end{array}$ \\
\hline Koordination des sekundären Antikörpers & $\begin{array}{l}\text { Verdünnung des Antikörpers 1:75 in 1\%igem } \\
\text { BSA in PBS, } 100 \mu \text { l je Zellprobe, } 1 \mathrm{~h} \text { bei } 37^{\circ} \mathrm{C} \\
\text { in Feuchtkammer }\end{array}$ \\
\hline Waschen & $\begin{array}{l}5 \text { min in PBS-Tween-Lösung, } 5 \text { min in PBS- } \\
\text { Lösung }\end{array}$ \\
\hline $\begin{array}{l}\text { Markierung der Gesamt-DNA mit dem } \\
\text { Fluoreszenzfarbstoff DAPI in Anti- } \\
\text { Verblassungslösung }\end{array}$ & $\begin{array}{l}20 \mu \mathrm{l} \text { Antifading-Mounting-Medium mit DAPI } \\
\text { je Zellprobe }\end{array}$ \\
\hline Abdeckung und Fixierung & Mit Deckgläschen und Nagellack \\
\hline
\end{tabular}

Die Zellproben wurden unter dem Fluoreszenzmikroskop gemessen (siehe 2.1). Jede Zellprobe wurde zunächst mit einem DAPI-Filtersystem (350 nm Anregung/460 nm Emission) zum Anfärben der Gesamt-DNA und danach mit einem dsred-Filtersystem, welcher den Fluoreszenzfarbstoff Cy3 (550/570 nm) des sekundären Antikörpers anregte und dessen Emission ermöglichte, belichtet und fotographiert. Je Probe wurden Bilder von zwei Zellbereichen angefertigt. Die Intensitäten der DAPI- und Cy3-Bilder wurden mit dem Programm ImageJ ausgewertet (siehe 2.2). Die angefärbten Kerne wurden eingegrenzt und innerhalb dieser Bereiche die Intensitäten von DAPI- und Cy3-Färbung gemessen. Die Werte der Cy3-Intensitäten wurden jeweils durch die der DAPIIntensitäten dividiert und der Mittelwert gebildet. Weiterhin wurde die Differenz aus mit 
Temozolomid und DMSO-behandelten Zellen und SLC-exprimierenden und Kontrollzellen gebildet, um zu zeigen, ob es eine OCT1-vermittelte Erhöhung an temozolomidinduzierten DNA-Addukten gab oder nicht.

\subsection{Durchflusszytometrie}

Eine Methode, um fluoreszierende Moleküle in Zellen nachzuweisen, ist die Durchflusszytometrie. In radioaktiven Aufnahmeexperimenten (siehe 4.2.1) wurde Doxorubicin als mögliches Substrat für MATE1 identifiziert. Um dieses Ergebnis zu verifizieren, sollte zusätzlich die Durchflusszytometrie angewandt werden. Doxorubicin besitzt die Eigenschaft zu fluoreszieren. Damit ist es möglich, die Doxorubicinaufnahme in MATE1HEK293-Zellen direkt zu messen.

Mit der Durchflusszytometrie können die Struktur und Eigenschaften einzelner Zellen durch Detektion von Lichtsignalen analysiert werden. Zellen werden in Suspension über eine Kapillare in einen schnell fließenden Hüllstrom gesogen und dadurch vereinzelt (Abb. 3-6). Die einzelnen Zellen werden an zwei Laserstrahlen aus Argonlaser (488 nm) und Diodenlaser $(635 \mathrm{~nm})$ vorbeigeleitet. Auf die Zellen treffendes Licht wird durch Beugung in Richtung des Laserstrahls (Vorwärtsstreulicht, FSC) und durch Reflektion im $90^{\circ}$-Winkel zu diesem (Seitwärtsstreulicht, SSC) gestreut und fällt dort auf jeweils einen Detektor. Über die Intensität des FSCs wird die Zellgröße bestimmt, das Seitwärtsstreulicht ist ein Maß für die Granularität der Zelle. Über die Intensität von Vorwärts- und Seitwärtsstreulicht wurden hier lebende Zellen von toten unterschieden (Abb. 3-7). Lebende Zellen besitzen mehr Lysosomen, Vakuolen und werden als ganze Zellen detektiert. Daher besitzen sie ein größeres SSC und FSC als tote Zellen und Zellbruchstücke. Die Durchflusszytometrie erlaubt außerdem die Anregung von in den Zellen befindlichen fluoreszierenden Molekülen. Die emittierte Fluoreszenzstrahlung wird dabei wie das SSC im $90^{\circ}$-Winkel zu den Zellen detektiert. Durch Vorschaltung eines Filters wird genau die Emissionswellenlänge des zu analysierenden fluoreszierenden Moleküls herausgefiltert. Hier wurde die Fluoreszenzintensität der Doxorubicinmoleküle mit einer Emissionswellenlänge von $570 \mathrm{~nm}$ detektiert, um zu testen, ob Doxorubicin über MATE1 in HEK293-Zellen aufgenommen wurde [31]. 


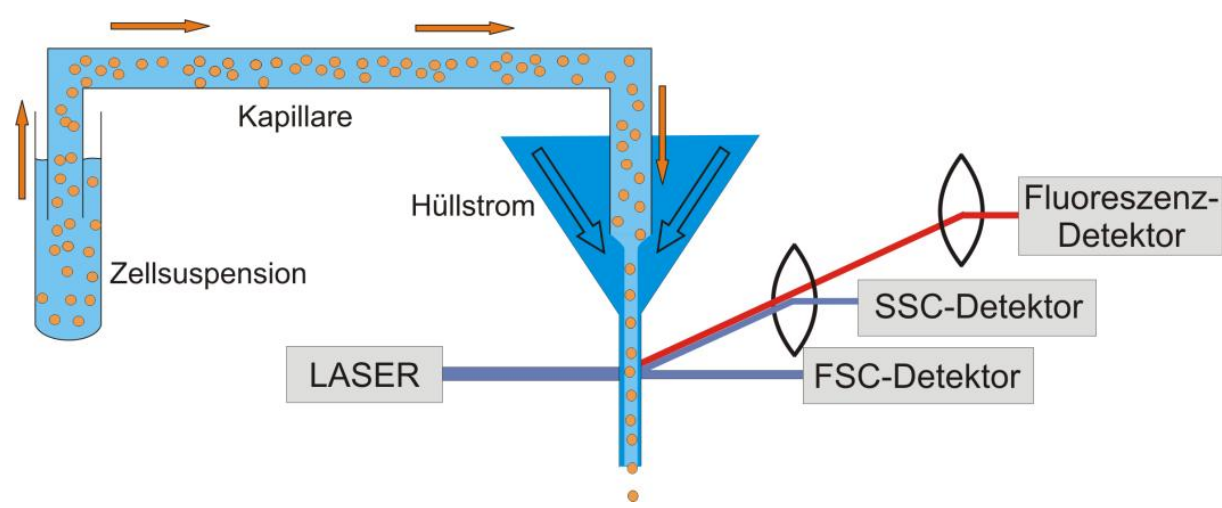

Abb. 3-6: Durchflusszytometrische Messung:

Die Zellen werden durch den Hüllstrom vereinzelt und an LASER-Strahl vorbeigeleitet. Bei Bestrahlung streuen sie Licht in Richtung des LASER-Strahls (FSC) und im 90\% Winkel dazu (SSC) und fluoreszieren. FSC, SSC und Fluoreszenz werden nach Filterung detektiert; modifiziert nach [31].

Ein Durchflusszytometrie-Experiment lief folgendermaßen ab:

- 1,5 $10^{5}$ MATE1-HEK293- und Kontrollzellen wurden in $2 \mathrm{ml}$ TREx-Medium in 6-LochZellkulturplatten ohne Polylysinbeschichtung ausgesät und für $24 \mathrm{~h}$ im Brutschrank inkubiert.

- Das Medium wurde abgenommen, die Zellen für $5 \mathrm{~min}$ in $2 \mathrm{ml}$ einer Lösung aus $100 \mu \mathrm{M}$ Doxorubicin in MR oder einer Lösung mit zusätzlich $500 \mu \mathrm{M}$ MPP als Hemmstoff inkubiert. Als Vergleichslösung diente reiner MR.

- Die Lösungen besaßen die pH-Werte 5,5, 7,4 oder 8,5, um die pH-Abhängigkeit der Doxorubicinaufnahme zu zeigen.

- Die Lösungen wurden von den Zellen abgenommen, $1 \mathrm{ml}$ PBS $\left(0^{\circ} \mathrm{C}\right)$ hinzugegeben, die Zellen direkt mit dem PBS von der Platte abgelöst und in ein Zentrifugenröhrchen überführt. Nach Verdünnung in $1 \mathrm{ml}$ MR wurde für $3 \mathrm{~min}$ bei $800 \mathrm{U} / \mathrm{min}$ und $4^{\circ} \mathrm{C}$ zentrifugiert. Die Zellen wurden zweimal mit $5 \mathrm{ml}$ PBS $\left(0^{\circ} \mathrm{C}\right)$ gewaschen und zentrifugiert.

- Das Zellpellet wurde in $300 \mu$ Pufferlösung resuspendiert, in ein Probenröhrchen überführt und im Durchflusszytometer gemessen. Es wurden je zwei Proben einer Versuchsbedingung gemessen.

Die Messung wurde über ein spezielles Computerprogramm gesteuert und mit einem weiteren Programm ausgewertet (siehe 2.2). Die Intensität von FSC und SSC wurde in einem Punktwolkendiagramm dargestellt (Abb. 3-6 a). Jeder Punkt stellt ein von einer Zelle gesendetes Signal dar. Nach visuellem Eindruck wurden gemäß den oben angegeben Kriterien zwei Bereiche identifiziert, die den lebenden und toten Zellen zugeordnet werden konnten. Nur von den eingekreisten, lebenden Zellen wurde die Fluoreszenz in einem Historgramm dargestellt (Abb. 3-6 b). Die Fluoreszenz der 
unterschiedlich behandelten Zellen wurde durch Bildung der mittleren Fluoreszenzwerte verglichen.

a)

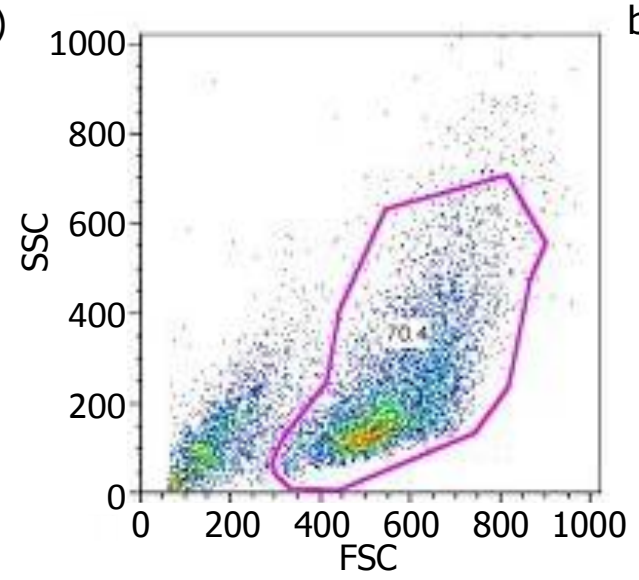

b) 150

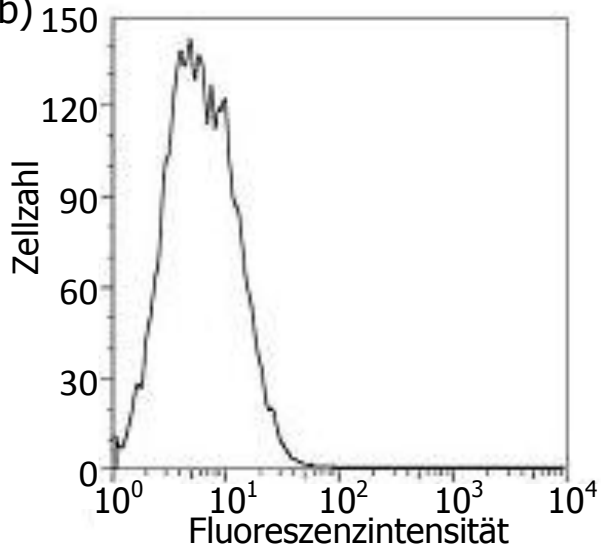

Abb. 3-7: Analyse einer durchflusszytometrischen Messung; a) Punktwolkendiagramm:

Über Vorwärts- (FSC) und Seitwärtsstreulicht (SSC) können lebende von toten Zellen unterschieden werden; b) Histogrammanalyse der Fluoreszenzintensitäten der lebenden Zellen (erstellt mit FlowJo, siehe 2.2)

\subsection{Expressionsanalyse von SLCs in Melanomzellen}

Es wurde untersucht, welche SLC-Proteine eine Rolle in der zielgerichteten Therapie des Malignen Melanoms spielen könnten (siehe 4.1). Dies ist der Fall, wenn Melanomzellen mehr Zytostatikamoleküle aufnehmen als gutartige Melanozyten. Um dies zu erkennen, wurde die mRNA-Expression von 28 ausgewählten SLC-Proteinen (siehe 1.2) in Melanomzelllinien und im Vergleich dazu in Melanozyten von gesunden Spendern (im Folgenden als Melanozyten bezeichnet) bestimmt. Die Expression wurde mittels der Polymerase-Kettenreaktion (PCR) untersucht, die dazu dient, die SLC-spezifischen Nukleinsäuresequenzen zu vervielfältigen und damit ihren Nachweis zu ermöglichen.

Als vorbereitende Schritte wurde zunächst die RNA aus Melanomzelllinien und Melanozyten isoliert (siehe 3.7.1) und diese in cDNA umgeschrieben (siehe 3.7.2). Anschließend wurde die PCR-Analyse durchgeführt. Mittels Reverse-Transkriptase-PCR (RT-PCR, siehe 3.7.3.1) wurde zunächst analysiert, welche der ausgewählten SLCProteine in Melanomzelllinien exprimiert waren. Anschließend wurde mittels TaqmanReal-Time-PCR die Expression der SLCs, welche in der RT-PCR-Analyse eine Expression zeigten, in Melanomzellinien und zusätzlich in Melanozyten quantifiziert (siehe 3.7.3.2).

\subsubsection{RNA-Isolierung und Messung der Konzentration}

Die Isolierung der Gesamt-RNA aus Melanomzelllinien und Melanozyten wurde das RNeasy Mini Kit verwendet (2.9). Mit diesem Kit werden alle RNA-Moleküle mit Längen unter $200 \mathrm{bp}$ abgetrennt, so dass die isolierte RNA an mRNA angereichert ist 
(Information aus dem Handbuch von Qiagen). Nach Isolierung der RNA nach dem in Abschnitt 3.7.1 beschriebenen Vorgehen wurden ihre Konzentration und Reinheit im Spektrophotometer gemessen. Es wurden nur RNA-Proben weiter verwendet, deren Ratio-Wert über 1,7 lag. Eine kleinere Zahl bedeutete, dass die Probe zu sehr mit Proteinen verunreinigt war.

\subsection{2 cDNA-Synthese}

Die isolierte RNA wurde im nächsten Schritt in cDNA umgewandelt, um sie vervielfältigen zu können. Zur Synthese wurde eine RNA-gesteuerte Polymerase, die reverse Transkriptase (RT) aus dem Moloney-Maus-Leukämie-Virus (M-MuLV-RT) eingesetzt. Da nur die mRNA die SLC-spezifischen Nukleinsäuresequenzen trägt, wurde sie selektiert. Das Reagenz, welches diese Selektion herbeiführte, war der Oligo-dT-Primer, ein Oligonukleotid aus Thyminmolekülen, welches an das 3'-Poly-Adenin-(A-)Ende der mRNA band (Abb. 3-8 a). Ausgehend von diesem Primer fand die Synthese des komplementären cDNA-Stranges durch die RT in 5'-Richtung des mRNA-Matrizenstrangs statt (Abb. 3-8 b). Die dafür benötigten Nukleotide wurden in Form von Desoxynukleosidtriphosphat-Molekülen (dNTPs) zugegeben.

a)

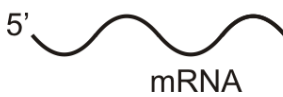

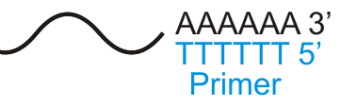
Primer b)

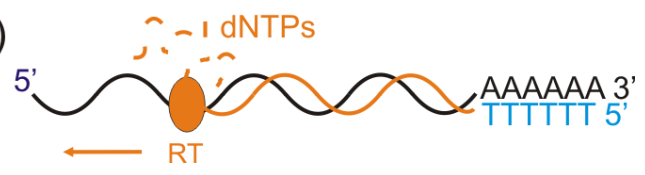

Abb. 3-8: cDNA-Synthese mittels Reverse-Transkriptase:

a) Bindung des Oligo-dT-Primers an Poly-Adenin-Ende der mRNA; b) CDNA-Synthese mittels RT aus freien Nukleotiden (dNTPS) in 5'-Richtung des mRNA-Stranges; modifiziert nach [95].

Für die in 3.7.3 dargestellten PCR-Analysen wurde die Superscript-II-RT von Invitrogen eingesetzt (2.9). Der Reaktionsansatz bestand aus den in Tab. 3-4 dargestellten Substanzen. Lösung 1 wurde bei $70^{\circ} \mathrm{C}$ für 10 min inkubiert um die Sekundärstrukturen der RNA aufzubrechen. Anschließend wurde Lösung 2 hinzugegeben und die cDNA bei $42{ }^{\circ} \mathrm{C}$ für $1 \mathrm{~h}$ synthetisiert. 
Tab. 3-4: Reaktionsansatz der cDNA-Synthese

\begin{tabular}{|c|c|}
\hline Bezeichnung & Zusammensetzung \\
\hline Lösung 1 & $\begin{array}{l}\text { - } 1 \mu \text { Oligo-dT-Primer } \\
-2 \mu \mathrm{g} \text { RNA } \\
\text { - mit nukleasefreiem Wasser auf } 17,5 \mu \text { l aufgefüllt }\end{array}$ \\
\hline Lösung 2 & $\begin{array}{l}-6 \mu \mathrm{l} \text { Puffer } \\
-1 \mu \mathrm{l} 10 \mathrm{mM} \text { dNTPs } \\
-0,25 \mu \mathrm{l} 200 \mathrm{u} / \mu \mathrm{l} \mathrm{RT} \\
-0,75 \mu \mathrm{l} \mathrm{H}_{2} \mathrm{O} \\
-3,5 \mu \mathrm{l} \mathrm{0,1} \mathrm{M} \mathrm{DTT} \\
-1 \mu \mathrm{l} 40 \mathrm{u} / \mu \mathrm{l} \mathrm{RNase-Inhibitor} \mathrm{RNaseOUT}\end{array}$ \\
\hline
\end{tabular}

\subsubsection{Polymerase-Kettenreaktion (PCR)}

Die PCR wurde eingesetzt, um die Expression von SLCs in Melanomzelllinien zu analysieren. Es kamen zwei Varianten dieses Verfahrens zum Einsatz. Die Standardvariante, die Reverse-Transkriptase-PCR (RT-PCR) diente der qualitativen Analyse. Für die Quantifizierung wurde die mit weniger Messunsicherheit behaftete, aber teurere Taqman-Real-Time-PCR verwendet. Die RNA-Isolierung und cDNA-Synthese waren die vorbereitenden Schritte für beide PCR-Varianten.

\subsubsection{RT-PCR}

Eine PCR dient dazu, DNA-Fragmente zu vervielfältigen, in diesem Fall die SLCspezifischen Sequenzen aus der cDNA von Melanomzellinien und Melanozyten. Damit nur diese SLC-spezifischen Sequenzen erkannt und vervielfältigt werden, verwendet man Oligonukleotide, welche Anfang und Ende der gesuchten Sequenz kennzeichnen. Sie dienen als Startpunkte für die nachfolgende Strangverdoppelung mittels Polymerase (siehe unten) und heißen deshalb Primer.

In [150] wurde die SLC-Expression in Nierenkrebszellen untersucht. Im Rahmen der vorliegenden Arbeit wurde vermutet, dass die mRNA von SLC-Proteinen auch in Melanomzellen exprimiert ist (siehe 1.5). Deshalb wurden die entsprechenden Primer übernommen (siehe 2.10 und 7.7). Da aber in 4.2.1 Zytostatikawechselwirkungen mit dem SLC-Protein MATE1 untersucht wurden, wurde es hier als notwendig angesehen, auch Primer für MATE1 und 2 zu verwenden (siehe 2.10) und auf diese Weise die MATEspezifischen-Nukleotidsequenzen mittels RT-PCR zu vervielfältigen.

Als Primer für MATE1 bzw. MATE2 wurden je zwei 19-24 bp lange Nukleotidsequenzen ausgewählt, die zur mRNA-Sequenz des SLCs komplementär waren und einen für MATE spezifischen Sequenzabschnitt mit einer Länge von 300-700 bp eingrenzten. Ein Primer, der "forward"-Primer, band an den Matrizenstrang (Abb. 3-9). Er stellte den Anfang des 
zu vervielfältigenden cDNA-Abschnitts dar. Der "reverse"-Primer band an den nicht kodierenden cDNA-Strang und bildete das Ende des zu vervielfältigenden Abschnitts. Die Doppelstrangsynthese lief von diesem ausgehend rückwärts ab.

Die ausgewählten Primer wurden in der RT-PCR eingesetzt. Eine RT-PCR läuft in den drei folgenden Schritten ab (Abb. 3-9):

- Denaturierung: Die cDNA-Strukturen wurden durch Erwärmung auf $94^{\circ} \mathrm{C}$ aufgebrochen und in zwei Einzelstränge getrennt, das heißt, sie wurden denaturiert.

- Primer-Hybridisierung: Durch Abkühlung der Reaktionstemperatur auf 50-65 ${ }^{\circ} \mathrm{C}$ wird die Primerbindung an jeweils einen der cDNA-Einzelstränge initiiert (siehe oben). Sie bilden den Startpunkt für die Taq-Polymerase (Schritt 3).

- Strangverlängerung: Der dritte Schritt der PCR ist die Verlängerung des jeweils zweiten DNA-Strangs mittels der Taq-Polymerase bei $72{ }^{\circ} \mathrm{C}$. Das Enzym füllte die beiden Einzelstränge des DNA-Abschnitts von den Primern ausgehend in 3'-Richtung des neu synthetisierten Strangs mit freien Nukleotiden auf und verdoppelte damit den zwischen den Primern liegenden DNA-Abschnitt.

Anschließend wiederholte sich die Reaktion mit der Denaturierung, jedoch mit einer verkürzten Reaktionszeit, da nur noch die kurzen vervielfältigten DNA-Abschnitte in Einzelstränge getrennt werden mussten. Den Reaktionsablauf von Denaturierung, Primer-Hybridisierung und Verlängerung des zweiten DNA-Strangs bezeichnet man als PCR-Zyklus. 


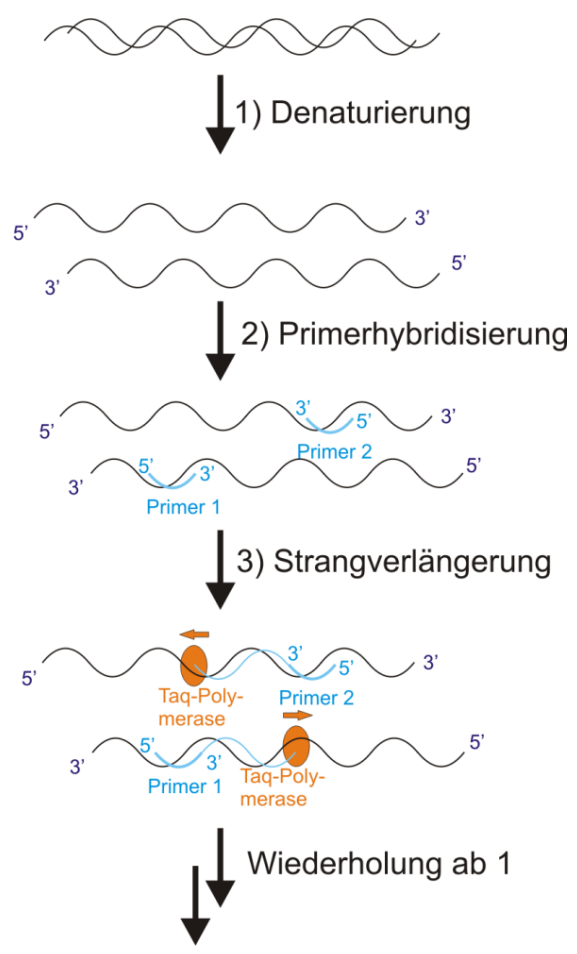

Abb. 3-9: Ablauf einer PCR zur Amplifikation von DNA-Abschnitten:

1) Denaturierung der DNA-Stränge in Einzelstränge durch Hitzeeinwirkung; 2) Hybridisierung der Primer mit DNA-Strängen; 3) Synthese von zwei neuen, zum Ausgangsstrang komplementären DNA-Strängen durch Taq-Polymerase; Zyklische Wiederholung ab Schritt 1; modifiziert nach [95].

Für eine RT-PCR wurde gemäß Tab. 3-6 folgender Reaktionsansatz verwendet:

- $8 \mu \mathrm{l}$ 1,25 mM dNTP-Lösung

- 5 l 10x-RT-PCR-Puffer

- $2 \mu \mathrm{l} 1 \mathrm{u} / \mu \mathrm{l} \mathrm{Taq-Polymerase}$

- je 1 Hl (20 pmol) der beiden SLC-spezifischen Primer

- 100 ng cDNA

- mit nukleasefreiem Wasser auf $50 \mu$ l aufgefüllt

Der Reaktionsansatz wurde in einen PCR-Thermo-Cycler überführt und die cDNAAbschnitte bei dem in Tab. 3-5 angegebenen Temperatur-Zeit-Profil vervielfältigt. Für das Referenzgen GAPDH wurden 20 Zyklen, für SLC-Sequenzen 35 Zyklen durchlaufen. Die PCR-Produkte wurden anschließend mittels Agarosegel-Elektrophorese aufgetrennt.

Tab. 3-5: Temperatur-Zeit-Profil einer RT-PCR

\begin{tabular}{|l|l|l|l|}
\hline Zeit (s) & Temperatur $\left({ }^{\circ} \mathbf{C}\right)$ & Reaktionsschritt & \\
\cline { 1 - 3 } & 94 & Anfangs-Denaturierung & \\
\hline 30 & 94 & Denaturierung & \multirow{2}{*}{ Zyklen } \\
\cline { 1 - 3 } & $50-65$ & Primerhybridisierung & \\
\hline 60 & 72 & Strangverlängerung & \\
\hline 600 & 72 & letzte Strangverlängerung & \\
\hline
\end{tabular}




\subsubsection{Taqman-Real-Time-PCR}

Mittels RT-PCR konnte analysiert werden, ob die mRNA von SLC-Proteinen in Melanomzellen exprimiert war. Eine Quantifizierung der Expressionslevel erfolgte mit der Taqman-Real-Time-PCR. Wie auch bei der RT-PCR werden hier Primer eingesetzt, welche eine zur mRNA eines SLC-Proteins komplementäre Nukleotidsequenz besitzen und einen zu vervielfältigenden DNA-Abschnitt eingrenzen. Um die Menge dieses Abschnitts quantifizieren zu können, werden zusätzlich sogenannte Taqman-Sonden innerhalb dieses Abschnitts an die DNA gebunden (Abb. 3-10 a). Taqman-Sonden sind Oligonukleotide, an deren 5'-Ende der sogenannte Reporter (R), in diesem Fall der Fluoreszenzfarbstoff FAM (6-Carboxyfluorescein) gebunden ist. Am 3'-Ende der Sonden befindet sich der Quencher Q. Bei intakter Sonde absorbiert letzterer die Fluoreszenzenergie des Reporters durch Förster-Resonanzenergietransfer (FRET) und verhindert damit die Emission als Fluoreszenz.

Ein Zyklus einer Taqman-Real-Time-PCR besteht wie die RT-PCR aus den Schritten Denaturierung, Primer-Hybridisierung und Verlängerung des zweiten DNA-Strangs mit der Taq-Polymerase (Abb. 3-9). Der Unterschied besteht nun aber darin, dass die TaqPolymerase bei der Taqman-Real-Time-PCR nicht nur DNA-Stränge synthetisiert, sondern außerdem eine Exonukleaseaktivität besitzt. Diese Eigenschaft bewirkte, dass die Polymerase die Taqman-Sonden von den DNA-Strängen löst und zersetzt (Abb. 3-10 b). Reporter und Quencher liegen dadurch weiter voneinander entfernt vor und das Emissionsspektrum des Reporters und das Absorptionsspektrum des Quenchers überlappen nicht mehr. Die vom Reporter abgegebene Energie wird als Fluoreszenz emittiert. Die Intensität des Fluoreszenzsignals ist proportional zur Menge der vervielfältigten DNA-Abschnitte [95], [124].

a) Taqman-Sonde: Reporter (R) Quencher (Q)

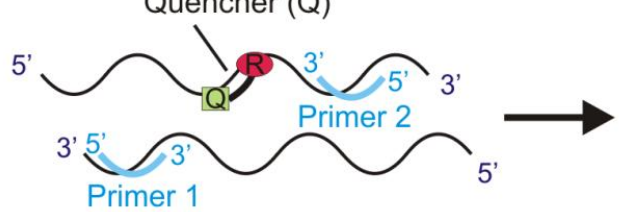

b)

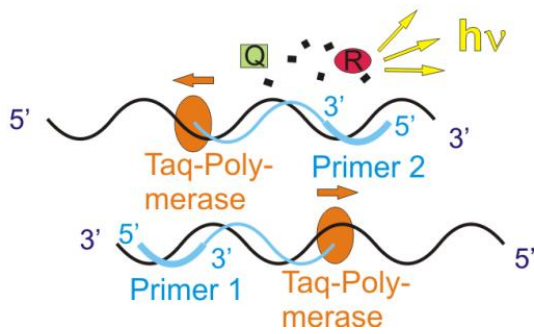

Abb. 3-10: Hybridisierung und Freisetzung der Taqman-Sonde bei der Taqman-Real-TimePCR:

a) Mit DNA hybridisierte Taqman-Sonde ist intakt, so dass der Quencher die vom Reporter emittierte Strahlung absorbiert; b) Durch Exonukleaseaktivität der TaqPolymerase wird die Taqman-Sonde vom Strang gelöst und zersetzt und Strahlung vom Reporter als Fluoreszenz emittiert. 
Der Reaktionsansatz einer Taqman-Real-Time-PCR setzte sich zusammen aus:

- 20 ng cDNA-Probe

- 12,5 $\mu \mathrm{l}$ Taqman Gene Expression Mastermix

- 1,25 $\mu$ l Taqman Gene Expression Assay

- mit nukleasefreiem Wasser auf $20 \mu$ l aufgefüllt

Die Proben wurden in den Thermo-Cycler (siehe 2.1) überführt. Außer den zu untersuchenden Proben wurden pro Zelllinie auch zwei Proben des Gens GAPDH als Referenz mitgeführt. Die Reaktion nach dem in Tab. 3-6 dargestellten Temperatur-Zeit-Profil durchgeführt. Es wurden drei Experimente an drei verschiedenen Versuchstagen mit unterschiedlichen RNA-Proben und zwei Proben pro Versuchsbedingung durchgeführt.

Tab. 3-6: Temperatur-Zeit-Profil einer Taqman-Real-Time-PCR

\begin{tabular}{|c|c|c|}
\hline Zeit (s) & Temperatur $\left({ }^{\circ} \mathrm{C}\right)$ & \\
\hline 120 & 50 & \\
\hline 600 & 95 & \\
\hline 15 & 95 & \multirow{2}{*}{40 Zyklen } \\
\hline 60 & 60 & \\
\hline
\end{tabular}

Das Progamm zur Steuerung des Thermo-Cyclers (2.2) liefert den Verlauf der Fluoreszenzintensität im Vergleich zu einem Referenzfarbstoff (ROX) und der Hintergrundfluoreszenz $\left(\Delta R_{n}\right)$ über der Zyklenanzahl (Abb. 3-11).

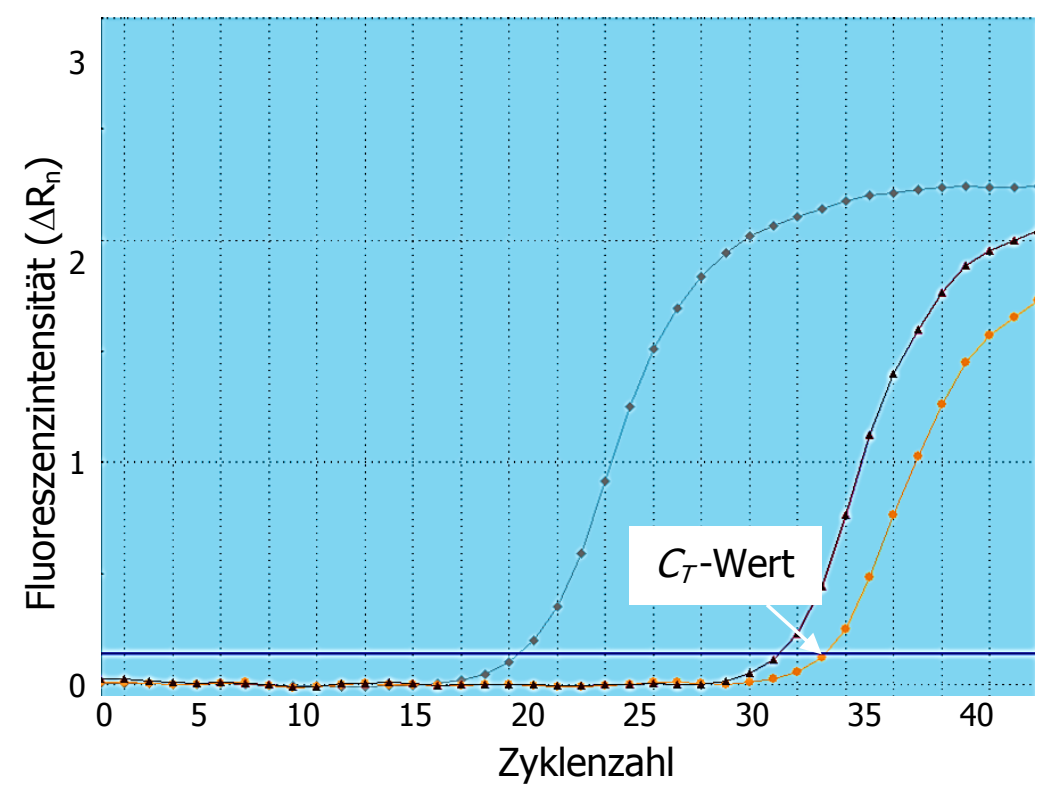

Abb. 3-11: Amplifikationskurve einer Taqman-Real-Time-PCR:

Verdoppelung der PCR-Produkte ab Grenze (blau); Zyklus, bei dem die Grenze überschritten wird, $\left(C_{T}\right.$-Wert); Fluoreszenzintensität relativ zum Referenzfarbstoff ROX (mit Mx Pro bestimmt, siehe 2.2).

Für die Auswertung ist der $C_{T}$-Wert ("Threshold-Cycle") von Bedeutung. Dieser gibt die Anzahl an PCR-Zyklen an, die mindestens erforderlich sind, um ein Fluoreszenzsignal der 
Taqman-Sonde zu detektieren, das sich vom Hintergrundrauschen abhebt [124]. Je höher ein Gen exprimiert ist, desto weniger Zyklen sind zum Erreichen des $C_{T}$-Werts erforderlich. Anhand des $C_{T}$-Werts konnte die Genexpression verschiedener Proben quantitativ verglichen werden. In Abb. 3-11 ist eine Amplifikationskurve einer TaqmanReal-Time-PCR dargestellt. Der Verlauf kann in vier Phasen eingeteilt werden. In der ersten und zweiten Phase erfolgt ein exponentieller Anstieg der Amplifikate und damit des Fluoreszenzsignals der Probe. In der ersten Phase, der Phase unterhalb des $C_{T^{-}}$ Werts, hebt sich die gemessene Fluoreszenz nicht von der Hintergrundfluoreszenz ab. In der zweiten Phase, gleich oder oberhalb des $C_{T}$-Werts, hebt die gemessene Fluoreszenz für die Amplifikate sich von der Hintergrundfluoreszenz ab. Nur bei exponentiellem Anstieg der Amplifikatmenge kann ein proportionaler Zusammenhang zur Ausgangsmenge der Probe angenommen werden. Daher ist der $C_{T}$-Wert der optimale Messpunkt. Je mehr PCR-Zyklen durchlaufen werden, desto stärker wirken gebildete Nebenprodukte, wie die zersetzten Sonden, als Inhibitoren der Reaktion und die eingesetzten Reagenzien werden aufgebraucht. Aus diesem Grund nimmt die Steigung der Kurve immer weiter ab, sie erreicht die dritte Phase, die Phase der linearen Steigung und schließlich die Plateauphase.

Für die Auswertung der Messungen wurden von den $C_{T}$-Werten des Referenzgens GAPDH die $C_{T}-$ Werte der zu untersuchenden SLC-Proben subtrahiert ( $\Delta C_{T}$-Wert). Die SLC-mRNA war in jedem Fall geringer als GAPDH exprimiert, ihr $C_{T}$-Wert war daher immer größer als der von GAPDH und damit war $\Delta C_{T}$ negativ. Je größer der Negativwert war, je größer also der Zyklenunterschied zwischen SLC-Probe und GAPDH war, desto geringer war die Expression der SLC-mRNA. Wurde eine ideale Verdoppelung der cDNAProben mit jedem Zyklus angenommen, so bedeutete beispielsweise der $\Delta C_{T}$-Wert -4 , dass die Expression der SLC-mRNA $2^{-4}$-fach geringer als die von GAPDH war [125]:

$$
\begin{aligned}
& \frac{c\left(c D N A_{S L C}\right)}{c\left(c D N A_{G A P D H}\right)}=2^{C_{T}(S L C)-C_{T}(G A P D H)}=2^{\Delta C_{T}} \\
& c \text { - Konzentration } \\
& C_{T} \text { - Threshold-Cycle }
\end{aligned}
$$

Die so berechneten $\Delta C_{T}$-Werte wurden statistisch ausgewertet (3.8).

\subsection{Statistische Auswertungen}

Die in Kapitel 4 dargestellten Messergebnisse wie z.B. die Transportraten eines radioaktiven Substrats, die Zellüberlebensanteile oder die Expressionsspiegel von SLCTransportern sind auf Grund von unbekannten Einflüssen fehlerbehaftet. Um aus diesen 
Ergebnissen eine verlässliche Aussage zu erhalten, wurden statistische Verfahren angewandt.

Im Allgemeinen wird hierfür Software eingesetzt, weil diese Verfahren auf komplexen Algorithmen beruhen, die nicht mehr manuell durchgeführt werden können, wie z.B. die Lösung von Matrizen. Zur Schätzung von statistischen Größen für Varianzanalysen, sowie zur Durchführung von multiplen statistischen Tests nach Tukey und Dunnett [133] kam hier die Software SAS 9.2 (siehe 2.2) zum Einsatz. ${ }^{2}$ Die Software führt diese Berechnungen auf der Grundlage eines Allgemeinen Linearen Modells (ALM) aus.

\subsubsection{Allgemeines Lineares Modell (ALM)}

Ein ALM dient dazu, den Zusammenhang zwischen einer beobachteten, gemessenen Größe $y_{i}$ und unbekannten Einflussgrößen $x_{i j}$ darzustellen. In der folgenden Linearkombination aus gewichteten Werten ist $\hat{Y}_{i}$ ein Schätzwert für den wahren Wert $y_{i}$ :

$$
\begin{aligned}
\hat{Y}_{i} & =a_{0} x_{i 0}+a_{1} x_{i 1}+\ldots+a_{p} x_{i p} \\
i & =\text { z. B. Zellart und } p+l \text { Einflussgrößen }
\end{aligned}
$$

Um den wahren Wert aus dem Schätzwert zu erhalten, muss ein Fehler $\varepsilon_{i}$ (Residuum) berücksichtigt werden:

$$
\begin{aligned}
y_{i} & =a_{0} x_{i 0}+a_{1} x_{i 1}+\ldots+a_{p} x_{i p}+\varepsilon_{i} \\
\varepsilon_{i} & =y_{i}-\hat{Y}_{i}
\end{aligned}
$$

Der Fehler $\varepsilon_{i}$ ist somit die Differenz zwischen dem mit Hilfe des Modells errechneten Schätzwert und dem real gemessenen oder beobachteten Wert.

Die Gewichtungskoeffizienten $a_{j}$ (Modellparameter) werden durch die Software SAS näherungsweise mit dem Maximum-Likelihood-Verfahren so bestimmt, dass der Fehler $\varepsilon_{i}$ minimal wird [84].

Die Einflussgrößen in den angepassten Modellen können kontinuierliche Größen, aber auch Indikatoren sein (0-1 kodierte Variablen: 0 für Melanozyten und 1 für Melanomzelllinien oder hinsichtlich einer Zytostatikumbehandlung: 0 unbehandelt und 1 behandelt).

Voraussetzung für die Bildung des Modells in dieser Form ist, dass die Residuen statistisch voneinander unabhängig, varianzhomogen und normalverteilt sind. Trifft die

\footnotetext{
${ }^{2}$ Die statistischen Analysen und die Anwendung der Software SAS wurde mit Unterstützung von Herrn A. Rosenberger, Abtl. Genetische Epidemiologie, Universität Göttingen durchgeführt.
} 
Bedingung der Normalverteilung nicht zu, so ist es unter der Zielsetzung des Testens von Hypothesen zulässig, die Messwerte vor der Verwendung zu logarithmieren. Diesen Schritt führt das SAS-Programm bei Bedarf aus.

Ein Beispiel für die Anwendung des ALM im Rahmen dieser Arbeit ist die Abschätzung der Hemmung der Aufnahme von $\left[{ }^{3} \mathrm{H}\right]$-MPP durch ein Zytostatikum. Dazu wurde die Hypothese aufgestellt, dass die Zytostatikumbehandlung keinen Einfluss auf die Ziel-

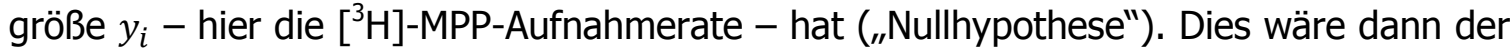
Fall, wenn der zugehörige Modellparameter $a_{b}$ gleich Null ist. Formal wird also die Hypothese geprüft:

$$
H_{0}: a_{b}=0
$$

Kann diese Hypothese statistisch verworfen werden, gilt die Zytostatikumbehandlung als signifikanter Einflussfaktor auf die Zielgröße. Im obigen Beispiel entspricht der Modellparameter $a_{b}$ dem geschätzten Behandlungseffekt, da der erwartete Wert der Zielgröße aus dem angepassten Modell wie folgt berechnet werden kann:

$$
\begin{aligned}
& \hat{Y}=a_{b} x_{b}+\sum_{k} a_{k} x_{k} \\
& \begin{array}{ll}
a_{b} \quad-\text { Gewichtsfaktor für Einfluss der Behandlung } \\
x_{b} \quad=\quad \begin{array}{l}
0: \text { keine Behandlung } \\
1: \text { Behandlung }
\end{array} \\
a_{k} x_{k}-\text { restliche gewichtete Einflussfaktoren }
\end{array}
\end{aligned}
$$

Die Einflussgröße $x_{b}$ ist ein Indikator: er hat den Wert 1, wenn die Messung nach einer Behandlung erfolgte und den Wert 0, wenn keine Behandlung mit einem Zytostatikum vorgenommen wurde. Damit ergibt sich der gesuchte Modellparameter aus dem ALM zu:

$$
\begin{aligned}
& \hat{Y}_{1}=a_{b}+\sum_{k} a_{k} x_{k} \\
& \hat{Y}_{0}=\sum_{k} a_{k} x_{k} \\
& \hat{Y}_{1}-\hat{Y}_{0}=a_{b}
\end{aligned}
$$

Das Programm SAS berechnet für diesen Parameter das Konfidenzintervall und führt die nachfolgend beschriebenen Tests durch.

\subsubsection{Statistische Tests}

Das Ziel von statistischen Tests auf der Basis von Varianzanalysen ist zu ermitteln, ob sich Eigenschaften einer oder mehrerer Gruppen von denen der Grundgesamtheit unterscheiden. Diese Eigenschaften können durch Einwirkung auf die Untersuchungsobjekte hervorgerufen werden, etwa durch Behandlung mit Zytostatika. Bei den in Abschnitt 4.2.1 beschrieben radioaktiven Aufnahmeversuchen waren die zu 
unterscheidenden Einflussfaktoren der pH-Wert von 7,5 oder 8,5, die Zellart (MATE1oder Kontrollzellen), und ob eine reine MR oder MR-Zytostatikumlösung vorlag. Diese drei Einflussfaktoren sind Indikatoren, die jeweils zwei Werte haben können. Damit ergeben sich acht Kombinationsmöglichkeiten, das heißt acht statistische Gruppen. Mit jeder Kombination wurden mehrere Experimente durchgeführt und die Messwerte aufgenommen.

Es folgte die Bildung der statistischen Größen jeder Gruppe und der Gesamtheit durch SAS, also der Gruppenmittelwerte, des Gesamtmittelwerts, der Varianz innerhalb jeder Gruppe $\left(S_{w}{ }^{2}\right)$ und der Varianz der Mittelwerte der Gruppen gegen den Gesamtmittelwert $\left(S_{b}^{2}\right)$. Die Varianz innerhalb der Gruppe ist die durch zufällige Streuung der Messwerte innerhalb der Gruppe entstehende Varianz. Die Varianz der Gruppenmittelwerte gegen den Gesamtmittelwert ist die Varianz, die auf die Wirkung des Einflussfaktors zurückzuführen ist. Zusammen addiert ergeben diese beiden Varianzen die Gesamtvarianz $S^{2}$. Die Nullhypothese wird verworfen, wenn der Anteil der Varianz zwischen den Gruppen im Vergleich zur Varianz innerhalb der Gruppen zu groß ist. Diese Testentscheidung wird mit Hilfe der F-Verteilung getroffen. Die Nullhypothese wird verworfen, wenn:

$$
\begin{aligned}
& F>f \\
& F=\frac{\left((n-k) \cdot S_{b}^{2}\right)}{\left((k-1) \cdot S_{w}^{2}\right)} \\
& f=0,95,(1-\alpha) \text {-Quantil der } F \text {-Verteilung } \\
& n=\text { Gesamtstichprobenzahl, } k=\text { Gruppenanzahl }
\end{aligned}
$$

$F$ ist ein Maß für die Abweichung der Streuung von der rein zufälligen Streuung. Je größer $F$ ist, desto stärker ist die Wirkung des Einflussfaktors. Ist $F=1$, so liegt keine Wirkung des Einflussfaktors vor, das heißt, die Streuung der Werte ist rein zufällig.

\subsubsection{Multiple Tests innerhalb eines ALM}

Wurde durch den $F$-Test festgestellt, dass eine signifikante Abweichung der Streuung von der rein zufälligen vorliegt, so ist noch nicht bekannt, welche der Gruppen diese verursacht haben. Es muss also zum Beispiel bestimmt werden, für welche der Zellinien die signifikante Abweichung vorliegt. Dies wird mit den multiplen Testverfahren nach Tukey und Dunnett durchgeführt.

Beim Tukey-Test werden die aus dem ALM berechneten Erwartungswerte einer Gruppe mit dem Gruppenmittelwert jeder anderen Gruppe paarweise verglichen. Das Programm liefert eine Auflistung mit den Signifikanzwerten jedes Paarvergleichs. Mit dem Tukey- 
Test wurde in dieser Arbeit bestimmt, ob es signifikante Unterschiede zwischen den Aufnahmeraten der MATE1- und Kontrollzellen bei $\mathrm{pH}$ 7,4 und pH 8,5 gab.

Beim Dunnett-Test werden die aus dem ALM berechneten Erwartungswerte mit dem einer Referenzgruppe verglichen [37]. Zum Beispiel bildete bei der Real-Time-PCR die SLC-Expression in den Melanozyten die Referenzgruppe. Damit konnte ermittelt werden, ob es eine signifikant verschiedene SLC-Expression in Melanomzelllinien und Melanozyten gab.

\subsubsection{Programmausführung}

Es wurde ein Programm für SAS erstellt, welches ein den Versuchen angepasstes Modell wiedergibt, die statistischen Koeffizienten berechnet, die Hypothesen mit den dafür erforderlichen Tests überprüft und die Ergebnisse ausgibt. Für die Versuchsarten RealTime-PCR, radioaktive Aufnahmeversuche und Zytotoxizitätstests, wurden die entsprechenden Faktoren und Messwerte eingegeben. Daraufhin lieferte das Programm als Ausgabedaten Mittelwerte der Messdaten mit 95 \%igen Konfidenzintervallgrenzen. Für die realtime-PCR-Experimente waren das die Mittelwerte der $\Delta C_{T}$-Werte, für die radioaktiven Aufnahmeversuche die Mittelwerte der Aufnahmeraten des radioaktiv markierten Substrats und für die Zytotoxizitätstests die prozentualen Anteile an überlebenden Zellen. Das Programm lieferte auch die Signifikanzangabe der Messwerte und der berechneten Größen. 


\section{Ergebnisse}

SLC-Proteine wie MATE1 und OCT1 könnten an Pharmakawechselwirkungen und toxischen Nebenwirkungen in nicht entarteten Zellen, besonders der Sekretionsorgane Leber und Niere beteiligt sein [183]. Andererseits ist bekannt, dass einige Zytostatika starke Nebenwirkungen in nicht entarteten Zellen, besonders der Leber und Niere, verursachen. Daher besteht ein Interesse daran, zu untersuchen, ob MATE1 und OCT1 auch am Zytostatikatransport in und aus nicht entarteten Zellen heraus beteiligt sein könnten.

Diese Arbeit soll dazu beitragen, diese Fragestellungen zu klären. Die zugrunde liegenden Experimente bestanden aus zwei Phasen. Im ersten Teil wurden Untersuchungen an Melanomzellen zur mRNA-Expression von SLC-Proteinen vorgenommen, die als Transporter für Zytostatika in Frage kamen.

In der zweiten Phase der Experimente ging es darum, aus einer Gruppe von Zytostatika diejenigen zu identifizieren, die eine Interaktion mit den speziellen SLC-Proteinen OCT1 bzw. MATE1 zeigten. Diese Messungen wurden in mit dem SLC-Gen transfizierten Modellzellen vorgenommen. Eine Interaktion war allerdings noch kein Nachweis für einen Transport der Zytostatika. Zur weiteren Klärung wurde daher für eine Reihe von Zytostatika bestimmt, ob die Expression von OCT1 bzw. MATE1 zu einer erhöhten Zytotoxizität führte. Für zwei Zytostatika wurden noch weiter gehende Untersuchungen durchgeführt: Für das fluoreszierende Zytostatikum Doxorubicin wurde die direkte Aufnahmerate in MATE1-Zellen bestimmt. Für das Zytostatikum Temozolomid wurde eine zusätzliche direkte Quantifizierung der OCT1- und MATE1-vermittelten Zellschäden durchgeführt, weil es in der Melanomtherapie angewendet wird.

\subsection{Expression von SLC-Transportern in Melanomzellen und Melanozyten}

Ob SLC-Transporter (siehe 1.2) Zytostatika in Tumorzellen transportieren könnten, wurde an Zellen des Malignen Melanoms untersucht. Im Vergleich dazu wurde auch die Expression in nicht entarteten Melanozyten bestimmt.

Für die nachfolgenden Experimente wurden die fünf Melanomzelllinien MelA, MelB, MelC, LIBR und KAII und zum Vergleich die Melanozyten von gesunden Spendern M02-09, M10-09 (MZ) und primären Melanozyten NHEM1, NHEM2 und NHEM3 (PMZ) eingesetzt (siehe 2.4). 
Neben OCT1 und MATE1 wurden die Mitglieder der SLC-Familie ausgewählt, welche auf Grund ihrer Substratspezifität Zytostatika transportieren könnten oder für welche in der Literatur bereits Wechselwirkungen mit Zytostatika beschrieben sind (siehe 1.2). Welche SLC-Transporter in Melanomzelllinien exprimiert waren, wurde zunächst mittels ReverseTranskriptase-PCR ermittelt. Anschließend wurde die Expression der SLC-mRNA mittels der sehr viel genaueren Methode Taqman-Real-Time-PCR bestimmt (siehe 3.7.3.2). Diese Methode wurde dann auch angewandt, um die Expression von SLC-mRNA in Melanozyten zu bestimmen. Die Expressionslevel wurden quantifiziert und die Höhe der Expression in Melanomzellen mit der in Melanozyten verglichen.

Nachfolgend sind die Ergebnisse der Taqman-Real-Time-PCR von Mitgliedern verschiedener SLC-Familien in Melanomzellinien, $\mathrm{MZ}$ und $\mathrm{PMZ}$ dargestellt. Die $\Delta C_{T}$-Werte geben an, wievielfach die mRNA eines SLC-Gens geringer als die des Referenzgens GAPDH exprimiert ist. Ein $\Delta C_{T}$-Wert von -3 würde wegen der exponentiellen Darstellungsweise bedeuten, dass die mRNA des SLC-Gens $2^{3}$-fach geringer als die Referenz-mRNA von GAPDH exprimiert ist (3.7.3.2). Dargestellt sind Erwartungswerte aus drei Experimenten mit Doppelbestimmung (Melanomzellinien und Melanozyten) bzw. einem Experiment mit Doppelbestimmung dreier verschiedener primärer Melanozyten.

Die $\Delta C_{T}$-Werte der Melanomzelllinien (z. B. Abb. 4-1, hellblaue Balken) wurden mit denen der MZ und PMZ (graue Balken) mittels Dunnett-Test (siehe 3.8) verglichen. Signifikante Unterschiede sind mit "*" gekennzeichnet. Signifikant höhere Expressionsspiegel einer SLC-mRNA in Melanomzelllinien sind als gemusterte Balken hervorgehoben (liniert bei signifikant höherer Expression als MZ oder PMZ, kariert bei signifikant höherer Expression als MZ und PMZ).

\subsubsection{Expression von LAT}

Die Expression der mRNA des L-Aminosäuretransporters 1 (LAT1, SLC7A5) ist insgesamt hoch. Sie variiert zwischen den Zellproben mit $\Delta C_{T}$-Werten zwischen $-2,95 \pm 0,53$ für PMZ und -7,84 $\pm 0,53$ für MelA (Abb. 4-1 a). Die Zellproben lassen sich gemäß ihrer LAT1-Expression in drei Gruppen einteilen. PMZ besitzen zu allen anderen Zelllinien signifikant höhere $\Delta C_{T}$-Werte $(\mathrm{p}<0,001)$. MZ, MelB, LIBR und KAII besitzen im Vergleich zu PMZ kleinere, untereinander ähnliche Werte. Die geringste LAT1-Expression liegt für MelA und MelC vor. Die Expression der LAT1-mRNA ist also in Melanomzelllinien signifikant niedriger als in Melanozyten. 
Die mRNA von LAT2 (SLC7A8) ist in der Melanomzellllinie MelB mit $\Delta C_{T}=-8,19 \pm 0,58$ am geringsten und in $M Z$ mit -4,50 \pm 0,58 am höchsten exprimiert (Abb. 3-1 b). Die Zellproben lassen sich entsprechend ihrer LAT2-Expression in zwei Gruppen einteilen. Die Melanomzelllinien MelA, MelB und MelC weisen signifikant kleinere $\Delta C_{T}$-Werte $(\mathrm{p}<$ 0,001) als die Melanomzelllinien LIBR und KAII und als MZ und PMZ auf, welche sich nicht signifikant unterscheiden.

a)

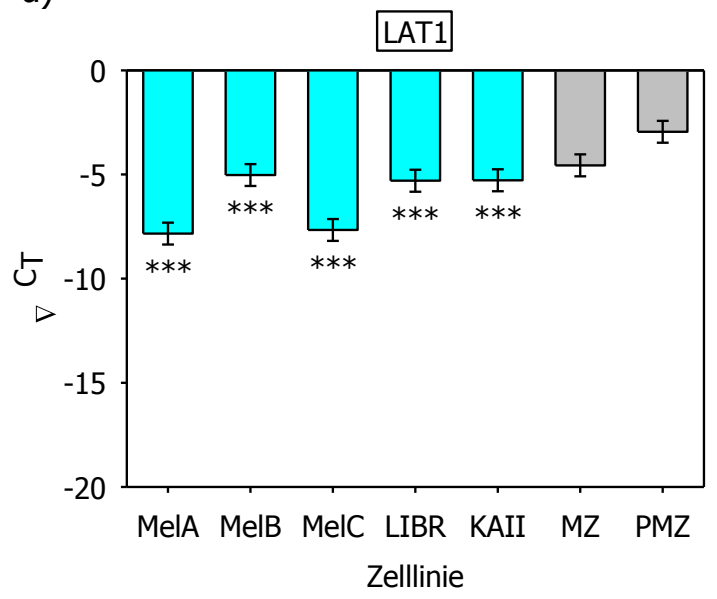

b)

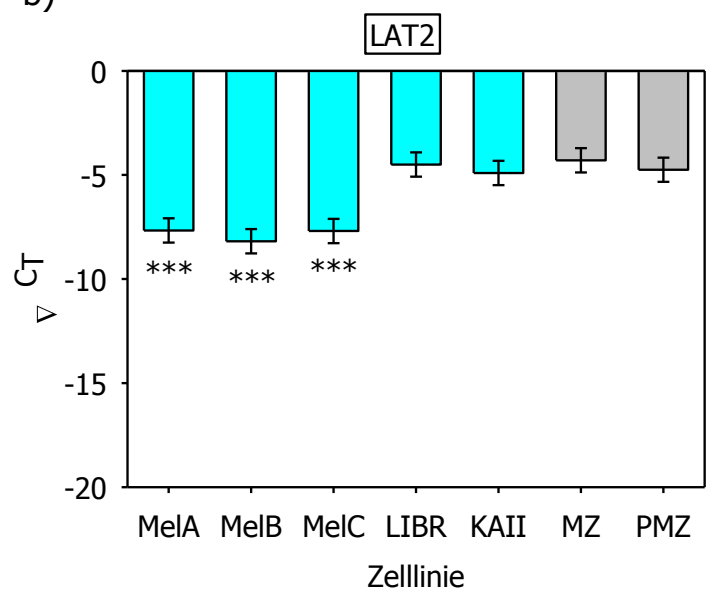

Abb. 4-1: Quantitative Expression von L-Aminosäuretransportern (LAT) in Melanomzellinien und Melanozyten:

$\triangle C_{T}$-Werte aus mittels Taqman-Real-Time-PCR-ermittelten $C_{T}$ (Referenzgen GAPDH) $C_{T}(S L C-m R N A)$ für Melanomzellinien (blau) und nicht entartete Melanozyten (Zellinien: MZ, primäre: $P M Z$, grau); Konfidenzintervalle mit Konfidenzniveau $95 \%$, $* * *=p<0,001=$ signifikante $\Delta C_{T}$-Unterschiede zwischen Melanomzellinen und Melanozyten

\subsubsection{Expression von MCT}

MCT1 (SLC16A1) ist in allen untersuchten Zellproben mit $\Delta C_{T}$-Werten zwischen $-6,28 \pm 0,34$ (MelB) und $-8,13 \pm 0,34$ (MelC) hoch exprimiert (Abb. 4-2 a). MelB und LIBR besitzen eine signifikant höhere MCT1-Expression als MZ, jedoch keine höhere als PMZ. Insgesamt ist MCT1 in den Melanomzellinien weder signifikant höher noch geringer als in Melanozyten exprimiert.

MCT4 (SLC16A3) ist in den Melanomzellinien und Melanozyten mit $\Delta C_{T}$-Werten zwischen $-9,56 \pm 0,54$ in MelB und -15,22 $\pm 0,54$ in MelC sehr unterschiedlich exprimiert (Abb. 4-2 b). Die MCT4-Expression ist jedoch in MelB nicht signifikant höher als in PMZ. Die Zellproben lassen sich nach ihrer MCT4-Expression in drei Gruppen einteilen. MelB und PMZ weisen eine signifikant höhere MCT4-Expression als MelA, LIBR, KAII und MZ auf. Diese wiederum weisen eine signifikant höhere MCT4-Expression gegenüber MelC auf. Die MCT4-Expression ist in Melanomzellinien nicht signifikant höher als in MZ und PMZ. 
a)

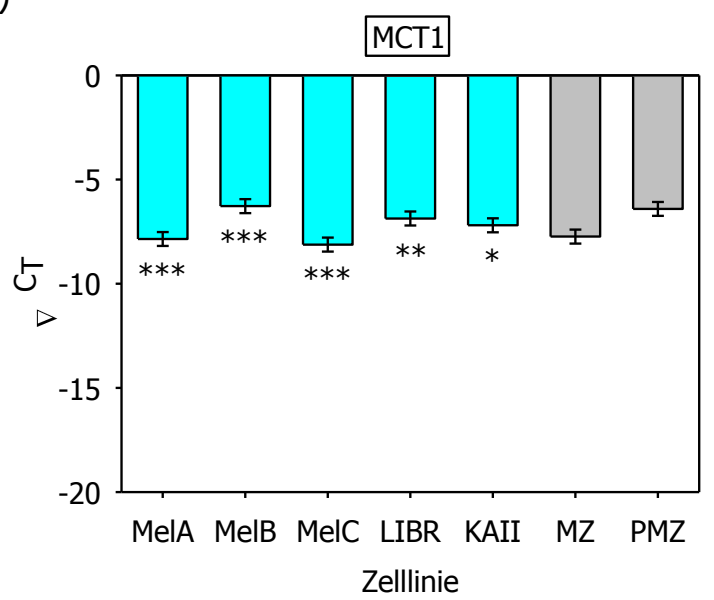

b)

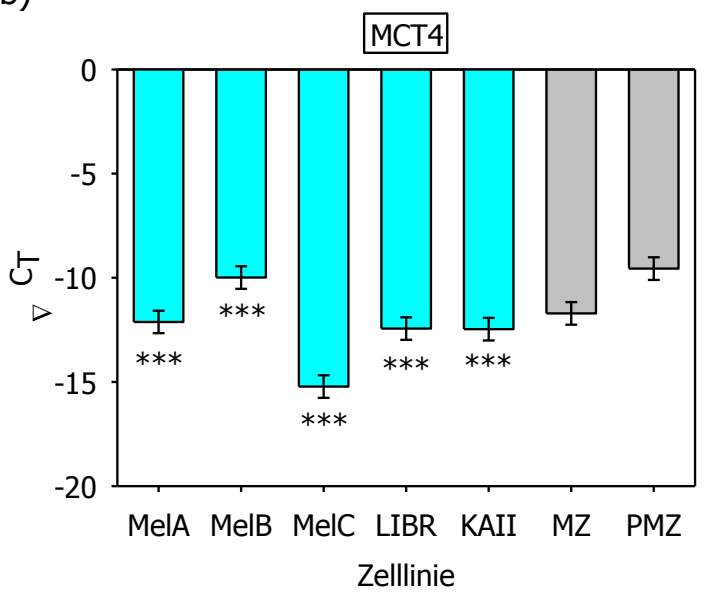

Abb. 4-2: Quantitative Expression von Monocarboxylattransportern (MCT) in Melanomzelllinien und Melanozyten:

$\triangle C_{T}$-Werte aus mittels Taqman-Real-Time-PCR-ermittelten $C_{T}$ (Referenzgen GAPDH) $C_{T}(S L C-m R N A)$ für Melanomzelllinien (blau) und nicht entartete Melanozyten (Zelllinien: $M Z$, primäre: $P M Z$, grau); Konfidenzintervalle mit Konfidenzniveau $95 \%,{ }^{* * *}=p<0,001,{ }^{* *}=p<0,01,{ }^{*}=p<0,05=$ signifikante $\Delta C_{T}$-Unterschiede zwischen Melanomzelllinen und Melanozyten

\subsubsection{Expression von RFT und ThTr1}

Der Folat-Transporter („Reduced-Folate"-Transporter, RFT, SLC19A1) ist in Melanomzellen mit $\Delta C_{T}$-Werten zwischen $-7,62 \pm 0,42$ für $\mathrm{PMZ}$ und $-11,35 \pm 0,42$ für MelC exprimiert (Abb. 4-3 a). Die Melanomzelllinien MelA, MelB und MelC besitzen eine signifikant geringere RFT-Expression als die Melanozyten ( $p<0,001$ bzw. $p<0,01$ ). Die Melanomzellinien LIBR und KAII unterscheiden sich in ihrer RFT-Expression nicht signifikant von Melanozyten. RFT ist also bei einer insgesamt mittleren Expression in den Melanomzelllinien gleich oder geringer exprimiert als in Melanozyten.

ThTr1 (SLC19A2) ist mit $\Delta C_{T}$-Werten zwischen $-5,17 \pm 0,43$ in PMZ und $-8,44 \pm 0,44$ in MelC exprimiert (Abb. 4-3 b). Die Expression ist in Melanomzelllinien tendenziell geringer als in den Melanozyten, zu der in PMZ sogar signifikant geringer. Wie RFT ist auch ThTr1 in MelA, MelB und MelC am geringsten, jedoch insgesamt hoch exprimiert. 
a)

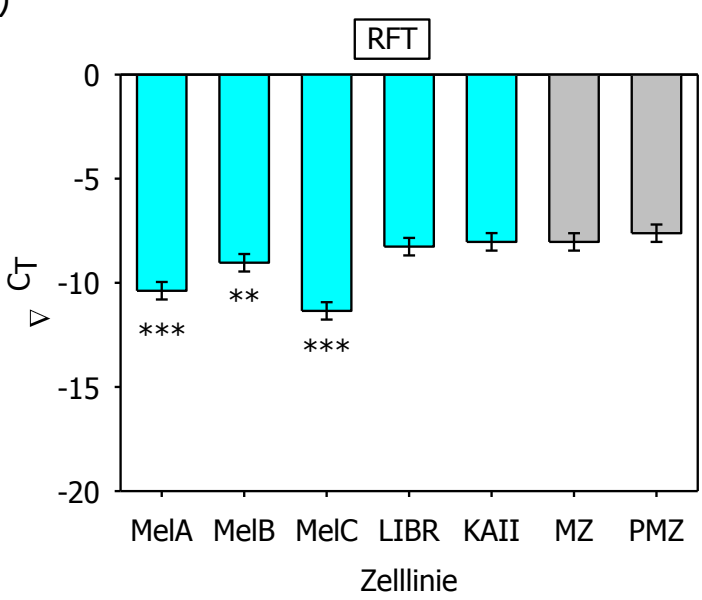

b)

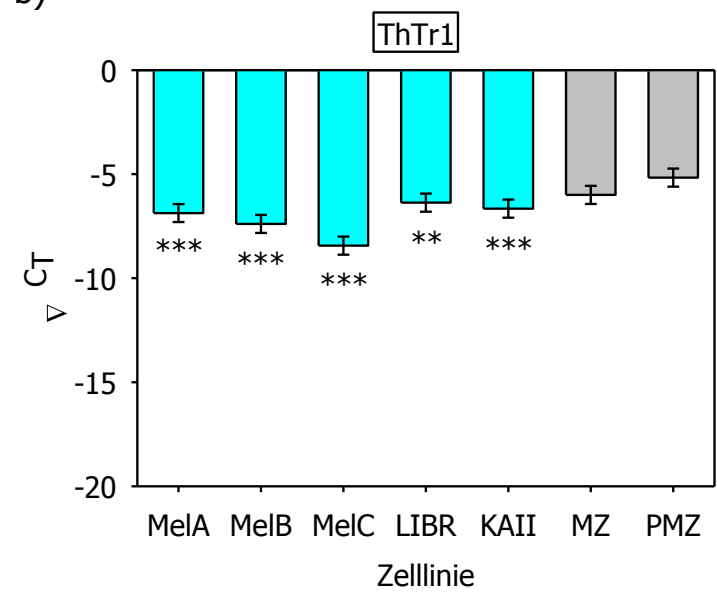

Abb. 4-3: Quantitative Expression des Folat- und Thiamintransporters 1 (RFT, ThTr1) in Melanomzellinien und Melanozyten:

$\triangle C_{T}$-Werte aus mittels Taqman-Real-Time-PCR-ermittelten $C_{T}$ (Referenzgen GAPDH) $C_{T}(S L C-m R N A)$ für Melanomzelllinien (blau) und nicht entartete Melanozyten (Zelllinien: $M Z$, primäre: $P M Z$, grau); Konfidenzintervalle mit Konfidenzniveau $95 \%,{ }^{* * *}=p<0,001,{ }^{* *}=p<0,01=$ signifikante $\Delta C_{T}$-Unterschiede zwischen Melanomzellinen und Melanozyten

\subsubsection{Expression von OATP}

Das Organische-Anionen-Transportprotein SLCO1A2 (OATPA) ist nur in der Melanomzelllinie MelA mit einem sehr geringen $\Delta C_{T}$-Wert von $-16,58 \pm 0,15$ exprimiert.

SLCO2B1 (OATPB) ist in den untersuchten Melanomzelllinien und Melanozyten sehr differentiell exprimiert. Die Expressionswerte variieren von $\Delta \mathrm{C}_{\mathrm{T}}=-7,63 \pm 0,86$ in den $\mathrm{MZ}$ bis zu keiner Expression in den Melanomzellinien LIBR und KAII (Abb. 4-4 a). Die Melanomzellinien MelA, MelB und MelC besitzen eine signifikant niedrigere SLCO2B1Expression als PMZ und MZ.

Dagegen ist SLCO1B1 (OATPC) nur in den Melanomzelllinien MelA, MelB, LIBR und KAII, nicht aber in Melanozyten und primären Melanozyten exprimiert (Abb. 4-4 b, karierte Balken). Für MelA ist der $\Delta C_{T}$-Wert mit $-14,48 \pm 0,23$ signifikant am höchsten. MelB, LIBR und KAII weisen untereinander eine nicht signifikant verschiedene OATPCExpression auf.

SLCO3A1 (OATPD) ist sowohl in Melanomzellen als auch Melanozyten und primären Melanozyten exprimiert (Abb. 4-4 c). Die $\Delta C_{T}$-Werte liegen zwischen -10,02 \pm 0,66 für MZ und 15,31 $\pm 0,72$ für KAII. Der Vergleich der OATPD-Expressionsraten zwischen Melanomzelllinien und Melanozyten ergibt eine signifikant geringere Expression für die Melanomzelllinien $(p<0,001)$ außer für die Melanomzelllinie MelB, für welche die Expression nicht signifikant verschieden von der der Melanozyten ist. 
SLCO4A1 (OATPE) ist in PMZ mit $\Delta C_{T}$-Werten von $-9,96 \pm 0,39$ am höchsten und in $M Z$ mit 14,06 \pm 0,35 am niedrigsten exprimiert (Abb. 4-4 d). Die Expressionsraten der Melanomzelllinien sind zwar signifikant höher als die von MZ (Abb. 4-4 d, linierte Balken, $p<0,001)$, allerdings auch signifikant niedriger als die von PMZ. Eine Ausnahme bildet MelB, dessen SLCO4A1-Expression nicht signifikant verschieden von der von PMZ ist.

a)

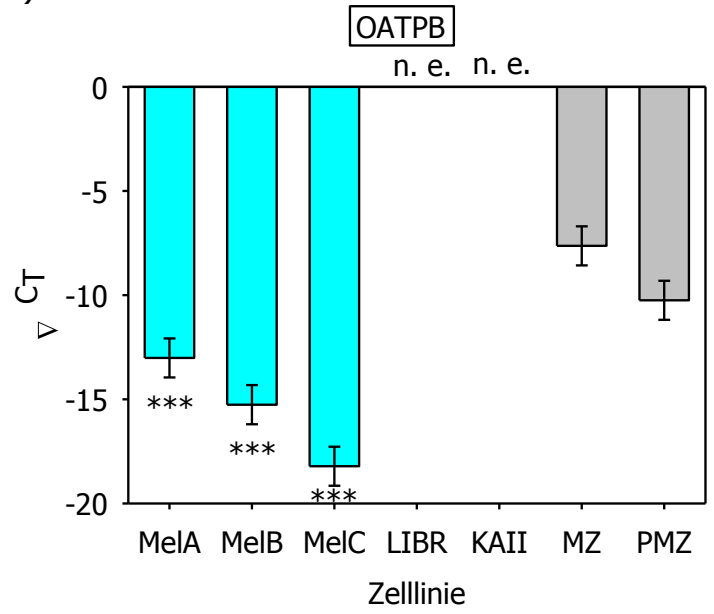

c)

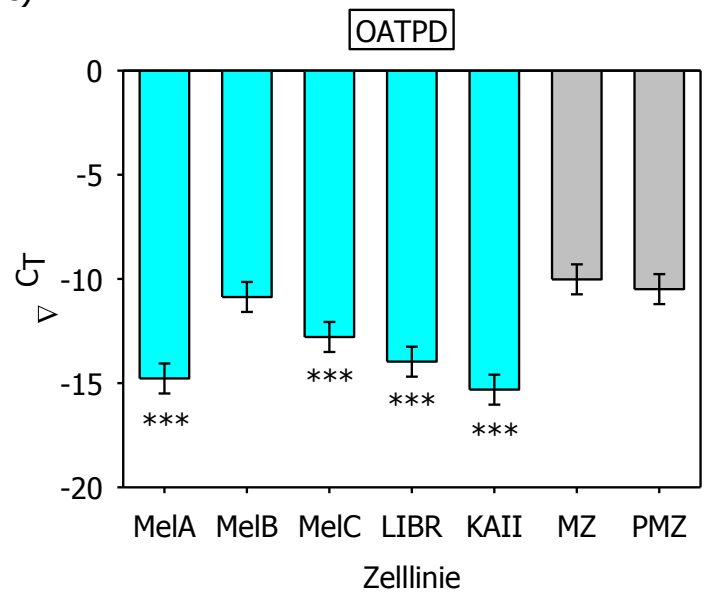

b)

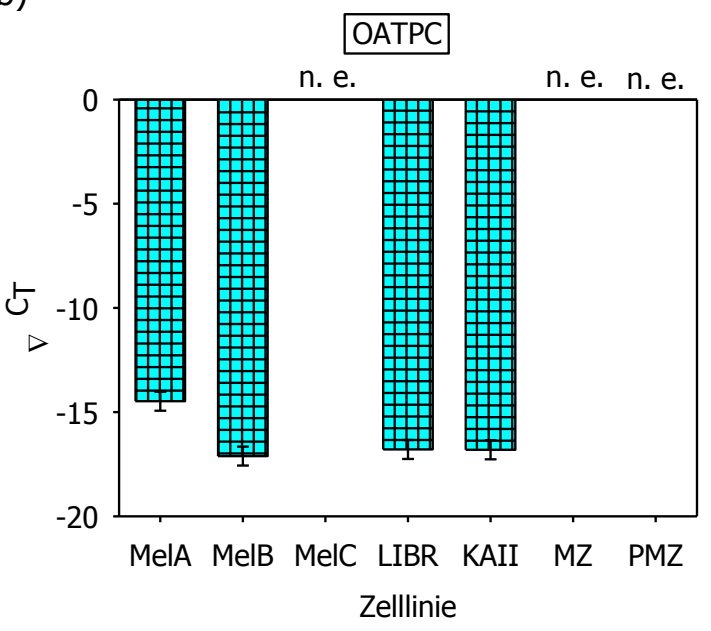

d)

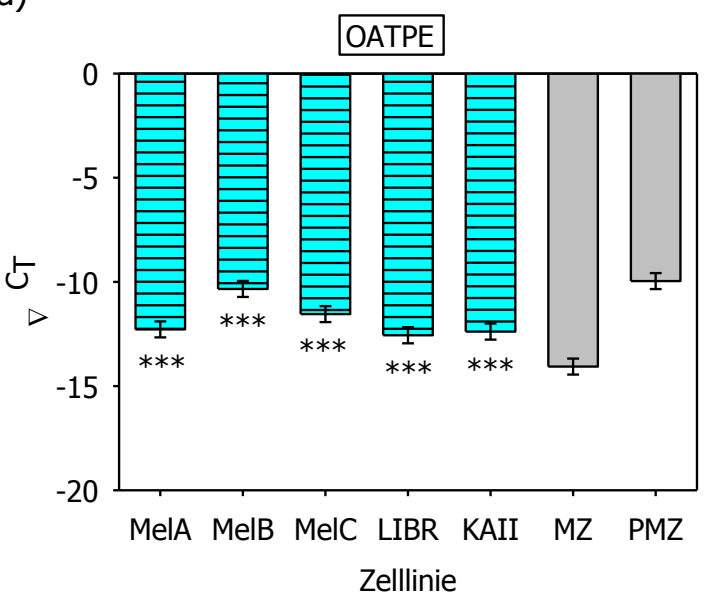

Abb. 4-4: Quantitative Expression der Organische-Anionen-Transportproteine (OATP, SLCO) in Melanomzellinien und Melanozyten:

$\triangle C_{T}$-Werte aus mittels Taqman-Real-Time-PCR-ermittelten $C_{T}$ (Referenzgen GAPDH) $C_{T}(S L C-m R N A)$ für Melanomzellinien (blau) und nicht entartete Melanozyten (Zellinien: $M Z$, primäre: $P M Z$, grau); $n$. e. = nicht exprimiert; Konfidenzintervalle mit Konfidenzniveau $95 \%,{ }^{* * *}=p<0,001,{ }^{* *}=p<0,01=$ signifikante $\Delta C_{T}$-Unterschiede zwischen Melanomzellinen und Melanozyten; linierte Balken: signifikant höhere Expression in Melanomzelllinie im Vergleich zu MZ oder PMZ; karierte Balken: signifikant höhere Expression in Melanomzelllinie im Vergleich zu MZ und PMZ

\subsubsection{Expression von OCT1}

Für OCT1 wurde in 4.2.1 gezeigt, dass OCT1 mit Zytostatika interagiert. Daher war es besonders wichtig, dieses SLC-Protein auf seine mRNA-Expression in Tumorzellen zu testen. Die Expressionsraten von OCT1 liegen zwischen $-12,81 \pm 0,42$ in $M Z$ 
und $-16,19 \pm 0,45$ in MelC (Abb. 4-5). OCT1 ist in allen Melanomzelllinien signifikant geringer exprimiert als in Melanozyten.

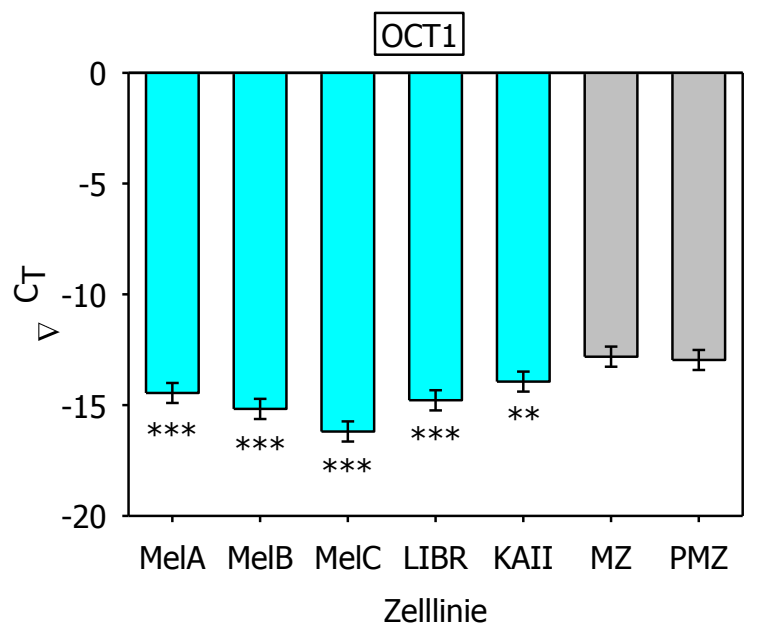

Abb. 4-5: Quantitative Expression des Organische-Kationen-Transporters (OCT) 1 in Melanomzellinien und Melanozyten:

$\triangle C_{T}$-Werte aus mittels Taqman-Real-Time-PCR-ermittelten $C_{T}$ (Referenzgen GAPDH) $C_{T}(S L C-m R N A)$ für Melanomzellinien (blau) und nicht entartete Melanozyten (Zellinien: $M Z$, primäre: $P M Z$, grau); Konfidenzintervalle mit Konfidenzniveau $95 \%, * * *=p<0,001, * *=p<0,01, *=p<0,05=$ signifikante $\Delta C_{T}$-Unterschiede zwischen Melanomzelllinen und Melanozyten

\subsubsection{Expression von ENT}

Der äquilibrierende Nukleosidtransporter ENT1 (SLC29A1) ist in Melanomzellen und Melanozyten mit $\Delta C_{T}$-Werten zwischen $-6,95 \pm 1,18$ in KAII und $-9,87 \pm 1,18$ in PMZ exprimiert (Abb. 4-6 a). Die Expressionsraten weisen sehr hohe Konfidenzintervalle von 1,18 Zyklen auf. Der Vergleich der ENT1-Expression in Melanomzelllinien mit der in Melanozyten ergibt keine signifikanten Unterschiede. Eine Ausnahme bildet KAII, in welcher ENT1 tendenziell höher als in MZ und signifikant höher als in PMZ exprimiert ist $(p<0,01)$.

ENT2 (SLC29A2) ist in Melanomzelllinien und Melanozyten im Vergleich zu ENT1 geringer exprimiert (Abb. 4-6 b). Die mittleren $\Delta C_{T}$-Werte liegen zwischen -9,62 $\pm 0,71$ für LIBR und $-13,33 \pm 0,64$ für $M Z$. Auffällig ist, dass ENT2 in allen getesteten Melanomzelllinien signifikant höher als in Melanozyten exprimiert ist, mit der Ausnahme einer nur tendenziell höheren Expression in MelB im Vergleich zu PMZ. 
a)

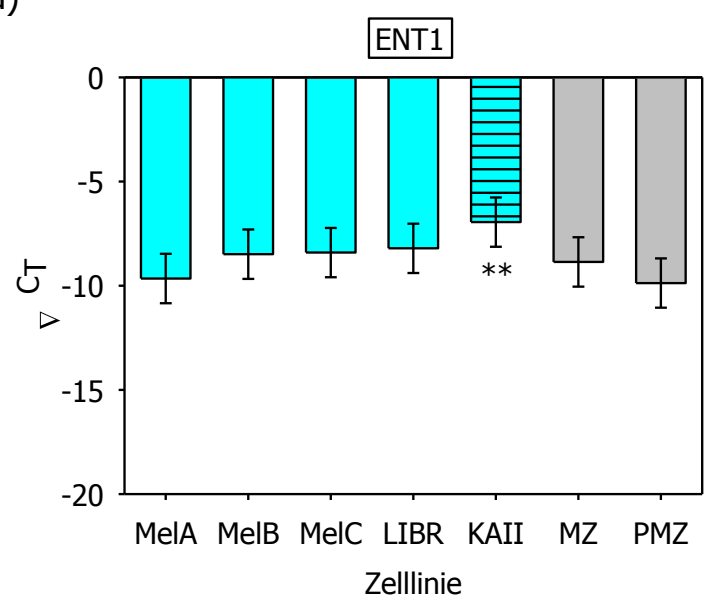

b)

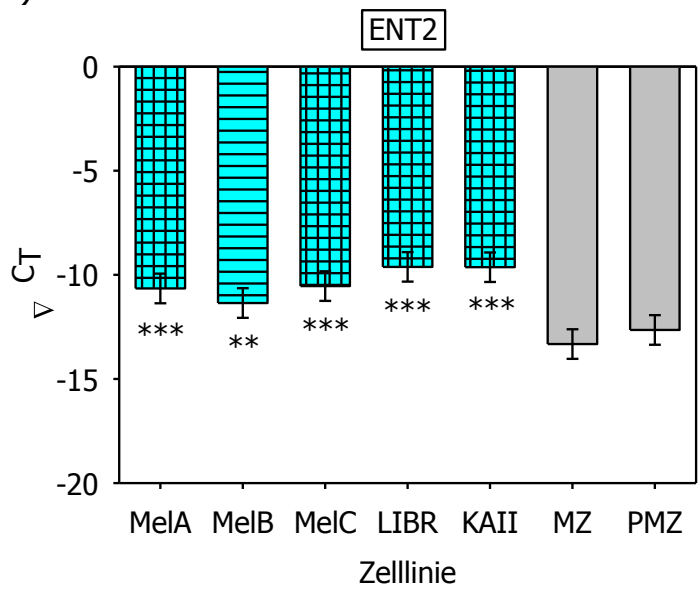

c)

ENT3

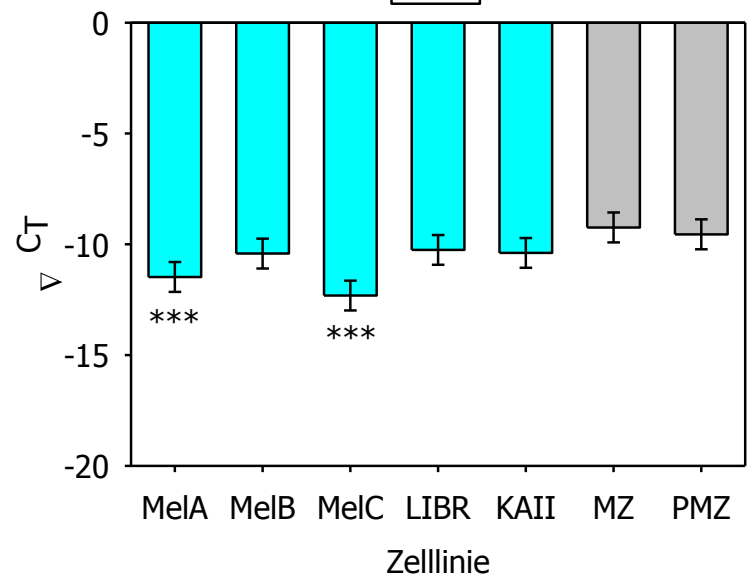

Abb. 4-6: Quantitative Expression der Nukleosid-Transporter (ENT) in Melanomzellinien und Melanozyten:

$\triangle C_{T}$-Werte aus mittels Taqman-Real-Time-PCR-ermittelten $C_{T}$ (Referenzgen GAPDH) $C_{T}(S L C-m R N A)$ für Melanomzelllinien (blau) und nicht entartete Melanozyten (Zellinien: $M Z$, primäre: $P M Z$, grau), Konfidenzintervalle mit Konfidenzniveau $95 \%,{ }^{* * *}=p<0,001,{ }^{* *}=p<0,01=$ signifikante $\Delta C_{T}$-Unterschiede zwischen Melanomzellinen und Melanozyten; linierte Balken: signifikant höhere Expression in Melanomzellinie im Vergleich zu MZ oder PMZ; karierte Balken: signifikant höhere Expression in Melanomzelllinie im Vergleich zu MZ und PMZ

ENT3 (SLC29A3) ist in den getesteten Zellproben mit $\Delta C_{T}$-Werten zwischen $-9,24 \pm 0,62$ in $\mathrm{MZ}$ und $-12,31 \pm 0,68$ in MelC exprimiert (Abb. 4-6 c). MelA und MelB sind gegenüber Melanozyten signifikant geringer exprimiert. MeIC, LIBR und KAII unterscheiden sich in ihrer ENT3-Expression nicht signifikant von den Melanozyten.

\subsubsection{Expression von MATE1}

Die $\Delta C_{T}$-Werte für MATE1 liegen zwischen $-11,33 \pm 0,45$ in $\mathrm{MZ}$ und $-13,27 \pm 0,50$ in LIBR (Abb. 4-7). MATE1 ist damit in den Zellproben nur gering differentiell exprimiert. Alle Melanomzelllinien weisen signifikant geringere Expressionsraten von MATE1 im Vergleich zu den Melanozyten auf ( $p<0,01$ bzw. $p<0,001$ ). 


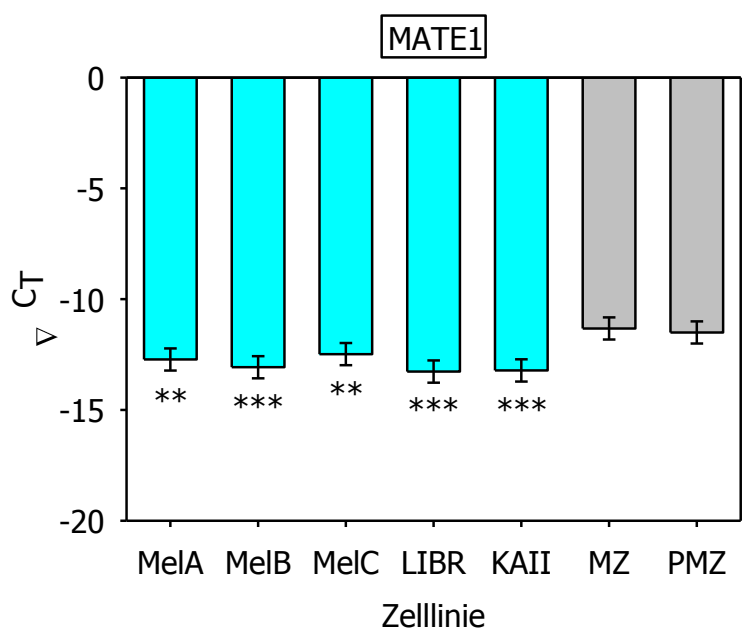

Abb. 4-7: Quantitative Expression des Multidrug-and-Toxin-Extrusion-(MATE-)1-Transporters in Melanomzellinien und Melanozyten:

$\triangle C_{T}$-Werte aus mittels Taqman-Real-Time-PCR-ermittelten $C_{T}$ (Referenzgen GAPDH) $C_{T}(S L C-m R N A)$ für Melanomzellinien (blau) und nicht entartete Melanozyten (Zellinien: $M Z$, primäre: $P M Z$, grau); Konfidenzintervalle mit Konfidenzniveau $95 \%,{ }^{* * *}=p<0,001,{ }^{* *}=p<0,01, *=p<0,05=$ signifikante $\Delta C_{T}$-Unterschiede zwischen Melanomzelllinen und Melanozyten

\subsubsection{Expression von MDR1}

Neben den bisher behandelten SLC-Proteinen, die vornehmlich Substanzen in Zellen aufnehmen, wurde in dieser Arbeit auch die Expression des Multidrug-ResistanceTransporters-1 (MDR1) untersucht, der ein Repräsentant der Effluxtransporter ist. Er gehört der ATP-Binding-Cassette-(ABC-)Familie an und wurde ausgewählt, da er in sehr vielen verschiedenen Zellarten exprimiert ist und Relevanz als Zytostatikatransporter erlangt hat [181].

MDR1 ist in allen untersuchten Zellproben bis auf MelC exprimiert (Abb. 4-8). Die Expression ist zwischen Melanomzellinien und Melanozyten sehr differentiell mit signifikant unterschiedlichen $\Delta C_{T}$-Werten zwischen $-8,61 \pm 0,55$ in KAII und $16,61 \pm 0,59$ in $M Z$. 


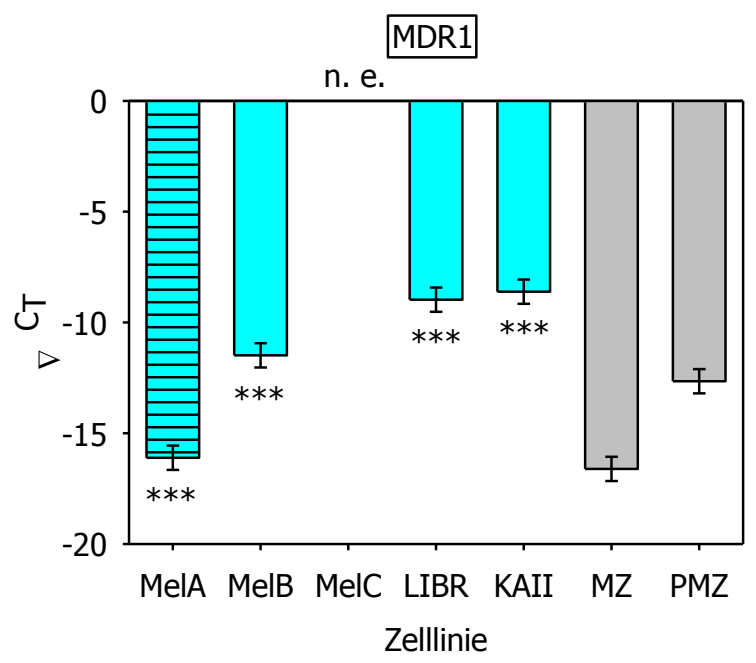

Abb. 4-8: Quantitative Expression des Effluxtransporters Multidrug-Resistance (MDR) 1 in Melanomzellinien und Melanozyten:

$\triangle C_{T}$-Werte aus mittels Taqman-Real-Time-PCR-ermittelten $C_{T}$ (Referenzgen GAPDH) $C_{T}(S L C-m R N A)$ für Melanomzelllinien (blau) und nicht entartete Melanozyten (Zelllinien: $M Z$, primäre: $P M Z$, grau); $n$. e. = nicht exprimiert; Konfidenzintervalle mit Konfidenzniveau $95 \%,{ }^{* * *}=p<0,001,{ }^{* *}=p<0,01=$ signifikante $\Delta C_{T}$ Unterschiede zwischen Melanomzellinen und Melanozyten; linierter Balken: signifikant niedrigere Expression in einer Melanomzellinie im Vergleich zu MZ oder PMZ

Neben den oben aufgeführten SLC-Transportern wurden weitere auf ihre Expression in Melanomzelllinien untersucht. MCT2, OCT2, OCT3, OAT1-OAT4, CNT1 - CNT3, OATP8 und MATE2 waren aber nicht in den untersuchten Zellen exprimiert und wurden somit in dieser Arbeit nicht weiter untersucht.

\subsection{Eignung von OCT1 und MATE1 als Zytostatikatransporter}

\subsubsection{Interaktion von OCT1 und MATE1 mit Zytostatika}

Sowohl OCT1 als auch MATE1 sind in Melanomzelllinien exprimiert, könnten also auch in der Melanomtherapie einen Einfluss auf die Zytostatikaakkumulation in Tumorzellen haben.

Vom OCT1-Protein ist bekannt, dass es Zytostatika transportieren kann. Dieses Protein wurde bereits in unserer Arbeitsgruppe in seiner Interaktion mit einer großen Anzahl von Zytostatika charakterisiert [60]. Die Kenntnisse zu OCT1 werden im Folgenden auf die Interaktion mit weiteren, in der Melanomtherapie eingesetzten Zytostatika erweitert. Neben OCT1 wurde auch MATE1 auf seine Eignung als Zytostatikumtransporter getestet. MATE1 ist ein SLC-Protein, welches eine Vielzahl an Substanzen, z. B. Medikamente transportiert. Über die Interaktion von MATE1 mit Zytostatika ist wenig bekannt. Deswegen sollte hier untersucht werden, ob MATE1 weitere Zytostatika transportieren kann. 
Als Modellsysteme für die Interaktionsanalysen von SLC-Proteinen mit Zytostatika dienten CHO- und HEK293-Zellen, welche das jeweilige Transportprotein exprimierten. CHO-OCT1-Zellen lagen bereits als fertiges Modellsystem vor (siehe 2.4). MATE1HEK293-Zellen wurden zunächst durch Transfektion der Zellen mit dem MATE1-Gen generiert.

\subsubsection{Funktionelle Charakterisierung von MATE1}

Um die funktionelle Expression von MATE1 in den transfizierten HEK293-Zellen zu überprüfen, wurden radioaktive Aufnahmeversuche durchgeführt. Im Folgenden sind die Ergebnisse zur funktionellen Charakterisierung des MATE1-Konstrukts in transient (4.2.1.1.1) und anschließend in stabil transfizierten HEK293-Zellen (4.2.1.1.2) dargestellt.

\subsection{Funktionelle Charakterisierung von MATE1 in transient transfizierten HEK293-Zellen}

Durch die transiente Transfektion wurde kontrolliert, ob die Klonierung des MATE1-Gens in den Expressionsvektor und die transiente Transfektion in HEK293-Zellen erfolgreich waren, so dass MATE1 in diesen Zellen eine Transportaktivität besaß.

Das MATE1-Gen wurde zunächst vom p-CMV-SPORT6-Expressionsvektor (Abb. 4-9, (1)) in den weiteren Expressionsvektor (pEF5/FRT/V5, Abb. 4-9, (2)) kloniert und diese Konstrukte transient in HEK293-Zellen transfiziert (3.2.4.1). Durch die Aufnahme von $\left[{ }^{3} \mathrm{H}\right]-\mathrm{MPP}$, welches ein Substrat von MATE1 ist, wurde untersucht, ob MATE1 in den beiden Expressionsvektoren eine Transportaktivität besaß. Damit sollte gezeigt werden, ob das MATE1-Gen bereits im pCMV-SPORT6-Vektor fehlerhaft eingebaut war und ob Klonierung und transiente Transfektion erfolgreich waren. Als Kontrolle dienten nicht transfizierte Flp-In-T-REx-Zellen (Abb. 4-9, (3)). Dargestellt ist die $\left[{ }^{3} \mathrm{H}\right]$-MPPAufnahmerate in Mammalian Ringer (Abb. 4-9, Referenz) und in Lösungen mit dem Hemmstoff unmarkiertem MPP. Da bekannt ist, dass die Transportaktivität von MATE1 pH-abhängig ist, wurden die Experimente bei $\mathrm{pH} 7,4$ und 8,5 durchgeführt (Abb. 4-9 a und b). Aufnahmelösungen bestanden aus reinem Mammalian Ringer mit $20 \mathrm{nM}$ $\left[{ }^{3} \mathrm{H}\right]-\mathrm{MPP}$ und $980 \mathrm{nM}$ MPP (Abb. 4-9, MR, Referenz) bzw. aus zusätzlich $500 \mu \mathrm{M}$ unmarkiertem MPP (MPP).

Die $\left[{ }^{3} \mathrm{H}\right]$-MPP-Aufnahmerate in Zellen mit MATE1-pCMV-SPORT6-Expressionsvektor betrug in $\mathrm{MR}$ bei $\mathrm{pH} 7,41,42 \pm 0,31 \mathrm{pmol} / 5 \mathrm{~min} /$ Loch (100 \%, Abb. 4-9, (1)). Relativ dazu wurde für Zellen mit MATE1-pEF5/FRT/V5-Expressionsvektor eine signifikant geringere Aufnahmerate von 45,48 $\pm 10,05 \%(p<0,001)$ und in Kontrollzellen eine 
Aufnahmerate von 26,28 $\pm 5,81 \%$ bestimmt (Abb. 4-9 a, linke drei Balken), welche signifikant geringer als die Aufnahme mit den beiden Expressionsvektoren war ( $p<$ 0,001). Bei Zugabe von $500 \mu \mathrm{M}$ MPP (Abb. 4-9 a, rechte drei Balken) wurde die $\left[{ }^{3} \mathrm{H}\right]$-MPP-Aufnahme in Zellen mit MATE1-pCMV-SPORT6-Vektor auf 14,27 $\pm 3,15 \%$, in Zellen mit MATE1-pEF5/FRT/V5-Vektor auf 11,22 $\pm 2,48 \%$ und in Kontrollzellen auf $12,70 \pm 2,81 \%$ gehemmt.

Bei pH 8,5 war die absolute $\left[{ }^{3} \mathrm{H}\right]$-MPP-Aufnahmerate in Zellen mit MATE1-pCMVSPORT6-Vektor in MR im Vergleich zu pH 7,4 1,6-fach auf 2,24 $\pm 0,50 \mathrm{pmol} / 5 \mathrm{~min} /$ Loch erhöht (Abb. 4-9 b, linker Balken, 100 \%). In Zellen mit MATE1-pEF5/FRT/V5-Vektor lag eine 1,4-fache $(40,78 \pm 9,01 \%)$ und in Kontrollzellen eine 1,3-fache Aufnahmerate $(12,65 \pm 2,80 \%)$ vor. Die Aufnahme von $\left[{ }^{3} \mathrm{H}\right]-M P P$ in Zellen mit MATE1-pCMV-SPORT6Vektor wurde auch bei pH 8,5 durch $500 \mu \mathrm{M}$ MPP vollkommen auf 7,99 $\pm 1,77 \%$ inhibiert. In pEF5/FRT/V5-Vektor-Zellen lag eine Hemmung auf 5,84 $\pm 1,29 \%$ und in Kontrollzellen eine Hemmung auf $8,35 \pm 1,85 \%$ vor.

a)

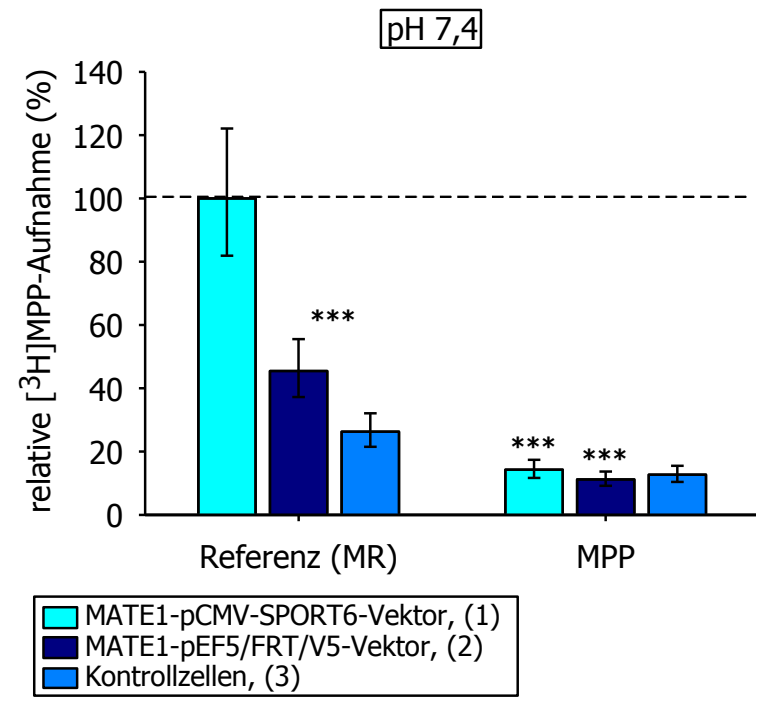

b)

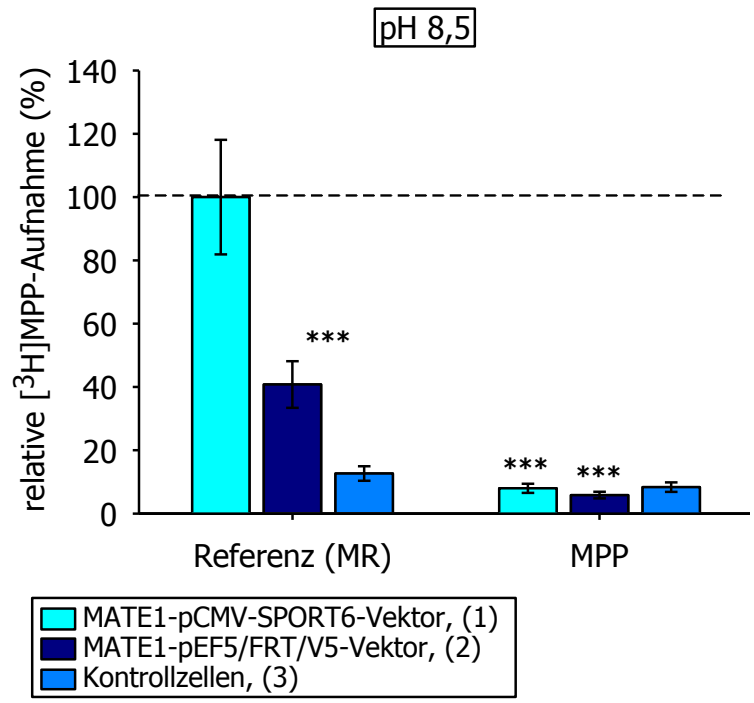

Abb. 4-9: Transportaktivität von MATE1 in transient transfizierten HEK293-Zellen:

Aufnahmerate von $20 \mathrm{nM}\left[{ }^{3} \mathrm{H}\right]-\mathrm{MPP}$ und $980 \mathrm{nM}$ MPP in mit dem Ausgangsvektor pCMV-SPORT6-MATE1 transfizierten (hellblau, 1), in mit dem Expressionsvektor pEF5/FRT/V5-MATE1 transfizierten (dunkelblau, 2) und in Zellen ohne Vektor (blau, 3), bei $\mathrm{pH} \mathrm{7,4} \mathrm{(a)} \mathrm{und} \mathrm{pH} \mathrm{8,5} \mathrm{(b),} \mathrm{in} \mathrm{reinem} \mathrm{Mammalian} \mathrm{Ringer} \mathrm{(MR)} \mathrm{und} \mathrm{unter}$ Zugabe von $500 \mu M$ MPP; prozentuale Aufnahmeraten im Vergleich zur Aufnahmerate im Ausgangsvektor 1 in MR; Konfidenzintervalle mit Konfidenzniveau 95\%; Signifikanz: $p<0,05=*, p<0,01=* *$ und $p<0,001=* * *$

Damit konnte gezeigt werden, dass MATE1 in den mit den Expressionsvektorkonstrukten transient transfizierten HEK293-Zellen eine Transportaktivität besaß und es konnte mit der stabilen Transfektion fortgefahren werden. 
Ebenso wie mit MATE1 wurde mit dem MATE2-Protein verfahren. Dieser Transporter zeigte schon im Ausgangsvektor keine Transportaktivität und wurde daher nicht weiter betrachtet.

\subsection{Funktionelle Charakterisierung von MATE1 in stabil transfizierten HEK293- Zellen}

Der Expressionsvektor pEF5/FRT/V5-MATE1 wurde stabil in HEK293-Zellen transfiziert und der Erfolg der Transfektion des MATE1-Konstrukts erneut über die [ $\left.{ }^{3} \mathrm{H}\right]$-MPPAufnahme in diese Zellen bestimmt. Um eine erhöhte Sicherheit bei der funktionellen Charakterisierung zu erzielen, wurden hier im Gegensatz zur transienten Transfektion zur Hemmung der $\left[{ }^{3} \mathrm{H}\right]$-MPP-Aufnahmerate drei verschiedene Substanzen eingesetzt (500 $\mu$ M MPP, TEA bzw. Chinin). In Abb. 4-10 sind die Ergebnisse der $\left[{ }^{3} \mathrm{H}\right]$-MPPAufnahme in stabil transfizierte MATE1- (1) und nicht mit MATE1 transfizierte Kontrollzellen dargestellt (2). Abb. 4-10 a zeigt die Ergebnisse der Experimente bei pH 7,4, Abb. 4-10 b diejenigen bei $\mathrm{pH} 8,5$.

Die absolute Aufnahme in MATE1-Zellen betrug bei $\mathrm{pH} 7,41,43 \pm 0,35 \mathrm{pmol} / 5 \mathrm{~min} /$ Loch (100 \%) und war damit 2,7-mal so hoch wie die in Kontrollzellen (37,36 $\pm 4,20 \%)$. Bei Zugabe von $500 \mu \mathrm{M}$ Chinin wurde die $\left[{ }^{3} \mathrm{H}\right]$-MPP-Aufnahmerate in MATE1-Zellen auf $21,77 \pm 2,95 \%$, bei Zugabe von $500 \mu \mathrm{M}$ MPP auf 21,28 $\pm 1,36 \%$ und bei Zugabe von $500 \mu \mathrm{M}$ TEA auf 62,81 $\pm 9,00 \%$ signifikant gehemmt $(p<0,001)$. Bei Anwesenheit von $500 \mu \mathrm{M}$ MPP wurde die $\left[{ }^{3} \mathrm{H}\right]$-MPP-Aufnahmerate auch in Kontrollzellen signifkant auf $18,97 \pm 1,21 \%$ gehemmt, doch betrug die Hemmung in MATE1-Zellen das 3,7-fache der Hemmung in Kontrollzellen.

Bei pH 8,5 lag in MATE1-Zellen in der MR-Referenzlösung eine 1,3-fach erhöhte $\left[{ }^{3} \mathrm{H}\right]$ MPP-Aufnahme im Vergleich zu pH 7,4 von 1,83 $\pm 0,44$ pmol/5 min/Loch (Abb. 4-10 b, Referenz, $100 \%$ ) vor. In Kontrollzellen betrug die Aufnahmerate 26,28 $\pm 3,03 \%$. Die Aufnahmerate wurde in MATE1-Zellen bei pH 8,5 auf 19,68 $\pm 2,66 \%$ (Chinin), auf $14,48 \pm 0,89 \%$ (MPP) bzw. auf 35,78 $\pm 5,13 \%$ (TEA) gehemmt $(p<0,001)$. Wie bei $\mathrm{pH} 7,4$ wurde auch bei $\mathrm{pH} 8,5$ die $\left[{ }^{3} \mathrm{H}\right]-\mathrm{MPP}$-Aufnahme in Kontrollzellen signifikant durch $500 \mu \mathrm{M}$ MPP gehemmt. Die Hemmung in MATE1-Zellen betrug bei pH 8,5 das 10,0-fache der Hemmung in Kontrollzellen. 
a)

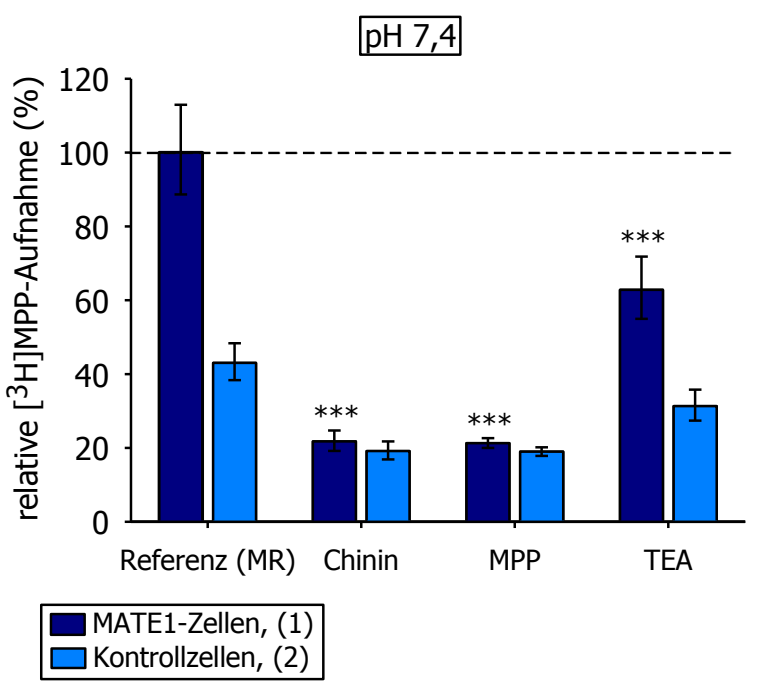

b)

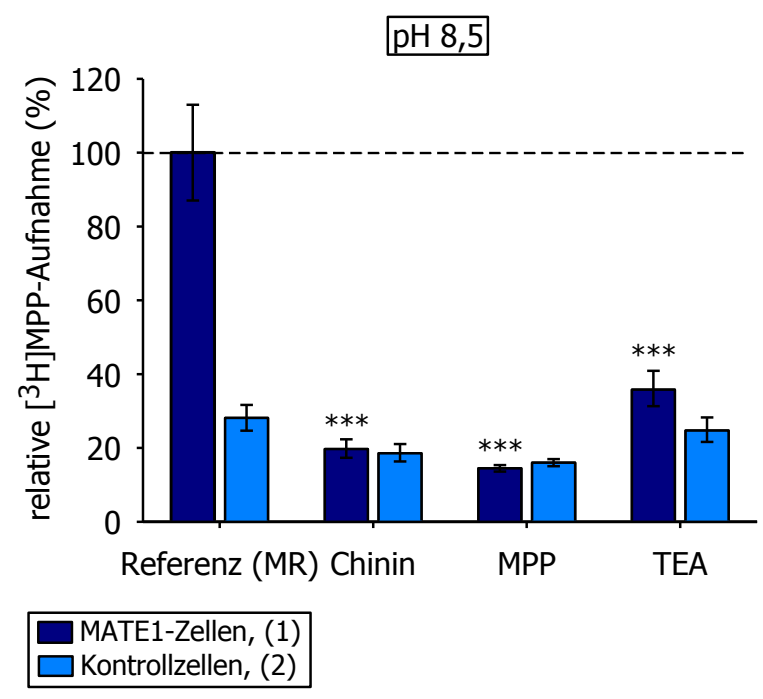

Abb. 4-10: Funktionelle Charakterisierung von MATE1 in stabil transfizierten HEK293Zellen:

Aufnahmerate von $\left.20 \mathrm{nM} \quad{ }^{3} \mathrm{H}\right]-\mathrm{MPP}$ und $980 \mathrm{nM}$ MPP in mit dem MATE1Expressionsvektor pEF5/FRT/V5-MATE1 transfizierten Zellen (dunkelblau, 1) und in

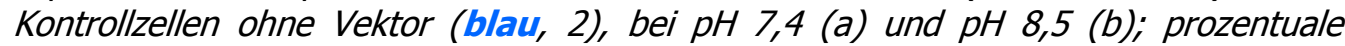
Aufnahmeraten in reinem MR (MATE1-Zellen $=100 \%$ ) und unter Zugabe von $500 \mu \mathrm{M}$ Chinin, MPP oder TEA; Konfidenzintervalle mit Konfidenzniveau $95 \%$; Signifikanz: $p<0,05=*, p<0,01=* *$ und $p<0,001=* * *$

Damit wurde die Transportaktivität von MATE1 in stabil transfizierten HEK293-Zellen gezeigt und die Zellen konnten als Modellsysteme zur weiteren Transportcharakterisierung von MATE1 (4.2.1.1.3) und Untersuchung der Interaktion von MATE1 mit Zytostatika eingesetzt werden (4.2.1.2.2).

4.2.1.1.3 Untersuchung der möglichen Kopplung von MATE1 mit dem NatriumProtonen-Austauscher NHE3

Da MATE1 Substrate gegen Protonen austauscht und in der Niere für den Efflux von Substraten zuständig ist, könnte er mit dem ebenfalls in der Niere exprimierten NatriumProtonen-Austauscher NHE3 gekoppelt sein. NHE3 nimmt Natrium in Zellen auf und transportiert dagegen Protonen heraus, wodurch ein einwärts gerichteter Protonengradient entsteht. Dieser könnte die Triebkraft für den im Effluxmodus transportierenden MATE1 darstellen (siehe 1.2.8).

Die Strategie, um die Kopplung zu zeigen, war hier, NHE3 zu inhibieren bzw. seine Triebkraft, den Natriumgradienten, zu senken, um so eine höhere intrazelluläre Protonenkonzentration zu erzeugen. Falls MATE1 und NHE3 miteinander gekoppelt sind, würde dies zu einer verstärkten Aufnahme von MATE1-Substraten führen. 
Als Modellsystem wurden die stabil transfizierten MATE1-HEK293-Zellen eingesetzt, welche auch das funktionelle NHE3-Protein besitzen [88]. Gemessen wurde die $\left[{ }^{3} \mathrm{H}\right]$-MPP-Aufnahme unter Zugabe des NHE3-Inhibitors Amilorid bzw. in natriumfreiem MR. Würde eine Kopplung von MATE1 und NHE3 vorliegen, müsste MATE1 mehr $\left[{ }^{3} \mathrm{H}\right]-M P P$ aufnehmen. Bei pH 8,5 müsste dieser Effekt verstärkt sein, da dann ein noch höherer auswärtsgerichteter $\mathrm{H}^{+}$-Gradient vorliegt.

Abb. 4-11 zeigt radioaktive Aufnahmeversuche von $\left[{ }^{3} \mathrm{H}\right]-\mathrm{MPP}$, welche analog zu den Versuchen in 4.2.1.1.2 durchgeführt wurden. Als Versuchslösungen dienten neben reinem MR (100\% in MATE1-Zellen), Lösungen mit zusätzlich $100 \mu \mathrm{M}$ bzw. 1 mM Amilorid oder aus natriumfreiem MR (siehe 2.8). Bei pH 7,4 (Abb. 4-11 a) und pH 8,5 (Abb. 4-11 b) hemmen sowohl Amilorid als auch natriumfreier MR die [ $\left.{ }^{3} \mathrm{H}\right]$-MPPAufnahme in MATE1-Zellen signifikant (dunkelblaue Balken, $\mathrm{p}<0,001$ ). $100 \mu \mathrm{M}$ Amilorid führen zu einer Hemmung auf 62,53 $\pm 3,52 \%$ (pH 7,4) bzw. 28,76 $\pm 1,62 \%(\mathrm{pH} \mathrm{8,5).}$ Die Hemmung wird durch eine Konzentrationserhöhung von Amilorid von $100 \mu \mathrm{M}$ auf $1 \mathrm{mM}$ verstärkt auf 45,68 $\pm 3,00(\mathrm{pH} \mathrm{7,4})$ bzw. $23,35 \pm 1,53 \%(\mathrm{pH} \mathrm{8,5})\left[{ }^{3} \mathrm{H}\right]$-MPPAufnahme im Vergleich zu reinem MR. Auffällig ist außerdem, dass die $\left[{ }^{3} \mathrm{H}\right]-\mathrm{MPP}$ Aufnahme bei $\mathrm{pH}$ 8,5 verstärkt gehemmt wird. natriumfreier MR führt zu einer Hemmung auf 51,56 $\pm 4,80(\mathrm{pH} \mathrm{7,4)}$ bzw. 13,69 $\pm 1,27 \%(\mathrm{pH} \mathrm{8,5})$. Auch in den Kontrollzellen (hellblaue Balken) liegt eine Hemmung der $\left[{ }^{3} \mathrm{H}\right]$-MPP-Aufnahme durch die zugegebenen Versuchslösungen vor. Bei pH 7,4 ist die Hemmung in MATE1-Zellen nur leicht höher als in Kontrollzellen (mindestens 1,7-fach), bei $\mathrm{pH} 8,5$ jedoch um mindestens das 6,5-fache höher als in Kontrollzellen. 
a)

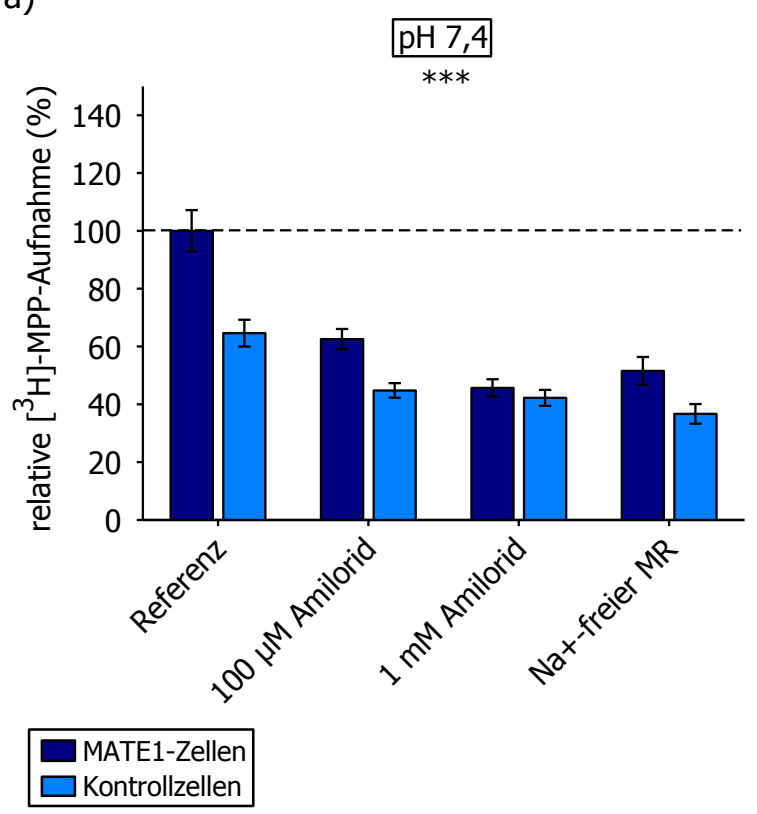

b)

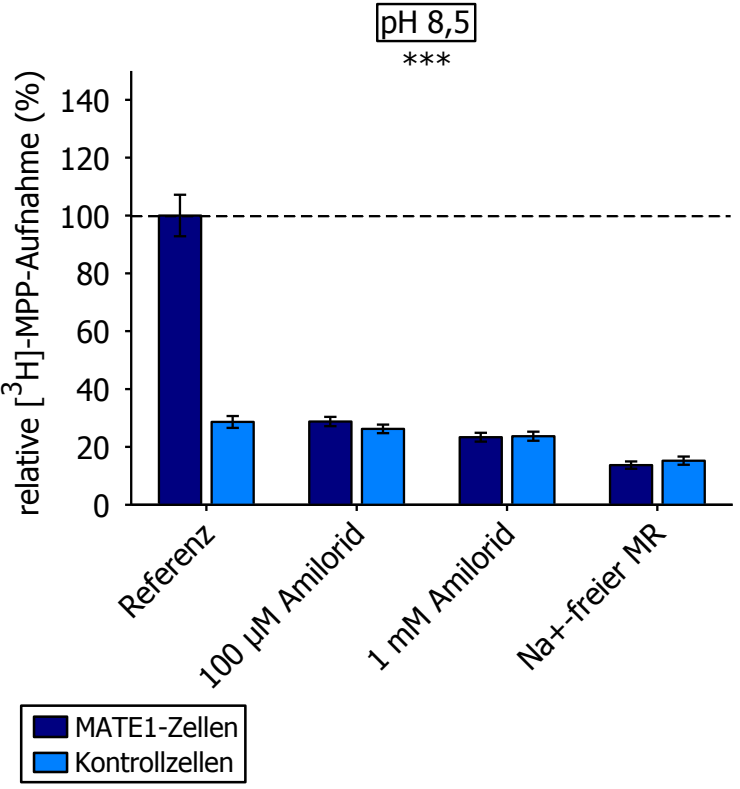

Abb. 4-11: Kopplung von MATE1 und NHE3:

Aufnahmerate von $20 \mathrm{nM}\left[\mathrm{P}^{3} \mathrm{H}\right]-\mathrm{MPP}$ und $980 \mathrm{nM}$ MPP in MATE1-HEK293 Zellen (dunkelblau) und Kontrollzellen (blau) bei pH 7,4 (a) und pH 8,5 (b); prozentuale Aufnahmeraten in reinem MR (MATE1-Zellen = $100 \%$ ) und unter Zugabe von $100 \mu \mathrm{M}$ bzw. $1 \mathrm{mM}$ Amilorid oder in natriumfreiem Ringer; Konfidenzintervalle mit Konfidenzniveau $95 \%$; Signifikanz: $p<0,05=*, p<0,01=* *$ und $p<0,001=* * *$

Die Ergebnisse zeigen, dass es keine erhöhte $\left[{ }^{3} \mathrm{H}\right]-\mathrm{MPP}-$ Aufnahme durch eine erhöhte intrazellluläre Protonenkonzentration gibt. Eine direkte Kopplung von MATE1 mit NHE3 konnte demnach nicht gezeigt werden. Welche Bedeutung die stattdessen beobachtete Hemmung haben kann, wird in Abschnitt 5.2.2.1 diskutiert.

\subsubsection{Interaktion von OCT1 und MATE1 mit Zytostatika verschiedener Wirkstoffklassen}

Unter Verwendung der CHO-OCT1- und MATE1-HEK293-Zellen sollte untersucht werden, ob die beiden SLC-Proteine Zytostatika in Zellen hinein- oder aus innen heraustransportieren können. Ein Maß für die Interaktion eines Zytostatikums mit OCT1 und MATE1 ist die cis-Inhibition der Aufnahmerate des Substrats $\left[{ }^{3} \mathrm{H}\right]-\mathrm{MPP}$ in Modellzellen durch dieses Zytostatikum. Die Bezeichnung "cis" bedeutet, dass sowohl $\left[{ }^{3} \mathrm{H}\right]-\mathrm{MPP}$ als auch das Zytostatikum von außen auf die Zellen wirken.

Die radioaktiven Aufnahmeversuche zur Interaktion von OCT1 und MATE1 mit Zytostatika wurden in stabil transfizierten (z. B. Abb. 4-12) und Kontrollzellen durchgeführt, um die SLC-vermittelte Inhibition zu bestimmen. Die [ $\left.{ }^{3} \mathrm{H}\right]$-MPP-Aufnahmerate wurde in reinem MR als Referenzlösung und unter Anwesenheit von je $100 \mu \mathrm{M}$ eines Zytostatikums bestimmt. Die prozentualen $\left[{ }^{3} \mathrm{H}\right]$-MPP-Aufnahmeraten wurden wie in 4.2.1.1 
im Vergleich zur Aufnahmerate in transfizierten Zellen in MR-Referenzlösung (100 \%) bei dem jeweiligen $\mathrm{pH}$-Wert bestimmt. Signifikante Hemmungen wurden zwischen Aufnahmeraten in transfizierten Zellen in MR und den Aufnahmeraten unter Anwesenheit des Zytostatikums bestimmt.

\subsection{Interaktion von OCT1 mit in der Melanomtherapie eingesetzten Zytostatika}

Die Versuche lieferten neue Erkenntnisse zur Interaktion von OCT1 mit Zytostatika,

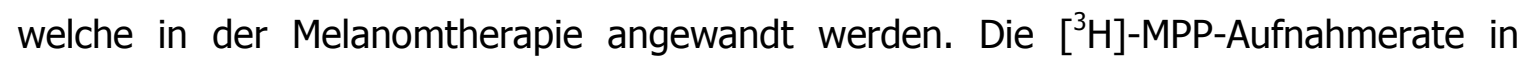
CHO-OCT1-Zellen betrug in der Referenzlösung MR 2,32 $\pm 0,51 \mathrm{pmol} / 5 \mathrm{~min} / \mathrm{Loch}$ (Abb. 4-12 $100 \%$ ) und ist damit um das 6,8-fache höher als die in CHO-Kontrollzellen. $100 \mu \mathrm{M}$ Nimustin hemmten die [ $\left.{ }^{3} \mathrm{H}\right]$-MPP-Aufnahmerate in CHO-OCT1-Zellen hoch-signifikant auf $50,12 \pm 9,55 \% \quad(p<0,001)$. Die weiteren Zytostatika Bleomycin, Estramustin, Mitomycin und Vindesin zeigten keine Hemmung.

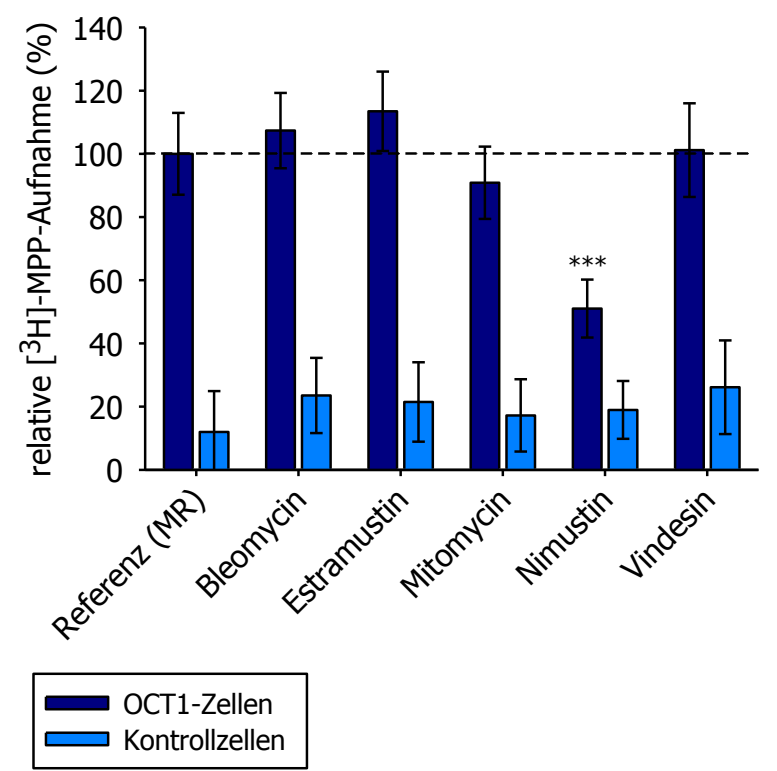

Abb. 4-12: Interaktion von OCT1 mit in der Melanomtherapie angewandten Zytostatika in CHO-Zellen:

Aufnahmerate von 20 nM [ $\left.{ }^{3} \mathrm{H}\right]-M P P$ und 980 nM MPP OCT1-CHO-Zellen (dunkelblau)

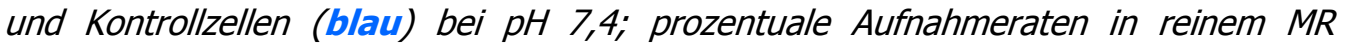
(OCT1-Zellen $=100 \%)$ und unter Zugabe von $100 \mu \mathrm{M}$ Zytostatikum; Konfidenzintervalle mit Konfidenzniveau $95 \%$; Signifikanz: $p<0,05=*, p<0,01=* *$ und $p<0,001=* * *$

\subsection{Interaktion von MATE1 mit Zytostatika verschiedener Wirkstoffklassen}

Über die Interaktion von MATE1 mit Zytostatika ist bisher wenig bekannt. MATE1 wurde daher auf die Interaktion mit einer Reihe von Zytostatika verschiedener Wirkstoffklassen getestet. Die Messungen wurden bei zwei verschiedenen $\mathrm{pH}-$ Werten durchgeführt, da die Aktivität von MATE1 wie schon erwähnt pH-abhängig ist. 


\subsection{Interaktion von MATE1 mit Alkylantien}

In Abb. 4-13 sind die Ergebnisse der Interaktion von Alkylantien mit MATE1 dargestellt. Bei pH 7,4 (Abb. 4-13 a) ist die absolute Aufnahme von $\left[{ }^{3} \mathrm{H}\right]-\mathrm{MPP}$ in der MRReferenzlösung in MATE1-Zellen 1,49 0,37 pmol/5 min/Loch (dunkelblauer Balken, $100 \%$ ) und damit 2,4-mal so hoch wie die in Kontrollzellen. Nur das Zytostatikum Bendamustin zeigte eine signifikante Hemmung auf 73,42 $\pm 7,71 \% \quad(p<0,01)$. Busulfan, Chlorambucil, Cyclophosphamid, Ifosfamid, Melphalan, Thiotepa und Treosulfan hemmten die $\left[{ }^{3} \mathrm{H}\right]-\mathrm{MPP}-A u f n a h m e$ in MATE1-Zellen nicht signifikant. Bei $\mathrm{pH}$ 8,5 erhöhte sich die absolute Aufnahme in MATE1-Zellen in MR mit $1,94 \pm 0,48 \mathrm{pmol} / 5 \mathrm{~min} /$ Loch auf das 1,3-fache des Werts bei pH 7,4 (Abb. 4-13 b, 100 \%). Die Kontrollzellen nahmen bei pH 8,5 28,12 $\pm 3,53 \%\left[{ }^{3} \mathrm{H}\right]$-MPP des Werts in MATE1-Zellen auf. Bendamustin zeigte in MATE1-Zellen bei pH 8,5 im Vergleich zu pH 7,4 eine erhöhte signifikante Hemmung auf 49,03 $\pm 5,15 \%$ im Vergleich zur MRReferenzlösung bei $\mathrm{pH} 8,5(\mathrm{p}<0,001)$. Die weiteren Alkylantien hemmten auch bei $\mathrm{pH}$ 8,5 nicht signifikant.

a)

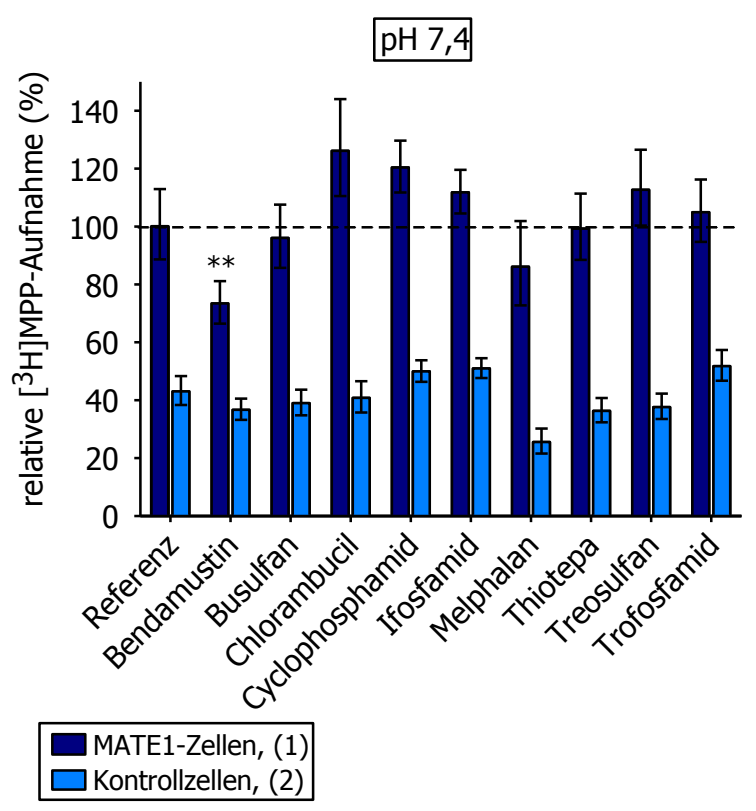

b)

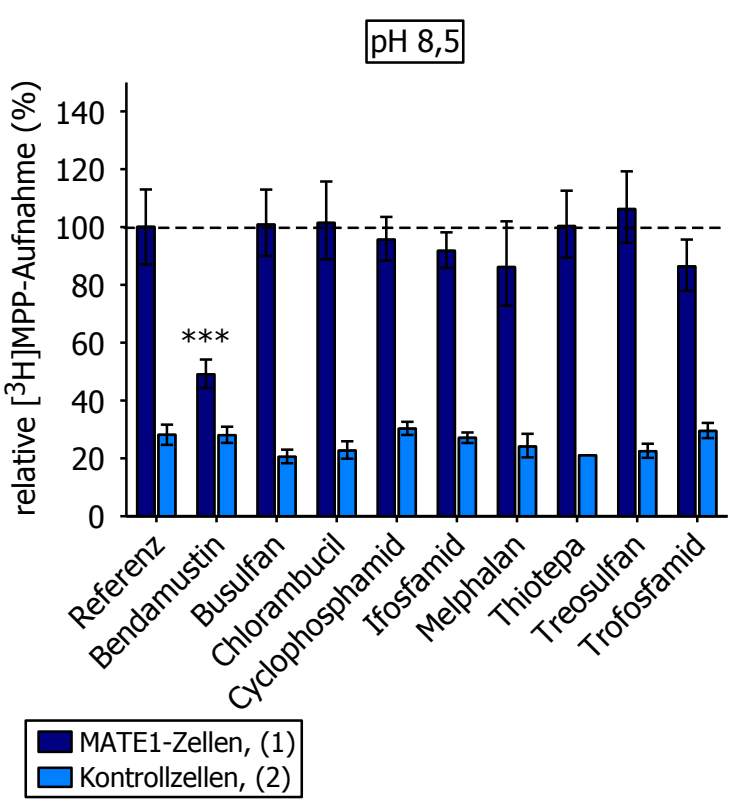

Abb. 4-13: Interaktion von MATE1 mit Alkylantien:

Aufnahmerate von $20 \mathrm{nM}\left[{ }^{3} \mathrm{H}\right]-\mathrm{MPP}$ und $980 \mathrm{nM}$ MPP in MATE1-HEK293 Zellen (dunkelblau) und Kontrollzellen (blau), bei $\mathrm{pH} \mathrm{7,4} \mathrm{(a)} \mathrm{und} \mathrm{pH} 8,5$ (b); prozentuale Aufnahmeraten in reinem MR (MATE1-Zellen $=100 \%$ ) und unter Zugabe von $100 \mu \mathrm{M}$ Zytostatikum; Konfidenzintervalle mit Konfidenzniveau 95\%; Signifikanz: $p<0,05=*, p<0,01=* *$ und $p<0,001=* * *$ 
4.2.1.2.2.2 Interaktion von MATE1 mit Antibiotika, Antimetaboliten und Interkalantien

Weitere Zytostatika, die auf die Interaktion mit MATE1 untersucht wurden, gehörten der Klasse der Antibiotika, Antimetabolite und Interkalantien an. Bei pH 7,4 hemmten die Interkalantien Doxorubicin und Mitoxantron die $\left[{ }^{3} \mathrm{H}\right]$-MPP-Aufnahme in MATE1-Zellen signifikant auf 62,36 $\pm 56,86 \%$ bzw. 26,79 $\pm 2,95 \%$ ( $p<0,001$, Abb. 4-14 a). Doxorubicin und Mitoxantron hemmten die $\left[{ }^{3} \mathrm{H}\right]-\mathrm{MPP}-A u f n a h m e$ bei $\mathrm{pH} 8,5$ verstärkt, bei Mitoxantron sogar bis auf das Niveau der Kontrollzellen nämlich auf 21,90 $\pm 2,41 \%$ bzw. $15,90 \pm 1,75 \%(p<0,001)$. Auch in den Kontrollzellen hemmten Doxorubicin und Mitoxantron die $\left[{ }^{3} \mathrm{H}\right]-M P P-A u f n a h m e$ bei beiden $\mathrm{pH}$-Werten signifikant, doch war die Hemmung um mindestens das 3,1-fache geringer als in den MATE1-Zellen. Der Antimetabolit Fludarabin hemmte die $\left[{ }^{3} \mathrm{H}\right]-M P P-A u f n a h m e$ in MATE1-Zellen mit einer Signifikanz von $\mathrm{p}<0,05$ bei $\mathrm{pH} 7,4$ auf $77,10 \pm 8,55 \%$ und bei $\mathrm{pH} 8,5$ auf $76,70 \pm 8,51 \%$, zeigte also keine pH-Abhängigkeit (Abb. 4-14 a und b). Weitere Antimetabolite, 5-Fluorouracil, Cladribin, Cytarabin, Gemcitabin und Methotrexat, sowie die Antibiotika Bleomycin und Mitomycin $\mathrm{C}$ hemmten weder bei $\mathrm{pH} 7,4$ noch bei $\mathrm{pH} 8,5$ die $\left[{ }^{3} \mathrm{H}\right]-M P P-A u f n a h m e$ in MATE1-Zellen signifikant.

a)

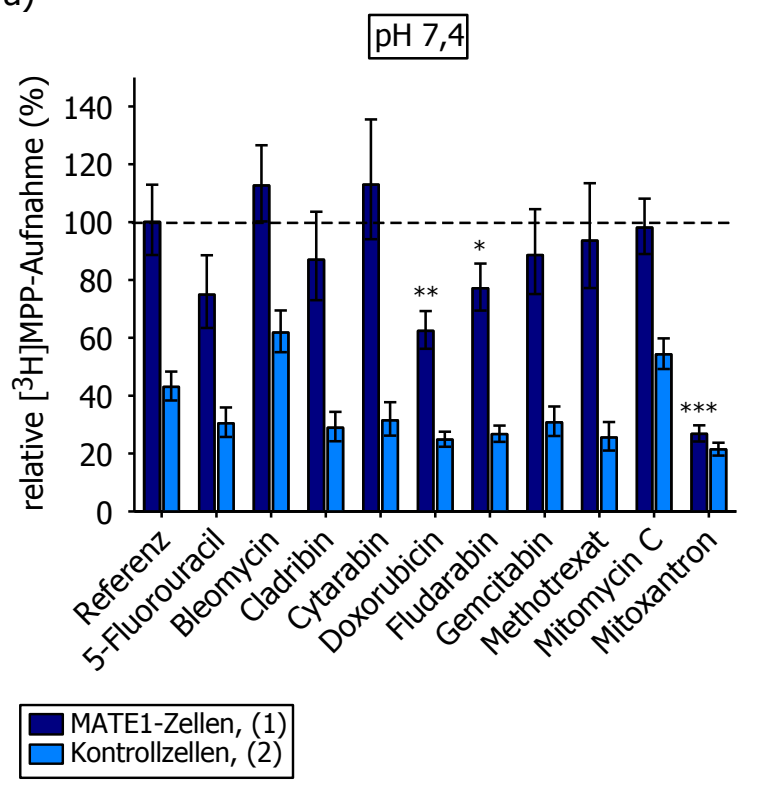

b)

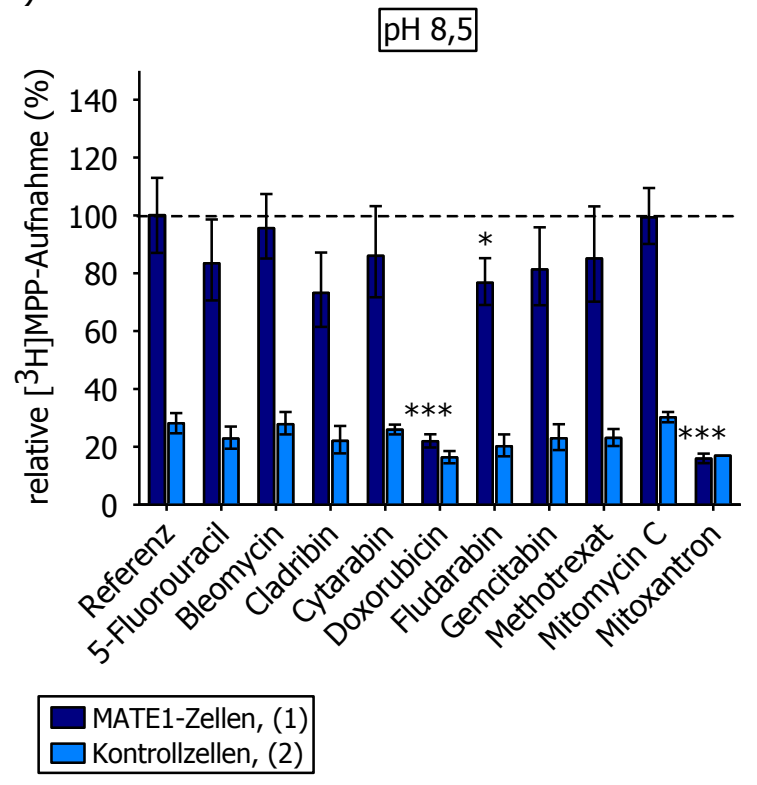

Abb. 4-14: Interaktion von MATE1 mit Antibiotika, Antimetaboliten und Interkalantien:

Aufnahmerate von $20 \mathrm{nM}[3 \mathrm{HJ}-\mathrm{MPP}$ und $980 \mathrm{nM}$ MPP in MATE1-HEK293 Zellen (dunkelblau) und Kontrollzellen (blau) bei $\mathrm{pH} 7,4$ (a) und $\mathrm{pH} 8,5$ (b); prozentuale Aufnahmeraten in reinem MR (MATE1-Zellen = $100 \%$ ) und unter Zugabe von $100 \mu \mathrm{M}$ Zytostatikum; Konfidenzintervalle mit Konfidenzniveau 95\%; Signifikanz: $p<0,05=*, p<0,01=* *$ und $p<0,001=* * *$ 
4.2.1.2.2.3 Interaktion von MATE1 mit Mitoseinhibitoren, Topoisomeraseinhibitoren und weiterer Zytostatika

Die Interaktion von verschiedenen weiteren Zytostatikaklassen mit MATE1 ist in Abb. 4-15 dargestellt. Die Topoisomeraseinhibitoren Etoposid und Irinotecan zeigten bei $\mathrm{pH}$ 7,4 eine signifikante, für Irinotecan sogar vollständige Hemmung der $\left[{ }^{3} \mathrm{H}\right]-\mathrm{MPP}-$ Aufnahme in MATE1-Zellen auf 65,88 $\pm 10,54 \%$ bzw. 27,41 $\pm 3,27 \%$ ( $p<0,01$ bzw. $p<0,001)$. Der Hormonrezeptorantagonist Tamoxifen wies ebenfalls eine signifikante Hemmung auf 60,11 $\pm 10,37 \%$ auf $(p<0,001)$. Die Hemmung durch Etoposid und Irinotecan war bei $\mathrm{pH}$ 8,5 (Abb. 4-15 b) erhöht. Etoposid hemmte die $\left[{ }^{3} \mathrm{H}\right]-\mathrm{MPP}-$ Aufnahme in MATE1-Zellen signifikant auf $40,71 \pm 6,51 \%$ und Irinotecan auf $21,89 \pm 2,61 \%$ ( $p<0,001)$. Nur Tamoxifen hemmte bei $\mathrm{pH} 8,5$ schwächer auf $84,42 \pm 10,67 \%$ ( $p<0,05)$. Bei $\mathrm{pH} 8,5$ zeigten auch die drei Mitoseinhibitoren Vinblastin, Vincristin und Vindesin eine signifikante Hemmung der $\left[{ }^{3} \mathrm{H}\right]-\mathrm{MPP}-A u f n a h m e$ in MATE1-Zellen auf 70,29 \pm 8,12 \%, 69,94 \pm 8,29 \% bzw. 70,41 $\pm 6,26 \%(p<0,001)$. Das Taxan Paclitaxel und Clodronsäure bewirkten weder bei $\mathrm{pH} 7,4$ noch bei 8,5 eine Hemmung der $\left[{ }^{3} \mathrm{H}\right]$-MPP-Aufnahme in MATE1-Zellen. Estramustin stimulierte die $\left[{ }^{3} \mathrm{H}\right]$ MPP-Aufnahme signifikant.

a)

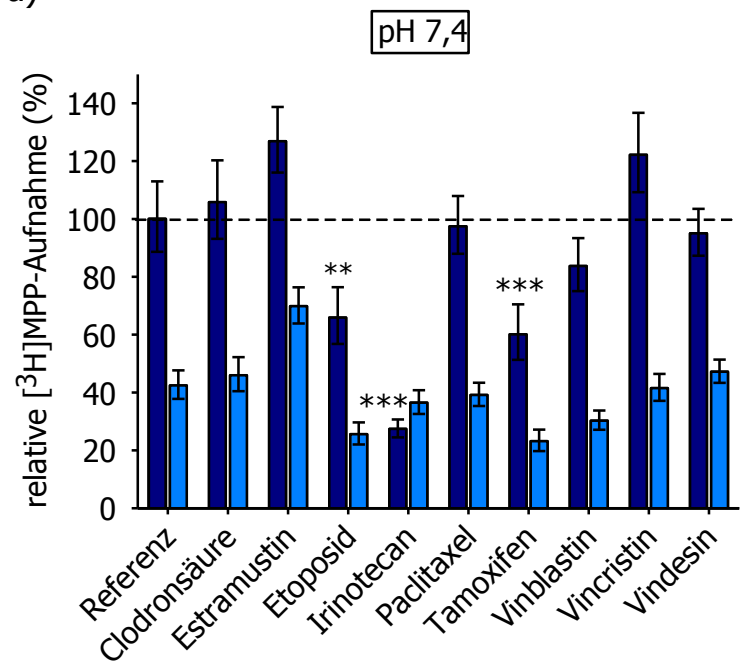

MATE1-Zellen, (1) $\square$ Kontrollzellen, (2) b)

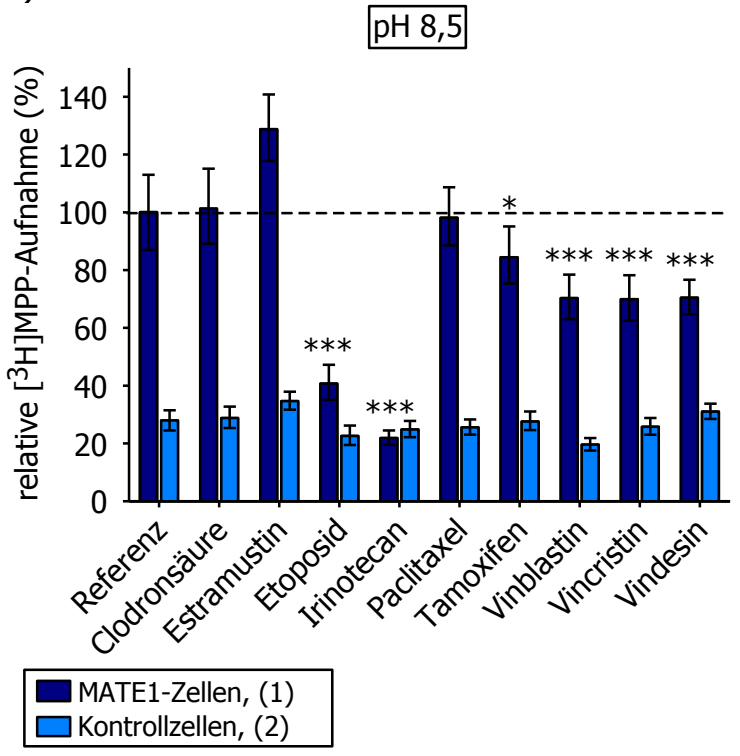

Abb. 4-15: Interaktion von MATE1 mit Mitoseinhibitoren, Topoisomeraseinhibitoren und weiteren Zytostatika:

Aufnahmerate von $20 \mathrm{nM}\left[{ }^{3} \mathrm{H}\right]-M P P$ und $980 \mathrm{nM}$ MPP in MATE1-HEK293 Zellen (dunkelblau) und Kontrollzellen (blau), bei $p H$ 7,4 (a) und pH 8,5 (b); prozentuale Aufnahmeraten in reinem MR (MATE1-Zellen $=100 \%$ ) und unter Zugabe von $100 \mu \mathrm{M}$ Zytostatikum; Konfidenzintervalle mit Konfidenzniveau 95\%; Signifikanz: $p<0,05=*, p<0,01=* *$ und $p<0,001=* * *$ 


\subsection{Konzentrationsabhängige Interaktion von MATE1 mit Mitoxantron und Irinotecan}

Im vorigen Abschnitt wurde gezeigt, dass Mitoxantron und Irinotecan von den untersuchten Zytostatika am stärksten mit MATE1 interagieren, indem sie die MATE1vermittelte [ $\left.{ }^{3} \mathrm{H}\right]$-MPP-Aufnahmerate in HEK293-Zellen um über $50 \%$ hemmten. Um ein $\mathrm{Maß}$ für die Stärke der Interaktion zu gewinnen, wurde der $\mathrm{IC}_{50}$-Wert der beiden Zyto-

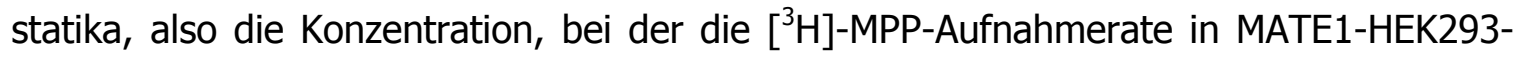
Zellen um 50 \% gehemmt wurde, bestimmt (Abb. 4-16 und Abb. 4-17).

In Abb. 4-16 und Abb. 4-17 a und b sind die absoluten Aufnahmewerte in MATE1-Zellen und Kontrollzellen dargestellt. In Abb. 4-16 und Abb. 4-17 c und d sind die Aufnahmewerte in MATE1-Zellen abzüglich der Werte der Kontrollzellen bei der jeweiligen Zytostatikumkonzentration dargestellt. Weiterhin wurde berücksichtigt, dass es einen nicht hemmbaren Anteil gab, so dass der hemmbare Anteil auf $100 \%$ gesetzt wurde. Bei pH 7,4 ergab sich für Mitoxantron ein $\mathrm{IC}_{50}$-Wert von 7,75 $\pm 2,88 \mu \mathrm{M}$ (Abb. 4-16 c) und für Irinotecan ein $\mathrm{IC}_{50}$-Wert von 4,35 $\pm 2,28 \mu \mathrm{M}$ (Abb. 4-17 c). Die bei pH 8,5 bestimmten $\mathrm{IC}_{50}$-Werte waren für Mitoxantron auf 0,62 $\pm 0,28 \mu \mathrm{M}$ (Abb. 4-16 d) und für Irinotecan auf 1,07 $\pm 0,74 \mu \mathrm{M}$ erniedrigt (Abb. 4-17 d). Deutlich ist weiterhin, dass es auch in den Kontrollzellen einen geringen hemmbaren Anteil gibt (Abb. 4-16 und Abb. 4-17 $a$ und $b)$. 
a)

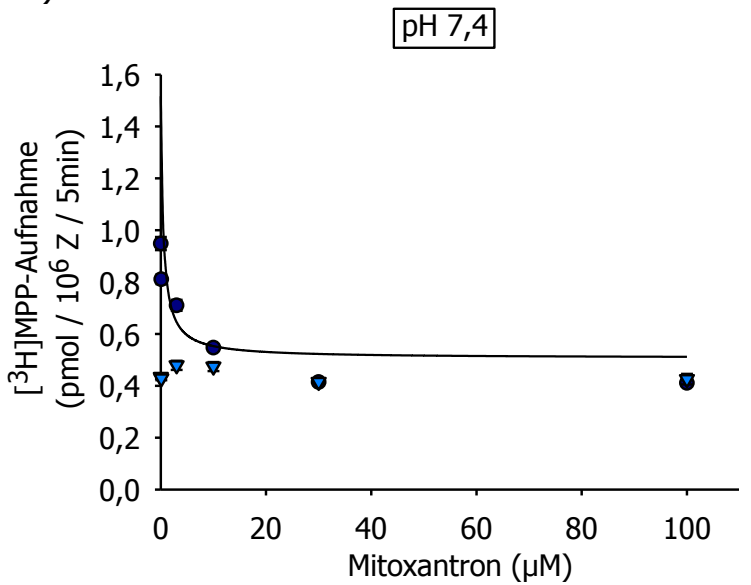

- MATE1-Zellen

$\nabla$ Kontrollzellen

c)

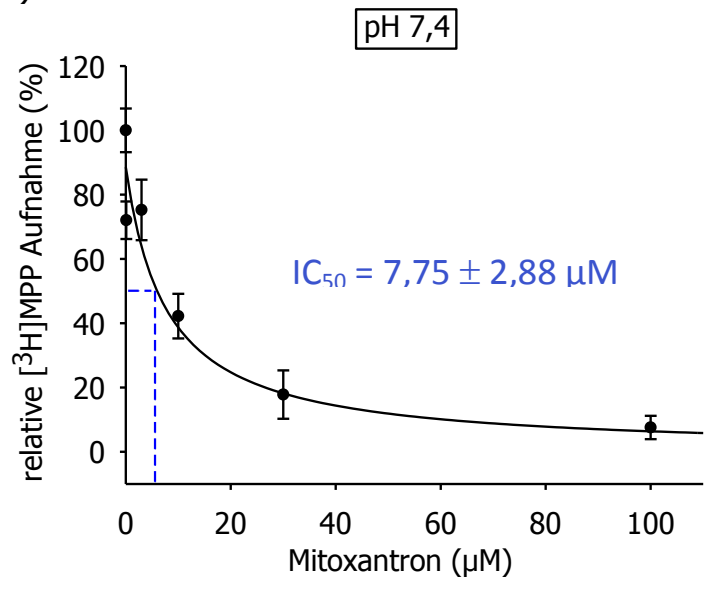

b)

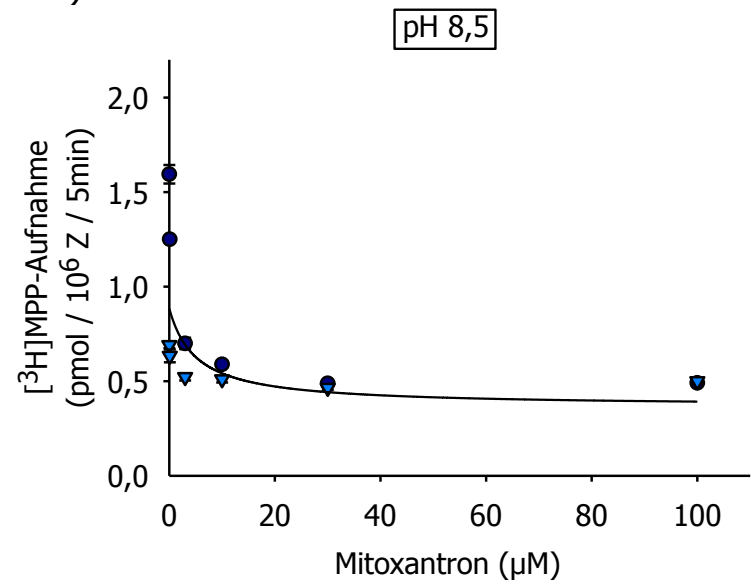

- MATE1-Zellen

$\nabla$ Kontrollzellen

d)

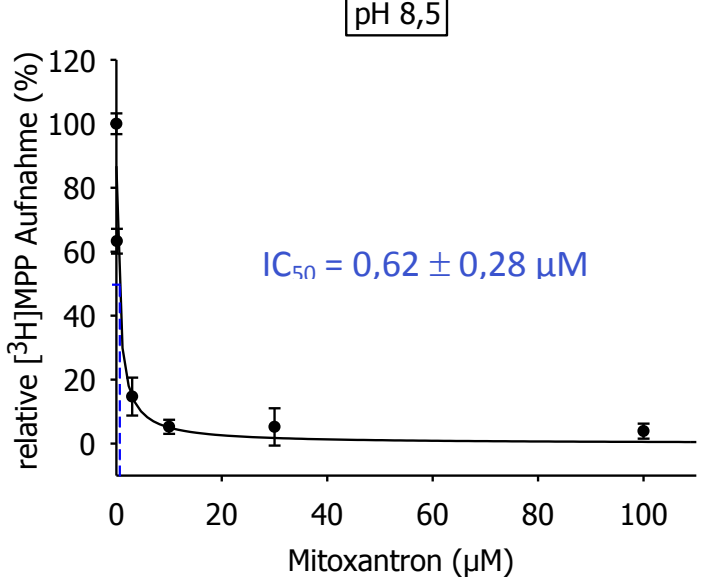

Abb. 4-16: Konzentrationsabhängigkeit der Interaktion von MATE1 mit Mitoxantron:

Absolute ( $a$ und b) und prozentuale ( $c$ und d) Aufnahmeraten von $20 \mathrm{nM} \mathrm{[3H]-MPP}$ und 980 nM MPP in MATE1-HEK293 Zellen und Kontrollzellen bei $p H 7,4(a, c)$ und $\mathrm{pH} 8,5(b, d)$, in MR (MATE1-Zellen = $100 \%$ ) und unter Zugabe von 0,1-100 $\mu \mathrm{M}$ Mitoxantron; prozentuale Aufnahmeraten in MATE1-Zellen nach Subtraktion der Kontrollzellwerte unter Berücksichtigung eines nicht hemmbaren Anteils $(M R=100 \%)$ 

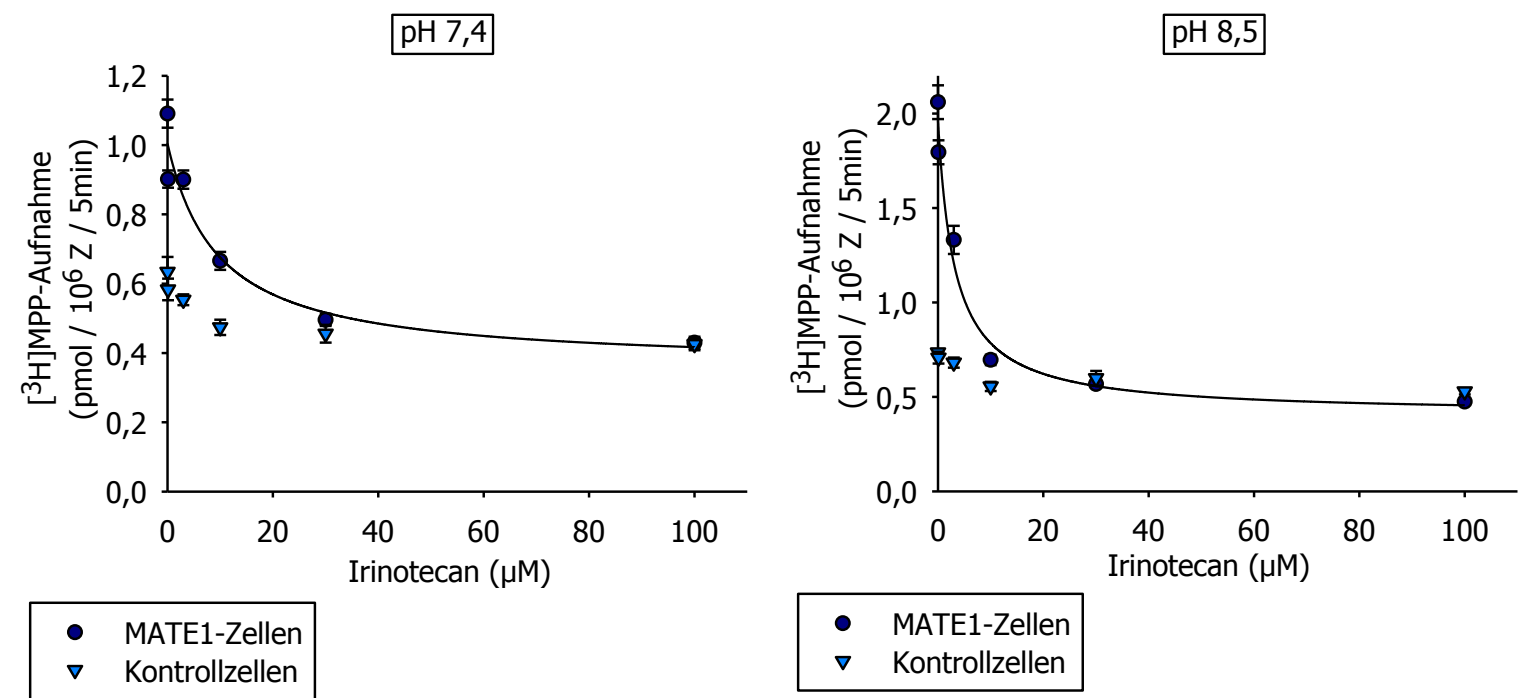

C)

- MATE1-Zellen

$\nabla$ Kontrollzellen

d)
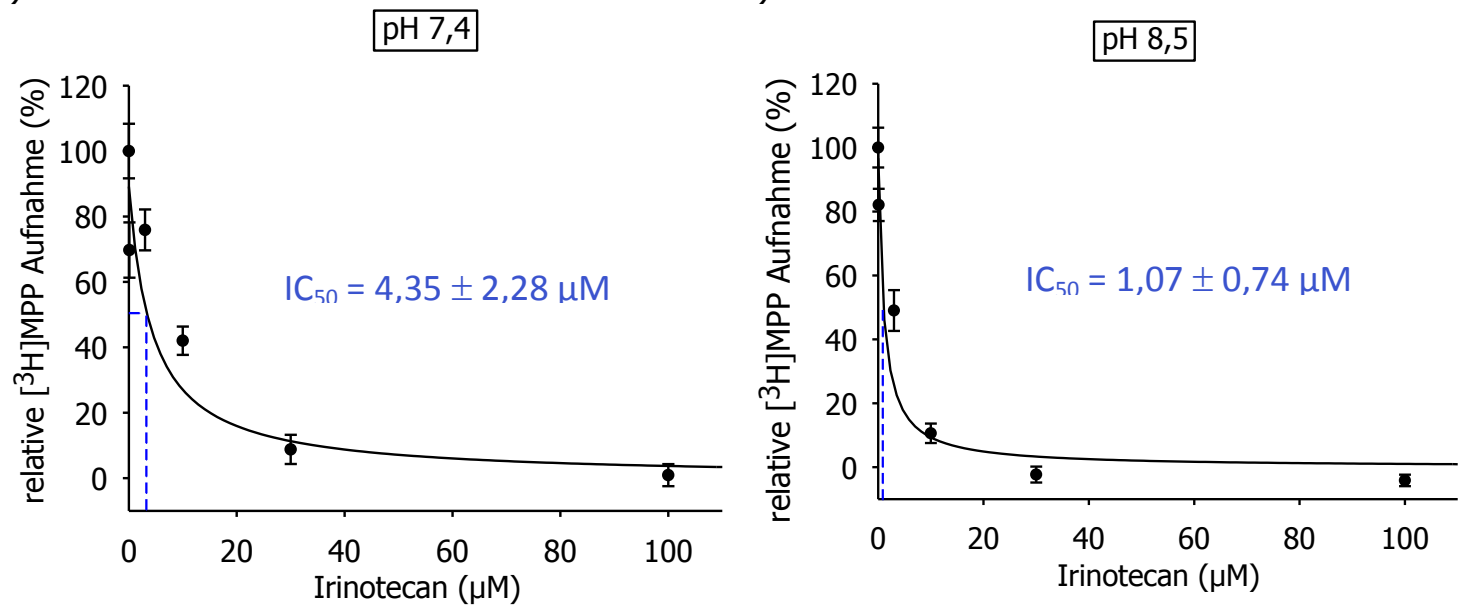

Abb. 4-17: Konzentrationsabhängigkeit der Interaktion von MATE1 mit Irinotecan:

Absolute ( $a$ und b) bzw. prozentuale ( $c$ und d) Aufnahmeraten von $20 \mathrm{nM}\left[{ }^{3} \mathrm{H}\right]-\mathrm{MPP}$ und $980 \mathrm{nM}$ MPP in MATE1-HEK293 Zellen und Kontrollzellen bei $\mathrm{pH} 7,4(a, c)$ und $\mathrm{pH}$ $8,5(b, d)$, in MR (MATE1-Zellen = $100 \%)$ und unter Zugabe von 0,1-100 $\mu \mathrm{M}$ Irinotecan; prozentuale Aufnahmeraten in MATE1-Zellen nach Subtraktion der Kontrollzel/werte unter Berücksichtigung eines nicht hemmbaren Anteils (MR = $100 \%)$

\subsubsection{Interaktion von OCT1 und MATE1 mit Temozolomid}

Der Transport von Temozolomid über OCT1 und MATE1 wurde wie für die anderen Zytostatika in Abschnitt 4.2.1.2 indirekt über die Interaktion mittels radioaktiven Aufnahmeversuchen bestimmt. Die für radioaktive Aufnahmeexperimente eingesetzte Zytostatikumkonzentration betrug $100 \mu \mathrm{M}$, für immunzytochemische Tests wurden dagegen $800 \mu \mathrm{M}$ Zytostatikum benötigt (siehe 3.5). Um die Kenntnisse mit denen aus immunzytochemischen Tests zum direkten Nachweis von temozolomid-induzierten DNASchäden in Verbindung zu bringen, wurde die Interaktion mit einer TemozolomidKonzentration in einem Bereich von 100-800 $\mu \mathrm{M}$ und zusätzlich die Interaktion mit seinen Metaboliten bestimmt. 
4.2.1.3.1 Interaktion von OCT1 mit Temozolomid in Abhängigkeit der TemozolomidKonzentration

Die $\left[{ }^{3} \mathrm{H}\right]$-MPP-Aufnahmerate in reinem $M R$ in OCT1-Zellen betrug $33,50 \pm 1,94$ $\mathrm{fmol} / 5 \mathrm{~min} /$ Loch und wurde auf $100 \%$ gesetzt. Temozolomid hemmte diese [ $\left.{ }^{3} \mathrm{H}\right]-\mathrm{MPP}$ Aufnahmerate in OCT1-CHO-Zellen in keiner der zugegebenen Konzentrationen zwischen 100 und $800 \mu \mathrm{M}$ signifikant.

\subsection{Interaktion von OCT1 und MATE1 mit Temozolomid in Abhängigkeit von dessen Metabolisierungszeit}

Temozolomid ist bei pH 7,4 und 8,5 instabil und zerfällt in seine Metabolite MTIC und AIC (1.4.1.2.4). Daher musste auch untersucht werden, ob OCT1 und MATE1 mit diesen Metaboliten interagierten. Um sicherzustellen, dass die für die nachfolgenden radioaktiven Transportexperimente eingesetzten Lösungen Temozolomid und Metabolite enthielten, wurde seine Zerfallsgeschwindigkeit in $\mathrm{MR}$ bei $\mathrm{pH} 7,4$ mittels chromatographischer Auftrennung per HPLC und Absorptionsdetektion bestimmt ${ }^{3}$. Abb. 4-18 zeigt die relative Größe des Absorptionspeaks von Temozolomid. Die Fläche des Peaks bei der ersten Messzeit (5 min) wurde auf $100 \%$ gesetzt. Nach etwa 171 min ist die Hälfte des Temozolomids in seine Metabolite zerfallen.

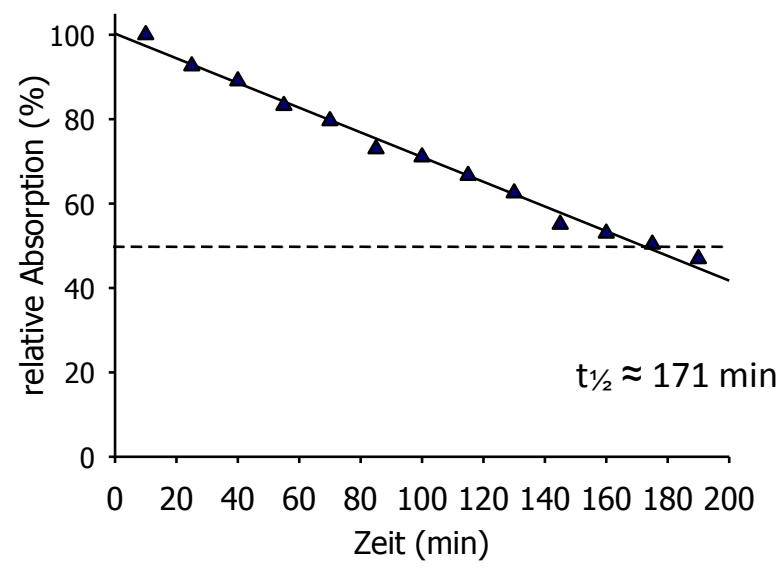

Abb. 4-18: Zerfallsgeschwindigkeit von Temozolomid in Mammalian Ringer:

Relative Absorption von Temozolomid in MR bei pH 7,4; Absorption der 1. Messung nach 10 min $=100 \%$; Messungen nach $10-190$ min; $t_{1 / 2}=$ Halbwertszeit des Zerfalls; HPLC: "reversed phase", Laufmittel $90 \%$ Wasser, $10 \%$ Methanol, $C_{12}$-Säule, Fluss $300 \mu \mathrm{l} / \mathrm{min}$

Die Interaktion von OCT1 und MATE1 mit Temozolomid und seinen Metaboliten wurde analog zu den Aufnahmeversuchen mit MATE1-Zellen in (siehe 4.2.1.2) bestimmt. Um Versuchslösungen mit unterschiedlichen Anteilen an Temozolomidmetaboliten zu

\footnotetext{
${ }^{3}$ Messungen freundlicherweise durchgeführt von Herrn Dr. Frauendorf, Institut für Organische und Biomolekulare Chemie, Abteilung Zentrale Analytik, Universität Göttingen
} 
erhalten, wurden $800 \mu \mathrm{M}$ Temozolomid vorher bis zu 180 min in MR inkubiert. Die erhöhte Konzentration von $800 \mu \mathrm{M}$ im Vergleich zu anderen Aufnahmeversuchen mit 100 M Zytostatika wurde gewählt, um einen Vergleich zu den nachfolgenden Versuchen zur Zellschädigung treffen zu können (siehe 4.2.3).

\subsection{Interaktion von OCT1 mit Temozolomid und seine Metaboliten}

Die absolute $\left[{ }^{3} \mathrm{H}\right]$-MPP-Aufnahmerate in reiner MR-Lösung in OCT1-Zellen wurde wieder auf $100 \%$ gesetzt. Unter Zugabe der Versuchslösungen mit den unterschiedlichen Metabolisierungszeiten von Temozolomid von 0, 15, 60 und 180 min wurde diese Aufnahmerate nicht signifikant gehemmt. Temozolomid und seine Metabolite zeigten also keine Interaktion mit OCT1.

Das verwendete Substrat $\left[{ }^{3} \mathrm{H}\right]-$ MPP hat eine hohe Affinität zu OCT1 mit einer MichaelisMenten-Konstante $\left(\mathrm{K}_{\mathrm{M}}\right)$ von 15-32 $\mu \mathrm{M}$ (Koepsell 2007). Da in einigen immunzytochemischen Tests mit OCT1 und Temozolomid ein Effekt gemessen wurde 4.2.3.1, sollte ausgeschlossen werden, dass die Interaktion mit Temozolomid vorhanden, aber zu gering war, um mittels $\left[{ }^{3} \mathrm{H}\right]-$ MPP-Aufnahme detektiert zu werden. Daher wurden die radioaktiven Aufnahmeversuche mit dem Substrat $\left[{ }^{14} \mathrm{C}\right]$-TEA wiederholt, welches eine geringere Affinität zu OCT1 besitzt ( $K_{M}=229 \mu \mathrm{M}$, Koepsell 2007). In Abb. 4-19 sind die relativen $\left[{ }^{14} \mathrm{C}\right]$-TEA-Aufnahmeraten in $\mathrm{OCT} 1-\mathrm{CHO}$ - und Kontrollzellen in Abhängigkeit der Temozolomidmetabolisierungszeit dargestellt. Es wurden $5 \mu \mathrm{M}\left[{ }^{14} \mathrm{C}\right]-\mathrm{TEA}$ und $95 \mu \mathrm{M}$ TEA eingesetzt.

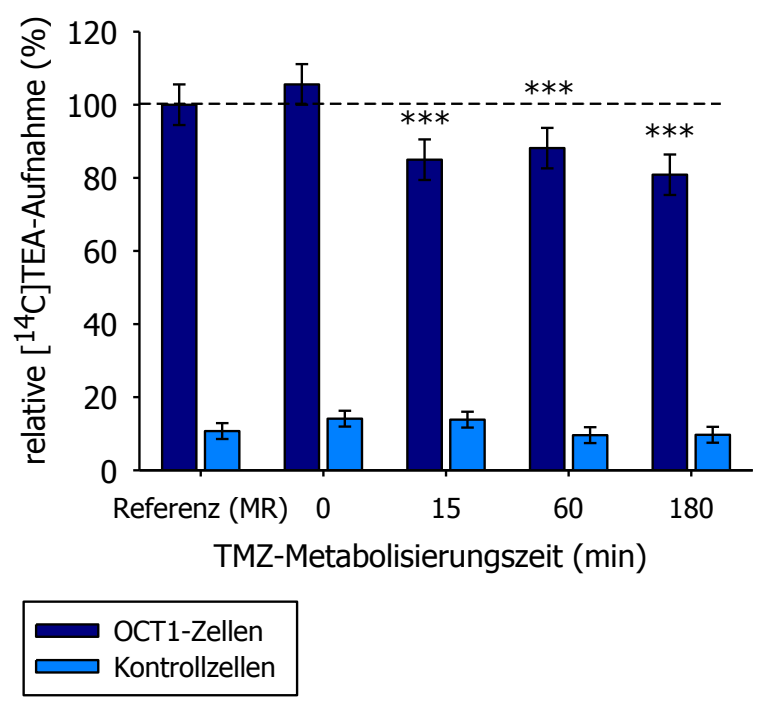

Abb. 4-19: Interaktion von OCT1 mit Temozolomid und seinen Metaboliten in CHO-Zellen:

Aufnahmerate von $5 \mu \mathrm{M}\left[{ }^{14} \mathrm{C}\right]$-TEA und $95 \mu \mathrm{M}$ TEA in OCT1-Zellen (dunkelblau) und Kontrollzellen (blau), prozentuale Aufnahmerate in MR (OCT1-Zellen $=100 \%)$ und in $M R$ mit unterschiedlich lange metabolisiertem Temozolomid $(800 \mu \mathrm{M})$; Konfidenzintervalle mit Konfidenzniveau 95\%; Signifikanz: $p<0,05=*$, $p<0,01=* *$ und $p<0,001=* * *$ 
Im Vergleich zur $\left[{ }^{14} \mathrm{C}\right]$-TEA-Aufnahmerate in reinem MR in OCT1-Zellen von 82,34 \pm 4,57 fmol/5 min/Loch (100 \%) wurde nach 15-minütiger Metabolisierung von Temozolomid in OCT1- nicht aber in Kontrollzellen eine signifikante Hemmung auf 84,96 \pm $5,54 \%(p<0,01)$, nach 60-minütiger Metabolisierung auf 88,13 $\pm 5,54 \%(p<0,05)$ und nach 180 min auf 80,85 $\pm 5,54 \%(p<0,001)$ gemessen. Bei direkter Zugabe des Temozolomids ohne vorherige Metabolisierung lag eine nicht signifikante leichte Stimulierung der $\left[{ }^{14} \mathrm{C}\right]-$ TEA-Aufnahme vor. OCT1 interagiert demnach in geringem Ausmaß mit den Temozolomid-Metaboliten MTIC und AIC, jedoch nicht mit Temozolomid, wie schon in 4.2.1.3.1 gezeigt wurde.

4.2.1.3.2.2 Interaktion von MATE1 mit Temozolomid in Abhängigkeit von dessen Metabolisierungszeit

Die Interaktion von Temozolomid und seinen Metaboliten wurde auch für MATE1 untersucht. Im Vergleich zur MR-Referenzlösung lag weder bei $\mathrm{pH} 7,4$ noch bei $\mathrm{pH} 8,5$ eine signifikante Hemmung der $\left[{ }^{3} \mathrm{H}\right]$-MPP-Aufnahmerate in Anwesenheit von Temozolomid und seinen Metaboliten und demnach keine Interaktion von MATE1 mit Temozolomid vor. MATE1 interagiert also weder mit Temozolomid noch mit seinen Metaboliten.

\subsubsection{MATE1-vermittelter Doxorubicintransport}

In Abschnitt 4.2.1.2.2.2 wurde neben anderen Zytostatika die Interaktion von Doxorubicin mit MATE1 untersucht. Damit wurde gezeigt, dass Doxorubicin entweder die Transportaktivität von MATE1 inhibiert oder dass es von MATE1 transportiert wird. An dieser Stelle wurde mittels direkter Messung der Doxorubicinaufnahme in MATE1HEK293-Zellen untersucht, welche der beiden Möglichkeiten vorlag. Da die Moleküle des Zytostatikums gegenüber anderen hier getesteten Zytostatika den Vorteil haben zu fluoreszieren, erfolgte die Quantifizierung der aufgenommenen Doxorubicinmenge über durchflusszytometrische Analysen (siehe 3.6). Abb. 4-20 zeigt exemplarisch zwei Analyseergebnisse. Dargestellt ist die über alle Zellen einer Messung gemittelte Fluoreszenzintensität. Als Referenzsignal dienten die Fluoreszenzintensitäten in reinem MR, welche die Grundfluoreszenz der Zellen wiedergeben (auf 1 normiert). Im Verhältnis dazu wurde das relative Fluoreszenzsignal bei Zugabe von $100 \mu \mathrm{M}$ Doxorubicin bestimmt. Alle Werte besitzen einen Wert größer als 1, das bedeutet, bei allen Versuchsbedinungen wurde Doxorubicin in die MATE1-Zellen wie auch in die

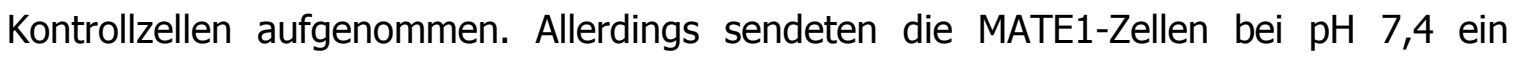
höheres relatives Fluoreszenzsignal als die Kontrollzellen aus. Bei pH 8,5 ist dieser Effekt 
verstärkt. Andererseits müsste sich bei Zugabe von $500 \mu \mathrm{M}$ MPP, welches ein Substrat von MATE1 ist (siehe 3.3), das von Doxorubicin ausgesendete Fluoreszenzsignal wieder verringern, falls eine MATE1-vermittelte Aufnahme vorliegt. Dies konnte nicht beobachtet werden. Weiterhin wurden Messungen bei pH 5,5 durchgeführt. Bei diesem pH-Wert müsste die Doxorubicin-aufnahme bei MATE1-vermittelter Aufnahme auf Grund der genannten pH-Abhängigkeit von MATE1 vermindert sein (siehe 1.2.8). Dies wurde ebenfalls nicht beobachtet. Zusammenfassend kann aus den durchflusszytometrischen Analysen die Kenntnis gewonnen werden, dass es eine Tendenz, jedoch keinen Nachweis für einen MATE1-vermittelten Doxorubicintransport gibt.

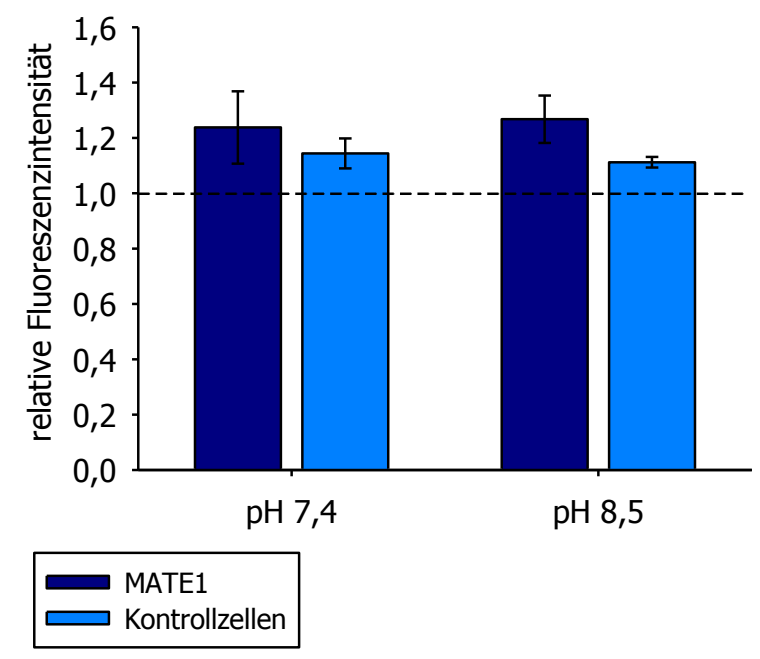

Abb. 4-20: MATE1-vermittelte Doxorubicinaufnahme in HEK293-Zellen:

Relative mittlere Fluoreszenzintensität von doxorubicin-behandelten MATE1(dunkelblau) und Kontrollzellen (blau) im Vergleich zur Grundfluoreszenz in MR, pro Messprobe $10^{4}$ Zellen; Messung bei $\mathrm{pH} 7,4$ und $\mathrm{pH} 8,5$

\subsubsection{Einfluss der MATE1- und OCT1-Expression auf die Anzahl temozolomid-induzierter $0^{6}$-Methylguanyl-DNA-Addukte}

In 4.2.1.3.2 wurde gezeigt, dass OCT1 in geringem Maße mit Temozolomidmetaboliten wechselwirkt. Ob diese Metabolite tatsächlich über OCT1 in die transfizierten CHO-Zellen aufgenommen wurden oder ob sie das SLC-Protein inhibierten, wurde durch Quantifizierung der durch Temozolomid induzierten $0^{6}$-Methylguanyl-DNA-Addukten in Modellzellen bestimmt. Es wurde mittels immunzytochemischen Tests (ICA, 3.5) untersucht, ob die Expression von OCT1 die Adduktzahl erhöhte. Auf die gleiche Weise wurde mit MATE1-HEK293-Zellen verfahren Abb. 4-22 und Abb. 4-23). 


\subsubsection{Einfluss von OCT1 auf die Anzahl temozolomid-induzierter DNA-Addukte}

In Abb. 4-21 sind Fluoreszenzbilder für eine ICA-Messung exemplarisch dargestellt. Die Bilder zeigen die Signale, welche in OCT1-CHO- ( $a$ und b) und CHO-Kontrollzellen (c und d) nach 3-stündiger Temozolomid-Inkubation (obere Reihe) und Inkubation mit seinem Lösungsmittel Dimethylsulfoxid (DMSO, untere Reihe) gemessen wurden. Gemessen wurden für jede Bedingung die Signale des Farbstoffs DAPI, als Maß für die Gesamt-DNA ( $a$ und $c$ ) und die Signale des Farbstoffs Cy3 als Maß für die Bildung der DNA-Addukte (b und d).

Verglichen mit den Signalen der Gesamt-DNA sind die der temozolomid-induzierten DNAAddukte sowohl in OCT1-Zellen als auch in Kontrollzellen weniger intensiv. Der Unterschied zwischen Signalen der DNA-Addukte und der Gesamt-DNA, also der Anteil an DNA-Addukten an der Gesamt-DNA, ist außerdem bei den mit Temozolomid behandelten OCT1-Zellen am geringsten. Bei den mit DMSO behandelten OCT1-Zellen und den mit Temozolomid bzw. DMSO behandelten CHO-Zellen ist der Unterschied zwischen DNA-Addukt-Signalen und Gesamt-DNA-Signalen größer. Daraus wird deutlich, dass in diesem Experiment die OCT1-Expression in CHO-Zellen zu einer Erhöhung der temozolomid-induzierten DNA-Addukte führte (Vergleich der Abb. 4-21 a mit c).

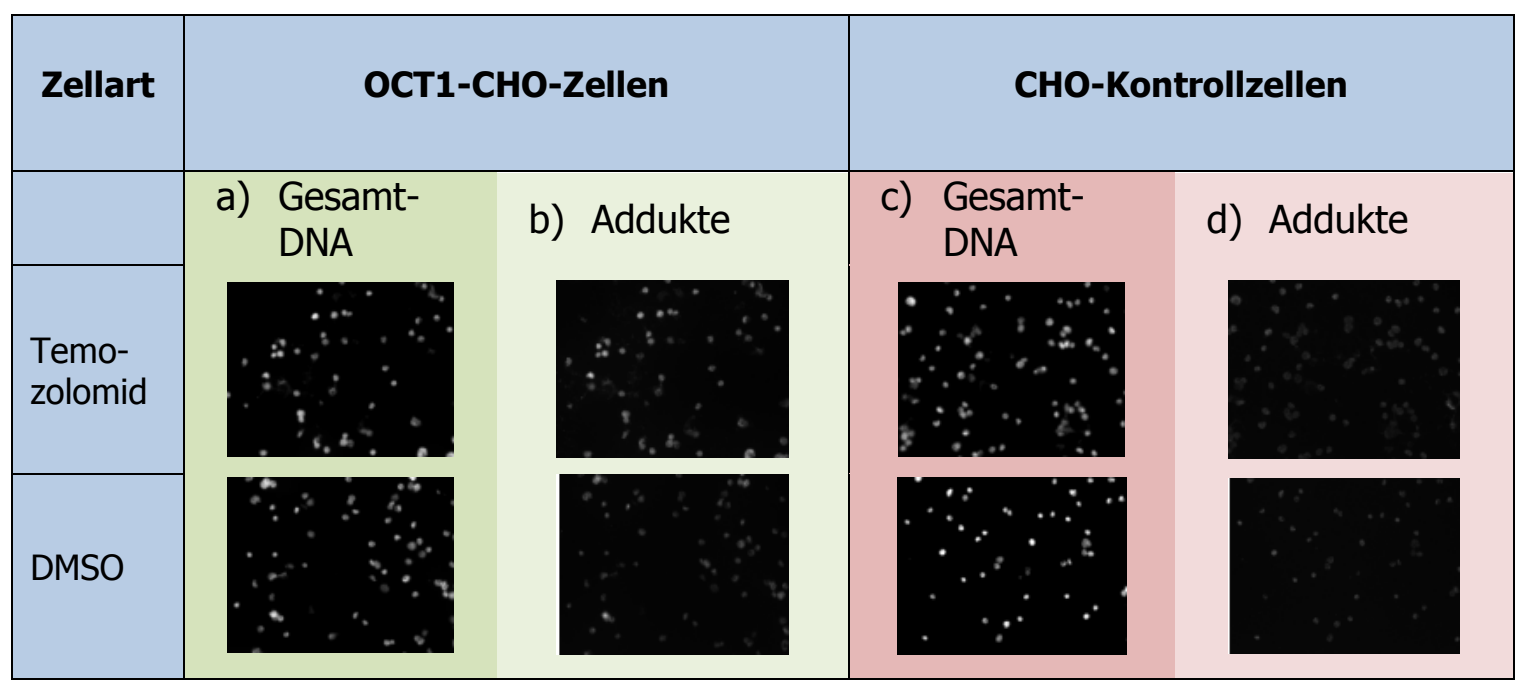

Abb. 4-21: Fluoreszenzfärbung von temozolomid-induzierten DNA-Addukten in OCT1-CHOZellen:

Bestimmung des Anteils an temozolomid-induzierten DNA-Addukten in OCT1-CHO(grün) und Kontrollzellen (rot) mittels ICA nach 3-stündiger Temozolomid- bzw. DMSO-Inkubation; DAPI-Färbung der Gesamt-DNA (a und c), Cy3-Färbung der DNAAddukte (b und d)

Bei zwei Experimenten zur relativen Anzahl der $0^{6}$-Methylguanyl-DNA-Addukte nach Temozolomid- bzw. DMSO-Behandlung ließ sich ein zeitlicher Anstieg der relativen DNAAdduktzahl in OCT1-Zellen, nicht jedoch in Kontrollzellen beobachten. Außerdem lag bei 
einer Inkubationszeit von 180 min mit Temozolomid eine etwa dreifache Anzahl an DNAAddukten im Vergleich zu den mit DMSO behandelten Zellen vor. In vier weiteren Experimenten wurde dagegen keine erhöhte Adduktzahl in temozolomid-behandelten im Vergleich zu DMSO-behandelten Zellen gemessen. Weiterhin trat keine erhöhte Adduktzahl in mit OCT1-transfizierten im Vergleich zu Kontrollzellen und kein zeitlicher Anstieg der relativen DNA-Adduktzahl auf. In Abb. 4-22 sind alle Experimente zusammengefasst. Nach 180-minütiger Temozolomidinkubation ist die Anzahl der von Temozolomid induzierten DNA-Addukte nicht signifikant, jedoch tendenziell höher.

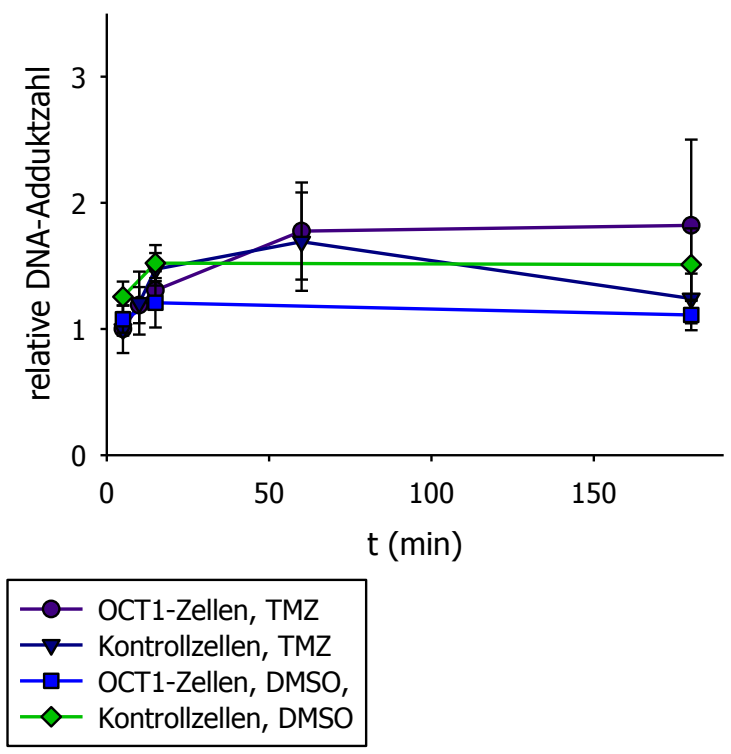

Abb. 4-22: Einfluss der OCT1-Expression auf die relative Anzahl an temozolomid-induzierten DNA-Addukten:

Behandlung von OCT1-Zellen und Kontrollzellen mit $800 \mu$ M Temozolomid ( $\bullet$ bzw. $\mathbf{v})$ bzw. DMSO (घ oder $\leadsto$ ) für 5-180 min; relative Adduktzahl als Quotient der Fluoreszenzsignale von DNA-Addukten und Gesamt-DNA

Zusammenfassend lässt sich nicht mit Sicherheit sagen, ob OCT1 Temozolomidmetabolite in Zellen transportiert und so dessen induzierte DNA-Addukte erhöht. Es gibt nach den Aufnahmeexperimenten in 4.2.1.3.2 eine Interaktion mit Temozolomidmetaboliten. Jedoch zeigen die Ergebnisse der ICA-Experimente in zwei Fällen eine OCT1-vermittelte Erhöhung der temozolomid-induzierten DNA-Addukte und in vier Fällen keine.

\subsubsection{Einfluss von MATE1 auf die Anzahl temozolomid-induzierter DNA-Addukte}

Es lag kein Anstieg der relativen Anzahl der DNA-Addukte in Abhängigkeit der MATE1Expression vor. In Abb. 4-23 sieht man keinen zeitlichen Anstieg der DNA-Adduktzahl in dem mit Temozolomid behandelt MATE1-Zellen, dagegen eine zeitlichen Anstieg bei den mit Temozolomid behandelten Kontrollzellen nach 180-minütiger Inkubation. 


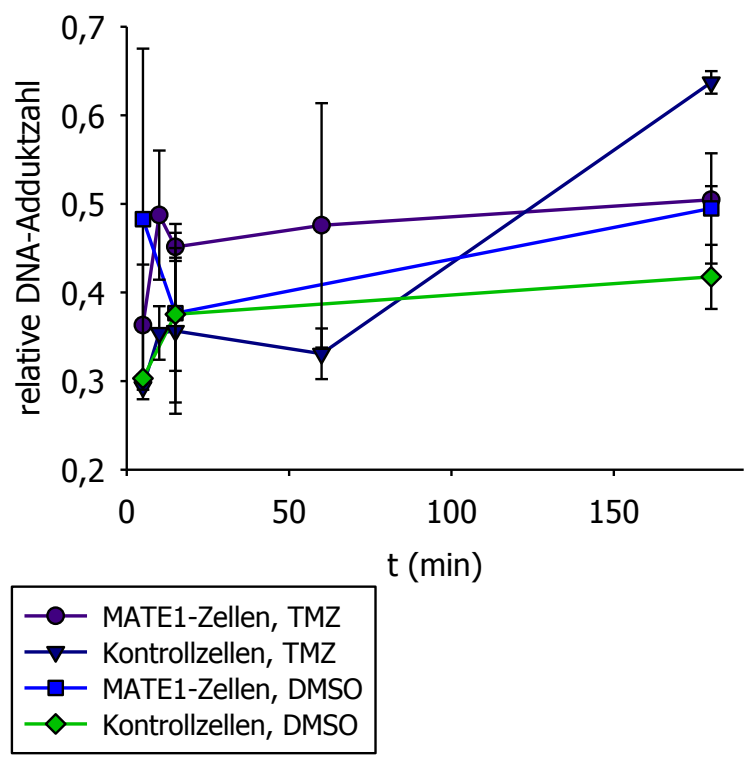

Abb. 4-23: Einfluss der MATE1-Expression auf die relative Anzahl an temozolomid-induzierten DNA-Addukten:

Behandlung von MATE1-Zellen und Kontrollzellen mit $800 \mu$ M Temozolomid $(\bullet$ bzw. v) bzw. DMSO (घ oder $\diamond)$ für 5-180 min; relative Adduktzahl als Quotient der Fluoreszenzsignale von DNA-Addukten und Gesamt-DNA

\subsubsection{MATE1- und OCT1-vermittelte Zytotoxizität}

In 4.2.1 wurden mittels cis-Inhibition des OCT1- und MATE1-vermittelten [ $\left.{ }^{3} \mathrm{H}\right]$-MPPTransports in Modellzellen Zytostatika identifiziert, welche mit den beiden SLC-Proteinen interagierten. Eine Interaktion könnte einerseits eine Inhibierung des SLC-Proteins durch die Zytostatika, ohne dass sie transportiert werden oder andererseits einen Transport dieser Zytostatika über MATE1 bzw. OCT1 in die Zellen bedeuten. Welcher dieser Fälle vorlag, wurde mittels Tests zur Zytotoxizität mit dem Reagenz WST1 untersucht (siehe

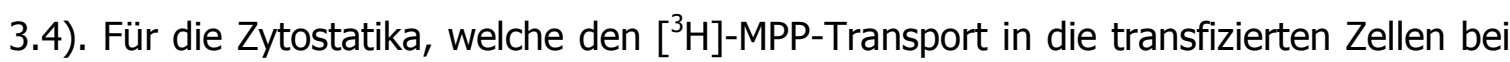
einem oder beiden pH-Werten um mehr als $50 \%$ hemmten, wurde die prozentuale Zellüberlebensrate relativ zu unbehandelten Zellen bestimmt. Es wurde untersucht, welchen Einfluss verschiedene Inkubationszeiten eines Zytostatikums auf die Zytotoxizität von OCT1-CHO-, MATE1-HEK293-Zellen und nicht transfizierten Kontrollzellen hatten (Abb. 4-24 und Abb. 4-25). Für MATE1 wurde außerdem der pHEinfluss der Versuchslösung MR bestimmt (Abb. 4-26). Für die Zytostatika Irinotecan und Mitoxantron, welche den $\left[{ }^{3} \mathrm{H}\right]$-MPP-Transport bei $\mathrm{pH} 7,4$ oder $\mathrm{pH} 8,5$ um über $50 \%$ hemmten (siehe 4.2.1.2.2), wurden Dosis-Wirkungskurven bei verschiedenen pH-Werten angefertigt (siehe 4.2.4.1.4). 


\subsubsection{Zeitabhängige Zytotoxizität}

Falls eine MATE1- oder OCT1-vermittelte Zytotoxizität durch ein Zytostatikum für mit den SLC-Proteinen interagierende Zytostatika vorliegt, kann diese abhängig von der Inkubationszeit des Zytostatikums sein. Das heißt, nur bei einer bestimmten Inkubationszeit tritt eine MATE1- bzw. OCT1-spezifische Zytotoxizität auf, bei anderen Zeiten tritt dagegen keine oder auch in nicht transfizierten Zellen eine Zytotoxizität auf. In Abb. 4-24 sind die relativen Anteile an überlebenden Zellen im Vergleich zu unbehandelten Zellen (sowohl transfizierte als auch Kontrollzellen $=100 \%$ ) in Abhängigkeit der Zytostatikuminkubationszeit dargestellt.

\subsection{OCT1-vermittelte Zytotoxizität von Nimustin und Temozolomid}

Das Zytostatikum Nimustin und die Metabolite von Temozolomid interagierten mit OCT1 (siehe 4.2.1). An dieser Stelle ist dargestellt, ob Nimustin und Temozolomidmetabolite zytotoxisch auf OCT1-Zellen und Kontrollzellen wirken, ob also die Interaktion zu einer erhöhten Zytotoxizität von OCT1-Zellen im Vergleich zu Kontrollzellen führt. In Abb. 4-24 $a$ und $b$ ist zu sehen, dass weder in OCT1-Zellen noch in Kontrollzellen und weder unter Zugabe von Nimustin (Abb. 4-24 a) noch Temozolomid und seinen Metaboliten (Abb. 4-24 b) eine Zytotoxizität vorliegt.

a)

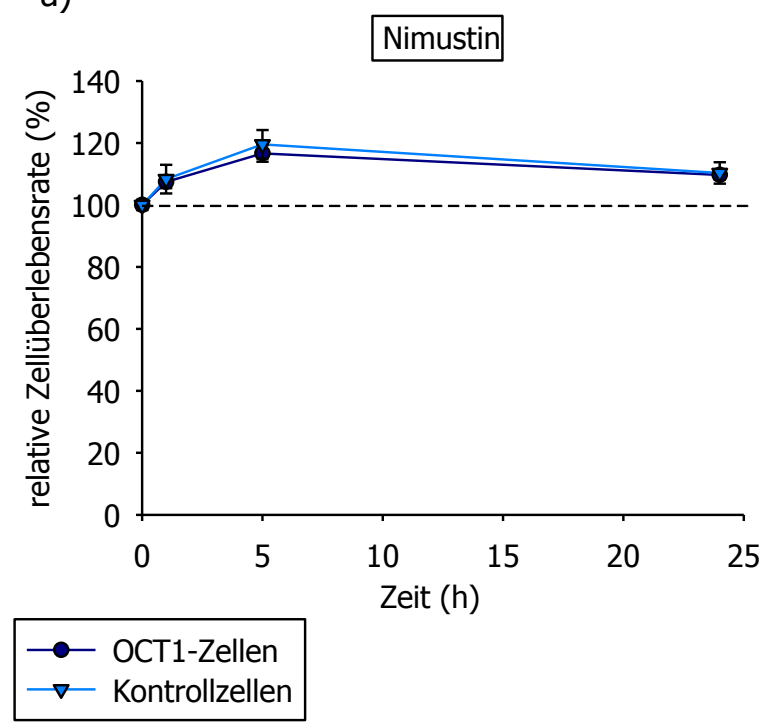

b)

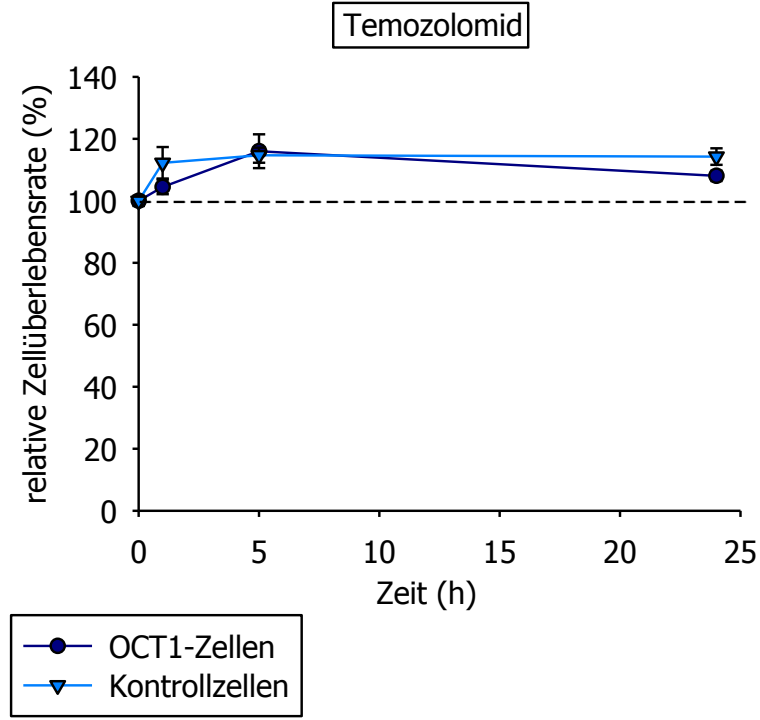

Abb. 4-24: OCT1-vermittelte Zytotoxizität von Nimustin und Temozolomid in Abhängigkeit der Zytostatikuminkubationszeit:

WST1-Test nach Behandlung von OCT1-Zellen (dunkelblau) und Kontrollzellen (blau) mit Nimustin (a) bzw. Temozolomid (Temozolomid, b); prozentuale Zellüberlebensrate im Vergleich zu unbehandelten Zellen (0 h, 100\%), Inkubationszeit 0-24 h 
4.2.4.1.2 MATE1-vermittelte Zytotoxizität von Doxorubicin, Etoposid, Irinotecan und Mitoxantron

Es wurde der Einfluss der Inkubationszeit der Zytostatika Doxorubicin, Etoposid, Irinotecan und Mitoxantron auf die Zytotoxizität von MATE1- und Kontrollzellen gemessen.

Das Zytostatikum Doxorubicin wirkte schon ab 15 min Inkubation hochsignifikant $(p<$ 0,001) zytotoxisch auf MATE1- und Kontrollzellen (Abb. 4-25 a). Die Zytotoxizität erhöhte sich mit längerer Inkubationszeit. Nach 15-minütiger Inkubation verringerte sich der Anteil an überlebenden Zellen auf 59,36 $\pm 10,33 \%$ (MATE1-Zellen) bzw. $60,43 \pm 10,33 \%$ (Kontrollzellen), nach $60 \mathrm{~min}$ auf 46,63 $\pm 10,33 \%$ bzw. $49,31 \pm 10,33 \%$ und nach 240 min auf $31,81 \pm 10,33 \%$ bzw. 34,05 $\pm 10,33 \%$. Die Zellüberlebensrate ist demnach in MATE1- und Kontrollzellen nicht signifikant verschieden. Die Zellbehandlung mit Etoposid führte nach 15 min zu keiner signifikanten Zellsterblichkeit (Abb. 4-25 b). Nach 60-minütiger Inkubation verringerte sich die Zellüberlebensrate in MATE1-Zellen signifikant auf 76,89 $\pm 8,29 \%(p<0,001)$ und in Kontrollzellen auf $77,14 \pm 8,29 \%(p<0,01)$ und nach 240 min in MATE1-Zellen auf $71,61 \pm 8,29 \%$ und in Kontrollzellen auf 71,89 $\pm 8,29 \%(p<0,001)$, wobei es zwischen MATE1- und Kontrollzellen keine signifikanten Unterschiede gab. Irinotecan bewirkte nach 15-minütiger Inkubation eine tendenziell, jedoch nicht signifikant höhere Zytotoxität auf eine Zellüberlebensrate von 76,11 $\pm 5,92 \%$ in MATE1- im Vergleich zu $86,05 \pm 5,92 \%$ in Kontrollzellen (Abb. 4-25 c). Nach 60 und 240-minütiger Inkubation blieb der Anteil an überlebenden MATE1-Zellen etwa gleich bei etwa 69,5\% und $75 \%$ bei Kontrollzellen $(p<0,001)$. Auch bei diesen Inkubationszeiten gibt es keine signifikant, aber tendenziell geringeren Zellüberlebensraten der MATE1-Zellen.

Das im Sinne der Aufgabenstellung interessanteste Zytostatikum Mitoxantron führte schon bei 15-minütiger Inkubation zu einem signifikant verringerten Anteil an überlebenden Zellen auf 69,80 \pm 7,97 \% (MATE1-Zellen, $\mathrm{p}<0,001$ ) bzw. $78,04 \pm 7,97 \%$ (Kontrollzellen, $p<0,01$, Abb. 4-25 d). Nach 60-minütiger Inkubation verringerte sich dieser Anteil auf 64,19 \pm 7,97 bzw. 71,38 \pm 7,97 \% und nach 240 min auf 38,43 $\pm 7,97 \%$ bzw. 35,57 $\pm 7,97 \%$ ( $p<0,001$ ). Nach 15- und 60-minütiger Inkubation mit Mitoxantron gab es keine signifikante, jedoch tendenziell höhere Zytotoxizität in MATE1-Zellen.

Temozolomid wirkte auch bei langen Inkubationszeiten von bis zu $24 \mathrm{~h}$ nicht zytotoxisch auf MATE1-Zellen und Kontrollzellen und wurde hier nicht dargestellt.

Zusammenfassend kann festgestellt werden, dass Doxorubicin und Mitoxantron am stärksten, jedoch unabhängig von einer MATE1-Expression zytotoxisch auf HEK293- 
Zellen wirken. Etoposid und Irinotecan wirken ebenso auf MATE1- und Kontrollzellen. Nicht signifikant, aber tendenziell liegt eine leicht erhöhte Zytotoxizität in MATE1-Zellen vor, die bei 15 min für Etoposid, Irinotecan und Mitoxantron am ausgeprägtesten ist. Für die nachfolgenden Experimente zur pH-Abhängigkeit wurde daher diese Inkubationszeit gewählt.

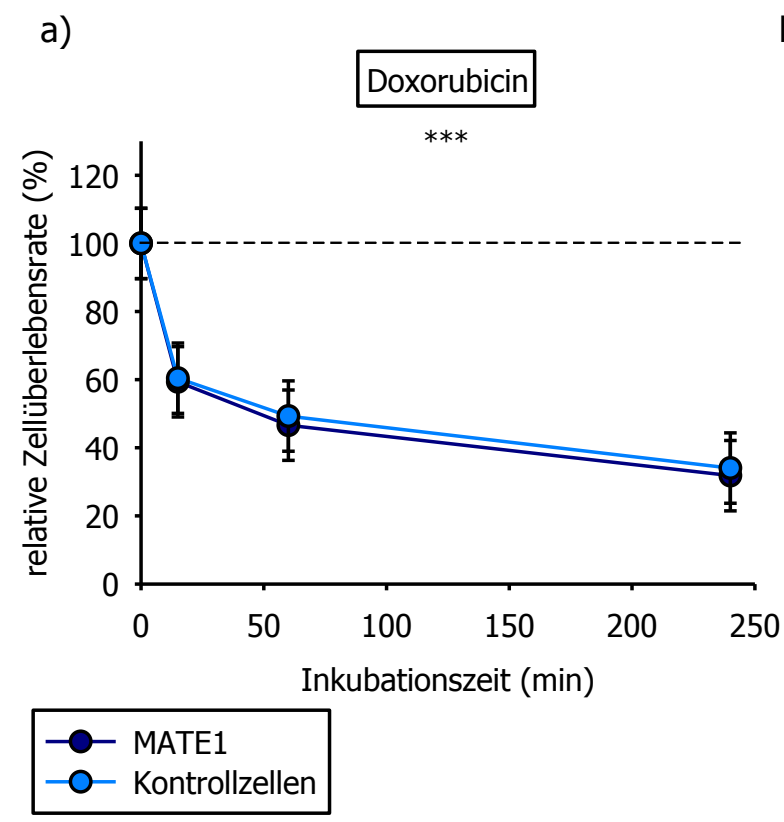

b)

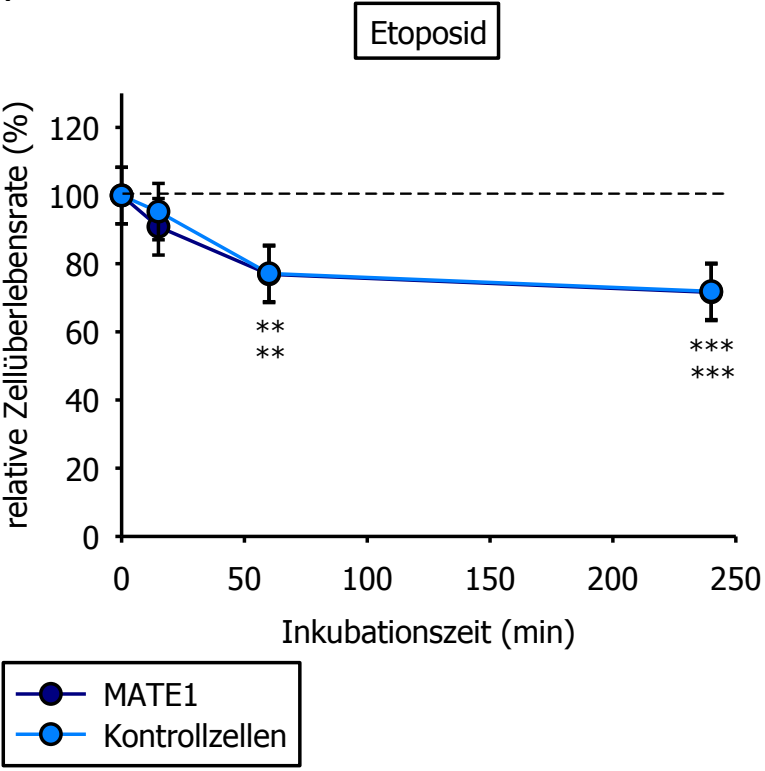

c)

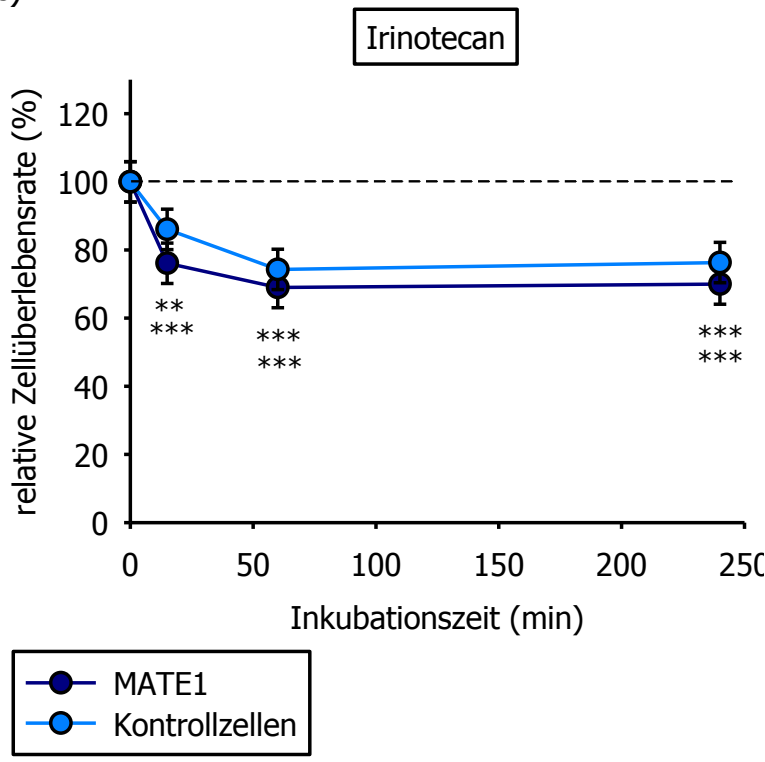

d)

Mitoxantron

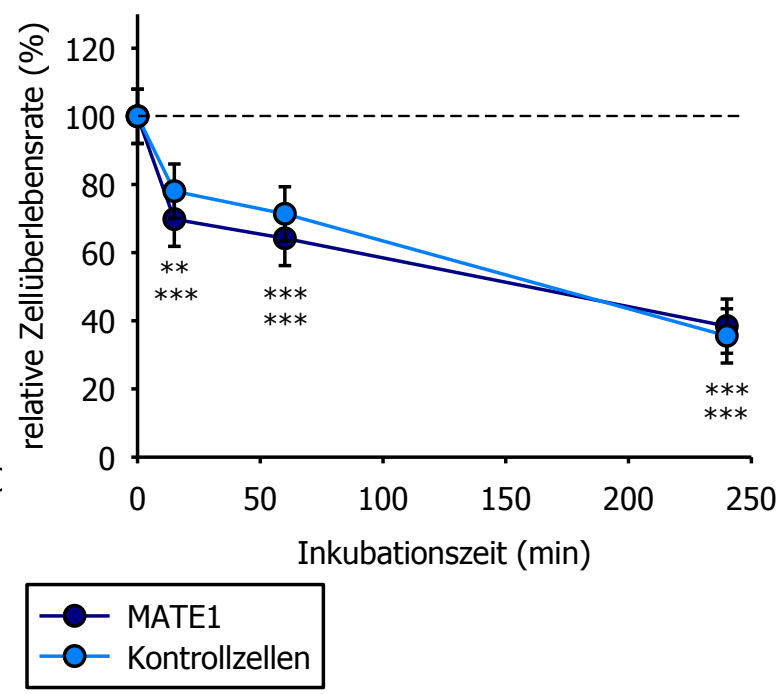

Abb. 4-25: Einfluss der Inkubationszeit auf die MATE1-vermittelte Zytotoxizität von Zytostatika:

WST1-Test nach Behandlung von MATE1-Zellen (dunkelblau) und Kontrollzellen (blau) mit Doxorubicin (a), Etoposid (b), Irinotecan (c) oder Mitoxantron (d); prozentuale Zellüberlebensrate im Vergleich zu unbehandelten Zellen (0 h, $100 \%$ ); Inkubationszeit des Zytostatikums in Medium (0-240 min); Konfidenzintervalle mit Konfidenzniveau $95 \%$; Signifikanz: $p<0,05=*, p<0,01=* *$ und $p<0,001=* * *$ 


\subsubsection{3 pH-Abhängigkeit der MATE1-vermittelten Zytotoxizität}

Da die Transportaktivität von MATE1 vom pH-Wert der Versuchslösung abhängig ist wurde bestimmt, welchen Einfluss der pH-Wert auf die Zytotoxizität von Zytostatika auf MATE1- und Kontrollzellen hat. In Abb. 4-26 sind die relativen Anteile an überlebenden Zellen in Abhängigkeit des pH-Werts der Versuchslösung MR dargestellt. Doxorubicin wirkt bei pH 5,5 nicht zytotoxisch (Abb. 4-26 a). Bei pH 7,4 und pH 8,5 bewirkte es dagegen sowohl in MATE1- Zellen (79,38 $\pm 11,97 \%$ und 70,97 $\pm 11,97 \%)$ als auch in Kontrollzellen $(67,53 \pm 11,97 \%$ und $72,86 \pm 11,97 \%)$ eine Zytotoxizität. Die Behandlung von MATE1-Zellen mit Etoposid bewirkte keine Zytotoxizität, unabhängig vom pH-Wert der Lösung (Abb. 4-26 b). Kontrollzellen weisen eine signifikante, jedoch $\mathrm{pH}$-Wert-unabhängige Zytotoxizität auf, welche bei $\mathrm{pH} 7,4$ signifikant höher als bei MATE1-Zellen ist $(p<0,05)$. Das dritte getestete Zytostatikum, Irinotecan wirkte bei keinem der drei pH-Werte und weder auf MATE1- noch auf Kontrollzellen signifikant zytotoxisch (Abb. 4-26 c). Für das Zytostatikum Mitoxantron wurden DosisWirkungskurven bei den drei pH-Werten gemessen (4.2.4.1.4).

Zusammenfassend lautet das Ergebnis: Nur Doxorubicin weist eine signifikante pHAbhängigkeit der Zytotoxizität in MATE1- und Kontrollzellen auf. 
a)

Doxorubicin

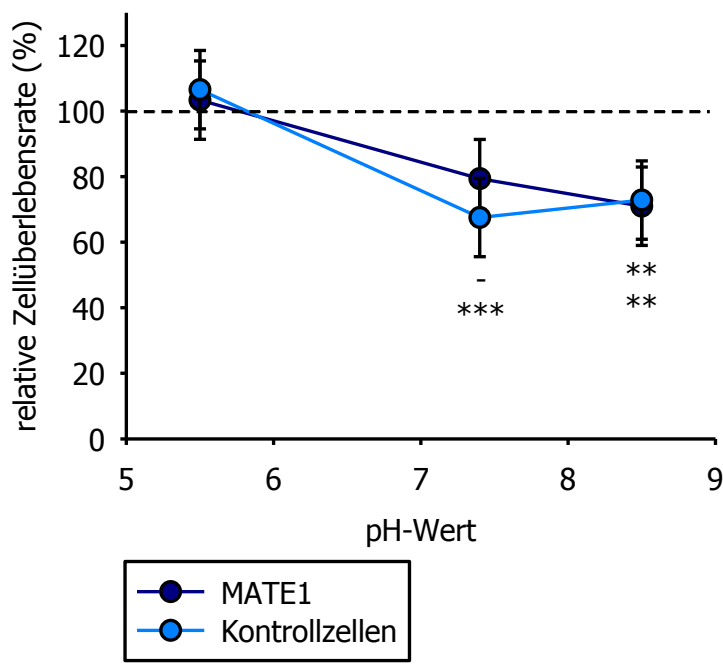

c)

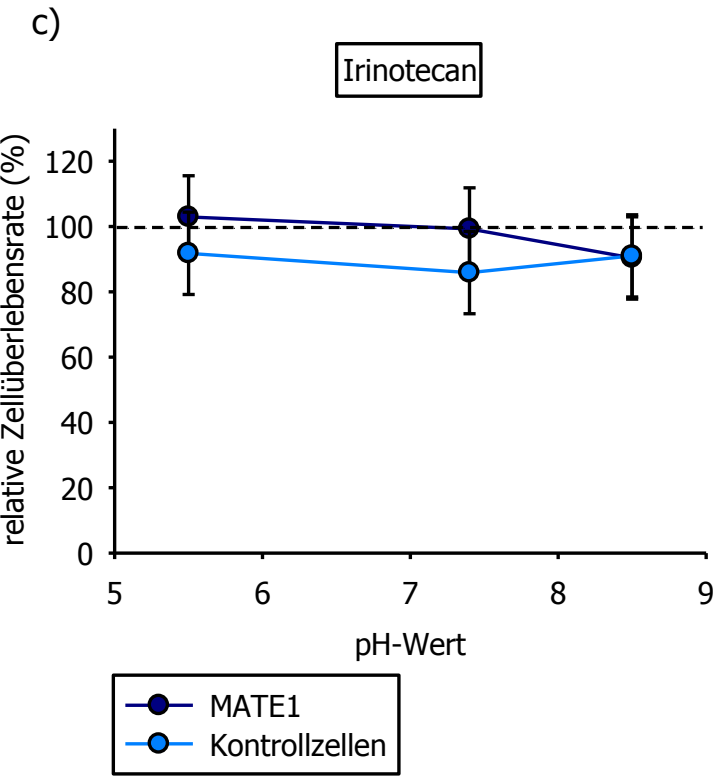

b)

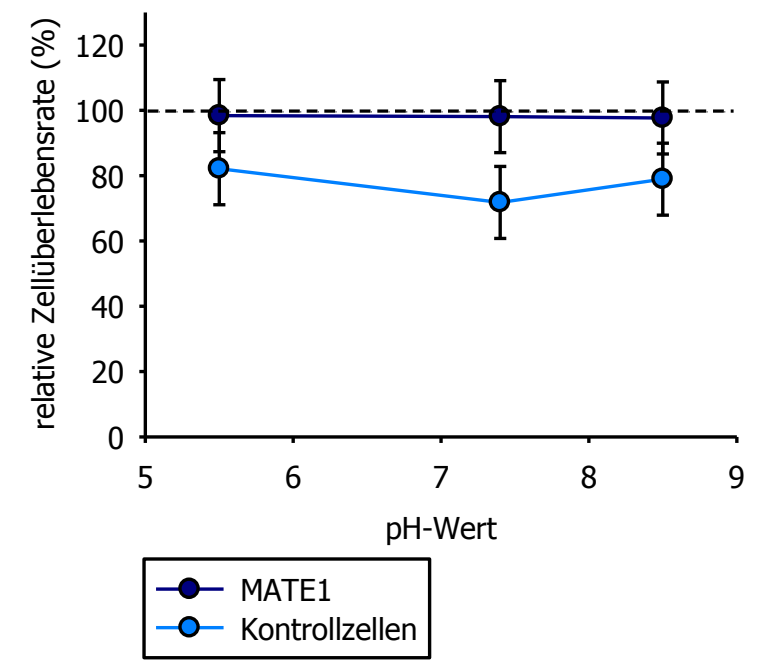

Etoposid

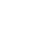


In Abb. 4-27 werden die Dosis-Wirkungskurven für Mitoxantron bei $\mathrm{pH}$ 5,5, 7,4 und 8,5 für MATE1- und Kontrollzellen wiedergegeben. Hier wird der Anteil an überlebenden Zellen dem von unbehandelten Zellen gegenübergestellt, und zwar in Abhängigkeit der logaritmischen Mitoxantronkonzentration. Die Zellüberlebensrate bei der Mitoxantronkonzentration $0 \mu \mathrm{M}$ wurde als $100 \%$ angesehen. Werte, die nicht in die Kurvenanpassung eingingen (Ausreißer), sind in weiß dargestellt (z. B. Abb. 4-27 b). Bei pH 5,5 ist der $\mathrm{EC}_{50}$-Wert für MATE1-Zellen etwa 4,0 $\pm 1,7 \mu \mathrm{M}$ und für Kontrollzellen etwa 8,7 \pm 1,8 $\mu \mathrm{M}$ (Abb. 4-27 a und b). Werden die Zytotoxizitätstests in MR-Lösungen mit pH 7,4 durchgeführt, so ergibt sich für MATE1-Zellen ein $\mathrm{EC}_{50}$-Wert von etwa 3,5 $\pm 1,6 \mu \mathrm{M}$ und für Kontrollzellen von etwa 8,7 $\mathrm{MM}$ (Abb. 4-27 c und d). Bei pH 8,5 liegt der $\mathrm{EC}_{50}$-Wert für MATE1-Zellen bei 4,4 $\pm 1,9 \mu \mathrm{M}$ und für Kontrollzellen bei 7,2 $\pm 2,3 \mu \mathrm{M}$ (Abb. 4-27 e und $f$ ).

Es ist zu erkennen, dass die $\mathrm{EC}_{50}$-Werte tendenziell in MATE1-Zellen etwas niedriger als in Kontrollzellen sind. Jedoch sind die Werte unabhängig vom pH-Wert wie es bei einer MATE1-vermittelten Zytotoxizität der Fall wäre. Der maximale Zytotoxizitätsanteil ist in MATE1- und Kontrollzellen ähnlich und liegt zwischen 30 und $50 \%$. 
a)

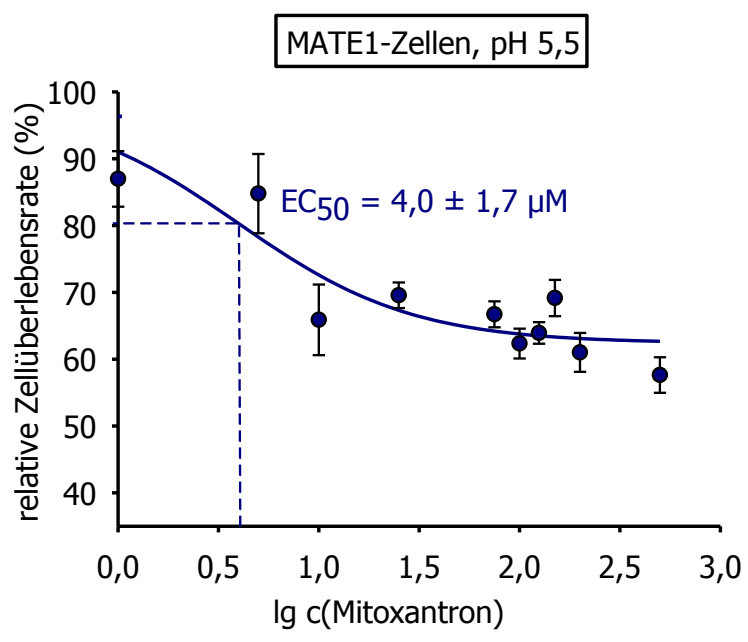

c)

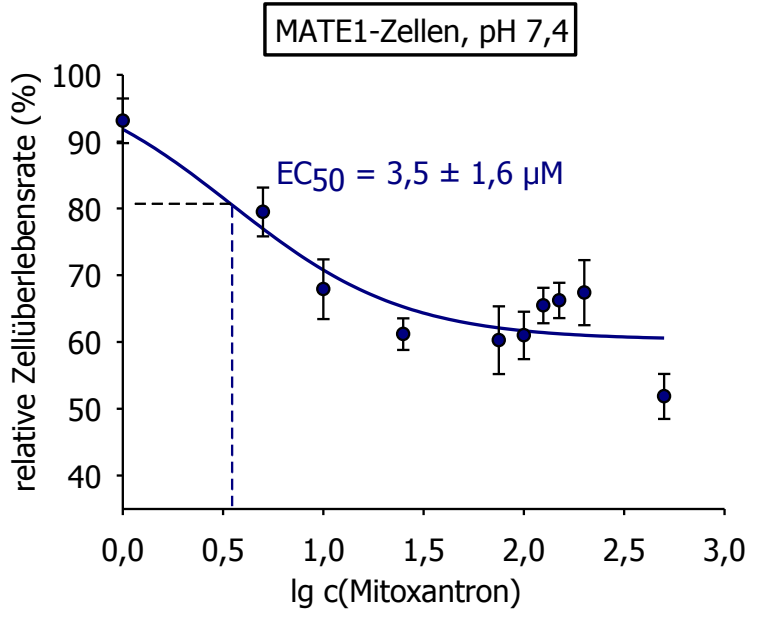

e)

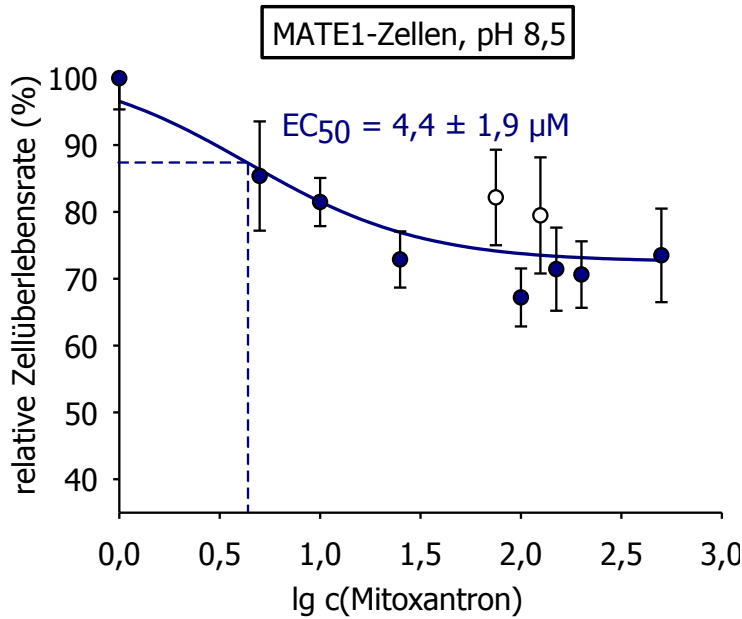

b)

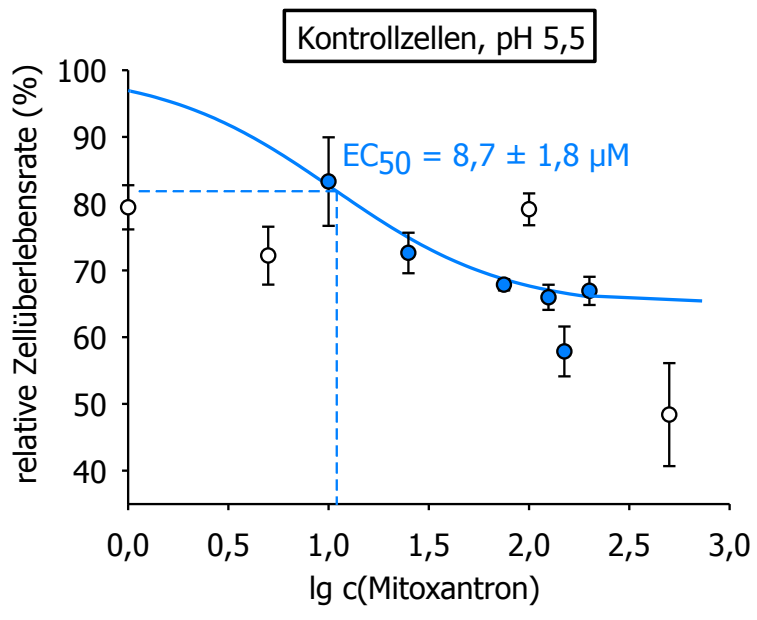

d)

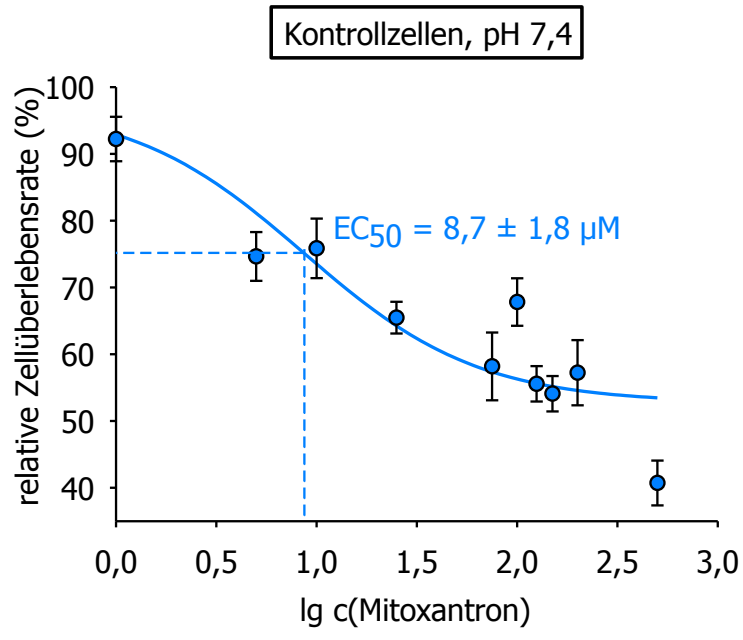

f)

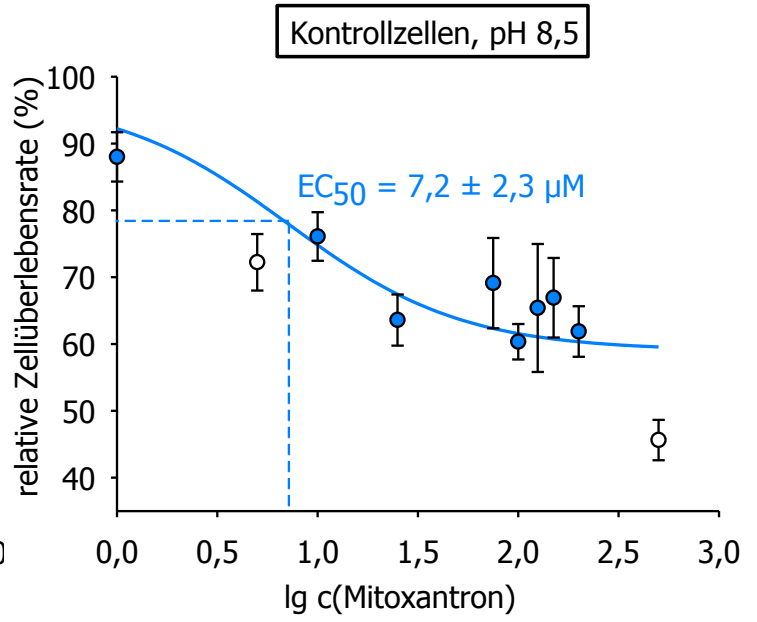

Abb. 4-27: Dosis-Wirkungskurven der MATE1-vermittelten Mitoxantronzytotoxizität:

WST1-Test nach 15-minütiger Behandlung von MATE1-Zellen (a, $c$ und e, dunkelblau) und Kontrollzellen (b, $d$ und $f$, blau) mit 0-300 $\mu$ M Mitoxantron in MR bei $\mathrm{pH}$ 5,5 (a und b), 7,4 (c und d) oder 8,5 (e und f); prozentuale Zellüberlebensrate im Vergleich zu unbehandelten Zellen, logaritmische (log 10$)$ Mitoxantronkonzentration; $E C_{50}=$ Konzentration bei halbmaximaler Zellsterberate 


\section{Diskussion}

Die Herausforderungen der heutigen Krebstherapie sind die Verbesserung der Ansprechrate von Chemotherapeutika, die Vermeidung von Pharmakawechselwirkungen, ausgelöst durch diese Medikamente, und toxische Nebenwirkungen auf nicht entartete Zellen.

Ein Grund für die geringen Ansprechraten der Zytostatika ist Resistenz der Tumorzellen, die neben anderen Ursachen durch Zytostatikaefflux bedingt sein kann [8], [148]. Tumorzellen besitzen Transportproteine, wie die ABC-Transporter, die einen schnellen Heraustransport der Zytostatika bewirken und so deren Akkumulation in den Zellen verhindern [82], [162], [181]. Ein Weg, diese efflux-bedingte Resistenz zu verringern, wäre eine erhöhte Akkumulation der Zytostatika in Tumorzellen - entweder durch Inhibierung des Efflux [181] oder durch erhöhten Influx der Zytostatika. Einen erhöhten Influx könnten die SLC-Transporter bewirken. Diese haben sich in der Vergangenheit bereits in Tumorzellen als mögliche Zytostatikatransporter erwiesen [60], [149]. Es wird vermutet, dass SLC-Transporter auch Zytostatika in Melanomzellen transportieren könnten.

In dieser Arbeit wird versucht, einen Beitrag zur Verbesserung der Krebstherapie, insbesondere der Melanomtherapie auf der Basis der SLC-Transporter zu leisten.

Wenn SLC-Transporter in malignen Melanozyten exprimiert wären, könnten diese Proteine genutzt werden, um mehr Moleküle von bestimmten Zytostatika in den Zellen zu akkumulieren und deren Sensitivität dadurch zu erhöhen. Wenn diese SLCTransporter außerdem in nicht entarteten Zellen geringer exprimiert wären, eigneten sie sich besonders gut für eine Therapie, da sie geringere Nebenwirkungen erzeugten. Wenn sie drittens zusätzlich zwischen Melanomzellen verschiedener Patienten variierten, so könnte man die Chemotherapie des Patienten individuell an dessen Transporterausstattung anpassen. Man würde ihm bevorzugt Zytostatika verabreichen, die über die individuell vorhandenen SLC-Transporter in maligne Zellen und möglichst wenig in nicht entartete Zellen transportiert werden.

Die Charakterisierung des MATE1-Transporters diente vor allem der Aufklärung der Transportwege von Zytostatika in Tumorzellen und nicht entartete Zellen hinein oder aus innen heraus. Ob MATE1 in Tumorzellen exprimiert ist und einen Zytostatikatransport vermitteln kann, war bisher unbekannt, ebenso seine Rolle bei Pharmakawechselwirkugen mit Zytostatika, insbesondere in Leber und Niere. Das Fernziel ist, Zytostatika 
so auszuwählen, dass diese Wechselwirkungen minimal sind, dabei aber die Wirksamkeit in den malignen Zellen optimal ist.

\subsection{SLC-Expression in Melanomzelllinien}

Transporter der SLC-Familie vermitteln im Allgemeinen den Transport von größeren hydrophilen Molekülen, welche die Zellmembran nicht oder nur begrenzt durch Diffusion überqueren können (siehe 1.1).

Die in dieser Arbeit für die Untersuchung ihrer Expression in Melanomzelllinien (MelA, MelB, MelC, LIBR und KAII) gewählten SLC-Transporter wurden erstens danach ausgewählt, ob sie bereits in anderen Tumorzellen gefunden wurden, und zweitens, ob sie als Zytostatikatransporter identifiziert wurden.

Das dritte Kriterium für die Wahl der zu untersuchenden SLC-Transporter war, ob sie auf Grund ihrer Substratspezifität Zytostatika transportieren könnten. Gesucht werden SLCTransporter, deren mRNA in Melanomzelllinien gegenüber nicht entarteten Melanozyten erhöht exprimiert ist. Es besteht in diesem Fall die Möglichkeit, dass die Zytostatikaaufnahme ebenfalls erhöht ist. Die Nebenwirkungen in den nicht entarteten Melanozyten sind dann vermutlich geringer. Im Folgenden wird die Expression von SLC-Transportern in Melanomzelllinien und nicht entarteten Melanozyten unter diesem Gesichtspunkt diskutiert. Die Ergebnisse zur Interaktion von ausgewählten SLC-Transportern mit Zytostatika werden in Abschnitt 5.2 betrachtet.

\subsubsection{Nicht in Melanomzelllinien exprimierte SLC-Transporter}

Wie in Abschnitt 4.1 beschrieben, war eine Reihe der ausgewählten SLC-Transporter nicht in Melanomzelllinien exprimiert. Sie erfüllen also die grundlegende Voraussetzung für die zielgerichtete Melanomtherapie nicht und können keine Zytostatika bevorzugt in Melanomzellen ohne sich nicht auch in nicht entartete Zellen zu transportieren. Sie haben damit hier keine Bedeutung und wurden bei den weiteren Untersuchungen nicht weiter berücksichtigt. Bei diesen Transportern handelte es sich um MCT2, OCT2, OCT3, OAT1 bis OAT4, CNT1 bis CNT3, OATP8 und MATE2. Die Charakterisierung dieser Transporter ist in Abschnitt 1.2 zu finden.

\subsubsection{SLC-Transporter mit nicht erhöhter Expression in Melanomzelllinien im Vergleich zu der in Melanozyten}

Bei den Untersuchungen wurden 12 SLC gefunden, die zwar in Melanomzellen exprimiert waren, aber gleich hoch oder geringer als in Melanozyten. Sie könnten also Zytostatika 
im Prinzip in Melanomzellen transportieren. Da jedoch wegen des gleichzeitigen Transports in nicht entartete Melanozyten mit hohen Nebenwirkungen zu rechnen ist, stellen sie keine geeigneten Transporter für die zielgerichtete Melanomtherapie dar und dementsprechend wurde die Interaktion dieser SLC-Transporter mit Zytostatika nicht weiter untersucht. Folgende Transporter gehören zu dieser Kategorie: LAT1, LAT2, MCT1, MCT4, RFT, ThTr1, OATPB, OATPD, ENT1 und ENT3. In Abschnitt 1.2 wurden die genauen Lokalisationen und Substratspezifität besonders im Hinblick auf Expression in anderen Tumorzellen und Interaktion mit Zytostatika erläutert.

Mitglieder dieser Gruppe sind auch OCT1 und MATE1. Auch für sie gilt, dass sie auf Grund ihres Expressionsprofils für die zielgerichtete Melanomtherapie eine geringe Rolle spielen. Diese beiden SLC-Transporter wurden aus anderen Gründen in dieser Arbeit genau charakterisiert. Wie in Abschnitt 5 erwähnt, stellt MATE1 auf Grund seiner vielfältigen Substratspezifität und Lokalisierung in Leber- und Nierenzellen einen aussichtsreichen Zytostatikatransporter dar. Er war bisher nicht intensiver im Hinblick auf Zytostatikainteraktion untersucht worden. OCT1 ist bereits für seine Interaktion mit einigen Zytostatika bekannt und seine Charakterisierung wurde in dieser Arbeit daher auf weitere Zytostatika erweitert.

\subsubsection{SLC-Transporter mit erhöhter Expression in Melanomzelllinien im Vergleich zu der in Melanozyten}

Das eigentliche Ziel der Untersuchungen war, genau diese Art von SLC-Transportern zu finden, die in Melanomzellen im Vergleich zu Melanozyten erhöht exprimiert waren. Zu dieser Gruppe gehören ENT2, OATPA und OATPC. Eine signifikant erhöhte SLCExpression in Melanomzelllinien im Vergleich zu nicht entarteten Melanozyten stellt die Voraussetzung für die zielgerichtete Melanomtherapie dar.

In den Untersuchungen stellte sich heraus, dass ENT2 in Melanomzelllinien höher als in nicht entarteten Melanozyten exprimiert war, in der überwiegenden Mehrzahl signifikant. Der zweite Schritt, nämlich die Interaktion mit Zytostatika, wurde nicht untersucht. Es ist aber aus der Literatur z. B. für ENT2 bekannt, dass Interaktionen existieren. ENT2 transportiert Zytostatika der Nukleosidanaloga, wie Cladribin und Fludarabin [178].

Hier wurde ein vielversprechender SLC-Transporter gefunden, der für die zielgerichtete Melanomtherapie geeignet sein könnte.

Auch für OATPA, OATPC und OATPE wurde eine höhere, überwiegend signifikante Expression gefunden. Trotzdem eignen sie sich OATPA und OATPC auf Grund ihrer geringen absoluten Expression nur bedingt als Zytostatikumtransporter. OATPE weist in 
Melanomzelllinien eine höhere Expression als in Melanozytenzelllinien, aber geringere als in primären Melanozyten auf. Die Expressionslevel könnten durch die Umwandlung der Melanomzellen in Zelllinien verringert worden sein.

Zusammenfassend kann festgestellt werden, dass ENT2 und Mitglieder der OATP-Familie als die für die zielgerichtete Melanomtherapie am besten geeigneten Transporter erscheinen. Um die hier gewonnenen Ergebnisse zu verifizieren, wäre es sinnvoll, noch mehr Melanomzellinien und primäre Tumorzellen zu untersuchen. Auf Grund der geringen Verfügbarkeit des Tumormaterials waren derartige Untersuchungen im Rahmen dieser Arbeit aber nicht möglich.

\subsubsection{ABC-Transporter MDR1}

Zusätzlich zu den bisher erwähnten Transportern wurde hier auch ein Effluxtransporter der ABC-Familie untersucht, um zu zeigen, dass in den untersuchten Melanomzellen eine Resistenz durch Efflux besteht, die die Akkumulation von Zytostatika verhindert. Der Multidrug-Resistance-Transporter MDR1 ist unter den Effluxproteinen der am häufigsten untersuchte Transporter.

Bei den eigenen Untersuchungen fiel auf, dass die Expression sehr stark zwischen den untersuchten Zellen differiert. Das Spektrum reicht von vernachlässigbarer Expression bei der Melanomzelllinie MelC bis zu hoher Expression bei den Melanomzelllinien LIBR und KAII (siehe 4.1.8). Die nicht entarteten Melanozyten besitzen eine Expression im mittleren Bereich. MDR1 kann also in allen betrachteten Zellen bis auf MelC zu einer Zytostatikaresistenz durch Heraustransport beitragen.

\subsection{Eignung von MATE1 und OCT1 als Zytostatikatransporter}

Bisher wurden speziell Melanomzellen betrachtet. Das Ziel der in diesem Abschnitt beschriebenen Untersuchungen ist die Ergründung der Bedeutung der beiden Proteine MATE1 und OCT1 für die Krebstherapie im Allgemeinen, nicht nur für die Behandlung von Melanomen.

Die Untersuchung dieser Proteine dient der Aufklärung der Wege, über die Zytostatika in (Krebs-)Zellen aufgenommen und heraustransportiert werden. Beide Proteine weisen eine Vielzahl von Substraten auf, darunter viele Medikamente und sogar einige Zytostatika. Außerdem können sie an Pharmakawechselwirkungen beteiligt sein [73], [183]. 


\subsubsection{OCT1 als Zytostatikumtransporter}

\subsubsection{Interaktion von OCT1 mit Zytostatika}

Der Organische-Kationen-Transporter (OCT) 1 ist besonders in der sinusoidalen Membran der Hepatozyten, außerdem in der basolateralen Membran der proximalen Tubuluszellen und in weiteren Zellen exprimiert und transportiert eine große Anzahl organischer Kationen, ungeladener und zwitterionischer Moleküle (Koepsell 2007). Darüber hinaus ist bekannt, dass OCT1 mit Zytostatika, die sehr unterschiedliche Strukturen aufweisen, interagiert, er somit eine Bedeutung in der Krebstherapie besitzen könnte [59]. Hier wurde die Charakterisierung auf in der Melanomtherapie angewandte Zytostatika erweitert.

In dieser Arbeit wurde untersucht, ob Temozolomid oder seine Metabolite von OCT1 transportiert werden können und OCT1 damit eine Bedeutung als Zytostatikumtransporter in der Melanomtherapie zukommt. Temozolomid ist ein Standardtherapeutikum beim Melanom (siehe 1.4.1.2.4). Es ist ein Monoalkylanz, welches bei pH 7,4 zerfällt und O 6 -Methylguanyl-DNA-Addukte bildet [135]. Die in dieser Arbeit gewonnenen Ergebnisse zeigten, dass Temozolomid die $\left[{ }^{3} \mathrm{H}\right]-\mathrm{MPP}-A u f n a h m e$ in OCT1-Zellen nicht hemmte, obwohl eine sehr hohe Temozolomidkonzentration von bis zu $800 \mu \mathrm{M}$ eingesetzt wurde. Diese liegt weit über der mit der therapeutischen Dosis von $200 \mathrm{mg} /\left(\mathrm{m}^{2} \cdot \mathrm{d}\right)$ nach fünftägiger Behandlung erreichten Plasmakonzentration von höchstens etwa $100 \mu \mathrm{M}$ [30], [72]. Eine mögliche Erklärung war, dass die Affinität von OCT1 für Temozolomid zwar vorhanden, aber zu gering war, um einen Einfluss auf die Aufnahme des mit einer sehr hohen Affinität bindenden Substrats $\left[{ }^{3} \mathrm{H}\right]-\mathrm{MPP}\left(\mathrm{K}_{\mathrm{M}}=15-32 \mu \mathrm{M},[79]\right)$ auszuüben. Allerdings wurde auch bei Aufnahme von $\left[{ }^{14} \mathrm{C}\right]-\mathrm{TEA}$, das mit $\mathrm{K}_{\mathrm{M}}=229 \mu \mathrm{M}$ [79] eine geringere Affinität für OCT1 besitzt, keine Interaktion mit Temozolomid beobachtet.

Da die Zytostatikummoleküle im menschlichen Körper in den Metaboliten MTIC und dieser weiter in AIC zerfällt (siehe 1.4.1.2.4 [135]), wurde auch untersucht, ob OCT1 mit diesen Molekülen interagierte. Zu diesem Zweck wurden die radioaktiven Aufnahmeversuche von $\left[{ }^{14} \mathrm{C}\right]$-TEA mit Temozolomidmetaboliten wiederholt. Da sie nicht als Substanzen vorlagen, mussten sie erst hergestellt werden. Es wurde dazu ausgenutzt, dass Temozolomid bei pH 7,4 und höher in wässriger Lösung spontan zerfällt. Die hier bestimmte Zerfallshalbwertszeit in MR betrug bei Raumtemperatur $3 \mathrm{~h}$ und lag damit über der von Denny et al. beschriebenen von $1,8 \mathrm{~h}$ im Plasma oder in Phosphatpuffer bei $37{ }^{\circ} \mathrm{C}$ und $\mathrm{pH} 7$ [33]. Die niedrigere Temperatur bei den in dieser Arbeit durchgeführten Experimenten ist wahrscheinlich der Grund für die längere Zerfalls- 
halbwertszeit von Temozolomid. Unter der zuvor gewonnenen Kenntnis der Zerfallshalbwertszeit von $3 \mathrm{~h}$ wurde die Interaktion von OCT1 mit TemozolomidMetaboliten bestimmt. Bereits nach einer Temozolomid-Metabolisierungszeit von $10 \mathrm{~min}$ zeigte sich eine leichte, aber signifikante Interaktion. Der primäre Metabolit von Temozolomid ist MTIC. Da er nur eine Halbwertszeit von etwa 2 min besitzt [33], ist ein Teil der MTIC-Moleküle schon zu dem weiteren Zerfallsprodukt AIC zerfallen. Daher ist sowohl eine Interaktion mit MTIC als auch mit dem MTIC-Zerfallsprodukt AIC möglich. Denkbar wäre auch eine Interaktion mit dem zweiten Zerfallsprodukt von MTIC, dem hochreaktiven Methyldiazoniumion, welches weiter zu einem Methylradikal und Stickstoff zerfällt (siehe 1.4.1.2.4).

Neben Temozolomid wurde auch das Alkylans Nimustin untersucht. Es wird beim Hirntumor und in Kombination mit Dacarbazin und Cisplatin beim Melanom eingesetzt. Es bildet Chlorethyladdukte, bevorzugt am $0^{6}$-Atom von Guanin [80]. Die hier gewonnenen Ergebnisse zeigen eine starke Interaktion mit OCT1.

Weitere Zytostatika, Mitomycin, Bleomycin, Estramustin und Vindesin interagierten nicht mit OCT1. Diese Zytostatika gelangen vermutlich über andere Wege in Tumorzellen. Für ein anderes Bleomycinmolekül (A5) ist beispielsweise bekannt, dass es über OCT6 transportiert wird [9].

\subsubsection{OCT-vermittelte Zellschäden und Zytotoxizität}

Die Interaktion von OCT1 mit MTIC oder AIC und Nimustin könnte bedeuten, dass OCT1 die Substanzen in Zellen aufnimmt oder nur durch diese Substanzen inhibiert wird. Um herauszufinden, welche dieser Alternativen vorlag, wurden die durch Temozolomid induzierten DNA-Schäden und zusätzlich die von Temozolomid oder TemozolomidMetaboliten vermittelte Zytotoxizität bestimmt. Letztere wurde auch für Nimustin ermittelt.

Die durch Temozolomid induzierten $0^{6}$-Methylguanyl-DNA-Addukte wurden immunzytochemisch quantifiziert (siehe 4.2.3.1). Ein Teil der in dieser Arbeit erhaltenen Ergebnisse zeigte eine signifikante Erhöhung der DNA-Addukte in OCT1-exprimierenden Zellen im Vergleich zu nicht exprimierenden Kontrollzellen. Diese Beobachtung ließ sich aber nicht sicher reproduzieren. Zudem wurde auch bei sehr langer Temozolomid-Inkubierung von $24 \mathrm{~h}$ keine Zytotoxizität ausgelöst. Eine naheliegende Erklärung für die fehlenden OCT1vermittelten Effekte ist die Reparatur durch Enzyme wie die $0^{6}$-MethylguanylMethyltransferase (MGMT) [98]. Für die nicht ausgelöste Zytotoxizität könnte zusätzlich ein zu wenig aktives Basenfehlpaarungssystem (MMR, mismatch repair) verantwortlich 
sein [58], [98]. Dieses erkennt die falsche Paarung der von Temozolomid induzierten methylierten Guaninreste mit Thyminresten und löst die fehlerhaften Nukleotide aus der DNA heraus, füllt sie allerdings wieder mit Thymin-Nukleotiden auf. Durch ständige Wiederholung dieser Prozedur kommt es zum Zellzyklusarrest und schließlich zur Apoptose [58], [98].

Eine weitere Erklärung für fehlende OCT1-vermittelte Effekte könnte der Efflux der Temozolomid-Metabolitmoleküle über ABC-Transporter sein, wodurch eine Bildung der durch Temozolomid induzierten DNA-Addukte verhindert wird.

Schließlich ist zu erwähnen, dass auch experimentelle Ursachen des ICA zu den schwankenden Ergebnissen der durch Temozolomid induzierten DNA-Addukte führen könnten. So könnten die Zellen mechanisch bis zum Aufbringen auf den Objektträger geschädigt worden sein oder die Antikörperbindung unvollständig gewesen sein (siehe 3.5).

Unter Berücksichtigung der Erkenntnisse über die Interaktion von OCT1 mit Temozolomid-Metaboliten lässt sich zusammenfassend schließen, dass OCT1 für die Aufnahme von Temozolomid-Metaboliten in Zellen verantwortlich sein könnte. Das Transportprotein stellt aber sicher nicht den einzigen Aufnahmeweg in die Zellen dar, da trotz der sehr hohen Konzentration von $800 \mu \mathrm{M}$ nur ein schwacher bis gar kein Effekt gemessen wurde. Temozolomid ist lipophil [3], so dass auch eine Diffusion möglich ist. Klarheit würden weitere Versuche zur direkten Messung der aufgenommenen Temozolomid- oder Temozolomid-Metabolitmenge z. B. per HPLC oder Massenspektrometrie liefern oder eine Wiederholung der hier durchgeführten Experimente unter Zugabe von MGMTInhibitoren wie $0^{6}$-Benzylguanin [98].

Auch für Nimustin wurde selbst bei einer sehr langen Inkubationszeit von $24 \mathrm{~h}$ keine Toxizität auf die OCT1-CHO-Zellen gemessen. Wahrscheinlich ist, dass OCT1 in seiner Aktivität durch das Zytostatikum inhibiert wird, es aber nicht in die Zellen aufgenommen wird. Da allerdings gar keine Zytotoxizität messbar war, ist es auch möglich, dass DNAReparaturmechanismen wirksam waren. Das am meisten aktive Reparatursystem ist MGMT [26], welches die von Nimustin gebildeten Chlorethlyladdukte wieder eliminiert. Weitere Reparatursysteme sind an der Reparatur von DNA-Doppelstrangbrüchen, die nach Adduktbildung durch Nimustin entstehen, beteiligt [80]. Denkbar ist außerdem, dass zwar eine Nimustin-Aufnahme in die Zellen erfolgte, es aber über ABC-Transporter wieder heraustransportiert wurde ohne eine Wirkung entfaltet zu haben. 


\subsubsection{MATE1 als Zytostatikatransporter}

Neben OCT1 war MATE1 ein weiterer Untersuchungsgegenstand. Er könnte eine Bedeutung bei aktuellen Problemen der Krebstherapie der Resistenz von Tumorzellen, gefährlichen Pharmakawechselwirkungen und toxischen Nebenwirkungen der Zytostatika haben. MATE1 ist aus mehreren Gründen ein vielversprechender Zytostatikatransporter: $\mathrm{Er}$ ist unter anderem in der luminalen Membran der proximalen Tubuluszellen in der Niere und der kanalikulären Membran der Hepatozyten in der Leber exprimiert [118]. Diese Organe stellen die Ausscheidungs- und Metabolisierungsorte für viele Medikamente dar. Viele Pharmakawechselwirkungen, darunter auch transportervermittelte, treten daher in diesen Organen auf [73], [183]. Die Funktion von MATE1 besteht in diesen Organen im zweiten Schritt der Sekretion von endogenen und exogenen Substanzen [111], [118], [157]. Er weist eine breite Substratspezifität nicht nur für Kationen, sondern auch für Zwitterionen, ungeladene Moleküle und sogar Anionen auf. Darunter befinden sich Toxine und Medikamente [111], [157]. Über die Interaktion von MATE1 mit Zytostatika ist wenig bekannt. Mitoxantron interagiert mit MATE1 [101]. Topotecan [157], sowie Oxaliplatin und Cisplatin sind Substrate von MATE1 [174]. Vor kurzem wurde der Transport von Cisplatin in vivo gezeigt. Nakamura et al. fanden eine erhöhte Nephrotoxizität in MATE1-knockout-Mäusen [109].

Auf Grund der oben aufgeführten Eigenschaften von MATE1 und der bisherigen Kenntnisse zur Interaktion mit Zytostatika wurde es als erfolgsversprechend angesehen, MATE1 im Hinblick auf seine Eignung als Transporter weiterer Zytostatika zu untersuchen.

Voraussetzung waren Testsysteme, in diesem Fall transfizierte HEK293-Zellen, die ein funktionelles MATE1-Protein aufwiesen. Nach Generierung von MATE1Vektorkonstrukten und der Transfektion in HEK293-Zellen wurde MATE1 funktionell charakterisiert. Anschließend wurde seine Interaktion mit Zytostatika und seine zytostatika-vermittelte Zytotoxizität bestimmt.

\subsubsection{Funktionelle Charakterisierung von MATE1 in transfizierten HEK293-Zellen}

Als Methoden zur Untersuchung, ob MATE1 in den transfizierten HEK293-Zellen funktionell aktiv war, wurden Aufnahmeversuche mit dem radioaktiven Modellsubstrat $\left[{ }^{3} \mathrm{H}\right]-M P P$ gewählt [118]. MATE1 ist zwar in der Literatur vorwiegend als Effluxtransporter bekannt [118], [157], dennoch wurde hier die Aufnahme von Substraten über MATE1 gemessen. Dies war experimentell leichter durchzuführen und es schien 
auch sinnvoll, weil Dangprapai et al. gezeigt haben, dass MATE1 eine bidirektionale und symmetrische Transportaktivität besitzt. Symmetrisch bedeutet, dass sich die Ergebnisse von Aufnahmeversuchen nicht signifikant von entsprechenden Effluxversuchen unterscheiden [29].

Die Versuche orientierten sich an den in unserer Arbeitsgruppe für andere SLCTransporter adaptierten Bedingungen [60], [150]. Die funktionelle Aktivität von MATE1 wurde durch drei Ergebnisse zunächst in transient, dann in stabil transfizierten Zellen nachgewiesen.

Die mit dem ursprünglichen Expressionsvektor MATE1-pCMV-SPORT6 transient transfizierten und die mit dem zweiten Expressionsvektor MATE1-pEF/FRT/V5 transfizierten Zellen zeigten bei einem pH-Wert von 7,4 beide eine signifikant höhere $\left[{ }^{3} \mathrm{H}\right]$-MPP-Aufnahme als die Kontrollzellen. Untereinander verglichen war die Aufnahmerate dabei in den mit MATE1-pCMV-SPORT6 transfizierten Zellen höher als die mit MATE1-pEF/FRT/V5 transfizierten Zellen. Ursache könnten die verschiedenen Promotoren der Vektoren und eine unterschiedliche Effektivität der Transfektion sein (siehe 3.2). Da MATE1 Substrate gegen Protonen austauscht, ist seine Aktivität pHabhängig. Ein höherer extrazellulärer pH-Wert, also ein erhöhter auswärts gerichteter Protonengradient sollte demnach zu einer erhöhten Triebkraft für die $\left[{ }^{3} \mathrm{H}\right]-\mathrm{MPP}-$ Aufnahme führen, falls eine MATE1-vermittelte Aufnahme vorliegt. Dies wurde hier bei einem von 7,4 auf 8,5 erhöhten pH-Wert beobachtet und damit wurden die Ergebnisse von Otsuka und Tanihara bestätigt, die eine maximale Transportaktivität von MATE1 bei $\mathrm{pH} 8,5$ zeigten [118]. Als weiterer Beleg für eine funktionelle MATE1-Expression in den transient transfizierten HEK293-Zellen wurde eine Hemmung durch unmarkiertes MPP beobachtet. Die Begründung ist, dass durch den sehr viel höheren Anteil an unmarkiertem MPP sehr viel weniger markiertes Substrat an die Bindungsstellen der MATE1-Moleküle binden kann und so die Transportrate von [ $\left.{ }^{3} \mathrm{H}\right]-M P P$ verringert wird.

In mit MATE1-pEF5-FRT-Vektorkonstrukten stabil transfizierten Zellen konnten diese drei Ergebnisse ebenfalls reproduziert werden. Erstens lag eine MATE1-vermittelte [ $\left.{ }^{3} \mathrm{H}\right]-\mathrm{MPP}$ Aufnahme vor, welche etwa zweimal so hoch wie die in nicht exprimierenden Kontrollzellen war. Zweitens wurde auch in den stabil transfizierten Zellen bei pH 8,5 eine erhöhte $\left[{ }^{3} \mathrm{H}\right]-M P P-A u f n a h m e ~ g e m e s s e n$, die wie oben erwähnt einen Hinweis auf die MATE1-vermittelte Aufnahme gab. Die MATE1-vermittelte Aufnahme von $1 \mu \mathrm{M}\left[{ }^{3} \mathrm{H}\right]-\mathrm{MPP}$ bei $\mathrm{pH}$ 8,5 betrug nach 5-minütiger Aufnahme das 3,9-fache der Rate in Kontrollzellen. Tanihara et al haben dagegen eine 8,7-fache Aufnahme von 4 nM MPP nach 15-minütiger Aufnahme gezeigt. Diese im Vergleich zu unseren Ergebnissen höhere 
Aufnahme könnte an der längeren Transportzeit liegen. Drittens inhibierten die unmarkierten Substanzen MPP, TEA und Chinin die Aufnahme von [ $\left.{ }^{3} \mathrm{H}\right]-M P P$. TEA ist ebenfalls ein MATE1-Substrat [139], [157]. Tanihara et al. haben eine 2,3-fache Aufnahme von MPP im Vergleich zu TEA mit $K_{M}-$ Werten von 0,10 $\pm 0,02 \mathrm{mM}$ für MPP und 0,38 $\pm 0,07 \mathrm{mM}$ für TEA, aber keine Interaktion von MATE1 mit Chinin gezeigt. Wir haben eine Inhibierung der $\left[{ }^{3} \mathrm{H}\right]$-MPP-Aufnahme von etwa $86 \%$ durch $500 \mu \mathrm{M}$ unmarkiertes MPP und etwa $61 \%$ durch TEA bei pH 8,5 gefunden. Im Gegensatz zu den Ergebnissen von Tanihara et al. wurde in den in dieser Arbeit durchgeführten Experimenten zudem eine MATE1-vermittelte Inhibierung durch Chinin beobachtet.

In den in dieser Arbeit durchgeführten Experimenten lagen im Vergleich zu den in der Literatur beschriebenen Versuchen andere Bedingungen, wie Konzentration, Temperatur und Transportzeit vor [157], so dass kein direkter Vergleich der hier gewonnenen mit den in der Literatur beschriebenen Ergebnissen möglich ist [139], [157]. Die drei oben diskutierten Beobachtungen belegen aber eine Aktivität von MATE1 in den transfizierten HEK293-Zellen und die Zellen konnten für die weitere Charakterisierung von MATE1 genutzt werden.

Um weitere Kenntnisse zur Transportaktivität von MATE1 zu gewinnen, wurde untersucht, ob die MATE1-Aktivität an NHE3 gekoppelt ist. Dieser ist wie MATE1 in der luminalen Membran der proximalen Tubuluszellen exprimiert [10]. NHE3 transportiert Protonen aus Zellen heraus und nimmt im Austausch dazu Natriumionen in die Zellen auf. Der entstehende einwärts gerichtete Protonengradient könnte die Triebkraft für den im Effluxmodus transportierenden MATE1 darstellen.

In dieser Arbeit wurden Experimente an HEK293-Zellen durchgeführt, die auch NHE3 exprimierten [88]. Durch Inhibierung von NHE3 mit dem Hemmstoff Amilorid [36], bzw. der Senkung seiner Triebkraft durch natriumfreie Versuchslösungen, sollte eine erhöhte intrazelluläre Protonenkonzentration bewirkt werden. Die Folge einer Kopplung von NHE3 und MATE1 wäre eine erhöhte Aufnahme von $\left[{ }^{3} \mathrm{H}\right]-\mathrm{MPP}$ gewesen. Die Ergebnisse

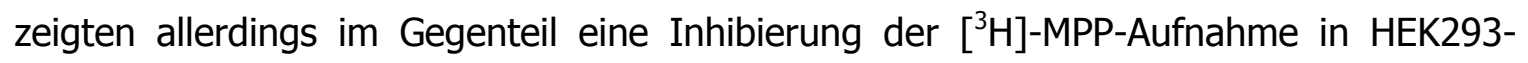
Zellen bei Abwesenheit von Natriumionen. Damit wurde, wie von Ohta und Imamura für das MATE1-Protein der Ratte, eine direkte Natriumabhängigkeit des humanen MATE1Transporters gezeigt [114]. Es konnte so aber nicht festgestellt werden, dass MATE1 mit NHE3 gekoppelt ist. Unter Anwesenheit von Amilorid war die $\left[{ }^{3} \mathrm{H}\right]-M P P-A u f n a h m e$ ebenfalls verringert anstatt erhöht, wie es bei einer Kopplung von NHE3 und MATE1 zu erwarten gewesen wäre. MATE1 ist also wie NHE3 sensitiv für Amilorid. Auf Grund dessen kationischer Struktur könnte es auch ein Substrat oder Inhibitor von MATE1 sein, 
da MATE1 vornehmlich Kationen transportiert [157]. Damit konnte auch mit diesem Versuchsansatz nicht nachgewiesen werden, dass NHE3 und MATE1 miteinander gekoppelt sind.

\subsubsection{Interaktion von MATE1 mit Zytostatika}

In Abschnitt 4.2.1.2.2 wurden die cis-Inhibierungs-Experimente der Aufnahme von $\left[{ }^{3} \mathrm{H}\right]$-MPP in MATE1-Zellen durch 28 Zytostatika beim physiologischen pH-Wert 7,4 beschrieben. Sieben Zytostatika übten eine signifikante Hemmung auf die Aufnahmerate des MATE1-Substrats $\left[{ }^{3} \mathrm{H}\right]$-MPP aus und könnten damit ein Substrat oder ein Inhibitor von MATE1 sein. Sie gehörten den Wirkstoffklassen Topoisomerasehemmstoffe, Interkalantien, Alkylantien, Hormonrezeptorantagonisten und Antimetabolite an. Die Ergebnisse bestätigen damit, dass MATE1 eine weite Substrat- und Inhibitorspezifität besitzt [118], [157], [159].

Im Folgenden werden die Ergebnisse der Interaktion von MATE1 mit diesen Zytostatika bei pH 7,4 im Hinblick auf einen möglichen Transport über MATE1 diskutiert. Die beiden Zytostatika Mitoxantron und Irinotecan inhibierten die $\left[{ }^{3} \mathrm{H}\right]$-MPP-Aufnahme um über $60 \%$ (Abb. 4-14 und Abb. 4-15). Mitoxantron ist sowohl ein Interkalans als auch ein Topoisomerasehemmstoff (siehe 1.4.1.3). Seine beiden symmetrischen basischen Aminogruppenpaare bestimmen seine pKs-Werte von etwa 6,0 und 8,3 [129]. Mitoxantron ist eine schwache Base und trägt bei pH 7,4 zwei positive Ladungen. Da MATE1 bevorzugt Kationen transportiert [118], besteht also die Möglichkeit, dass Mitoxantron von MATE1 transportiert wird. Ein Maß für die Affinität von MATE1 für Mitoxantron stellt der $\mathrm{IC}_{50}$-Wert dar. Der in dieser Arbeit bestimmte $\mathrm{IC}_{50}$-Wert von 7,8 \pm 2,9 $\mu \mathrm{M}$ für die Aufnahme von $\left[{ }^{3} \mathrm{H}\right]-\mathrm{MPP}$ ist denen, die für Metformin und TEA bestimmt wurden, von 4,4 $\pm 1,3 \mu \mathrm{M}$ und 5,2 $\pm 0,9 \mu \mathrm{M}$ sehr ähnlich [101]. Das Camptotecinderivat Irinotecan (siehe 1.4.1.4) wird enzymatisch in der Leber, aber auch in anderen Zellen zu SN38 hydrolysiert [130]. Seine Exkretion erfolgt größtenteils über die Galle [93]. Da MATE1 in der Leber exprimiert ist [118], könnte der SLC-Transporter also bewirken, dass Irinotecan ausgeschieden wird. Des Weiteren wurde gezeigt, dass die SLC22-Transporter OCT1, OCT2 [59] und OCT3 [150] mit Irinotecan interagieren. Drittens wurde für das strukturell sehr ähnliche Camptothecinderivat Topotecan gezeigt, dass es ein Substrat von MATE1 ist [157]. Diese drei Gründe sprechen dafür, dass Irinotecan ebenfalls ein Substrat von MATE1 ist. Bisher sind noch keine Ergebnisse für die Interaktion von MATE1 mit Irinotecan bekannt. In dieser Arbeit wurde diese Interaktion mit einem $\mathrm{IC}_{50^{-}}$ Wert von 4,4 $\pm 2,3 \mu \mathrm{M}$ belegt, der dem $\mathrm{IC}_{50}$-Wert für Mitoxantron sehr ähnlich ist (siehe oben). 
Zwei weitere mit MATE1 interagierende Zytostatika waren Doxorubicin (Abb. 4-14) und Etoposid (siehe Abb. 4-15). Der Wirkmechanismus von Doxorubicin ist noch nicht vollständig aufgeklärt. Es wirkt sowohl als Interkalans als auch als Topoisomerasehemmstoff (siehe 1.4.1.3) und bildet außerdem nach Reduktion des Chinonteils zu Hydrochinon reaktive Sauerstoffspezies, die zu DNA-Strangbrüchen führen [103]. Doxorubicin besitzt für die Hydroxygruppen des Hydrochinonanteils einen $\mathrm{pK}_{\mathrm{s}}$-Wert von etwa 7,8 und für die Aminogruppe einen $\mathrm{pK}_{\mathrm{s}}$-Wert von etwa 8,4 (berechnet mit Sparc,

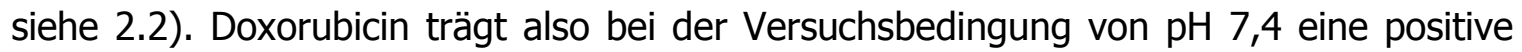
Ladung und könnte ein Substrat von MATE1 darstellen. Dass Doxorubicin über SLCTransporter mit einer Substratspezifität für Kationen transportiert werden kann, wurde bereits für OCTN1 und OCT6 beschrieben [115], [116].

Weitere Zytostatika, die mit MATE1 interagierten, waren das Alkylans Bendamustin und der Estrogenrezeptorantagonist Tamoxifen (siehe Abb. 513 und Abb. 5 15). Die Interaktion von MATE1 und Bendamustin ist, wenn man dessen Struktur betrachtet, unerwartet. Bendamustin ist eine schwache Säure, die bei $\mathrm{pH} 7,4$ negativ geladen ist ( $\mathrm{pK}_{\mathrm{S}}$-Wert der Carboxylgruppe $=4,5$, berechnet mit Sparc). In diesem Fall wird bestätigt, dass MATE1 auch mit weiteren Anionen, außer z. B. Estronsulfat, wie von Tanihara et al. gezeigt, interagieren kann [132]. Tamoxifen besitzt einen $\mathrm{pK}_{\mathrm{S}}$-Wert von etwa 8,5 und ist beim pH-Wert 7,4 positiv geladen (berechnet mit Sparc), könnte also in dieser Hinsicht von MATE1 transportiert werden. Ein weiteres Zytostatikum interagierte beim pH-Wert 7,4 mit MATE1, das Nukleosidanalogon Fludarabin (siehe Abb. 5 14). Die Interaktion ist zwar signifikant, jedoch ist sie verglichen mit den anderen Zytostatika gering und daher bei der Untersuchung von MATE1 nicht weiter von Bedeutung.

Die voranstehende Diskussion zeigt, dass MATE1 bei dem pH-Wert 7,4 ein Transporter der anfangs in diesem Abschnitt genannten Zytostatika sein könnte. Die Experimente zur Interaktion von MATE1 mit Zytostatika wurden nicht nur beim physiologischen pH-Wert 7,4, sondern auch bei $\mathrm{pH} 8,5$ durchgeführt, um die Interaktionen mit MATE1 besser identifizieren zu können. Wie von Otsuka et al. beschrieben und in dieser Arbeit in Abschnitt 5.2.1.1.2 bestätigt wurde, besaß MATE1 bei diesem $\mathrm{pH}$-Wert eine höhere Aktivität (Otsuka). Die Untersuchungen wurden besonders im Hinblick auf die Möglichkeit des MATE1-vermittelten Zytostatikatransports bei Tumorzellen durchgeführt. Tumore weisen eine saure extrazelluläre Umgebung auf (Gerweck), besitzen also einen nach innen gerichteten Protonengradienten. MATE1 würde also unter diesen Bedingungen Protonen aufnehmen und Zytostatika heraustransportieren. Um die Erkenntnisse der untersuchten Zellsysteme auf diese Bedingungen zu übertragen, 
müsste demnach ein extrazellulär saures Millieu geschaffen und die intrazelluläre Inhibierung der Zytostatika auf die Effluxrate von [ $\left.{ }^{3} \mathrm{H}\right]$-MPP gemessen werden. Da dies experimentell sehr schwierig war, wurden in dieser Arbeit stattdessen Aufnahmeexperimente bei erhöhtem extrazellulären $\mathrm{pH}$ von 8,5 durchgeführt und die Inhibierung $\operatorname{der}\left[{ }^{3} \mathrm{H}\right]$-MPP-Aufnahme durch von außen auf die Zellen gegebene Zytostatika bestimmt. Dies war zulässig, da wie schon erwähnt Dangprapai et al. zeigten, dass MATE1 nicht nur ein bidirektionaler, sondern auch ein symmetrischer Transporter ist, dessen Transportkinetik für den Influx sich nicht von der des Efflux unterscheidet [29].

Bei der Auswertung der oben genannten radioaktiven Aufnahmeversuche bei $\mathrm{pH}$ 8,5 fiel auf, dass die Hemmung der MATE1-vermittelten [ $\left.{ }^{3} \mathrm{H}\right]$-MPP-Aufnahme durch Zytostatika gegenüber der bei pH 7,4 verstärkt war (siehe z. B. Abb. 4-13 b).

Diese erhöhte Hemmung der [ $\left.{ }^{3} \mathrm{H}\right]$-MPP-Aufnahmerate durch Zytostatika bei pH 8,5 lässt sich folgendermaßen erklären. Die $\left[{ }^{3} \mathrm{H}\right]$-MPP-Aufnahmerate setzt sich zusammen aus einem MATE1-abhängigen Anteil und einem Anteil, der durch andere Effekte hervorgerufen wird. Beim pH-Wert 8,5 ist die Triebkraft durch den größeren Protonen-

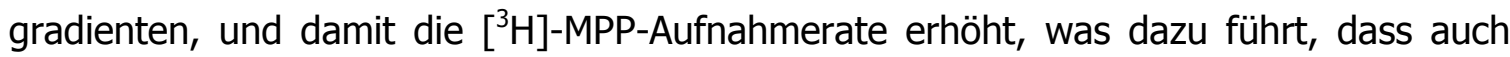
die Hemmung durch Zytostatika erhöht wird. Das trifft auf alle untersuchten Zytostatika bis auf Tamoxifen zu. Zusätzlich interagierten bei diesem $\mathrm{pH}-$ Wert auch die Vincaalkaloide Vinblastin, Vincristin und Vindesin mit MATE1 (siehe Abb. 5 15), die als Mitosehemmstoffe wirken. Für Doxorubicin und Etoposid fällt auf, dass die Hemmung bei pH 8,5 sehr viel stärker ist als bei $\mathrm{pH} 7,4$. Hiefür sind vermutlich zusätzlich andere Effekte die Ursache.

Es ist zweitens möglich, dass eine Affinitätsänderung der Zytostatika gegenüber MATE1 durch eine Strukturänderung der Zytostatikummoleküle bei der pH-Wert-Erhöhung auf 8,5 auftritt. Für Irinotecan ist die Strukturänderung nachgewiesen [42], so dass es fast komplett in seiner Carboxylatform vorliegt. MATE1 interagiert also verstärkt mit dieser Form von Irinotecan, da die Interaktion bei pH 8,5 erhöht ist.

Durch die pH-Wert-Erhöhung kommt es zu einer Ladungsänderung einiger Zytostatika zu negativeren Werten gegenüber der Ladung bei $\mathrm{pH}$ 7,4. MATE1 besitzt aber eine bevorzugte Substratspezifizität für Kationen [132]. Es ist aus diesem Grund unwahrscheinlich, dass die Zytostatikamoleküle bei pH 8,5 eine erhöhte Affinität zu MATE1 aufweisen. Deshalb kann die beobachtete erhöhte Hemmung durch einige Zytostatika nicht mit einer Affinitätsänderung erklärt werden. 
Anders verhält es sich für das Zytostatikum Tamoxifen: Dieses interagierte bei $\mathrm{pH}$ 8,5 geringer mit MATE1 als bei $\mathrm{pH}$ 7,4. Tamoxifen mit einem $\mathrm{pK}_{\mathrm{s}}$-Wert von 8,5 (Sparc) ändert dabei seine Ladung auch zu negativeren Werten, das heißt, von positiv geladen zu vorwiegend neutral. Im Fall von Tamoxifen könnte also die bevorzugte Substratspezifität von MATE1 für Kationen die verringerte Hemmung bei pH 8,5 erklären.

Neben der Interaktion von Zytostatika mit MATE1 wurden bei den radioaktiven Aufnahmeexperimenten noch weitere Beobachtungen gemacht. So trat auch eine leichte Hemmung der Aufnahmerate von $\left[{ }^{3} \mathrm{H}\right]-M P P$ in Kontrollzellen auf. Dies ist damit zu erklären, dass HEK293-Zellen endogene Transporter exprimieren. Ahlin et al. zeigten, dass OCT2 in HEK293-Zellen leicht exprimiert ist [4].

Einige Zytostatika, wie z. B. Estramustin, inhibierten die $\left[{ }^{3} \mathrm{H}\right]-\mathrm{MPP}-A u f n a h m e$ in MATE1HEK293-Zellen nicht, sondern stimulierten sie (Abb. 4-15). Dies ist durch das als Natriumphosphat vorliegende Estramustin zu erklären, welches basisch reagiert, also zu einer extrazellulären pH-Erhöhung und damit Erhöhung der MATE1-Aktivität führen könnte.

Bei den Experimenten zur $\mathrm{IC}_{50}$-Bestimmung fiel auf, dass die $\left[{ }^{3} \mathrm{H}\right]$-MPP-Aufnahme durch Mitoxantron und Irinotecan nicht zu $100 \%$ gehemmt werden konnte. Der nicht hemmbare, MATE1-unspezifische Anteil könnte unter anderem durch endogene Transporter wie den schwach exprimierten OCT2 [4]oder durch Diffusion entstanden sein.

\subsubsection{MATE1-vermittelte Zytotoxizität}

Bei den Experimenten zur MATE1-vermittelten Zytotoxizität wurden die Zytostatika getestet, welche beim pH-Wert 7,4 oder 8,5 eine Hemmung der $\left[{ }^{3} \mathrm{H}\right]$-MPP-Aufnahme um über $50 \%$ aufwiesen. Es wurden die Inkubationszeiten variiert um ein Zeitfenster zu bestimmen, in dem die Inkubation weder zu kurz war, so dass noch keine Wirkung eintreten konnte, noch zu hoch, als dass vorwiegend andere Aufnahmewege in die Zellen genutzt wurden. Unter einer Inkubationszeit von 15 min trat kein Effekt auf. Bereits bei 15-minütiger Inkubation war ein Effekt auf MATE1- und auf Kontrollzellen messbar. Jedoch konnte nur bei den Zytostatika Irinotecan und Mitoxantron eine tendenzielle, aber nicht signifikante MATE1-vermittelte Zytotoxizität beobachtet werden. Die nachfolgenden Versuche zur pH-Abhängigkeit der Zytotoxizität wurden durchgeführt, um eine MATE1-vermittelte Zytotoxizität eindeutig erkennen zu können, da seine Aktivität, wie bereits erwähnt, von einem Protonengradienten abhängig ist [118]. 
Für Doxorubicin ergibt sich eine pH-abhängige jedoch MATE1-unabhängige Zytotoxizität. Wahrscheinlich ist, dass der pH-Wert einen Einfluss auf die Struktur von Doxorubicin besitzt. Zusammen mit den Ergebnissen zur Interaktion von Doxorubicin mit MATE1 (siehe Abb. 4-14) und der direkten Fluoreszenzmessung des aufgenommenen Doxorubicins (siehe Abb. 4-20) ergibt sich, dass Doxorubicin MATE1 entweder inhibiert oder ein anteiliger Transport von Doxorubin über MATE1 stattfindet. Für einen Transport sprechen die tendenziellen Aufnahmeergebnisse der Durchflusszytometriemessung und die MATE1-vermittelte Interaktion und dass, wie bereits erwähnt, andere SLCTransporter mit einer Substratspezifität für Kationen, OCTN1 und OCT6, Doxorubicin transportieren [115], [116]. Ota et al. wiesen nach, dass Eierstockkrebszellen bei OCT6Expression sensitiver für Doxorubicin waren [117]. Gegen einen alleinigen MATE1vermittelten Doxorubicintransport und für eine Inhibierung von MATE1 spricht, dass es hinsichtlich der Zytotoxizität keinen Unterschied zwischen MATE1- und Kontrollzellen gab. Zusammengefasst zeigen die Ergebnisse zum MATE1-vermittelten Doxorubicintransport, dass es vermutlich einen anteiligen Transport, aber auch noch andere, hier nicht aufgeklärte Transportmechanismen gibt.

Für Etoposid wurde nach 15-minütiger Inkubation unabhängig vom pH-Wert keine signifikante Zytotoxizität bestimmt. Eine zu geringe Inkubationszeit könnte der Grund dafür sein, jedoch war bei längeren Inkubationszeiten eine Zytotoxizität für MATE1- und nicht exprimierende Kontrollzellen messbar. Wie bei Doxorubicin wäre auch hier ein anteiliger Transport über MATE1 denkbar, dem allerdings ein Efflux über $A B C$ Transporter folgen könnte, die in HEK293-Zellen exprimiert sind [4]. Bei längerer Inkubationszeit würden andere Aufnahmewege überwiegen. Natürlich ist es auch im Fall von Etoposid möglich, dass MATE1 inhibiert wird, ohne dass Etoposid transportiert wird.

Auf den ersten Blick liefern die eigenen Untersuchungen noch keine eindeutige Antwort auf die Frage, ob MATE1 Irinotecan transportiert. Unter Berücksichtigung der Ergebnisse zur Interaktion von MATE1 mit Irinotecan kann man Folgendes vermuten:

Irinotecan wird nicht von MATE1 transportiert, sondern inhibiert das SLC-Protein. Die Inhibierung würde entweder durch Lacton- und Carboxylatfrom von Irinotecan oder nur durch die inaktive Carboxylatform verursacht werden, da sie bei pH 7,4 etwa zur Hälfte, bei pH 8,5 ausschließlich vorliegt [42]. Eine Inhibierung würde die fehlende Zytotoxizität nach 15-minütiger Inkubation in MR bei verschiedenen pH-Werten erklären (Abb. 4-26). Sie würde jedoch nicht erklären, warum die Zytotoxizitätstests im Medium bei 15 min eine Zytotoxizität ergaben, die tendenziell in MATE1-Zellen im Vergleich zu Kontrollzellen erhöht ist (Abb. 4-25). Eine Erklärung für diese Beobachtung wäre eine MATE1- 
vermittelte intrazelluläre Aufnahme des Irinotecanmetaboliten SN38. Die radioaktiven Aufnahmeexperimente und die Zytotoxizitätstests zur pH-Abhängigkeit wurden in MR durchgeführt, die WST-Tests zur Abhängigkeit der Inkubationszeit aber in Medium. Dieser experimentelle Unterschied könnte der Grund für die unterschiedliche Zytotoxizität sein. Das verwendete Zellkulturmedium enthielt fetales Kälberserum (FCS) mit etwa 1000 Inhaltsstoffen, die noch nicht alle identifiziert sind [141]. Darunter könnten auch Carboxylesterasen sein, Enzyme, die Irinotecan zu SN38 metabolisieren [130]. Im Unterschied dazu findet keine Metabolisierung in MR statt. Der Effekt der MATE1-vermittelten Zytotoxizität könnte deswegen nicht signifikant sein, weil SN38 eventuell zusätzlich andere Wege in die Zelle nimmt, z. B. über in HEK293-Zellen exprimierte endogene Transporter, wie OCTN2 und OATPE [4].

Eine andere Vermutung ist, dass Irinotecan zwar über MATE1 in die Zellen aufgenommen wird, dem jedoch ein Efflux über die in HEK293-Zellen exprimierten Effluxproteine MDR1 und MRP1 folgt [4]. Um die Frage des MATE1-vermittelten Transports über Irinotecan endgültig zu klären, müssten weitere Experimente durchgeführt werden, wie z. B. die direkte Messung von eventuell aufgenommenem Irinotecan und SN38 über HPLC.

Für Mitoxantron wurden Dosis-Wirkungs-Kurven angefertigt, da dieses Zytostatikum eine sehr hohe Hemmung bei radioaktiven Aufnahmeexperimenten mit $\left[{ }^{3} \mathrm{H}\right]-\mathrm{MPP}$ zeigte (Abb. 4 14). Die halbmaximale Zytotoxizität ( $\mathrm{EC}_{50}$-Wert) der MATE1-Zellen war halb so groß wie die der Kontrollzellen (Abb. 4 27). MATE1 übte also eindeutig einen Effekt auf die durch Mitoxantron ausgelöste Zytotoxizität aus. Falls eine ausschließlich durch MATE1 vermittelte Zytotoxizität vorgelegen hätte, wäre sie auf Grund der schon erwähnten pH-Abhängikeit der MATE1-Transportaktivität bei $\mathrm{pH}$ 5,5 am geringsten und bei $\mathrm{pH} 8,5$ am höchsten gewesen und zusätzlich in den MATE1-Zellen erhöht. Hier wurden keine pH-abhängige Zytotoxizität und keine erhöhte absolute Zytotoxizität in MATE1-Zellen beobachtet. Es könnte demnach eine anteilige, jedoch keine ausschließliche MATE1-vermittelte Zytotoxizität vorliegen. Möglicherweise ist ein weiterer Transporter an der Mitoxantronaufnahme beteiligt. Pan et al. beschreiben eine Transporter-vermittelte Mitoxantronaufnahme in MDCKII-Zellen [120]. Sie vermuten weiter, dass OCTN2 dieser Transporter sein könnte. OCTN2 ist auch in HEK293-Zellen exprimiert [4]. Also könnte dieser SLC-Transporter möglicherweise einen weiteren Transportweg für Mitoxantron in den hier eingesetzten HEK293-Zellen darstellen. Davon abgesehen kann die Möglichkeit einer reinen Inhibierung von MATE1 durch Mitoxantron nicht ausgeschlossen werden. 


\subsubsection{Physiologische und pharmakologische Bedeutung von MATE1}

In dieser Arbeit wurde gezeigt, dass MATE1 in Melanomzelllinien exprimiert ist. Wie schon erklärt, ist MATE1 ein bidirektionaler Transporter, der abhängig vom pH-Wert Substrate in Zellen hinein- oder aus ihnen heraustransportieren kann. Tumorzellen von soliden Tumoren besitzen in ihrer extrazellulären Umgebung einen kleineren $\mathrm{pH}$-Wert als in ihrem Inneren. [50]. MATE1 würde, falls er in Tumorzellen aktiv ist, im Effluxmodus wirken und Zytostatika heraustransportieren. Damit könnte er zur Resistenz der Tumorzellen beitragen.

Neben dieser möglichen ungünstigen Eigenschaft könnte MATE1 auch die Ursache weiterer Probleme bei der Krebstherapie sein. Es kann nämlich im menschlichen Körper durch die Interaktion von Zytostatika mit MATE1 zu Pharmakawechselwirkungen, speziell pharmakokinetischen Wechselwirkungen, kommen. Damit bezeichnet man die Beeinflussung der Aufnahme, Verteilung oder Ausscheidung eines Moleküls durch ein anderes Molekül [14], [143]. Pharmakokinetische Wechselwirkungen unter Beteiligung von MATE1 könnten besonders in den Ausscheidungsorganen Leber und Niere sowie im Skelettmuskel auftreten, in deren Zellen MATE1 hoch exprimiert ist [99], [118]. MATE1 vermittelt den Efflux sehr verschiedener Substanzen, darunter endogene Substanzen und exogene Substanzen wie Toxine und Medikamente. Daher können Pharmakawechselwirkungen mit MATE1 mit der Folge der Störung seiner Transportaktivität schwerwiegende Auswirkungen haben. Direkte toxische Wirkungen durch Anreicherung von Toxinen oder Störungen des Ionenhaushalts wären möglich, da MATE1 besonders Kationen transportiert.

Es wurde bereits mehrfach beschrieben, dass Transportproteine an Pharmakawechselwirkungen in Leber und Niere beteiligt sind [73], [183]. Pharmakawechselwirkungen unter Beteiligung von MATE1 wurden in vitro bei der Inhibierung der MATE-vermittelten Metforminaufnahme durch Cimetidin in renalen Epithelzellen beschrieben [163]. Außerdem wiesen Kusuhara et al. Pharmakawechselwirkungen mit MATE1 nach. In vitro zeigten sie die verminderte Metforminaufnahme in kanalikulären Membranvesikeln durch Pyrimethamin und in vivo führte die Anwesenheit von Pyrimethamin zur Inhibierung der renalen Metformin-Clearance und Kreatinin-Clearance [86]. In einer Studie am Menschen wurde von Imamura et al. eine Inhibierung der MATE1- und MATE2-vermittelten Kreatininsekretion durch das Fluorochinolon DX-619 beobachtet [69]. Es ist daher wahrscheinlich, dass auch die in dieser Arbeit 
nachgewiesenen Interaktionen von MATE1 mit Zytostatika Pharmakawechselwirkungen auslösen können.

Von physiologischer und pharmakologischer Bedeutung ist auch das Zusammenwirken von MATE1 mit anderen Transportern. Dies ist in Nieren- und Leberzellen bei verschiedenen Substanzen beobachtet worden und könnte auch bei den in dieser Arbeit behandelten Zytostatika der Fall sein. Der andere SLC-Transporter übernimmt dabei denn ersten Schritt der Sekretion, die Aufnahme der Substanz vom Blut in die Zellen, und MATE1 den zweiten Schritt, die Abgabe in den Urin und die Galle. Da MATE1 sowohl in der luminalen Membran der proximalen Tubuluszellen, als auch in der kanalikulären Membran der Hepatozyten exprimiert ist [118] und dort vermutlich für die Exkretion der Zytostatika in Urin bzw. Galle verantwortlich ist, stellt sich die Frage, wie die Zytostatika in diese Zellen aufgenommen werden. Falls sie über Transporter in die Zellen aufgenommen werden, könnte MATE1 also mit diesen bei der Sekretion der Zytostatika zusammenwirken. Ein Zusammenspiel wurde bereits mit OCT2 von König et al. für die renale Clearance von Metformin gezeigt [81]. Lai et al. wiesen sogar in vivo bei der Ratte und beim Affen nach, dass MATE1 beim Transport des Antibiotikums PN-288034 mit OAT3 gekoppelt ist [87]. Einen Hinweis auf die Kollaboration von MATE1 mit anderen Transportern beim Transport von Zytostatika fanden Nakamura et al. und Filipski et al.. Sie zeigten, dass MATE1-knockout-Mäuse eine erhöhte Nephrotoxizität für das Zytostatikum Cisplatin aufwiesen [109] bzw., dass OCT2-knockout-Mäuse eine verringerte cisplatin-induzierte Nephrotoxizität aufwiesen [44]. Es ist also wahrscheinlich, dass diese beiden Transporter beim Cisplatin-Transport zusammenwirken.

Es ist daher möglich, dass MATE1 auch beim Transport der in dieser Arbeit diskutierten, mit MATE1 interagierenden Zytostatika mit weiteren SLC-Transportern zusammenwirkt. Abb. 5-1 gibt eine Übersicht über Transporter, die wie MATE1 in den proximalen Tubuluszellen (a) und den Hepatozyten (b) exprimiert sind. 

a) Proximale Tubuluszelle
b) Hepatozyt

luminale

basolaterale

Membran

Urin

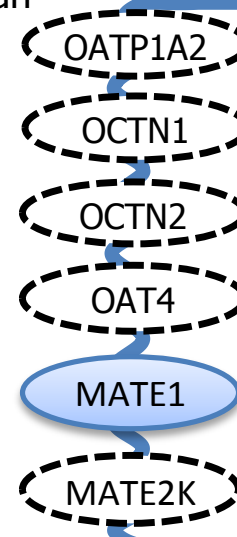

Membran

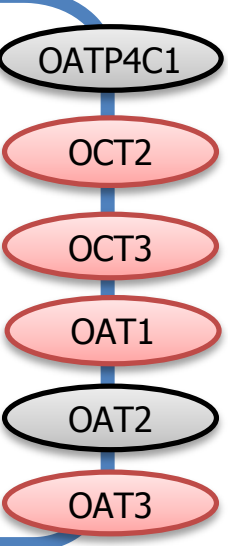

OATP1A2

OATP1B1

OATP2B1

OATP1B3

OCT1

ОСТ3

OCTN2

OAT2
MATE1

kanalikuläre

Membran

Galle

Abb. 5-1: Kandidaten für ein Zusammenspiel mit MATE1 beim Zytostatikatransport:

Mitglieder der SLC21-, SLC22- und SLC47-Familie, die wie MATE1 in den proximalen Tubuluszellen (a) oder Hepatozyten (b) exprimiert sind; mit denselben Zytostatika wie MATE1 interagierende SLC-Transporter (rot), in der gegenüberliegenden Zellmembran exprimierte Transporter (grau), in derselben Membran exprimierte (gestrichelt); basolaterale Membranen: Transport zwischen Blut und Zelllumen, luminale Membran der proximalen Tubuluszellen: Transport zwischen Zelllumen und Urin; kanalikuläre Membran der Hepatozyten: Transport zwischen Zelllumen und Galle [61], [70], [79], [131], [160]

Geeignet für ein Zusammenspiel mit MATE1 sind die Transporter, die in der gegenüberliegenden Membran von MATE1, also der basolateralen Membran der proximalen Tubuluszellen und der sinusoidalen (basolateralen) Membran der Hepatozyten exprimiert sind (Abb. 5-1, grau und rot). Besonders geeignet sind die Transporter, von denen bekannt ist, dass sie mit denjenigen Zytostatika interagieren, die auch mit MATE1 interagieren (Abb. 5-1, rot, Tab. 5-1). OCT1, OCT2 und OCT3 interagieren beispielsweise mit Mitoxantron, Irinotecan und Etoposid [59], [150]. In der Niere ist daher ein Zusammenwirken von MATE1 mit OCT2 und OCT3 bei der Sekretion dieser Zytostatika denkbar (Abb. 5-1). In der Leber könnte MATE1 bei der Sekretion dieser Zytostatika mit OCT1 zusammenwirken (Abb. 5-1 b). In der Niere ist zudem ein Zusammenwirken von MATE1 mit OAT3 beim Transport von Bendamustin mit OCT3 und OAT1 beim Transport von Tamoxifen möglich [59], [150]. 
Tab. 5-1: Mögliche Transporter-Kandidaten für ein Zusammenspiel mit MATE1

\begin{tabular}{|l|l|l|l|l|l|l|}
\hline $\begin{array}{l}\text { Interagierendes } \\
\text { Zytostatikum }\end{array}$ & OCT1 & OCT2 & OCT3 & OAT1 & OAT3 & OCTN1 \\
\hline Mitoxantron & + & + & + & - & + & + \\
\hline Irinotecan & + & + & + & u & u & u \\
\hline Doxorubicin & $\mathrm{u}$ & $\mathrm{u}$ & - & $\mathrm{u}$ & $\mathrm{u}$ & + \\
\hline Etoposid & + & + & + & $\mathrm{u}$ & $\mathrm{u}$ & $\mathrm{u}$ \\
\hline Bendamustin & - & - & - & - & + & $\mathrm{u}$ \\
\hline Tamoxifen & $\mathrm{u}$ & $\mathrm{u}$ & + & + & - & $\mathrm{u}$ \\
\hline
\end{tabular}

Transporter der SLC22-Familie, die in der basolateralen Membran der proximalen Tubuluszellen oder der Hepatozyten exprimiert sind und mit den Zytostatika interagieren, die auch mit MATE1 interagieren; + = Interaktion, - = keine Interaktion, u = unbekannt [59], [115], [116], [149]

Weitere Transportproteine, die als Kandidaten für ein Zusammenwirken mit MATE1 in Frage kommen, sind die in den proximalen Tubuluszellen oder Hepatozyten exprimierten Transporter, von denen bekannt ist, dass sie andere Zytostatika oder andere Medikamente transportieren, also vornehmlich Mitglieder der SLC21- und SLC22-Familie (Abb. 5-1, grau) [61], [70], [79], [131], [160]. In der Leber könnten dies vor allem OATPC (OATP1B1) und OATP8 (OATP1B3) sein, die Methotrexat transportieren; OATPC transportiert zusätzlich Paclitaxel [2], [152]. Der in der basolateralen Membran der proximalen Tubuluszellen lokalisierte OATP4C1 transportiert auch Methotrexat [61].

Außerdem könnte MATE1 auch mit Transportern im Skelettmuskel zusammenwirken. Da diese Zellen jedoch keinen Ausscheidungsweg für Zytostatika darstellen, sind sie unter dieser Betrachtung weniger von Bedeutung. Erwähnt sei allerdings, dass der im Skelettmuskel exprimierte Transporter OCTN1 [75] Mitoxantron und Doxorubicin in die Zellen aufnehmen kann [115]. MATE1 könnte sie ebenfalls aufnehmen oder wieder aus diesen Zellen heraustransportieren und so Nebnwirkungen von Mitoxantron und Doxorubicin beeinflussen.

Zuletzt ist darauf hinzuweisen, dass es Transportproteine gibt, die in derselben Membran der proximalen Tubuluszellen und Hepatozyten exprimiert sind (Abb. 5-1, gestrichelt) und daher für die mit MATE1-interagierenden Zytostatika ebenfalls wie MATE1 den Efflux in Urin oder Galle vermitteln können. In der luminalen Membran der proximalen Tubuluszellen sind das MATE2, OCTN1, OCTN2 und OAT4 und sowohl in proximalen Tubuluszellen als auch Hepatozyten sind es ABC-Transporter, die auch eine Vielzahl an Zytostatika transportieren [183]. 


\subsection{Ausblick}

Es wurde im Rahmen der Arbeit festgestellt, dass der SLC-Transporter ENT2 in Melanomzellen im Vergleich zu nicht entarteten Melanozyten erhöht exprimiert ist. Er könnte sich als Transporter in der zielgerichteten Krebstherapie eignen. Da ENT2 bereits aus der Literatur als Transporter der Nukleosidanaloga bekannt ist, wäre der nächste Schritt, zu zeigen, ob eine ENT2-vermittelte Zytotoxizität in den untersuchten Zellen vorliegt, ob also die Zytotoxizität bei Behandlung mit Zytostatika der Nukleosidanaloga in den Melanomzellen höher als in den Melanozyten ist. Bei positivem Ergebnis könnte dann zu Invivo-Experimenten an Mäusen übergegangen werden.

Ein weiteres Ergebnis war die Beobachtung, dass Transporter der OATP-Familie eine innerhalb der untersuchten Zellen sehr differentielle Expression aufwiesen. Sie sind aber in den untersuchten Melanomzellinien insgesamt nicht ausreichend hoch exprimiert, um als Zytostatikatransporter dienen zu können. Es wäre sinnvoll, die Untersuchungen auf weitere Melanomzelllinien und primäre Melanomzellen auszuweiten, mit der Intention, dort auch ausreichend hoch exprimierte OATP-Transporter zu finden.

OCT1 wies eine Interaktion mit Nimustin und Temozolomidmetaboliten auf, jedoch wurden keine sicheren Ergebnisse gewonnen, die es erlaubten zu entscheiden, ob OCT1 diese Substanzen in Zellen aufnimmt. Es wäre besonders hilfreich, die aufgenommene Zytostatikum- oder Metabolitmenge direkt, z. B. mit HPLC und MS, zu messen.

MATE1 interagierte mit den Zytostatika Mitoxantron, Irinotecan, Doxorubicin und Etoposid. Die Interaktionen der Zytostatika mit MATE1 können zu Pharmakawechselwirkungen führen. Hier wäre es angebracht, die Einflüsse der Zytostatika auf bekannte, von MATE1 transportierte Medikamente wie Metformin, zunächst in vitro und anschließend in vivo in Mäusen zu untersuchen.

Die Versuche zur MATE1-vermittelten Zytotoxizität lieferten keine endgültige Aussage über eine MATE1-vermittelte Aufnahme der Zytostatika in die Zellen. Gerade mit Mitoxantron, für das ein eindeutiger Anteil der MATE1-vermittelten Zytotoxizität gemessen wurde, wären weitere Versuche angebracht, um Sicherheit zu gewinnen, ob der Transport über MATE1 tatsächlich stattgefunden hat. Hierbei bieten sich direkte radioaktive Transportexperimente mit radioaktiv markiertem Zytostatikum oder HPLC und MS an.

MATE1 könnte, falls ein Zytostatikumtransport vorliegt, mit anderen SLC-Transportern zusammenwirken. Um diese Vermutungen zu bestätigen, sind Messungen mit doppelt transfizierten Zellen, welche sowohl MATE1 als auch den möglicherweise mit ihm zusammenwirkenden zweiten Transporter exprimieren, durchzuführen. 


\section{Literatur}

[1] Abdel-Haleem, A. M. ; El-Zeiry, M. I. ; Mahran, L. G. ; Abou-Aisha K. ; Rady, M. H. ; Rohde, J. ; Mostageer, M. ; Spahn-Langguth, H.: Expression of RFC/SLC19A1 is associated with tumor type in bladder cancer patients. In: PLoS One 6 (2011), Nr. 7, S. 1-7

[2] Abe, T. ; Unno, M.: LST-2, a human liver-specific organic anion transporter, determines methotrexate sensitivity in gastrointestinal cancers. In: Gastroenterology 120 (2001), S. 1689-1699

[3] Agarwala, S. S. ; Kirkwood, J. M.: Temozolomide, a novel alkylating agent with activity in the central nervous system, may improve the treatment of advanced metastatic melanoma. In: Oncologist 5 (2000), Nr. 2, S. 144-151

[4] Ahlin, G. ; Hilgendorf, C. ; Karlsson, J. ; Szigyarto, C. A. ; Uhlén, M. ; Artursson, P.: Endogenous gene and protein expression of drug-transporting proteins in cell lines routinely used in drug discovery programs. In: Drug. Metab. Dispos. 37 (2009), Nr. 12, S. 2275-2283

[5] Aktories, K. ; Förstermann, U. ; Hofmann, F. ; Starke, K.: Pharmakologie und Toxikologie. 9. überarb. Aufl. München : Urban \& Fischer, 2005

[6] Alberts, B. ; Johnson, A. ; Lewis, J. ; Raff, M. ; Roberts, K. ; Walter, P.: Molecular biology of the cell. 4. Aufl. New York : Garland Science, 2002

[7] Alebouyeh, M. ; Takeda, M. ; Onozato, M. L. ; Tojo, A. ; Noshiro, R. ; Hasannejad, H. ; Inatomi, J. ; Narikawa, S. ; Huang, X. L. ; Khamdang, S. ; Anzai, N. ; Endou, $\mathrm{H}$.: Expression of human organic anion transporters in the choroid plexus and their interactions with neurotransmitter metabolites. In: J. Pharmacol. Sci. 93 (2003), Nr. 4, S. 430-436

[8] Ambudkar, S. V. ; Dey, S. ; Hrycyna, C. A. ; Ramachandra, M. ; Pastan, I. ; Gottesman, M. M.: Biochemical, cellular, and pharmacological aspects of the multidrug transporter. In: Annu. Rev. Pharmacol. Toxicol. 39 (1999), S. 361-398

[9] Aouida, M. ; Poulin, R. ; Ramotar, D.: The human carnitine transporter SLC22A16 mediates high affinity uptake of the anticancer polyamine analogue bleomycin-A5. In: J. Biol. Chem. 285 (2010), Nr. 9, S. 6275-6284 
[10] Aronson, P. S.: Ion exchangers mediating $\mathrm{NaCl}$ transport in the proximal tubule. In: Wien. Klin. Wochenschr. 109 (1997), Nr. 12-13, S. 435-440

[11] Baldwin, S. A. ; Beal, P. R. ; Yao, S. Y. ; King, A. E. ; Cass, C. E. ; Young, J. D.: The equilibrative nucleoside transporter family, SLC29. In: Pflügers Arch. - Eur. J. Physiol. 447 (2004), Nr. 5, S. 735-743

[12] Ballestero, M. R. ; Monte, M. J. ; Briz, O. ; Jimenez, F. ; Gonzalez-San Martin F. ; Marin, J. J.: Expression of transporters potentially involved in the targeting of cytostatic bile acid derivatives to colon cancer and polyps. In: Biochem. Pharmacol. 72 (2006), Nr. 6, S. 729-738

[13] Bennett, D. C. ; Medrano, E. E.: Molecular regulation of melanocyte senescence. In: Pigment Cell Res. 15 (2002), S. 242-250

[14] Beynen, J. H. ; Schellens, J. H.: Drug interactions in oncology. In: Lancet Oncol. 5 (2004), Nr. 8, S. 489-496

[15] Burckhardt, B. C. ; Burckhardt, G.: Transport of organic anions across the basolateral membrane of proximal tubule cells. In: Rev. Physiol. Biochem. Pharmacol. 146 (2003), S. 95-158

[16] Burckhardt, G. ; Burckhardt, B. C.: In vitro and in vivo evidence of the importance of organic anion transporters (OATs) in drug therapy. In: Fromm, M. F. ; Kim, R. B.: Drug Transporters. Handb. Exp. Pharmacol. 201, Berlin : Springer, 2011, S. 29-104

[17] Bustamante, J. ; Bredeston, L. ; Malanga, G. ; Mordoh, J.: Role of Melanin as a scavenger of active oxygen species. In: Pigment Cell Res. 6 (1998), S. 348-353

[18] Cano-Soldado, P. ; Pastor-Anglada, M.: Transporters that translocate nucleosides and structural similar drugs: structural requirements for substrate recognition. In: Med. Res. Rev. (2011), doi 10.1002/med.20221

[19] Carcoforo, P. ; Soliani, G. ; Bergossi, L. ; Basaglia, E. ; Virgili, A. R. ; Pagani, W. ; Pozza, E. ; Feggi, L. M.: Reliability and accuracy of sentinel node biopsy in cutaneous malignant melanoma. In: Tumori 88 (2002), Nr. 3; S. 14-16

[20] Chandra, P. ; Brouwer, K. L.: The complexities of hepatic drug transport: current knowledge and emerging concepts. In: Pharm. Res. 21 (2004), Nr. 5, S. 719-735 
[21] Chapman, P. B. ; Einhorn, L. H. ; Meyers, M. L. ; Saxman, S. ; Destro, A. N. ; Panageas, K. S. ; Begg, C. B. ; Agarwala, S. S. ; Schuchter, L. M. ; Ernstoff, M. S. ; Houghton, A. N. ; Kirkwood, J. M.: Phase III multicenter randomized trial of the Dartmouth regimen versus dacarbazine in patients with metastatic melanoma. In: J. Clin. Oncol. 17 (1999), Nr. 9, S. 2745-2751

[22] Chen, K. G. ; Valencia, J. C. ; Gillet, J. P. ; Hearing, V. J. ; Gottesman, M. M.: Involvement of $\mathrm{ABC}$ transporters in melanogenesis and the development of multidrug resistance of melanoma. In: Pigment Cell Melanoma Res. 22 (2009), Nr. 6, S. 740-749

[23] Chi, M. ; Dudek, A. Z.: Vaccine therapy for metastatic melanoma: systematic review and meta-analysis of clinical trials. In: Melanoma Res. 21 (2011), Nr. 3, S. $165-174$

[24] Chiarion-Sileni, V. ; Nortilli, R. ; Aversa, S. M. ; Paccagnella, A. ; Medici, M. ; Corti, L. ; Favaretto, A. G. ; Cetto, G. L. ; Monfardini, S.: Phase II randomized study of dacarbazine, carmustine, cisplatin, and tamoxifen versus dacarbazine alone in advanced melanoma patients. In: Melanoma Res. 11 (2001), Nr. 2, S. 189-196

[25] Chin, L. ; Garraway, L. A. ; Fisher, D. E.: Malignant melanoma: genetics and therapeutics in the genomic era. In: Genes Dev. 20 (2006), S. 2149-2182

[26] Christmann, M. ; Verbeek, B. ; Roos, W. P. ; Kaina, B.: $0^{6}-$ Methylguanine-DNA methyltransferase (MGMT) in normal tissues and tumors: enzyme activity, promoter methylation and immunohistochemistry. Biochim. Biophys. Acta. 1816 (2011), Nr. 2, S. 179-190

[27] Ciarimboli, G. ; Holle, S.K.; Vollenbröcker, B. ; Hagos, Y. ; Reuter, S. ; Burckhardt, G. ; Bierer, S. ; Herrmann, E. ; Pavenstädt, H. ; Rossi, R. ; Kleta, R. ; Schlatter, E.: New clues for nephrotoxicity induced by ifosfamide: preferential renal uptake via the human organic cation transporter 2. In: Mol. Pharm. 8 (2011), Nr. 1, S. 270-279

[28] Cornford, E. M. ; Young, D. ; Paxton, J. W. ; Finlay, G. J. ; Wilson, W. R. ; Pardridge, W. M.: Melphalan penetration of the blood-brain barrier via the neutral amino acid transporter in tumor-bearing brain. In: Cancer Res. 52 (1992), S. 138143 
[29] Dangprapai, Y. ; Wright, S. H.: Interaction of $\mathrm{H}^{+}$with the extracellular and intracellular aspects of hMATE1. In: Am. J. Physiol. Renal Physiol. 301 (2011), S. $520-528$

[30] Darkes, M. J. ; Plosker, G. L. ; Jarvis, B.: Temozolomide - a review of its use in the treatment of malignant gliomas, malignant melanoma and other advanced cancers. Am. J. Cancer 1 (2002), Nr. 1, S. 55-80

[31] Davey, H. M. ; Kell, D. B.: Flow cytometry and cell sorting of heterogeneous microbial populations: the importance of single-cell analyses. In: Microbiol. Rev. 60 (1996), Nr. 4, 641-696

[32] Demirci, H. ; McCormick, S. A. ; Finger, P. T.: Topical mitomycin chemotherapy for conjunctival malignant melanoma and primary acquired melanosis with atypia: clinical experience with histopathologic observations. In: Arch. Ophthalmol. 118 (2000), Nr. 7, S. 885-891

[33] Denny, B. J. ; Wheelhouse, R. T. ; Stevens, M. F. ; Tsang, L. L. ; Slack, J. A.: NMR and molecular modeling investigation of the mechanism of activation of the antitumor drug temozolomide and its interaction with DNA. In: Biochemistry 33 (1994), Nr. 31, S. 9045-9051

[34] Di Cresce, C. ; Koropatnick, J.: Antisense treatment in human prostate cancer and melanoma. In: Curr. Cancer Drug Targets 10 (2010), Nr. 6, S. 555-65

[35] Diel, I. J. ; Jaschke, A. ; Solomayer, E. F. ; Gollan, C. ; Bastert, G. ; Sohn, C. ; Schuetz, F.: Adjuvant oral clodronate improves the overall survival of primary breast cancer patients with micrometastases to the bone marrow - a long-term follow-up. In: Ann. Oncol. 19 (2008), Nr. 12, S. 2007-2011

[36] Dunham, P. B. ; Kelley, S. J. ; Logue, P. J.: Extracellular $\mathrm{Na}^{+}$inhibits $\mathrm{Na}^{+} / \mathrm{H}^{+}$ exchange: Cell shrinkage reduces the inhibition. In: Am. J. Physiol. Cell Physiol. 287 (2004), S. 336-344

[37] Dunnett, C.: A Multiple comparison procedure for comparing several treatments with a control. In: J. Am. Stat. Assoc. 50 (1955), Nr. 272, S. 1096-1121 
[38] Elwood, J. ; Whitehead, S. M. ; Davison, J. ; Stewart, M. ; Galt, M.: Malignant melanoma in england: risks associated with naevi, freckles, social class, hair colour, and sunburn. In: Int. J. Epidemiol. 19 (1990), Nr. 4, S. 801-810

[39] Emmert, S. ; Zutt, M. ; Haenssle, H. ; Neumann, C. ; Kretschmer, L.: Inefficacy of vindesine monotherapy in advanced stage IV malignant melanoma patients previously treated with other chemotherapeutic agents. In: Melanoma Res. 13 (2003), Nr. 3, S. 299-302

[40] Essner, R. ; Conforti, A. ; Kelley, M. C. ; Wanek, L. ; Stern, S. ; Glass, E. ; Morton, D. L.: Efficacy of lymphatic mapping, sentinel lymphadenectomy, and selective complete lymph node dissection as a therapeutic procedure for early-stage melanoma. In: Ann. Surg. Oncol. 6 (1999), Nr. 5, S. 442-449

[41] Eton, O. ; Legha, S. S. ; Bedikian, A. Y. ; Lee, J. J ; Buzaid, A. C. ; Hodges, C. ; Ring, S. E. ; Papadopoulos, N. E. ; Plager, C. ; East, M. J. ; Zhan, F. ; Benjamin, R. S.: Sequential biochemotherapy versus chemotherapy for metastatic melanoma: results from a phase III randomized trial. In: J. Clin. Oncol. 20 (2002), Nr. 8, S. 2045-2052

[42] Fassberg, J. ; Stella, V.: A kinetic and mechanistic study of the hydrolysis of camptothecin and some analogues. In: J. Pharm. Sci. 81 (1992), Nr. 7, S. 676684

[43] Fecher, L. A. ; Cummings, S. D. ; Keefe, M. J. ; Alani, R. M.: Toward a molecular classification of melanoma. In: J. Clin. Oncol. 25 (2007), Nr. 12, S. 1606-1620

[44] Filipski, K. K. ; Mathijssen, R. H. ; Mikkelsen, T. S. ; Schinkel, A. H. ; Sparreboom, A.: Contribution of organic cation transporter 2 (OCT2) to cisplatin-induced nephrotoxicity. In: Clin. Pharmacol. Ther. 86 (2009), Nr. 4, S. 396-402

[45] Fromm, M. F. ; Kim, R. B.: Drug Transporters. Handb. Exp. Pharmacol. 201, Berlin : Springer, 2011

[46] Furr, B. J. ; Jordan, V. C.: The pharmacology and clinical uses of tamoxifen. In: Pharmacol. Ther. 25 (1984), S. 127-205

[47] Fyfe, A. J. ; McKay, P.: Toxicities associated with bleomycin. In: J. R. Coll. Physicians Edinb. 40 (2010), S. 213-215 
[48] Ganapathy, V. ; Smith, S. B. ; Prasad, P. D.: SLC19: the folate/thiamine transporter family. In: Pflügers Arch. - Eur. J. Physiol. 447 (2004), Nr. 5, S. 641646

[49] Garbe, C. ; Eigentler, T.: Therapie des malignen Melanoms im Stadium der Fernmetastasierung. In: Der Hautarzt 2 (2004), S. 195-213

[50] Gerweck, L. E. ; Seetharaman, K.: Cellular pH gradient in tumor versus normal tissue: potential exploitation for the treatment of cancer. In: Cancer Res. 56 (1996), S. $1194-1198$

[51] Gidding, C. E. ; Kellie, S. J. ; Kamps, W. A. ; de Graaf, S. S.: Vincristine revisited. In: Crit. Rev. Oncol. Hematol. 29 (1999), Nr. 3, S. 267-287

[52] Gilchrest, B. A. ; Eller, M. S. ; Geller, A. C. ; Yaar, M.: The pathogenesis of melanoma induced by ultraviolet radiation. In: N. Engl. J. Med. 340 (1999), Nr. 17, S. $1341-1348$

[53] Goukassian, D. A. ; Gilchrest, B. A.: The interdependence of skin aging, skin cancer, and DNA repair capacity: a novel perspective with therapeutic implications. In: Rejuvenation Res. 7 (2004), Nr. 3, S. 175-185

[54] Gray, J. H. ; Owen, R. P. ; Giacomini, K. M.: The concentrative nucleoside transporter family, SLC28. In: Pflügers Arch. - Eur. J. Physiol. 447 (2003), Nr. 5, S. $728-734$

[55] Greene, M. H. ; Clark, W. H. ; Tucker, M. A. ; Kraemer, K. H. ; Elder, D. E. ; Fraser, M. C.: High risk of malignant melanoma in melanoma-prone families with dysplastic nevi. In: Ann. Intern. Med. 102 (1985), Nr. 4, S. 458-465

[56] Greig, N. H. ; Soncrant T. T. ; Shetty, H. U. ; Momma, S. ; Smith, Q. R. ; Rapoport, S. I.: Brain uptake and anticancer activities of vincristine and vinblastine are restricted by their low cerebrovascular permeability and binding to plasma constituents in rats. In: Cancer Chemother. Pharmacol. 26 (1990), Nr. 4, S. $263-268$

[57] Guchelaar, H.-J. ; Richel, D. J. ; Schaafsma, M. R.: Clinical and toxicological aspects of the antineoplastic drug cladribine: a review. In: Ann. Hematol. 69 (1994), S. 223-230 
[58] Günther, W. ; Pawlak, E. ; Damasceno, R. ; Arnold, H. ; Terzis, A. J.: Temozolomide induces apoptosis and senescence in glioma cells cultured as multicellular spheroids. In: Br. J. Cancer 88 (2003), S. 463-469

[59] Gupta, S. ; Burckhardt, G. ; Hagos, Y.: SLC22 transporter family proteins as targets for cytostatic uptake into tumor cells. In: Biol. Chem. 392 (2011), Nr. 1-2, S. $117-124$

[60] Gupta, S.: Expression of SLC transporters in Chronic Lymphocytic Leukaemia cells and their interaction with cytostatics. Göttingen, Georg-August-Universität, Biologie, Diss., 2009

[61] Hagenbuch, B. ; Gui, C.: Xenobiotic transporters of the human organic anion transporting polypeptides (OATP) family. In: Xenobiotica 38 (2008), Nr. 7-8, S. 778-801

[62] Hagos, Y. ; Wolff, N. A.: Assessment of the Role of Renal Organic Anion Transporters in Drug-Induced Nephrotoxicity. In: Toxins 2 (2010), S. 2055-2082

[63] Hagos, Y. ; Stein, D. ; Ugele, B. ; Burckhardt, G. ; Bahn, A.: Human renal organic anion transporter 4 operates as an asymmetric urate transporter. In: J. Am. SoC. Nephrol. 18 (2007), S. 430-439

[64] Hainsworth, J. D. ; Greco, F. A.: Etoposide: Twenty years later. In: Ann. Oncol. 6 (1995), Nr. 4, S. 325-341

[65] Halestrap, A. P. ; Meredith, D.: The SLC16 gene family-from monocarboxylate transporters (MCTs) to aromatic amino acid transporters and beyond. In: Pflügers Arch. - Eur. J. Physiol. 447 (2004), Nr. 5, S. 619-628

[66] He, L. ; Vasiliou, K. ; Nebert, D. W.: Analysis and update of the human solute carrier (SLC) gene superfamily. In: Hum. Genomics 3 (2009), Nr. 2, S. 195-206

[67] Hediger, M. A. ; Romero, M. F. ; Peng, J. ; Rolfs, A. ; Takanaga, H. ; Bruford, E.: The ABCs of solute carriers: physiological, pathological and therapeutic implications of human membrane transport proteins. In: Pflügers Arch. - Eur. J. Physiol. 447 (2004), S. 465-468

[68] Hersey, P. ; Bastholt, L. ; Chiarion-Sileni, V. ; Cinat, G. ; Dummer, R. ; Eggermont, A. M. ; Espinosa, E. ; Hauschild, A. ; Quirt, I. ; Robert, C. ; 
Schadendorf, D.: Small molecules and targeted therapies in distant metastatic disease. In: Ann. Oncol. 20 (2003), Nr. 6, S. 35-40

[69] Imamura, Y. ; Murayama, N. ; Okudaira, N. ; Kurihara, A. ; Okazaki, O. ; Izumi, T. ; Inoue, K. ; Yuasa, H. ; Kusuhara, H. ; Sugiyama, Y.: Prediction of fluoroquinolone-induced elevation in serum creatinine levels: a case of drugendogenous substance interaction involving the inhibition of renal secretion. In: Clin. Pharmacol. Ther. 89 (2011), Nr. 1, S. 81-88

[70] Kalliokoski, A. ; Niemi, M.: Impact of OATP transporters on pharmacokinetics. In: Proc. Natl. Acad. Sci. 158 (2009), Nr. 3, S. 693-705

[71] Khan, N. ; Khan, M. K. ; Almasan, A. ; Singh, A. D. ; Macklis, R.: The evolving role of radiation therapy in the management of malignant melanoma. In: Int. J. Radiat. Oncol. Biol. Phys. 80 (2011), Nr. 3, S. 645-654

[72] Kim, H. ; Likhari, P. ; Parker, D. ; Statkevich, P. ; Marco, A. ; Lin, C. C. ; Nomeir, A. A.: High-performance liquid chromatographic analysis and stability of antitumor agent temozolomide in human plasma. In: J. Pharm. Biomed. Anal. 24 (2001), Nr. 3, S. 461-468

[73] Kindla, J. ; Fromm, M. F. ; König, J.: In vitro evidence for the role of OATP and OCT uptake transporters in drug-drug interactions. In: Expert Opin. Drug Metab. Toxicol. 5 (2009), S. 489-500

[74] Kirkwood, J. M. ; Strawderman, M. H. ; Ernstoff, M. S. ; Smith, T. J. ; Borden, E. C. ; Blum, R. H.: Interferon Alfa-2b Adjuvant Therapy of High-Risk, Resected Cutaneous Melanoma: The Eastern Cooperative Oncology Group Trial EST 1684. In: J. Clin. Oncol. 14 (1996), Nr. 1, S. 7-17

[75] Knauer, M. ; Urquhart, B.: Human skeletal muscle drug transporters determine local exposure and toxicity of statins. In: Circ. Res. 106 (2010), S. 297-306

[76] Kobayashi, N. ; Nakagawa, A. ; Muramatsu, T. ; Yamashina, Y. ; Shirai, T. ; Hashimoto, M. W. ; Ishigaki, Y. ; Ohnishi, T. ; Mori, T.: Supranuclear melanin caps reduce ultraviolet induced DNA photoproducts in human epidermis. In: J. Invest. Dermatol. 110 (1998), S. 806-810 
[77] Kobayashi, Y. , Ohshiro, N. ; Sakai, R. ; Ohbayashi, M. ; Kohyama, N. ; Yamamoto, T.: Transport mechanism and substrate specificity of human organic anion transporter 2 (hOat2 [SLC22A7]). In: J. Pharm. Pharmacol. 57 (2005), Nr. 5, S. $573-578$

[78] Koepsell, H. ; Endou, H.: The SLC22 drug transporter family. In: Pflügers Arch. Eur J. Physiol. 447 (2004), S. 666-676

[79] Koepsell, H. ; Lips, K. ; Volk, C.: Polyspecific organic cation transporters: structure, function, physiological roles, and biopharmaceutical implications. In: Pharm. Res. 24 (2007), Nr. 7, S. 1227-1251

[80] Kondo, N. ; Takahashi, A. ; Mori, E. ; Noda, T. ; Su, X. ; Ohnishi, K. ; McKinnon, P. J. ; Sakaki, T. ; Nakase, H., Ohnishi, T.: DNA ligase IV is a potential molecular target in Nimustine (ACNU) sensitivity. In: Cancer Sci. 101 (2010), Nr. 8, S. 18811885

[81] König, J. ; Zolk, O. ; Singer, K. ; Hoffmann, C. ; Fromm, M. F.: Double-transfected MDCK cells expressing human OCT1/MATE1 or OCT2/MATE1: determinants of uptake and transcellular translocation of organic cations. In: Br. J. Pharmacol. 163 (2011), S. 546-555

[82] Koshiba, S. ; An, R. ; Saito, H. ; Wakabayashi, K. ; Tamura, A. ; Ishikawa, T.: Human ABC transporters ABCG2 (BCRP) and ABCG4. In: Xenobiotica 37 (2008), Nr. 7-8, S. $863-888$

[83] Kraemer, K. H. ; Lee, M. M. ; Scotto, J.: Xeroderma pigmentosum. Cutaneous, ocular, and neurologic abnormalities in 830 published cases. In: Arch. Dermatol. 123 (1987), Nr. 2, S. 241-250

[84] Kreyszig, E.: Statistische Methoden und ihre Anwendungen. 5. Aufl. Göttingen : Vandenhoeck \& Ruprecht, 1975

[85] Kurzrock, R. ; Markman, M.: Targeted Cancer Therapy. Totowa, USA : Humana Press, 2008

[86] Kusuhara, H. ; Ito, S. ; Kumagai, Y. ; Jiang, M. ; Shiroshita, T. ; Moriyama, Y. ; Inoue, K. ; Yuasa, H. ; Sugiyama, Y.: Effects of a MATE protein inhibitor, pyrimethamine, on the renal elimination of metformin at oral microdose and at 
therapeutic dose in healthy subjects. In: Clin. Pharmacol. Ther. 89 (2011), Nr. 6, S. $837-844$

[87] Lai, Y. ; Sampson, K. E. ; Balogh, L. M. ; Brayman, T. G. ; Cox, S. R. ; Adams, W. J. ; Kumar, V. ; Stevens, J. C.: Preclinical and clinical evidence for the collaborative transport and renal secretion of an oxazolidinone antibiotic by organic anion transporter 3 (OAT3/SLC22A8) and multidrug and toxin extrusion protein 1 (MATE1/SLC47A1). In: J. Pharmacol. Exp. Ther. 334 (2010), Nr. 3, S. 936-944

[88] Lang, K. ; Wagner, C. ; Haddad, G. ; Burnekova, O. ; Geibel, J.; Intracellular pH activates membrane-bound $\mathrm{Na}^{+} / \mathrm{H}^{+}$exchanger and vacuolar $\mathrm{H}^{+}$-ATPase in human embryonic kidney (HEK) cells. In: Cell Physiol. Biochem. 13 (2003), S. 257-262

[89] Larkin, J. ; Gore, M.: Malignant melanoma (metastatic). In: Clin. Evid. (Online), (2008), pii 1718

[90] Legha, S. S. ; Ring, S. ; Papadopoulos, N. ; Plager, C. ; Chawla, S. ; Benjamin, R.: A prospective evaluation of a triple-drug regimen containing cisplatin, vinblastine, and dacarbazine (CVD) for metastatic melanoma. In: Cancer 64 (1989), Nr. 10, S. 2024-2029

[91] Leonard, G. D. ; Fojo, T. ; Bates, S. E.: The role of ABC transporters in clinical practice. In: Oncologist 8 (2003), S. 411-424

[92] Lin, J. ; Raoof, D. A. ; Thomas, D. G. ; Greenson, J. K. ; Giordano, T. J. ; Robinson, G. S. ; Bourner, M. J. ; Bauer, C. T. ; Orringer, M. B. ; Beer, D. G.: Ltype amino acid transporter-1 overexpression and melphalan sensitivity in Barrett's adenocarcinoma. In: Neoplasia 6 (2004), Nr. 1, S. 74-84

[93] Lokiec, F. ; Canal, P. ; Gay, C. ; Chatelut, E. ; Armand, J. P. ; Roché, H. ; Bugat, R. ; Goncalvès, E. ; Mathieu-Boué, A.: Pharmacokinetics of irinotecan and its metabolites in human blood, bile, and urine. In: Cancer Chemother. Pharmacol. 36 (1995), Nr. 1, S. 79-82

[94] Longley, D. B. ; Harkin, P. ; Johnston, P. G.: 5-fluorouracil: mechanisms of action and clinical strategies. In: Nat. Rev. Cancer 3 (2003), S. 330-338

[95] Lottspeich, F. ; Engels, J. W.: Bioanalytik. 2. Aufl., München : Spektrum, 2006 
[96] Lui, P. ; Cashin, R. ; Machado, M. ; Hemels, M. ; Coreyl-Lisle, P. K. ; Einarson, T. R.: Treatments for metastatic melanoma: synthesis of evidence from randomized trials. In: Cancer Treat. Rev. 33 (2007), Nr. 8, S. 665-680

[97] Maanen, M. J. ; Smeets, C. J. ; Beijnen, J. H.: Chemistry, pharmacology and pharmacokinetics of $\mathrm{N}, \mathrm{N}^{\prime}, \mathrm{N}^{\prime \prime}$-triethylenethiophosphoramide (ThioTEPA). In: Cancer Treat. Rev. 26 (2000), Nr. 4, S. 257-268

[98] Marchesi, F. ; Turriziani, M. ; Tortorelli, G. ; Avvisati, G. ; Torino, F. ; De Vecchis, L.: Triazene compounds: mechanism of action and related DNA repair systems. In: Pharmacol. Res. 56 (2007), Nr. 4, S. 275-287

[99] Masuda, S. ; Terada, T. ; Yonezawa, A. ; Tanihara, Y. ; Kishimoto, K. ; Katsura, T. ; Ogawa, O. ; Inui, K.: Identification and functional characterization of a new human kidney-specific $\mathrm{H}^{+}$/organic cation antiporter, kidney-specific multidrug and toxin extrusion 2. In: J. Am. Soc. Nephrol. 17 (2006), Nr. 8, S. 2127-2135

[100] Mekhail, T. M. ; Markman, M.: Paclitaxel in cancer therapy. In: Expert Opin. Pharmakother. 3 (2002), Nr. 6, S. 755-766

[101] Meyer zu Schwabedissen, H. E. ; Verstuyft, C. ; Kroemer, H. ; Becquemont, K. L. ; Kim, R. B.: Human multidrug and toxin extrusion 1 (MATE1/SLC47A1) transporter: functional characterization, interaction with OCT2 (SLC22A2), and single nucleotide polymorphisms. In: Am. J. Physiol. Renal Physiol. 298 (2010), Nr. 4, S. 997-1005

[102] Mini, E. ; Nobili, S. ; Caciagli, B. ; Landini, I. ; Mazzei, T.: Cellular pharmacology of gemcitabine. In: Ann. Oncol. 17 (2006), Nr. 5, S. 7-12

[103] Minotti, G. ; Menna, P. ; Salvatorelli, E. ; Cairo, G. ; Gianni, L.: Anthracyclines: molecular advances and pharmacologic developments in antitumor activity and cardiotoxicity. In: Pharmacol. Rev. 56 (2004), Nr. 2, S. 185-229

[104] Mohan, R. ; Panda, D.: Kinetic stabilization of microtubule dynamics by estramustin is associated with tubulin acetylation, spindle abnormalities, and mitotic arrest. In: Cancer Res. 68 (2008), S. 6181-6189 
[105] Monzon, J. ; Liu, L. ; Brill, H. ; Goldstein, A. M. ; Tucker, M. A. ; From, L. ; McLaughlin, J. ; Hogg, D. ; Lassam, N. J.: CDKN2A mutations in multiple primary melanomas. In: N. Engl. J. Med. 338 (1998), S. 879-887

[106] Morris, M. E. ; Felmlee, M. A.: In: Overview of the proton-coupled MCT (SLC16A) family of transporters: characterization, function and role in the transport of the drug of abuse gamma-hydroxybutyric acid. AAPS J. 10 (2008), Nr. 2, S. 311-21

[107] Mössner, R. ; Schulz, U. ; Krüger, U. ; Middel, P. ; Schinner, S. ; Füzesi, L. ; Neumann, C. ; Reich, K.: Agonists of peroxisome proliferator-activated receptor $Y$ inhibit cell growth in malignant melanoma. In: J. Invest. Dermatol. 119, (2002), Nr. 3, S. 576-582

[108] Mullangi, R. ; Ahlawat, P. ; Srinivas, N. R.: Irinotecan and its active metabolite, SN-38: review of bioanalytical methods and recent update from clinical pharmacology perspectives. In: Biomed. Chromatogr. 24 (2010), Nr. 1, S. 104123

[109] Nakamura, T. ; Yonezawa, A. ; Hashimoto, S. ; Katsura, T. ; Inui, K.: Disruption of multidrug and toxin extrusion MATE1 potentiates cisplatin-induced nephrotoxicity. In: Biochem. Parmacol. 80 (2010), Nr. 11, S. 1762-1767

[110] Nakanishi, T. ; Tamai, I.: Solute carrier transporters as targets for drug delivery and pharmacological intervention for chemotherapy. In: J. Pharm. Sci. 100 (2011), Nr. 9, S. 3731-3750

[111] Nies, A. T. ; Koepsell, H. ; Damme, K. ; Schwab, M.: Organic cation transporters (OCTs, MATEs), in vitro and in vivo evidence for the importance in drug therapy. In: Fromm, M. F. ; Kim, R. B.: Drug Transporters. Handb. Exp. Pharmacol. 201, Berlin : Springer, 2011, S. 105-67

[112] O'Sullivan, J. M. ; Huddart, R. A.; Norman, A. R. ; Nicholls, J. ; Dearnaley, D. P. ; Horwich, A.: Predicting the risk of bleomycin lung toxicity in patients with germcell tumours. In: Ann. Oncol. 14 (2003), S. 91-96

[113] Oberdisse, E. ; Hackenthal, E. ; Kuschinsky, K.: Pharmakologie und Toxikologie. 3. überarb. Aufl., Berlin : Springer (2002) 
[114] Ohta, K. ; Imamura, Y.: Functional characterization of multidrug and toxin extrusion protein 1 as a facilitative transporter for fluoroquinolones. In: $J$. Pharmacol. Exp. Ther. 328 (2009), Nr. 2, S. 628-634

[115] Okabe, M. ; Szakács, G. ; Reimers, M. A. ; Suzuki, T. ; Hall, M. D. ; Abe, T. ; Weinstein, J. N. ; Gottesman, M. M.: Profiling SLCO and SLC22 genes in the NCI60 cancer cell lines to identify drug uptake transporters. In: Mol. Cancer Ther. 7 (2008), Nr. 9, S. 3081-3091

[116] Okabe, M. ; Unno, M. ; Harigae, H. ; Kaku, M. ; Okitsu, Y. ; Sasaki, T. ; Mizoi, T. ; Shiiba, K. ; Takanaga, H. ; Terasaki, T. ; Matsuno, S. ; Sasaki, I. ; Ito, S. ; Abe, T.: Characterization of the organic cation transporter SLC22A16: a doxorubicin importer. In: Biochem. Biophys. Res. Commun. 333 (2005), Nr. 3, S. 754-762

[117] Ota, K. ; Ito, K. ; Akahira, J. ; Sato, N. ; Onogawa, T. ; Moriya, T. ; Unno, M. ; Abe, T. ; Niikura, H. ; Takano, T. ; Yaegashi, N.: Expression of organic cation transporter SLC22A16 in human epithelial ovarian cancer: a possible role of the adriamycin importer. In: Int. J. Gynecol. Pathol. 26 (2007), Nr. 3; S. 334-340

[118] Otsuka, M. ; Matsumoto, T. ; Morimoto, R. ; Arioka, S. ; Omote, H. ; Moriyama, Y.: A human transporter protein that mediates the final excretion step for toxic organic cations. In: Proc. Natl. Acad. Sci. USA 102 (2005), Nr. 50, S. 1792317298

[119] Pallavicini, M. G.: Cytosine arabinoside: molecular pharmakinetic and cytokinetic considerations. In: Pharmacol. Ther. 25 (1984), S. 207-238

[120] Pan, G. ; Elmquist, W. F.: Mitoxantrone permeability in MDCKII cells is influenced by active influx transport. In: Mol. Pharm. 4, Nr. 3, S. 475-483

[121] Pastor-Anglada, M. ; Cano-Soldado, P.: SLC28 genes and concentrative nucleoside transporter (CNT) proteins. In: Xenobiotica 38 (2008), Nr. 7-8, S. 972-994

[122] Pérez-Tomás, R.: Multidrug resistance: retrospect and prospects in anti-cancer drug treatment. In: Curr. Med. Chem. 13 (2006), Nr. 16, S. 1859-1876

[123] Peskin, A. V. ; Winterbourn, C. C.: A microtiter plate assay for superoxide dismutase using a water-soluble tetrazolium salt (WST-1). In: Clin. Chim. Acta 293 (2000), Nr. 1-2, S. $157-166$ 
[124] Pfaffl, M. W.: Quantification strategies in real-time PCR. In: Bustin, S. A.: $A-Z$ of quantitative PCR. La Jolla, USA : International University Line, 2004, S. 87-112

[125] Pfaffl, M. W.: Real-Time RT-PCR: neue Ansätze zur exakten mRNA Quantifizierung. In: Biospektrum 1 (2004), S. 92-95

[126] Pineda, M. ; Fernández, E. ; Torrents, D. ; Estévez R. ; López, C. ; Camps, M. : Lloberas, J. ; Zorzano, A. ; Palacín, M.: In: Identification of a membrane protein, LAT-2, that Co-expresses with 4F2 heavy chain, an L-type amino acid transport activity with broad specificity for small and large zwitterionic amino acids. J. Biol. Chem. 274 (1999), Nr. 28, S. 19738-19744

[127] Pinheiro, C. ; Reis, R. M. ; Ricardo, S. ; Longatto-Filho, A. ; Schmitt, F. ; Baltazar, F.: Expression of monocarboxylate transporters 1, 2, and 4 in human tumours and their association with CD147 and CD44. In: J. Biomed. Biotechnol. (2010), 2010: 427694

[128] Quagliana, J. M. ; Stephens, R. L. ; Baker, L. H. ; Costanzi, J. J.: Vindesine in patients with metastatic malignant melanoma: a Southwest Oncology Group study. In: J. Clin. Oncol. 2 (1984), Nr. 4, S. 316-319

[129] Raghunand, N. ; Mahoney, B. ; van Sluis, R. ; Baggett, B. ; Gillies, R. J.: Acute metabolic alkalosis enhances response of $\mathrm{C} 3 \mathrm{H}$ mouse mammary tumors to the weak base mitoxantrone. In: Neoplasia 3 (2001), Nr. 3, S. 227-235

[130] Rivory, L. P. ; Bowles, M. R. ; Robert, J. ; Pond, S. M.: Conversion of irinotecan (CPT-11) to its active metabolite, 7-ethyl-10-hydroxycamptothecin (SN-38), by human liver carboxylesterase. In: Biochem. Pharmacol. 52 (1996), Nr. 7, S. 11031111

[131] Rizwan, A. N. ; Burckhardt, G.: Organic anion transporters of the SLC22 family: biopharmaceutical, physiological, and pathological roles. In: Pharm. Res. 24 (2007), Nr. 3, S. 450-470

[132] Rosenberg, S. A. ; Yang, J. C. ; Topalian, S. L. ; Schartzentruber, D. J. ; Weber, J. S. ; Parkinson, D. R. ; Seipp, C. A. ; Einhorn, J. H. ; White, D. E.: Treatment of 283 consecutive patients with metastatic melanoma or renal cell cancer using high-dose bolus interleukin 2. In: JAMA 271 (1994), Nr. 12, S. 907-913 
[133] Rüger, B.: Test- und Schätztheorie. München : Oldenbourg, 1999

[134] Rünger, T. M. ; Kotas, M. ; Poot, M. ; Leverkus, M. ; Epe, B. ; Jeggo, P. A. ; Hellfritsch, D.: Reduced joining of DNA ends correlates with chromosomal instability in three melanoma cell lines. In: Tumor Biol. 24 (2003), S. 100-108

[135] Saleem, A. ; Brown, G. D. ; Brady, F. ; Aboagye, E. O. ; Osman, S. ; Luthra, S. K. ; Ranicar, A. S. ; Brock, C. S. ; Stevens, M. F. ; Newlands, E. ; Jones, T. ; Price, P.: Metabolic activation of temozolomide measured in vivo using positron emission tomography. In: Cancer Res. 63 (2003), Nr. 10, S. 2409-2415

[136] Salloum, E. ; Khan, K. K. ; Cooper, D. L.: Chlorambucil-induced seizures. In: Cancer 79 (1997), Nr. 5, S. 1009-1013

[137] Sarosi, G. ; Leyland-Jones, B. ; Soochan, P. ; Cheson, D. B.: The systemic administration of intravenous melphalan. In: J. Clin. Oncol. 6 (1988), Nr. 11, S. $1768-1782$

[138] Sasse, A. D. ; Sasse, E. ; Clark, L. G ; Ulloa, L. ; Clark, O. A.: Chemoimmunotherapy versus chemotherapy for metastatic malignant melanoma. In: Cochrane Database Syst. Rev. 1 (2007), CD005413

[139] Sato, T.; Masuda, S. ; Yonezawa, A. ; Tanihara, Y.: Transcellular transport of organic cations in double-transfected MDCK cells expressing human organic cation transporters hOCT1/hMATE1 and hOCT2/hMATE1. In: Biochem. Pharmacol. 76 (2008), S. 894-903

[140] Schiffer, R. ; Neis, M. ; Höller, D. ; Rodriguez, F. ; Geier, A. ; Gartung, C. ; Lammert, F. ; Dreuw, A. ; Zwadlo-Klarwasser, G. ; Merk, H. ; Jugert, F. ; Baron, J. M.: Active influx transport is mediated by members of the organic anion transporting polypeptide family in human epidermal keratinocytes. In: J. Invest. Dermatol. 120 (2003), Nr. 2, S. 285-291

[141] Schroedel, A.: Die Rolle des fetalen Kälberserums in Zellkulturmedien. In: Biologie in unserer Zeit 37 (2007), S. 289

[142] Schulten, H.-J. ; Gunawan, B. ; Otto, F. ; Hassmann, R. ; Hallermann, C. ; Noebel, A. ; Füzesi, L.: Cytogenetic characterization of complex karyotypes in seven 
established melanoma cell lines by multiplex fluorescence in sito hybridization and DAPI banding. In: Cancer Genet. Cytogenet. 133 (2002), S. 134-141

[143] Scripture, C. D. ; Figg, W. D.: Drug interactions in cancer therapy. In: Nat. Rev. Cancer 6 (2006), Nr. 7, S. 546-558

[144] Seegenschmiedt, M. H. ; Keilholz, L. ; Altendorf-Hofmann, A. ; Urban, A. ; Schell, H. ; Hohenberger, W. ; Sauer, R.: Palliative radiotherapy for recurrent and metastatic malignant melanoma: prognostic factors for tumor response and longterm outcome: a 20-year experience. In: Int. J. Radiat. Oncol. Biol. Phys. 44 (1999), Nr. 3, S. 607-618

[145] Seigler, H. F. ; Lucas, V. S. ; Pickett, N. J. ; Huang, A. T.: DTIC, CCNU, bleomycin and vincristine (BOLD) in metastatic melanoma. In: Cancer 46 (1980), Nr. 11, S. 2346-2348

[146] Shahrokni, A. ; Rajebi, M. R. ; Saif, M. W.: Toxicity and efficacy of 5-fluorouracil and capecitabine in a patient with TYMS gene polymorphism: A challenge or a dilemma? In: Clin. Colorectal Cancer 8 (2009), Nr. 4, S. 231-234

[147] Shapira, A. ; Assaraf, Y. G. ; Epstein, D. ; Livney, Y. D.: Beta-casein nanoparticles as an oral delivery system for chemotherapeutic drugs: impact of drug structure and properties on co-assembly. In: Pharm. Res. 27 (2010), Nr. 10, S. 2175-2186

[148] Sharom, F. J.: ABC multidrug transporters: structure, function and role in chemoresistance. In: Pharmacogenomics 9 (2008), Nr. 1, S. 105-127

[149] Shnitsar, V. ; Eckardt, R. ; Gupta, S. ; Grottker, J. ; Müller, G. A. ; Koepsell, H. ; Burckhardt, G. ; Hagos, Y.: Expression of human organic cation transporter 3 in kidney carcinoma cell lines increases chemosensitivity to melphalan, irinotecan, and vincristine. In: Cancer Res. 69 (2009), Nr. 4, S. 1494-1501

[150] Shnitsar, V.: Expression von polyspezifischen Transportern in renalen Tumoren und ihre Bedeutung für die Chemotherapie. Göttingen, Georg-August-Universität, Biologie, Diss., 2008

[151] Smith, K. M. ; Slugoski, M. D. ; Cass, C. E. ; Baldwin, S. A., Karpinski, E. ; Young, J. D.: Cation coupling properties of human concentrative nucleoside transporters hCNT1, hCNT2, and hCNT3. In: Mol. Membr. Biol. 24 (2007), Nr. 1, S. 53-64 
[152] Smith, N. ; Acharya, M.: Identification of OATP1B3 as a high-affinity hepatocellular transporter of Paclitaxel. In: Cancer Biol. Ther. 4 (2005), S. 815818

[153] Spurgeon, S. ; Yu, M. ; Phillips, J. D. ; Epner, E. M.: Cladribine: not just another purine analogue? In: Expert Opin. Investig. Drugs 18 (2009), Nr. 8, S. 1169-1181

[154] Sullivan1, J. M. ; Huddart, R. A. ; Norman, A. R. ; Nicholls, J. ; Dearnaley, D. P. ; Horwich, A.: Predicting the risk of bleomycin lung toxicity in patients with germcell tumours. In: Ann. Oncol. 14 (2003), Nr. 1, S. 91-96.

[155] Swerdlow, A. J. ; English, J. ; MacKie, R. M. ; O`Doherty, C. J. ; Hunter J. A. ; Clark, J. ; Hole, D. J.: Benign melanocytic naevi as a risk factor for malignant melanoma. In: Br. Med. J. 292 (1986), S. 1555-1559

[156] Tageja, N. ; Nagi, J.: Bendamustine: something old, something new. In: Cancer Chemother. Pharmacol. 66 (2010), Nr. 3, S. 413-423

[157] Tanihara, Y. ; Masuda, S. ; Sato, T. ; Katsura, T. ; Ogawa, O. ; Inui, K.: Substrate specificity of MATE1 and MATE2-K, human multidrug and toxin extrusions $/ \mathrm{H}^{+}-$ organic cation antiporters. In: Biochem. Pharmacol. 74 (2007), Nr. 2, S. 359-371

[158] Tanizawa, A. ; Fujimori, A. ; Fujimori, Y. ; Pommier, Y.: Comparison of topoisomerase I inhibition, DNA damage, and cytotoxicity of camptothecin derivatives presently in clinical trials. In: J. Natl. Cancer Inst. 86 (1994), Nr. 11, S. 836-842

[159] Terada, T. ; Inui, K.: Physiological and pharmacokinetic roles of $\mathrm{H}^{+}$/organic cation antiporters (MATE/SLC47A). In: Biochem. Pharmacol. 75 (2008), S. 1689-1696

[160] The International Consortium, Giacomini, K. M ; Huang, S. M. ; Tweedie, D. J. ; Benet, L.Z. ; Brouwer, K.L. ; Chu, X. ; Dahlin, A. ; Evers, R. ; Fischer, V. ; Hillgren, K. M. ; Hoffmaster, K. A. ; Ishikawa, T. ; Keppler, D. ; Kim, R. B. ; Lee, C. A. ; Niemi, M. ; Polli, J. W. ; Sugiyama, Y. ; Swaan, P. W. ; Ware, J. A. ; Wright, S. H. ; Yee, S. W. ; Zamek-Gliszczynski, M. J. ; Zhang, L.: Membrane transporters in drug development. In: Nat. Rev. Drug Discov. 9 (2010), S. 215-236. 
[161] Tomasz, M. ; Palom, Y.: The mitomycin bioreductive antitumor agents: Crosslinking and alkylation of DNA as the molecular basis of their activity. In: Pharmacol. Ther. 76 (1997), 73-87

[162] Toyoda, Y. ; Hagiya, Y. ; Adachi, T. ; Hoshijima, K. ; Kuo, M. T. ; Ishikawa, T.: MRP class of human ATP binding cassette (ABC) transporters: historical background and new research directions. In: Xenobiotica 38 (2008), Nr. 7-8, S. 833-862

[163] Tsuda, M. ; Terada, T. ; Mizuno, T. ; Katsura, T. ; Shimakura, J. ; Inui, K.: Targeted disruption of the multidrug and toxin extrusion 1 (MATE1) gene in mice reduces renal secretion of metformin. In: Mol. Pharmacol. 75 (2009), Nr. 6, S. $1280-1286$

[164] Tsutsumida, A. ; Furukawa, H. ; Yamamoto, Y. ; Sugihara, T.: Treatment strategy for cutaneous malignant melanoma. In: Int. J. Clin. Oncol. 10 (2005), S. 311-317

[165] Ugurel, S. ; Becker, J. C.: Therapie des inoperabel metastasierten Melanoms. In: Der Hautarzt 62 (2011), Nr. 6, S. 423-429

[166] Uwai, Y. ; Taniguchi, R. ; Motohashi, H. ; Saito, H. ; Okuda, M. ; Inui, K.: Methotrexate-loxoprofen interaction: involvement of human organic anion transporters hOAT1 and hOAT3. In: Drug. Metab. Pharmacokinet. 19 (2004), Nr. 5, S. $369-374$

[167] Volpato, M. ; Phillips, R. M.: Tailoring targeted therapy to individual patients: lessons to be learnt from the development of mitomycin C. In: Cancer Genomics Proteomics 4 (2007), S. 175-186

[168] Wagner, R. ; Kozlov, A. P. ; Moskalik, K. G.: Laser radiation therapy of skin melanoma. In: Strahlentherapie 157 (1981), Nr. 10, S. 670-672

[169] Wang, Q. ; Morris, M. E.: The role of monocarboxylate transporter 2 and 4 in the transport of gamma-hydroxybutyric acid in mammalian cells. In: Drug. Metab. Dispos. 35 (2007), S. 1393-1399

[170] Wu, C. P. ; Calcagno, A. M. ; Ambudkar, S. V.: Reversal of ABC drug transportermediated multidrug resistance in cancer cells: evaluation of current strategies. In: Curr. Mol. Pharmacol. 1 (2008), Nr. 2, S. 93-105 
[171] Yamaguchi, Y. ; Hearing, V. J.: Physiological factors that regulate skin pigmentation. In: Biofactors 35 (2009), Nr. 2, S. 193-199

[172] Yanagida, O. ; Kanai, Y. ; Chairoungdua, A. ; Kim, D. K. ; Segawa, H. ; Nii, T. ; Cha, S. H. ; Matsuo, H. ; Fukushima, J. ; Fukasawa, Y. ; Tani, Y. ; Taketani, Y. ; Uchino, H. ; Kim, J. Y. ; Inatomi, J. ; Okayasu, I. ; Miyamoto, K. ; Takeda, E. ; Goya, T. ; Endou, H.: Human L-type amino acid transporter 1 (LAT1): characterization of function and expression in tumor cell lines. In: Biochim. Biophys. Acta 1514 (2001), Nr. 2, S. 291-302

[173] Yonezawa, A. ; Inui, K.: Importance of the multidrug and toxin extrusion MATE/SLC47A family to pharmacokinetics, pharmacodynamics/toxicodynamics and pharmacogenomics. In: Br. J. Pharmacol. (2011), doi: 10.1111/j.14765381.2011.01394.x

[174] Yonezawa, A. ; Masuda, S. ; Yokoo, S. ; Katsura, T. ; Inui, K.: Cisplatin and oxaliplatin, but not carboplatin and nedaplatin, are substrates for human organic cation transporters (SLC22A1-3 and multidrug and toxin extrusion family). In: $J$. Pharmacol. Exp. Ther. 319 (2006), Nr. 2, S. 879-886

[175] Young, J. D. ; Yao, S. Y. ; Sun, L. ; Cass, C. E. ; Baldwin, S. A.: Human equilibrative nucleoside transporter (ENT) family of nucleoside and nucleobase transporter proteins. In: Xenobiotica 38 (2008), Nr. 7-8, S. 995-1021

[176] Zhang, J. ; Tian, Q. ; Yung Chan, S. ; Li Chuen, S. ; Zhou, S. ; Duan, W. ; Zhu, Y. Z.: Metabolism and transport of oxazaphosphorines and the clinical implications. In: Drug. Metab. Rev. 37 (2005), Nr. 4, S. 611-703

[177] Zhang, J. ; Tian, Q. ; Zhou, S.: Clinical Pharmacology of Cyclophosphamide and Ifosfamide. In: Curr. Drug Ther. 1 (2006), Nr. 1, S. 55-84.

[178] Zhang, J. ; Visser, F. ; King, K. M. ; Baldwin, S. A. ; Young, J. D. ; Cass, C. E.: The role of nucleoside transporters in cancer chemotherapy with nucleoside drugs. In: Cancer Metastasis Rev. 26 (2007), S. 85-110

[179] Zhang, S. ; Lovejoy, K. S. ; Shima, J. E. ; Lagpacan, L. L. ; Shu, Y. ; Lapuk, A. ; Chen, Y. ; Komori, T. ; Gray, J. W. ; Chen, X. ; Lippard, S. J. ; Giacomini, K. M.: In: Cancer Res. 66 (2006), Nr. 17, S. 8847-8857 
[180] Zhang, X. ; Gordon, J. R. ; Xiang, J.: Advances in dendritic cell-based vaccine of cancer. In: Cancer Biother. Radiopharm. 17 (2002), Nr. 6, S. 601-619

[181] Zhou, S.-F.: Structure, function and regulation of P-glycoprotein and its clinical relevance in drug disposition. In: Xenobiotica 38 (2008), Nr. 7-8, S. 802-832

[182] Zitelli, J. A. ; Brown, C. D. ; Hanusa, B. H.: Surgical margins for excision of primary cutaneous melanoma. In: J. Am. Acad. Dermatol. 37 (1997), Nr. 3, S. $422-429$

[183] Zolk, O. ; Form M. F.: Transporter-mediated drug uptake and efflux: important determinants of adverse drug reactions. In: Clin. Pharmacol. Ther. 89 (2011), Nr. 6, S. 798-805 


\section{Anhang}

\subsection{Abbildungsverzeichnis}

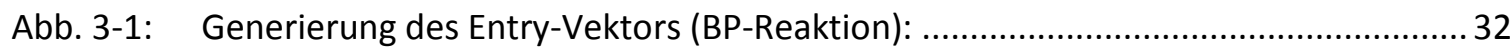

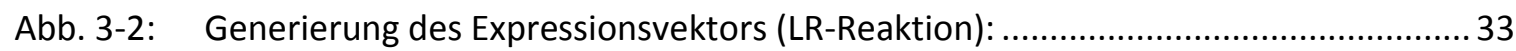

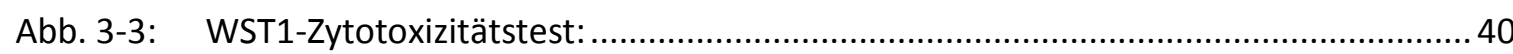

Abb. 3-4: Koordination eines Antikörpers mit 06-Methylguanyl-DNA-Addukt als Antigen: .... 41

Abb. 3-5: Indirektes ICA zur Detektion von temozolomid-induzierten O6-Methylguanyl-DNA-

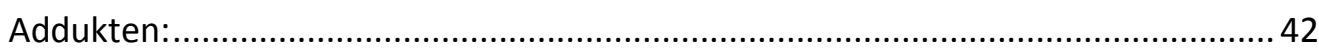

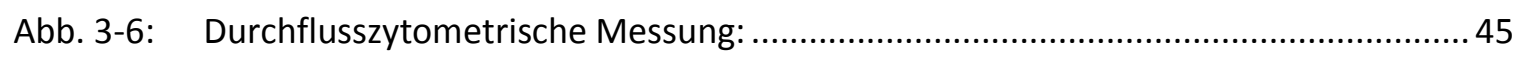

Abb. 3-7: Analyse einer durchflusszytometrischen Messung; a) Punktwolkendiagramm: ........ 46

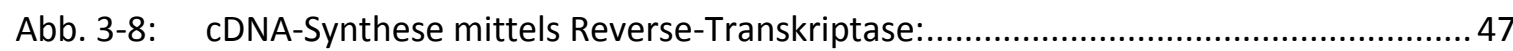

Abb. 3-9: Ablauf einer PCR zur Amplifikation von DNA-Abschnitten: ......................................... 50

Abb. 3-10: Hybridisierung und Freisetzung der Taqman-Sonde bei der

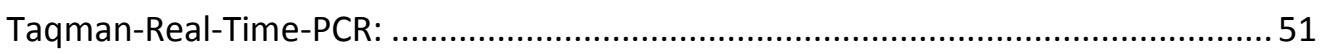

Abb. 3-11: Amplifikationskurve einer Taqman-Real-Time-PCR:.............................................. 52

Abb. 4-1: Quantitative Expression von L-Aminosäuretransportern (LAT) in Melanomzelllinien

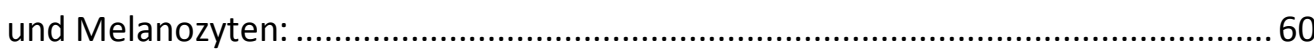

Abb. 4-2: Quantitative Expression von Monocarboxylattransportern (MCT) in Melanomzellinien und Melanozyten:

Abb. 4-3: Quantitative Expression des Folat- und Thiamintransporters 1 (RFT, ThTr1) in Melanomzelllinien und Melanozyten: ................................................................... 62

Abb. 4-4: Quantitative Expression der Organische-Anionen-Transportproteine (OATP, SLCO) in Melanomzellinien und Melanozyten:

Abb. 4-5: Quantitative Expression des Organische-Kationen-Transporters (OCT) 1 in Melanomzellinien und Melanozyten:

Abb. 4-6: Quantitative Expression der Nukleosid-Transporter (ENT) in Melanomzelllinien und Melanozyten:

Abb. 4-7: Quantitative Expression des Multidrug-and-Toxin-Extrusion-(MATE-)1-Transporters in Melanomzelllinien und Melanozyten:

Abb. 4-8: Quantitative Expression des Effluxtransporters Multidrug-Resistance (MDR) 1 in Melanomzelllinien und Melanozyten:

Abb. 4-9: Transportaktivität von MATE1 in transient transfizierten HEK293-Zellen:.....................69

Abb. 4-10: Funktionelle Charakterisierung von MATE1 in stabil transfizierten HEK293-Zellen:

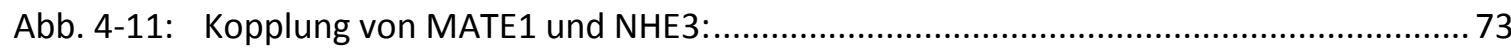

Abb. 4-12: Interaktion von OCT1 mit in der Melanomtherapie angewandten Zytostatika in CHO-

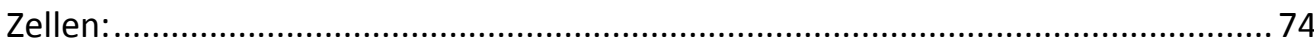

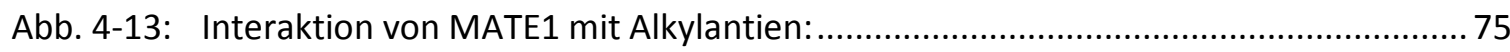

Abb. 4-14: Interaktion von MATE1 mit Antibiotika, Antimetaboliten und Interkalantien: .......... 76 Abb. 4-15: Interaktion von MATE1 mit Mitoseinhibitoren, Topoisomeraseinhibitoren und

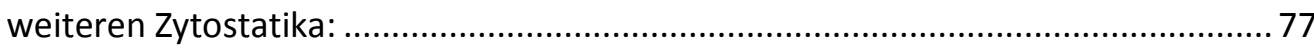

Abb. 4-16: Konzentrationsabhängigkeit der Interaktion von MATE1 mit Mitoxantron:............... 79

Abb. 4-17: Konzentrationsabhängigkeit der Interaktion von MATE1 mit Irinotecan:.................... 80 
Abb. 4-18: Zerfallsgeschwindigkeit von Temozolomid in Mammalian Ringer:

Abb. 4-19: Interaktion von OCT1 mit Temozolomid und seinen Metaboliten in CHO-Zellen: .... 82

Abb. 4-20: MATE1-vermittelte Doxorubicinaufnahme in HEK293-Zellen:

Abb. 4-21: Fluoreszenzfärbung von temozolomid-induzierten DNA-Addukten in OCT1-CHO-

Zellen:

Abb. 4-22: Einfluss der OCT1-Expression auf die relative Anzahl an temozolomid-induzierten DNA-Addukten:

Abb. 4-23: Einfluss der MATE1-Expression auf die relative Anzahl an temozolomid-induzierten DNA-Addukten:

Abb. 4-24: OCT1-vermittelte Zytotoxizität von Nimustin und Temozolomid in Abhängigkeit der Zytostatikuminkubationszeit:

Abb. 4-25: Einfluss der Inkubationszeit auf die MATE1-vermittelte Zytotoxizität von Zytostatika: 90

Abb. 4-26: PH-Abhängigkeit der MATE1-vermittelten Zytotoxizität von Zytostatika:....................92

Abb. 4-27: Dosis-Wirkungskurven der MATE1-vermittelten Mitoxantronzytotoxizität:..............94

Abb. 7-1: Kandidaten für ein Zusammenspiel mit MATE1 beim Zytostatikatransport: 113

\subsection{Tabellenverzeichnis}

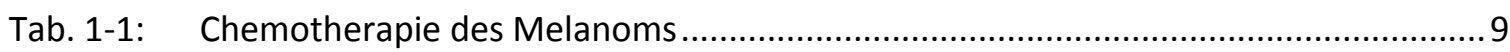

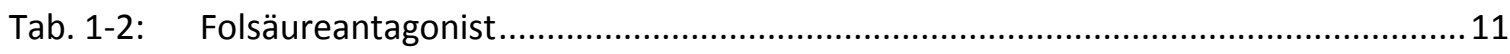

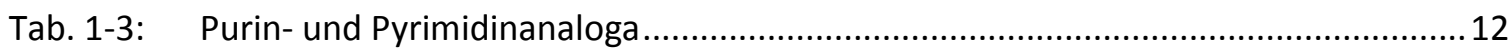

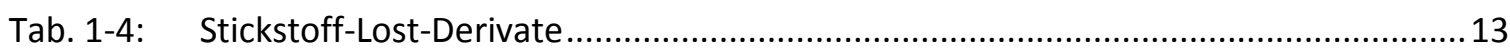

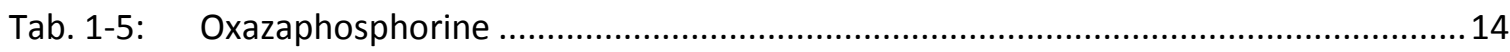

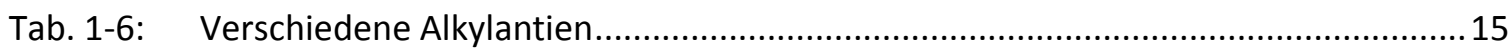

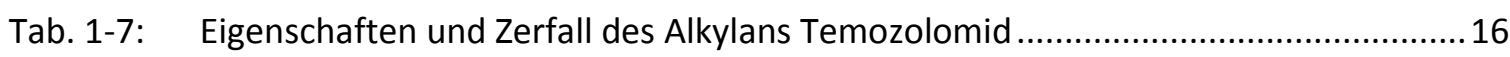

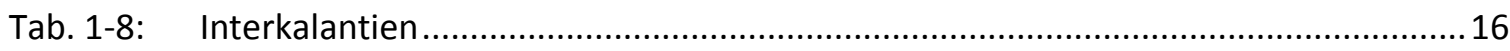

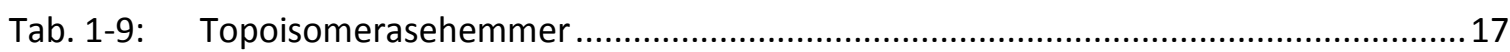

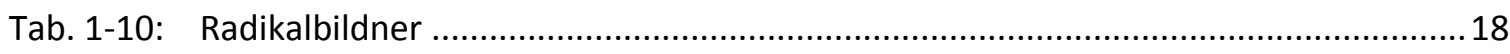

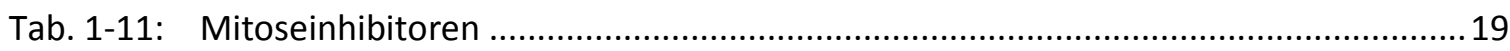

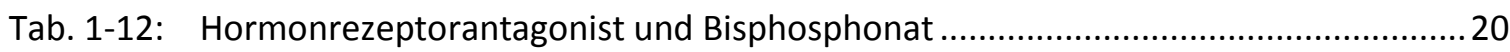

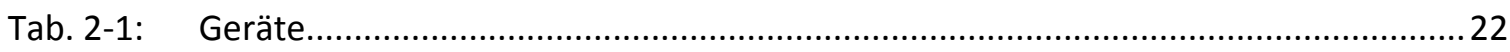

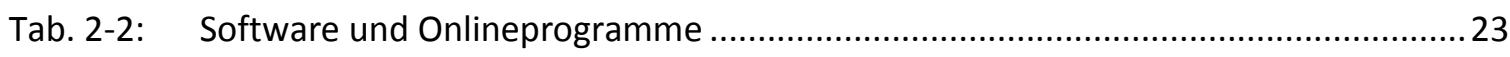

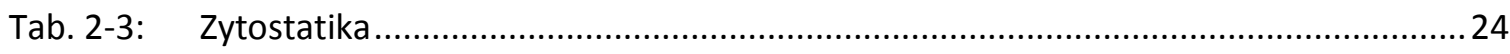

Tab. 2-4: $\quad$ Für Klonierung und stabile Transfektion verwendete Vektoren..................................25

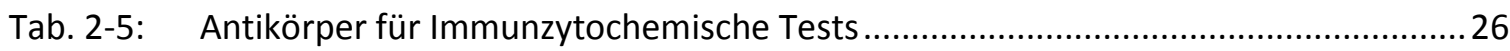

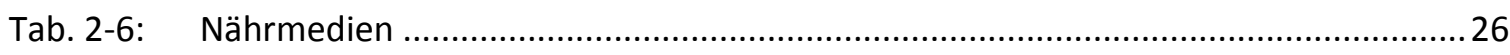

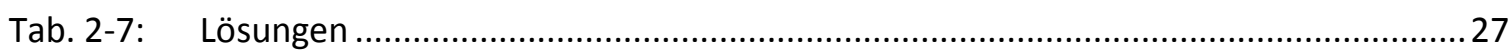

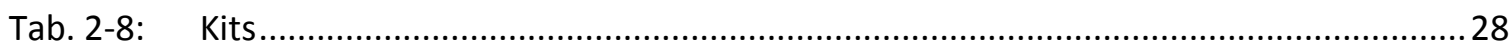

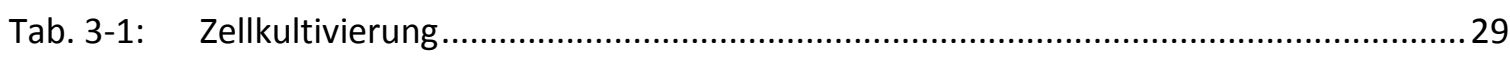

Tab. 3-2: Versuchsbedingungen des WST1-Tests mit MATE1-HEK293-Zellen ............................. 40

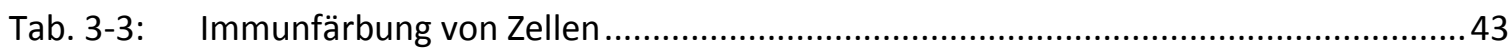

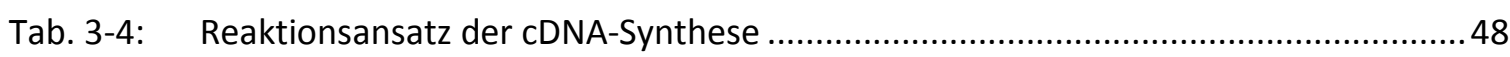

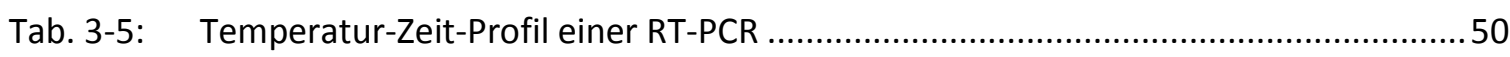

Tab. 3-6: Temperatur-Zeit-Profil einer Taqman-Real-Time-PCR ............................................... 52 
Tab. 5-1: Mögliche Transporter-Kandidaten für ein Zusammenspiel mit MATE1 ................. 114

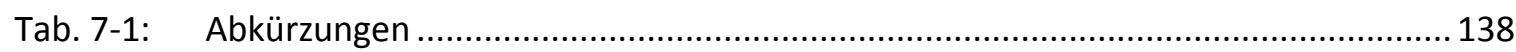

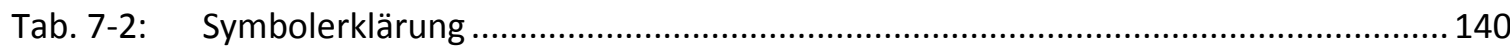

Tab. 7-3: Chemikalien und biologische Substanzen........................................................ 141

Tab. 7-4: $\quad$ RT-PCR-Primer für SLC7-Transporter ............................................................. 143

Tab. 7-5: $\quad$ RT-PCR-Primer für SLC16-Transporter ........................................................ 143

Tab. 7-6: $\quad$ RT-PCR-Primer für SLC19-Transporter ......................................................... 143

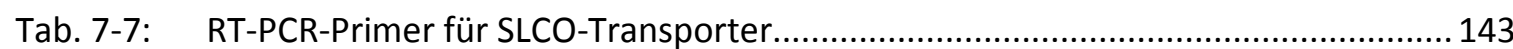

Tab. 7-8: $\quad$ RT-PCR-Primer für SLC22-Transporter ....................................................... 143

Tab. 7-9: $\quad$ RT-PCR-Primer für SLC28-Transporter ........................................................... 144

Tab. 7-10: RT-PCR-Primer für SLC29-Transporter ............................................................. 144

Tab. 7-11: RT-PCR-Primer für SLC47-Transporter ........................................................ 144

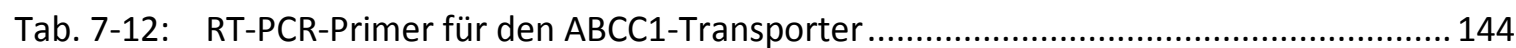

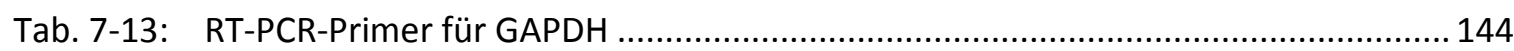

Tab. 7-14: Taqman gene expression assays ........................................................... 145

\subsection{Abkürzungen}

Tab. 7-1: Abkürzungen

\begin{tabular}{|l|l|}
\hline Abkürzung & Bedeutung \\
\hline ABC & ATP binding cassette \\
\hline AGT & Alkylguanyltransferase \\
\hline AIC & 4-Aminoimidazol-5-carboxamid \\
\hline ATP & Adenosintriphosphat \\
\hline attB & attachment side B \\
\hline BHD & BCNU, Hydroxyurea, Dacarbazin \\
\hline BOLD & Bleomycin, Vincristin, Cisplatin, Tamoxifen \\
\hline bp & Basenpaar \\
\hline BSA & bovine serum albumin, Rinderserumalbumin \\
\hline CDNA & complementary DNA \\
\hline CHO & chinese hamster ovary \\
\hline CNT & Konzentrierender Nukleosidtransporter \\
\hline CO 2 & Kohlenstoffdioxid \\
\hline CVD & Cisplatin, Vindesin, Dacarbazin \\
\hline Cy3 & Indocarbocyanin \\
\hline DAC-Tam & Dacarbazin, Nimustin, Cisplatin, Tamoxifen \\
\hline DAPI & 4',6-Diamidin-2-phenylindol \\
\hline DBCT & Dacarbazin, BCNU, Cisplatin, Tamoxifen \\
\hline dd & double distilled, zweifach destilliert \\
\hline DDI & drug-drug interaction, Arzneimittelwechselwirkung \\
\hline DMEM & Dulbecco's Modified Eagle Medium \\
\hline DMSO & Dimethylsulfoxid \\
\hline DNA & desoxy ribonucleic acid, Desoxyribonukleinsäure \\
\hline dNTP & Desoxyribonukleosidtriphosphat \\
\hline
\end{tabular}




\begin{tabular}{|c|c|}
\hline Abkürzung & Bedeutung \\
\hline DPM & decays per minute, Zerfälle pro Minute \\
\hline DTIC & Dacarbazin \\
\hline E.coli & Escherichia coli \\
\hline EDTA & Ethylendiamintetraacetat \\
\hline ENT & Äquilibrierender Nukleosidtransporter \\
\hline FAM & 6-Carboxyfluorescein \\
\hline FCS & fetal calf serum, fetales Kälberserum \\
\hline FRET & Förster-Resonanzenergietransfer \\
\hline FSC & forward scatter light, Vorwärtsstreulicht \\
\hline GADPH & Glycerinaldehyd-3-phosphat-Dehydrogenase \\
\hline Gem-Treo & Gemcitabin-Treosulfan \\
\hline HEK & human embryonic kidney \\
\hline HEPES & 2-(4-(2-Hydroxyethyl)- 1-piperazinyl)-ethansulfonsäure \\
\hline HPLC & high pressure liquid chromatography, Hochdruckflüssigkeitschromatographie \\
\hline ICA & Immuno cytological assay, Immuncytochemischer Test \\
\hline LAT & L-Aminosäuretransporter \\
\hline LB & Luria Broth \\
\hline M & Mol pro Liter \\
\hline MAPK & mitogenaktivierte Proteinkinase \\
\hline MATE & Multidrug and toxin extrusion \\
\hline MCT & Monocarboxylattransporter \\
\hline MDR & multidrug resistance \\
\hline $\mathrm{MgCl}_{2}$ & Magnesiumchlorid \\
\hline MeG & Methylguanin \\
\hline MGMT & Methylguanyl-Methyltransferase \\
\hline MMR & mismatch repair, Basenfehlpaarungsreparatur \\
\hline MPP & 1-Methyl-4-phenylpyridinium \\
\hline MR & Mammalian Ringer \\
\hline mRNA & messenger ribonucleic acid, Boten-Ribonukleinsäure \\
\hline MS & Massenspektrometrie \\
\hline MTIC & 5-(3-Methyl-1-triazeno)imidazol-4-carboxamid \\
\hline MZ & Melanozyten \\
\hline $\mathrm{NaHCO}_{3}$ & Natriumhydrogencarbonat \\
\hline $\mathrm{NaOH}$ & Natriumhydroxid \\
\hline NHE & Natrium-Protonen-Austauscher \\
\hline NHEM & normal human epidermal melanocytes \\
\hline OAT & Organische-Anionen-Transporter \\
\hline OATP & Organische-Anionen-Transportpeptid \\
\hline OCT & Organische-Kationen-Transporter \\
\hline OCTN & Organische-Kationen/Carnitin-Transporter \\
\hline OligodT & Oligo-Desoxythymidin \\
\hline p53 & Protein mit Masse von etwa 53 Kilodalton \\
\hline PBS & phosphate buffered saline, phosphatgepufferte Salzlösung \\
\hline
\end{tabular}




\begin{tabular}{|l|l|}
\hline Abkürzung & Bedeutung \\
\hline PCR & polymerase chain reaction, Polymerase-Kettenreaktion \\
\hline PMZ & primäre Melanozyten \\
\hline Q & quencher \\
\hline R & reporter \\
\hline RB1 & Retinoblastomprotein 1 \\
\hline RFT & reduced folate transporter, Reduzierte-Folate-Transporter \\
\hline RNA & ribonukleic acid, Ribonukleinsäure \\
\hline ROX & 6-Carboxyrhodamin \\
\hline RT & Reverse Transkriptase \\
\hline SA & Spezifische Aktivität \\
\hline SLC & solute carrier \\
\hline SN38 & 7-Ethyl-10-hydroxy-camptothecin \\
\hline SSC & side scatter light, Seitwärtsstreulicht \\
\hline Std & Standard \\
\hline TEA & Tetraethylammonium \\
\hline ThTr & Thiamintransporter \\
\hline Temozolomid & Temozolomid \\
\hline Tris & Tris(hydroxymethyl)-aminomethan \\
\hline u & unit \\
\hline U & Umdrehungen \\
\hline UV & ultraviolett \\
\hline w & well \\
\hline WST & water soluble tetrazolium salt, wasserlösliches Tetrazoliumsalz \\
\hline Z & Zelle \\
\hline
\end{tabular}

\section{$7.4 \quad$ Symbolerklärung}

\section{Tab. 7-2: Symbolerklärung}

\begin{tabular}{|l|l|}
\hline Symbol & Bedeutung \\
\hline${ }^{14} \mathrm{C}$ & Kohlenstoffisotop 14 \\
\hline${ }^{3} \mathrm{H}$ & Tritium \\
\hline $\mathrm{C}$ & Konzentration \\
\hline $\mathrm{C}_{\mathrm{T}}$ & threshold cycle, Schwellenwert-Zyklus \\
\hline $\mathrm{EC}_{50}$ & mittlere effective Konzentration \\
\hline $\mathrm{IC}_{50}$ & mittlere inhibitorische Konzentration \\
\hline $\mathrm{K}_{\mathrm{M}}$ & Michaelis-Menten-Konstante \\
\hline $\mathrm{m}$ & Masse \\
\hline $\mathrm{N}^{1} / \mathrm{N}^{3} / \mathrm{N}^{7}$ & Stickstoffatom mit der Nummer 1, 3 oder 7 \\
\hline $\mathrm{O}^{6}$ & Sauerstoffatom mit der Nummer 6 \\
\hline $\mathrm{pH}$ & negativer dekadischer Logaritmus der Wasserstoffionenkonzentration \\
\hline $\mathrm{pK}$ & negativer dekadischer Logaritmus der Säurekonstante \\
\hline $\mathrm{V}$ & Volumen \\
\hline
\end{tabular}




\subsection{Chemikalien und biologische Substanzen}

Tab. 7-3: Chemikalien und biologische Substanzen

\begin{tabular}{|c|c|c|}
\hline Bezeichnung & Artikelnummer & Herkunft \\
\hline 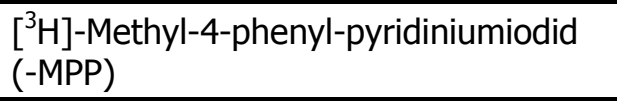 & ART 0150 & $\begin{array}{l}\text { American Radiolabeled } \\
\text { Chemicals, St. Louis, USA }\end{array}$ \\
\hline Agarose & $35-1020$ & $\begin{array}{l}\text { PEQLAB Biotechnologie, } \\
\text { Erlangen }\end{array}$ \\
\hline Agarosegel-Elektrophorese-Ladepuffer & $15628-050$ & Invitrogen, Carlsbad, USA \\
\hline Agarosegel-Elektrophorese-Marker & R0611 / 15628-050 & $\begin{array}{l}\text { Fermentas, St. Leon / } \\
\text { Invitrogen }\end{array}$ \\
\hline Amphotericin & $0246-2$ & Roth, Karlsruhe \\
\hline Ampicillin & US 11259 & $\begin{array}{l}\text { Amersham Bioscience, } \\
\text { Freiburg }\end{array}$ \\
\hline BSA (Rinderserumalbumin) & A-3912 & $\begin{array}{l}\text { Sigma Aldrich, } \\
\text { Taufkirchen }\end{array}$ \\
\hline Calciumchlorid $\left(\mathrm{CaCl}_{2}\right)$ & 2382 & Merck, Darmstadt \\
\hline Chinin & Q1125 & Sigma Aldrich \\
\hline Desoxynukleosidtriphosphate (dNTPs) & $20-3011$ & PEQLAB Biotechnologie \\
\hline Dimethylsulfoxid (DMSO) & 4720.1 & Roth \\
\hline $\begin{array}{l}\text { DMEM-HG (Dulbecco's } \\
\text { Modified Eagle Medium, high glucose) }\end{array}$ & T043-50 & Biochrom, Berlin \\
\hline DMEM-LG (DMEM low glucose) & A1314 & Applichem, Darmstadt \\
\hline Ethanol (EtOH), absolut & $\mathrm{A} 1613$ & Applichem \\
\hline Ethidiumbromid & $\mathrm{E}-8751$ & Sigma Aldrich \\
\hline FCS (fötales Kälberserum) & $10270-106$ & Gibco, Eggenstein \\
\hline Glucose & A3666 & Applichem \\
\hline Glycerol & 104092 & Merck \\
\hline Glycin & G-7126 & Sigma Aldrich \\
\hline Hefeextrakt & Y1625 & Sigma Aldrich \\
\hline $\begin{array}{l}\text { HEPES (2-(4-(2-Hydroxy-ethyl)-1- } \\
\text { piperazinyl)-ethan-sulfonsäure) }\end{array}$ & 9105.3 & Roth \\
\hline Hygromycin & P21014 & PAA, Pasching \\
\hline $\begin{array}{l}\text { Immuno Select Antifading } \\
\text { Mounting Medium DAPI (4',6- } \\
\text { Diamidin-2-phenylindol) }\end{array}$ & SQ-IS-12002 & Squarix, Marl \\
\hline Kaliumchlorid $(\mathrm{KCl})$ & A2939 & Applichem \\
\hline Kanamycin & $11815-024$ & Gibco \\
\hline Lipofectamin & $18324-012$ & Invitrogen \\
\hline L-Prolin & $13,154-7$ & Sigma Aldrich \\
\hline Magermilchpulver & 70166 & Sigma Aldrich \\
\hline Magnesiumchlorid $\left(\mathrm{MgCl}_{2}\right)$ & A1036 & Applichem \\
\hline Magnesiumsulfat $\left(\mathrm{MgSO}_{4}\right)$ & A6287 & Applichem \\
\hline Melanocyte Growth Medium M2 & C-24300 & Promo Cell \\
\hline Methanol $(\mathrm{MeOH})$, absolut & A0688.9010 & Applichem \\
\hline Methyl-4-phenylpyridinium-iodid (MPP) & D-048 & Sigma Aldrich \\
\hline Natriumchlorid $(\mathrm{NaCl})$ & A2942 & Applichem \\
\hline
\end{tabular}




\begin{tabular}{|l|l|l|}
\hline Bezeichnung & Artikelnummer & Herkunft \\
\hline $\begin{array}{l}\text { Natrium-Ethylendiamintetraacetat } \\
\text { (-EDTA) }\end{array}$ & E-5513 & Sigma Aldrich \\
\hline Natriumhydrogencarbonat $\left(\mathrm{NaHCO}_{3}\right.$ ) & A4993 & Applichem \\
\hline Natriumhydroxid (NaOH) & A3910 & Applichem \\
\hline Oligo dT & $32-2063-1 / 1$ & $\begin{array}{l}\text { Eurofins MWG Operon, } \\
\text { Ebersberg }\end{array}$ \\
\hline $\begin{array}{l}\text { PBS (Phosphat-gepufferte NaCl- } \\
\text { Lösung) }\end{array}$ & A0964 & Applichem \\
\hline Penicillin / Streptomycin & P11-010 & PAA \\
\hline Pepsin & P7012 & Sigma Aldrich \\
\hline Poly-D-Lysin & P1149 & Sigma Aldrich \\
\hline Proteinase K & P2308 & Sigma Aldrich \\
\hline $\begin{array}{l}\text { RNaseOUT }{ }^{\text {M }} \text { Recombinant } \\
\text { Ribonuclease Inhibitor }\end{array}$ & $10777-019$ & Invitrogen \\
\hline RPMI-1640, 40 u / $\mu \mathrm{l}$ & R6504-50L & Sigma Aldrich \\
\hline Salzsäure (HCl) & 4625.2 & Roth \\
\hline Supplemental Mix & C-39420 & Promo Cell \\
\hline Szintillationsflüssigkeit Luma Safe & 3097 & $\begin{array}{l}\text { Perkin Elmer, Waltham, } \\
\text { USA }\end{array}$ \\
\hline Taqman Gene Expression Mastermix & 4389016 & $\begin{array}{l}\text { Applied Biosystems, } \\
\text { Forster City, USA }\end{array}$ \\
\hline Taq-Polymerase, c = 1 u / $\mu \mathrm{l}$ & in eigener Arbeitsgruppe isoliert \\
\hline Tetraethylammoniumchlorid & T2265 & Sigma Aldrich \\
\hline $\begin{array}{l}{ }^{14} \text { C]-Tetraethylammonium-bromid } \\
\text { (TEA) }\end{array}$ & ARC-0577-50 & Biotrend, Köln \\
\hline Trishydroxymethylaminomethan (Tris) & 1.01549 & Merck \\
\hline Triton X-100 & 3051.2 & Roth \\
\hline Trypsin & $27250-042$ & Gibco \\
\hline Trypton & A-1553 & Applichem \\
\hline Tween20 & P-1379 & Sigma Aldrich \\
\hline WST1-Reagenz & 11644807001 & Rochè, Basel, Schweiz \\
\hline
\end{tabular}

\subsection{RT-PCR-Primer}

In Tab. 7-4 bis Tab. 7-13 sind das Gen, an dessen Sequenz die Primer binden, der Name des Primers, die Primersequenz in 5'-3'-Richtung, die Produktgröße in Basenpaaren (bp) und die Hybridisierungstemperatur der Primer $\left(\mathrm{T}_{\mathrm{Hyb}}\right)$ angegeben. Der Name setzt sich aus dem Proteinnamen und seiner Position, der Nummer des ersten Nukleotids, an das der Primer an die mRNA bindet, zusammen. Bindet der Primer an den kodierenden DNAStrang, so bezeichnet man inn als "forward"-Primer (for), bindet er dagegen an den nicht-kodierenden Strang, so bezeichnet man inn als „reverse"-Primer (rev). 
Tab. 7-4: RT-PCR-Primer für SLC7-Transporter

\begin{tabular}{|c|c|c|c|c|}
\hline Gen & Primer & Sequenz (5'-3'-Richtung) & Größe (bp) & $\mathbf{T}_{\mathrm{Hyb}}\left({ }^{\circ} \mathrm{C}\right)$ \\
\hline \multirow{2}{*}{$\begin{array}{l}\text { SLC7A5 } \\
\text { (LAT1) }\end{array}$} & LAT1_1001for & cgtggacttcgggaactatcac & \multirow{2}{*}{558} & \multirow{2}{*}{57,2} \\
\hline & LAT1_1558rev & ttctgacacaggacggtcgt & & \\
\hline \multirow{2}{*}{$\begin{array}{l}\text { SLC7A8 } \\
\text { (LAT2) }\end{array}$} & LAT2_976for & agccctctgctatgctgaac & \multirow{2}{*}{454} & \multirow{2}{*}{55,9} \\
\hline & LAT2_1429rev & ctgaaggaaagccagtgcga & & \\
\hline
\end{tabular}

Tab. 7-5: RT-PCR-Primer für SLC16-Transporter

\begin{tabular}{|c|c|c|c|c|}
\hline Gen & Primer & Sequenz (5'-3'-Richtung) & Größe (bp) & $\mathrm{T}_{\mathrm{Hyb}}\left({ }^{\circ} \mathrm{C}\right)$ \\
\hline \multirow{2}{*}{$\begin{array}{l}\text { SLC16A1 } \\
\text { (MCT1) }\end{array}$} & MCT1_1183for & gtatttctttgcggcttccgttg & \multirow{2}{*}{512} & \multirow{2}{*}{57,6} \\
\hline & MCT1_1694rev & agactggactttcctcctccttg & & \\
\hline \multirow{2}{*}{$\begin{array}{l}\text { SLC16A7 } \\
\text { (MCT2) }\end{array}$} & MCT2_334for & ggttggattgtggttggagc & \multirow{2}{*}{564} & \multirow{2}{*}{55,7} \\
\hline & MCT2_897rev & cttagaagtggtttgattgggtcc & & \\
\hline \multirow{2}{*}{$\begin{array}{l}\text { SLC16A3 } \\
\text { (MCT4) }\end{array}$} & MCT4_864for & accatcctgggcttcattgac & \multirow{2}{*}{450} & \multirow{2}{*}{56,7} \\
\hline & MCT4_1313rev & tggctctttgggcttcttccta & & \\
\hline
\end{tabular}

Tab. 7-6: RT-PCR-Primer für SLC19-Transporter

\begin{tabular}{|c|c|c|c|c|}
\hline Gen & Primer & Sequenz (5'-3'-Richtung) & Größe (bp) & $\mathrm{T}_{\mathrm{Hyb}}\left({ }^{\circ} \mathrm{C}\right)$ \\
\hline \multirow{2}{*}{$\begin{array}{l}\text { SLC19A1 } \\
\text { (RFT) }\end{array}$} & RFT_886for & tctggtgggtcttcaactcg & \multirow{2}{*}{486} & \multirow{2}{*}{55,6} \\
\hline & RFT_1372rev & aactggaactgcttgcgga & & \\
\hline \multirow{2}{*}{$\begin{array}{l}\text { SLC19A2 } \\
\text { (ThTr) }\end{array}$} & ThTr1_1241for & ctgtgggtaacatttgggtgtg & \multirow{2}{*}{481} & \multirow{2}{*}{55,1} \\
\hline & ThTr1_1721rev & tagtcaagtggctgctgtgaag & & \\
\hline
\end{tabular}

Tab. 7-7: RT-PCR-Primer für SLCO-Transporter

\begin{tabular}{|c|c|c|c|c|}
\hline Gen & Primer & Sequenz (5'-3'-Richtung) & Größe (bp) & $\mathrm{T}_{\mathrm{Hyb}}\left({ }^{\circ} \mathrm{C}\right)$ \\
\hline \multirow{2}{*}{$\begin{array}{l}\text { SLC21A3 } \\
\text { (SLCO1A2) }\end{array}$} & hOATP-A_831for & caggagttaacgtgctcactg & \multirow{2}{*}{460} & \multirow{2}{*}{55,3} \\
\hline & hOATP-A_1413rev & gatggacagttgcaatccac & & \\
\hline \multirow{2}{*}{$\begin{array}{l}\text { SLC21A9 } \\
\text { (SLCO2B1) }\end{array}$} & hOATP-B_382for & cctaaagagctccatctccac & \multirow{2}{*}{443} & \multirow{2}{*}{56,5} \\
\hline & hOATP-B_956rev & ctggcatctggttaatgtcc & & \\
\hline \multirow{2}{*}{$\begin{array}{l}\text { SLC21A6 } \\
\text { (SLCO1B1) }\end{array}$} & hOATP-C_662for & tcattggctttaccctgggatc & \multirow{2}{*}{551} & \multirow{2}{*}{52,6} \\
\hline & hOATP-C_1224rev & ggcaattccaacggtgttcag & & \\
\hline \multirow{2}{*}{$\begin{array}{l}\text { SLC21A11 } \\
\text { (SLCO3A1) }\end{array}$} & hOATP-D_1205for & atcccgaaggtcaccaagcac & \multirow{2}{*}{205} & \multirow{2}{*}{64} \\
\hline & hOATP-D_1409rev & ccaggaagatacccagacaagcac & & \\
\hline \multirow{2}{*}{$\begin{array}{l}\text { SLC21A12 } \\
\text { (SLCO4A1) }\end{array}$} & hOATP-E_524for & atcgccagctcctacgacattg & \multirow{2}{*}{513} & \multirow{2}{*}{54,5} \\
\hline & hOATP-E_1073rev & gggaacggcggtgaagaaag & & \\
\hline
\end{tabular}

Tab. 7-8: RT-PCR-Primer für SLC22-Transporter

\begin{tabular}{|c|c|c|c|c|}
\hline Gen & Primer & Sequenz (5'-3'-Richtung) & Größe (bp) & $\mathbf{T}_{\mathrm{Hyb}}\left({ }^{\circ} \mathrm{C}\right)$ \\
\hline \multirow{2}{*}{$\begin{array}{l}\text { SLC22A1 } \\
\text { (OCT1) }\end{array}$} & OCT1_115for & gtggatgacattctggagca & \multirow{2}{*}{485} & \multirow{2}{*}{53,6} \\
\hline & OCT1_599rev & ccgagagagccaaacaaga & & \\
\hline \multirow{2}{*}{$\begin{array}{l}\text { SLC22A2 } \\
\text { (OCT2) }\end{array}$} & OCT2_2199for & accaagagtgaaccctaatgc & \multirow{2}{*}{606} & \multirow{2}{*}{54,2} \\
\hline & OCT2_2803rev & tagaccaggaatggcgtga & & \\
\hline \multirow{2}{*}{$\begin{array}{l}\text { SLC22A3 } \\
\text { (OCT3) }\end{array}$} & OCT3_1293for & tgtcactgcgttcttaccag & \multirow{2}{*}{433} & \multirow{2}{*}{54,3} \\
\hline & OCT3_1725rev & tccttctttctgtctttgtcgg & & \\
\hline \multirow{2}{*}{$\begin{array}{l}\text { SLC22A6 } \\
\text { (OAT1) }\end{array}$} & hOAT1_933for & gggcaccttgattggctatgtc & \multirow{2}{*}{502} & \multirow{2}{*}{58} \\
\hline & hOAT1_1434rev & gatgacaaggaagcccacaagc & & \\
\hline
\end{tabular}




\begin{tabular}{|c|c|c|c|c|}
\hline \multirow{2}{*}{$\begin{array}{l}\text { SLC22A7 } \\
\text { (OAT2) }\end{array}$} & hOAT2_835for & tctgcacgctggcttctgac & \multirow{2}{*}{552} & \multirow{2}{*}{59,4} \\
\hline & hOAT2_1386rev & tgtctgtctgagcaccgtaggg & & \\
\hline \multirow{2}{*}{$\begin{array}{l}\text { SLC22A8 } \\
\text { (OAT3) }\end{array}$} & hOAT3_871for & cttcctatcatcctggtggac & \multirow{2}{*}{549} & \multirow{2}{*}{53,6} \\
\hline & hOAT3_1419rev & tagaggaagaggcagctgaag & & \\
\hline \multirow{2}{*}{$\begin{array}{l}\text { SLC22A9 } \\
\text { (OAT4) }\end{array}$} & hOAT4_130for & catggcgttctcgaagctc & \multirow{2}{*}{593} & \multirow{2}{*}{54,0} \\
\hline & hOAT4_722rev & cgcagtagatgacgaatgttg & & \\
\hline
\end{tabular}

Tab. 7-9: RT-PCR-Primer für SLC28-Transporter

\begin{tabular}{|c|c|c|c|c|}
\hline Gen & Primer & Sequenz (5'-3'-Richtung) & Größe (bp) & $\mathrm{T}_{\mathrm{Hyb}}\left({ }^{\circ} \mathrm{C}\right)$ \\
\hline \multirow{2}{*}{$\begin{array}{l}\text { SLC28A1 } \\
\text { (CNT1) }\end{array}$} & CNT1_1146for & tctttgtgagccagaccgag & \multirow{2}{*}{460} & \multirow{2}{*}{55,3} \\
\hline & CNT1_1605rev & aggatgtaggagcagatgagc & & \\
\hline \multirow{2}{*}{$\begin{array}{l}\text { SLC28A2 } \\
\text { (CNT2) }\end{array}$} & CNT2_1068for & atgactggagggtttgccac & \multirow{2}{*}{443} & \multirow{2}{*}{56,5} \\
\hline & CNT2_1510rev & accatctcagccaccattgg & & \\
\hline \multirow{2}{*}{$\begin{array}{l}\text { SLC28A3 } \\
\text { (CNT3) }\end{array}$} & CNT3_171for & gagaacgagaacacatcagg & \multirow{2}{*}{551} & \multirow{2}{*}{52,6} \\
\hline & CNT3_721rev & tacattatgagcccaccgaa & & \\
\hline
\end{tabular}

Tab. 7-10: RT-PCR-Primer für SLC29-Transporter

\begin{tabular}{|c|c|c|c|c|}
\hline Gen & Primer & Sequenz (5'-3'-Richtung) & Größe (bp) & $\mathrm{T}_{\mathrm{Hyb}}\left({ }^{\circ} \mathrm{C}\right)$ \\
\hline \multirow{2}{*}{$\begin{array}{l}\text { SLC29A1 } \\
\text { (ENT1) }\end{array}$} & ENT1_1114for & tgaggtcaagtccagcatcg & \multirow{2}{*}{462} & \multirow{2}{*}{55,9} \\
\hline & ENT1_1575rev & caggcagtccttctgtccat & & \\
\hline \multirow{2}{*}{$\begin{array}{l}\text { SLC29A2 } \\
\text { (ENT2) }\end{array}$} & ENT2_723for & gctcctccagtctgatgaga & \multirow{2}{*}{513} & \multirow{2}{*}{54,5} \\
\hline & ENT2_1235rev & accaggtagccattagaaacg & & \\
\hline \multirow{2}{*}{$\begin{array}{l}\text { SLC29A3 } \\
\text { (ENT3) }\end{array}$} & ENT3_470for & actggtgaaggtggacact & \multirow{2}{*}{513} & \multirow{2}{*}{54,1} \\
\hline & ENT3_987rev & ggtagatgaggctggtgatga & & \\
\hline
\end{tabular}

Tab. 7-11: RT-PCR-Primer für SLC47-Transporter

\begin{tabular}{|l|l|l|l|l|}
\hline Gen & Primer & Sequenz (5'-3'-Richtung) & Größe (bp) & $\mathbf{T}_{\text {Hvb }}\left({ }^{\circ} \mathbf{C}\right)$ \\
\hline \multirow{2}{*}{$\begin{array}{l}\text { SLC47A1 } \\
\text { (MATE1) }\end{array}$} & MATE1_910for & tcatgctgtgcatggagtggtg & \multirow{2}{*}{510} & \multirow{2}{*}{58,6} \\
\cline { 2 - 3 } & MATE1_1419rev & Agatgatgatccctgaccacaga & & \multirow{2}{*}{483} \\
\hline $\begin{array}{l}\text { SLC47A2 } \\
\text { (MATE2) }\end{array}$ & MATE2_195for & atcgtgagcactgtgttctgC & 53,3 \\
\cline { 2 - 3 } & MATE2_677rev & tgggagatgttggcata & & \\
\hline
\end{tabular}

MATE1_1419rev, MATE2_195for und MATE2_677rev wurden aus (Masuda) übernommen.

Tab. 7-12: RT-PCR-Primer für den ABCC1-Transporter

\begin{tabular}{|l|l|l|l|l|}
\hline Gen & Primer & Sequenz (5'-3'-Richtung) & Größe (bp) & $\mathbf{T}_{\text {Hvb }}\left({ }^{\circ} \mathbf{C}\right)$ \\
\hline \multirow{2}{*}{$\begin{array}{l}\text { ABCC1 } \\
\text { (MRP1) }\end{array}$} & MRP1_4421for20 & aaggacttcgtgtcagccct & \multirow{2}{*}{476} & \multirow{2}{*}{57,2} \\
\cline { 2 - 3 } & MRP1_4897rev22 & tttggtttcagtgtgggaggc & & \multirow{2}{*}{518} \\
\hline $\begin{array}{l}\text { ABCC4 } \\
\text { (MRP4) }\end{array}$ & MRP4_1812for20 & atgcggaagttagcagacac & 53,6 \\
\cline { 2 - 3 } & MRP4_2329rev21 & ccagtatgaaagccaccaatc & & \\
\hline
\end{tabular}

Tab. 7-13: RT-PCR-Primer für GAPDH

\begin{tabular}{|l|l|l|l|l|}
\hline Gen & Primer & Sequenz (5'-3'-Richtung) & Größe (bp) & $\mathbf{T}_{\text {Hyb }}\left({ }^{\circ} \mathbf{C}\right)$ \\
\hline \multirow{2}{*}{ GAPDH } & GAPDH_334 for & tcaccatcttccaggagcg & \multirow{2}{*}{582} & \multirow{2}{*}{58,0} \\
\cline { 2 - 5 } & GAPDH_905rev & ctgcttcaccaccttcttga & & \\
\hline
\end{tabular}




\subsection{Taqman-Real-Time-PCR-Primer}

In Tab. 7-14 sind die Gensequenz, an die die Primer binden, das zugehörige Protein und die Nummer des Primers dargestellt.

Tab. 7-14: Taqman gene expression assays

\begin{tabular}{|l|l|l|}
\hline Gen & Protein & Taqman-Primer \\
\hline SLC7A5 & LAT1 & Hs00185826_m1 \\
\hline SLC7A8 & LAT2 & Hs00794796_m1 \\
\hline SLC16A1 & MCT1 & Hs00161826_m1 \\
\hline SLC16A7 & MCT2 & Hs00190974_m1 \\
\hline SLC16A3 & MCT4 & Hs00358829_m1 \\
\hline SLC19A1 & RFT & Hs00953342_m1 \\
\hline SLC19A2 & ThTr1 & Hs00294767_m1 \\
\hline SLC21A3 & SLCO1A2 & Hs00366488_m1 \\
\hline SLC21A9 & SLCO2B1 & Hs00200670_m1 \\
\hline SLC21A6 & SLCO1B1 & Hs00272374_m1 \\
\hline SLC21A11 & SLCO3A1 & Hs00203184_m1 \\
\hline SLC21A12 & SLCO4A1 & Hs00249583_m1 \\
\hline SLC21A8 & SLCO1B3 & Hs00251986_m1 \\
\hline SLC22A1 & OCT1 & Hs00427554_m1 \\
\hline SLC22A2 & OCT2 & Hs00533907_m1 \\
\hline SLC22A3 & OCT3 & Hs00222691_m1 \\
\hline SLC22A6 & OAT1 & Hs00537914_m1 \\
\hline SLC22A7 & OAT2 & Hs00198527_m1 \\
\hline SLC22A8 & OAT3 & Hs00188599_m1 \\
\hline SLC22A9 & Hs00218486_m1 \\
\hline SLC28A1 & OAT4 & Hs00188418_m1 \\
\hline SLC28A2 & CNT1 & Hs00188407_m1 \\
\hline SLC28A3 & CNT2 & Hs00223220_m1 \\
\hline SLC29A1 & CNT3 & Hs00155426_m1 \\
\hline SLC29A2 & ENT1 & Hs00983219_m1 \\
\hline SLC29A3 & ENT2 & Hs00217320_m1 \\
\hline SLC47A1 & ENT3 & Hs00945650_m1 \\
\hline SLC47A2 & MATE1 & Hs001844991_m1 \\
\hline ABCB1 & MATE2 & Hs99999905_m1 \\
\hline & MDR1 & \\
\hline & GAPDH & \\
\hline & & \\
\hline
\end{tabular}




\section{Danksagung}

Ich bedanke mich bei all denjenigen, die zum Gelingen dieser Arbeit beigetragen haben. Mein Dank richtet sich an erster Stelle an Frau Prof. Dr. C. Steinem und Herrn Prof. Dr. G. Burckhardt für ihre Betreuung und Gutachtertätigkeit. Herrn Prof. Dr. G. Burckhardt danke ich außerdem für die Eröffnung der Möglichkeit dieses sehr interessante Thema zu bearbeiten, die stetige Diskussionsbereitschaft und wohlwollende Unterstützung.

Ganz besonders danke ich Herrn PD Dr. Y. Hagos, der mich in der täglichen Forschungsarbeit mit vielen wertvollen Anregungen beraten hat, stets diskussionsbereit war und die Arbeit mit vielen Ideen vorangebracht hat.

Herrn Prof. Dr. J. Brockmöller danke ich für die Teilnahme an meinem Thesis Committee.

Ich danke unserem Kooperationspartner Herrn Prof. Dr. S. Emmert, der mir die Möglichkeit eröffnet hat, in seinem Institut meinen Erfahrungshorizont zu erweitern.

Ich danke außerdem Herrn A. Rosenberger für die Hilfe bei statistischen Auswertungen.

Mein Dank richtet sich auch an die Arbeitsgruppe Vegetative Physiologie und Pathophysiologie, besonders an Frau Prof. Dr. B. C. Burckhardt und an Herrn PD Dr. W. Krick für ihre sehr hilfreichen wissenschaftlichen Auskünfte.

Danke auch an die technischen Assistenten, Gesche Dallmeyer, Sören Petzke und Reinhard Schirmer für die ausgezeichnete Anleitung und Unterstützung im Labor.

Danke auch ganz besonders an Waja Wegner und Dr. Nina Schnedler für die vielen Ratschläge und Ermunterungen.

Ganz besonders danke ich auch meiner Familie und meinen Freunden, die mir jederzeit zur Seite standen und mich sehr unterstützt haben.

Die vorliegende Arbeit ist das Ergebnis der Forschungsarbeit im Rahmen einer Stipendiatenstelle im GRK1034 und wurde von der DFG finanziert. 


\section{Lebenslauf}

Name:

Geburtsdatum:

Geburtsort:

Staatsangehörigkeit:

Schulbildung:

1989 - 1993

1993 - 1995

1995 - 2002

$06 / 2002$

Studium:

$10 / 2002-02 / 2008$

$04 / 2006-06 / 2006$

$03 / 2007-10 / 2007$

02/2008

$04 / 2008-05 / 2008$

$06 / 2008-08 / 2011$

$06 / 2008-05 / 2011$

Julia Frieda Grottker

27.01.1983

Braunschweig

Deutsch

Grundschule Watenbüttel in Braunschweig

Orientierungsstufe Wendeburg

Hoffmann-von-Fallersleben-Gymnasium, Braunschweig

Abschluss Abitur

Studium Chemie Diplom in Göttingen

Auslandssemester im Institut für Organische Chemie an der Universität Florenz

Diplomarbeit in der Abteilung Biomolekulare Chemie, Prof. Dr. C. Steinem, Institut für Organische und Biomolekulare Chemie, Universität Göttingen: „Untersuchung des spannungsabhängigen Verhaltens von OmpF und seiner LECE-Mutante in Nano-BLMs"

Diplomabschluss in Chemie in Göttingen

Praktikum in der Abteilung Vegetative Physiologie und Pathophysiologie, Prof. Dr. G. Burckhardt, Zentrum für Physiologie und Pathophysiologie an der Universität Göttingen

Forschungsprojekt mit dem Ziel der Promotion in der Abteilung Vegetative Physiologie und Pathophysiologie, Prof. Dr. G. Burckhardt, Zentrum für Physiologie und Pathophysiologie, Universität Göttingen: „Expression von SLC-Transportern in Melanomzellen und Charakterisierung von MATE1 und OCT1 in ihrer Funktion als Zytostatikatransporter"

Stipentiatin im Graduiertenkolleg 1034 „Die Bedeutung genetischer Polymorphismen in der Onkologie: Von den Grundlagen zur individualisierten Therapie" 


\section{Veröffentlichungen}

Grottker, J. ; Rosenberger, A. ; Burckhardt, G. ; Hagos, Y.: Interaction of human multidrug and toxin extrusion 1 (MATE1) transporter with antineoplastic agents. In: Drug Metabol. Drug Interact. (2011), accepted.

Shnitsar, V. ; Eckardt, R. ; Gupta, S. ; Grottker, J. ; Müller, G. A. ; Koepsell, H. ; Burckhardt, G. ; Hagos, Y.: Expression of human organic cation transporter 3 in kidney carcinoma cell lines increases chemosensitivity to melphalan, irinotecan, and vincristine. In: Cancer Res. 69 (2009), Nr. 4, S. 1494-1501

\section{Kongresse}
$12.06 .2008-14.06 .2008$
CESAR Göttingen
22.11.2008 - 23.11.2008 Göttinger Transporttage
21.06.2009 - 24.06.2009 Minerva School of Pharmacogenetics in Tel-Aviv, Israel
17.10.2009 - 18.10.2009 Göttinger Transporttage, Vortrag
27.05.2010 - 28.05.2010 7. Transportkolloquium in Rauischholzhausen, Poster
16.10.2010 - 17.10.2010 Göttinger Transporttage
25.11.2010 - 26.11.2010 Optical imaging workshop in Göttingen

\section{Fachtagungen des GRK1034}

$\begin{array}{ll}\text { 03.07.2008 -05.07.2008 } & \text { Klausurtagung V in Göttingen, Poster } \\ \text { 05.09.2008 } & \text { Nachfolgeantrag GRK1034, 2. Förderperiode, Poster } \\ \text { 09.07.2009-11.07.2008 } & \text { Klausurtagung VI in Volpriehausen, Poster } \\ \text { 30.07.2010 } & \text { Klausurtagung VII1 in Göttingen, Poster } \\ \text { 13.10.2010 - 16.10.2010 } & \text { Klausurtagung VII2 in Friedrichshafen, Vortrag }\end{array}$

